\title{
Funktionelle Analyse des Transkriptionsfaktors Pitx3 während der Entwicklung dopaminerger Neuronen im murinen Mittelhirn
}

\author{
Dissertation \\ zur Erlangung des mathematisch-naturwissenschaftlichen Doktorgrades \\ „Doctor rerum naturalium“ \\ der Georg-August-Universität zu Göttingen \\ im GAUSS-Promotionsprogramm (Biologie)
}

vorgelegt von

Christian Krug

aus Nordhausen

Göttingen, September 2012 


\section{Betreuungsausschuss:}

\section{Referent: Prof. Dr. Ahmed Mansouri}

Korreferent: Jun. Prof. Dr. Gregor Bucher

\section{Mitglieder der Prüfungskommission:}

\section{Referent: Prof. Dr. Ahmed Mansouri}

(Molekulare Zelldifferenzierung, MPI-BPC, Göttingen)

Korreferent: Jun. Prof. Dr. Gregor Bucher

(Entwicklungsbiologie, Georg-August Universität, Göttingen)

Beisitzer: Prof. Dr. Ralf Heinrich

(Zelluläre Neurobiologie, Georg-August Universität, Göttingen)

Beisitzer: Prof. Dr. Reinhard Schuh

(Molekulare Organogenese, MPI-BPC, Göttingen)

Beisitzer: Prof. Dr. Ernst. A. Wimmer

(Entwicklungsbiologie, Georg-August Universität, Göttingen)

Beisitzer: Prof. Dr. Andreas Wodarz

(Stammzellbiologie, Universitätsmedizin Göttingen) 


\section{Abbildungsverzeichnis}

Seite

\begin{tabular}{|c|c|c|}
\hline Abb. 1 & $\begin{array}{l}\text { Lage, axonale Projektionen und Funktion der dopaminergen Neurone des } \\
\text { Mittelhirns. }\end{array}$ & 3 \\
\hline Abb. 2: & Der Entwicklungszyklus der Maus. & 4 \\
\hline Abb. 3: & $\begin{array}{l}\text { Schematische Darstellung eines Mausembryos während der späten } \\
\text { Gastrulation. }\end{array}$ & 5 \\
\hline Abb. 4: & Neurulation des Zentralen Nervensystems. & 7 \\
\hline Abb. 5: & Induktion der mDA Neurone. & 11 \\
\hline Abb. 6: & $\begin{array}{l}\text { Überblick über die zeitliche Expression Faktoren, die für die Induktion und } \\
\text { Differenzierung der mDA Neurone relevant sind. }\end{array}$ & 15 \\
\hline Abb. 7: & Übersicht über die Entwicklung der mDA Neurone. & 17 \\
\hline Abb. 8: & Mausembryonen an Tag E12.5 (Shh-Cre ${ }^{+/ \text {Pitx30E }}$ und Foxa2-Cre+/Pitx30E) & 27 \\
\hline Abb. 9: & $\begin{array}{l}\text { Die Überexpression von Pitx3 im ventralen Mittelhirn führt zu einer Erhöhung } \\
\text { der mDA Neurone an Tag E12.5. }\end{array}$ & 30 \\
\hline Abb. 10: & $\begin{array}{l}\text { Die Überexpression von Pitx3 im ventralen Mittelhirn führt zu einer Erhöhung } \\
\text { der mDA Neurone an Tag E15.5. }\end{array}$ & 32 \\
\hline Abb. 11: & $\begin{array}{l}\text { Die Überexpression von Pitx3 im ventralen Mittelhirn führt zu einer Erhöhung } \\
\text { der Lmx1a/b-positiven Zellen in der VZ und SVZ an Tag E12.5. }\end{array}$ & 34 \\
\hline Abb. 12: & Mausembryonen an Tag E12.5 (Wnt1-Cre ${ }^{+/ \text {Pitx30E }}$ und En1-Cre ${ }^{+/ P i t x 30 E}$ ) & 36 \\
\hline Abb. 13: & $\begin{array}{l}\text { Die Überexpression von Pitx3 im dorso-ventralen Mittelhirn führt zu einer } \\
\text { Erhöhung der medialen mDA Neurone an Tag E12.5. }\end{array}$ & 38 \\
\hline Abb. 14: & $\begin{array}{l}\text { Die Überexpression von Pitx3 im dorso-ventralen Mittelhirn führt zu einer } \\
\text { Erhöhung der mDA Neurone im VTA an Tag E15.5. }\end{array}$ & 40 \\
\hline Abb. 15: & $\begin{array}{l}\text { Die Überexpression von Pitx3 im dorso-ventralen Mittelhirn bewirkt eine } \\
\text { caudale Verschiebung der TH- Expression an Tag E15.5 und führt zu } \\
\text { Entwicklungsstörungen im Bereich des Mittelhirns. }\end{array}$ & 41 \\
\hline Abb. 16: & $\begin{array}{l}\text { Die Überexpression von Pitx3 im ventralen Mittelhirn führt zu einer Erhöhung } \\
\text { der Lmx1a/b-positiven Zellen in der VZ an Tag E12.5. }\end{array}$ & 44 \\
\hline Abb. 17: & $\begin{array}{l}\text { Bei den Wnt1-Cre } / \text { Pitx30E } \text { Mutanten sind keine Migrationseffekte an Tag E12.5 } \\
\text { erkennbar. }\end{array}$ & 45 \\
\hline Abb. 18: & $\begin{array}{l}\text { Bei den Wnt1-Cre+/Pitx30E Mutanten zeigt sich eine starke ektopische } \\
\text { Wnt1-Expression im Bereich der VZ und SVZ an Tag E12.5. }\end{array}$ & 47 \\
\hline Abb. 19: & $\begin{array}{l}\text { Die ektopische Wnt1- Expression der Wnt1-Cre }{ }^{+/ P i t x 30 E} \text { Mutanten bewirkt eine } \\
\text { Inhibierung der Shh- Expression sowie eine reduzierte Neurogenese an Tag } \\
\text { E12.5. }\end{array}$ & 48 \\
\hline Abb. 20: & $\begin{array}{l}\text { Die Überexpression von Lmx1a bzw. Lmx1b in der Wnt1- Domäne (Wnt1- } \\
\text { Cre+/Lmx1aOE bzw. Wnt1-Cre+/Lmx1b0E) bewirkt Entwicklungsdefekte und eine } \\
\text { starke Reduktion der mDA Neurone an Tag E12.5. }\end{array}$ & 50 \\
\hline Abb. 21: & $\begin{array}{l}\text { Die ektopische Expression von Lmx1a bzw. Lmx1b in der Wnt1- Domäne } \\
\text { bewirkt eine ektopische Expression von Wnt1 sowie eine Reduktion der Shh- } \\
\text { Expression an Tag E12.5. }\end{array}$ & 51 \\
\hline Abb. 22: & $\begin{array}{l}\text { Verpaarungsschema der konditionalen Pitx3-Überexpression unter Angabe } \\
\text { der Genotypen. }\end{array}$ & 79 \\
\hline
\end{tabular}




\section{Tabellenverzeichnis}

Seite

Tab. 1: Verwendete Chemikalien und Reagenzien, die im Rahmen der vorliegenden Arbeit verwendet wurden.

Tab. 2: $\quad$ Angesetzte Puffer-Lösungen, die im Rahmen der vorliegenden Arbeit verwendet 70 wurden.

Tab. 3: Standardansatz für eine PCR mit 10 Proben.

Tab. 4: Verwendete Primer zur Genotypsierung unter Angabe der Orientierung und Sequenz.

Tab. 5: Standard-PCR Programm. 73

Tab. 6: Verwendete Plasmide unter Angabe der eingefügten cDNA Sequenzen.

Tab. 7: Reaktionsansatz für die Herstellung einer DIG-markierten Probe aus cDNATemplates.

Tab. 8: Verwendete transgene Mauslinien für die konditionale Überexpression von Pixt3 (und Lmx1a und Lmx1b) mittels des Cre-LoxP-Systems.

Tab. 9: Verwendete Bezeichnung der doppeltransgenen Pitx3 Mausmutanten.

Tab. 10: Fixierungsdauer des embryonalen Gewebes in einer 4\%igen PFA-Lösung

Tab. 11: Aufsteigende Lösungsmittelreihe zur Entwässerung des embryonalen Gewebes.

$\begin{array}{llllll}\text { Tab. 12: } & \begin{array}{l}\text { Protokoll für die Hämatoxylin-Eosin-Färbung (HE-Färbung) auf } \\ \text { Paraffinschnitten. }\end{array} & & \mathbf{8 3}\end{array}$

Tab. 13: Liste der verwendeten primären Antikörper für die IIF auf Gewebeschnitten. 84

Tab. 14: Liste der verwendeten sekundären Antikörper für die IIF auf Gewebeschnitten. 85

Tab. 15: Protokoll für die IIF auf Paraffin-Gewebeschnitten. 


\section{Abkürzungsverzeichnis}

$$
\#
$$

-/- $\quad$ homozygot für das Knockout-Allel

+/- $\quad$ heterozygot für das Knockout-Allel

${ }^{\circ} \mathrm{C} \quad$ Grad Celsius

$\mu \mathbf{l} \quad$ Mikroliter

$\mu \mathrm{m} \quad$ Mikrometer

AADC Aromatische-L-Aminosäure-Decarboxylase

Abb.

Abbildung

Aldh1a1 engl. „Aldehyde dehydrogeanse family 1, subfamily A1“, auch bekannt als AHD2 und

AP $\quad$ Raldh1

a-p antero-posterior

AS Abteilungsstock

AVE Anteriores viscerales Endoderm

BCIP 5-Bromo-4-chloro-3-indolylphosphat

BDNF engl. „Brain-derived neurotrophic factor"

bHLH engl. Basic helix-loop-helix

Bmp engl. „Bone morphogenetic protein“

BP Bodenplatte

bp Basenpaare

Bpl Basaplatte

BrdU 5'-Brom-2'-deoxyuridin

BSA Rinderserumalbumin (Bovine serum albumin)

CA Anlage des Cerebellums

Cb Cerebellum

Cb Cerebellum

cDNA engl. „complementary DNA“, komplementäre DNA

Cdx2 engl. „Caudal-type homebox 2“

ChIP Chromatin-Immunopreziptation

Cre engl. "Cyclization recombination"

D2R Dopaminrezeptor D2

DAPI 4,6-Diamidino-2-Phenylindol

DAT Dopamintransporter

DBH Dopamin-ß-Hydroxylase

DC Diencephalon

DEPC Dimethylpyrocarbonat

dest. destilliert

$\mathbf{d H}_{2} \mathbf{0} \quad$ destilliertes Wasser

DIG Digoxigenin-11-UTP

Dlk1 engl. „Delta-like 1 protein“, auch FA1 genannt

DMEM Dulbecco's Modified Eagle Medium

DMSO Dimethylsulfoxid

DNA Desoxyribonucleinsäure

dNTP Desoxynukleosidtriphosphat

DP Dachplatte

d-v dorso-ventral

E Embryonalstadium (in Tagen) 


\begin{tabular}{|c|c|}
\hline E.coli & Escherischia coli \\
\hline EDTA & Ethylendiamintetraacetat \\
\hline eGFP & engl. "enhanced green fluorescent protein" \\
\hline Emx1/2 & engl. „Empty spiracles homolog 1“ \\
\hline En1/2 & engl. „Engrailed“ 1/2 \\
\hline engl. & englisch \\
\hline et al. & und andere \\
\hline EtOH & Ethanol \\
\hline FCS & fetales Kälberserum (Fetal calv serum) \\
\hline Fgf8 & engl. „Fibroblast growth factor" \\
\hline Foxa2 & engl „Forkhead box $A$ 2“ \\
\hline g & Erdbeschleunigung \\
\hline Gbx2 & engl. „Gastrulation and brain-specific homeobox protein 2 " \\
\hline GDNF & engl. „Glia cell line-derived neurotrophic factor" \\
\hline Girk2 & engl. „G-protein-gated inwardly rectifying K channel subunit“ \\
\hline Gli & engl. "GLI-Kruppel family member" \\
\hline GP & Grundplatte \\
\hline HCl & Salzsäure \\
\hline IHC & Immunohistochemie \\
\hline IRES & engl. "internal ribosomal enry site \\
\hline ISH & in situ Hybridisierung \\
\hline IsO & Isthmisches Organisationszentrum \\
\hline IZM & Innere Zellmasse \\
\hline Klhl1 & engl. „kelch-like 1“ \\
\hline LacZ & das LacZ Gen codiert für das Enzym ß-Galactosidase \\
\hline L-DOPA & L-3,4-Dihydroxyphenylalanin \\
\hline $\mathbf{L m x 1 a / b}$ & engl. „Lim homeodomain transcription factor“ $1 \mathrm{a} / \mathrm{b}$ \\
\hline LoxP & engl. „Locus of crossing over in P1“ \\
\hline $\mathbf{M}$ & molar \\
\hline $\mathbf{m A}$ & Milliampere \\
\hline $\begin{array}{l}\text { mDA } \\
\text { (Neuronen) }\end{array}$ & mittelhirn-dopaminerge Neuronen, dopaminerge Neuronen des Mittelhirns \\
\hline MHG & Mittel-Hinterhirn-Grenze \\
\hline $\min$ & Minute \\
\hline ml & Milliliter \\
\hline $\mathbf{m M}$ & Millimolar \\
\hline Mm & Millimeter \\
\hline mRNA & engl. „messenger ribonucleic acid“ \\
\hline Ms & Mesencephalon \\
\hline Msx1/2 & engl. „Muscle segment homeobox $1 / 2^{\prime \prime}$ \\
\hline MT & Metencephalon \\
\hline MZ & Mantelzone \\
\hline Ngn2 & engl. „Neurogenin $2^{\prime \prime}$ \\
\hline Nkx6.1 & engl. „NK6 homeobox 1“ \\
\hline Nurr1 & $\begin{array}{l}\text { engl. „Nuclear receptor related } 1 \text { protein“, auch Nr4a2 = engl. „Nuclear receptor } \\
\text { subfamily 4, group A, member } 2 \text { " }\end{array}$ \\
\hline OD & optische Dichte \\
\hline Otx2 & engl. „Orthodenticle homologue 2 " \\
\hline Pax2 & engl. „Paired box gene 2“ \\
\hline
\end{tabular}




\begin{tabular}{|c|c|}
\hline PCR & engl. "polymerase chain reaction", Polymerase-Kettenreaktion \\
\hline Pitx3 & engl. „Paired-like homeodomain transcription factor 3 “ \\
\hline pS & pures Serum \\
\hline Ptpru & eng. „Protein tyrosine phosphatase receptor type $U^{\prime \prime}$ \\
\hline r2-r5 & Rhombomere 2 - 5 \\
\hline RC2 & engl. „Radial glial cell marker $2^{\prime}$ \\
\hline Ret & engl. „Ret proto-oncogene“ \\
\hline RNA & Ribonucleinsäure \\
\hline rpm & Umdrehungen pro Minute (engl. "rounds per minute") \\
\hline $\mathbf{R R F}$ & Retrorubales Feld \\
\hline $\mathbf{R S}$ & Retinolsäure \\
\hline RT & Raumtemperatur \\
\hline sek & Sekunde(n) \\
\hline Shh & engl. „Sonic hedgehog" \\
\hline SMRT & engl. "silencing mediator of retinoic acid and thyroid hormone receptor" \\
\hline SN & Substantia nigra \\
\hline Sox2 & engl. „SRY-box containing gene $2^{\prime \prime}$ \\
\hline SVZ & subventrikuläre Zone \\
\hline TC & Telencephalon \\
\hline Teg & Tegmentum \\
\hline TF & Transkriptionsfaktor(en) \\
\hline Tgf-ß & engl. "Transforming growth factor beta" \\
\hline TH & Tyrosinhydroxylase \\
\hline UTP & Uridintriphosphat \\
\hline VA & Volumenanteil \\
\hline Vmat2 & Vesikulärer Monoamintransporter 2 \\
\hline VTA & ventrales tegmentales Areal \\
\hline $\mathbf{V Z}$ & ventrikuläre Zone \\
\hline Wnt(1) & engl. „wingless-type MMTV integration site family, member” (1) \\
\hline ZNS & zentrales Nervensystem \\
\hline
\end{tabular}




\section{Inhaltsverzeichnis}

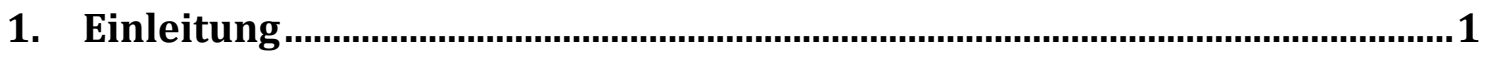

1.1 Lage und Funktion dopaminerger Neuronen im adulten Gehirn ................. 1

1.2 Die frühe Embryonalentwicklung der Maus ......................................................... 3

1.3 Die Entstehung des Zentralnervensystems.................................................... 5

1.4 Die Entwicklung dopaminerger Neuronen des Mittelhirns ........................... 9

1.4.1. Die Bedeutung der Bedeutung der BP und des IsO für die Entwicklung des ventralen Mittelhirns

1.4.2. Induzierung des dopaminergen Areals und Determinierung der mDA

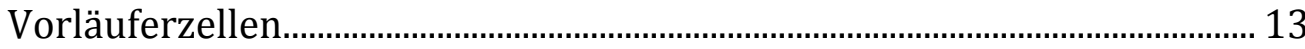

1.4.3. Frühe Differenzierung dopaminerger Neuronen.............................................. 16

1.4.4. Späte Differenzierung dopaminerger Neuronen.............................................. 19

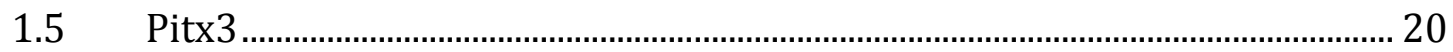

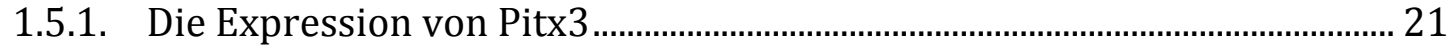

1.5.2. Die Funktion von Pitx3 während der Embryonalentwicklung .................... 21

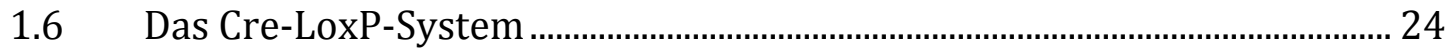

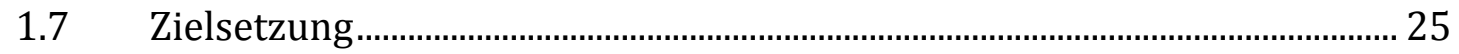

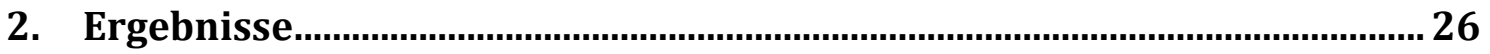

2.1 Überexpression von Pitx3 im ventralen Mittelhirn: Shh-Cre ${ }^{+/ P i t x 30 E}$ und Foxa2-Cre ${ }^{+/ P i t x 30 E}$

2.1.1 Pitx3 bewirkt eine Erhöhung der mDA Neuronen im Bereich des ventralen tegmentalen Areals (VTA).

2.1.2 Pitx3 hat einen positiven Einfluss auf die Expression von Lmx1a und Lmx1b

2.2 Überexpression von Pitx3 im dorsalen und ventralen Mittelhirn - Wnt1$\mathrm{Cre}^{+/ P i t x 30 E}$ und En1-Cre ${ }^{+/ P i t x 30 E}$

2.2.1. Pitx3 bewirkt eine Erhöhung der mDA Neuronen im Bereich des ventralen tegmentalen Areals (VTA).

2.2.2. Pitx3 hat einen positiven Einfluss auf die Expression von Lmx1a und Lmx1b in der Ventrikulären Zone (VZ).

2.2.3. Die Pitx3-Überexpression in der Wnt1-Domäne (Wnt1-Cre ${ }^{+/ P}{ }^{-}{ }^{20 E}$ ) hat keinen Einfluss auf die radiale Migration der mDA Neuronen...

2.2.4. Die Pitx3-Überexpression in der Wnt1-Domäne (Wnt1-Cre+/Pitx30E) bewirkt eine ektopische Wnt1-Expression und erhöhte Proliferation im ventralen Mittelhirn 
2.3 Überexpression von Lmx1a und Lmx1b in der Wnt1- Domäne - Wnt1$\mathrm{Cre}^{+/ \mathrm{Lm} x 1 \mathrm{aOE}}$ und Wnt1-Cre ${ }^{+/ \mathrm{Lm} x 1 \mathrm{bOE}}$

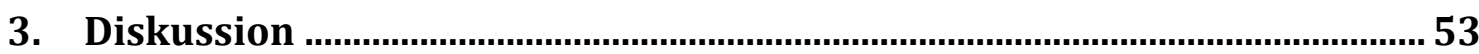

3.1. Überexpression von Pitx3 im Mittelhirn ........................................................ 54

3.2. Pitx3 bewirkt eine Erhöhung der mDA Neuronen im Bereich des ventralen tegmentalen Areals (VTA).

3.3. Pitx3 hat einen positiven Einfluss auf die Expression von Lmx1a/b und Wnt1

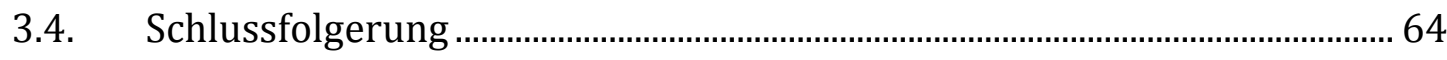

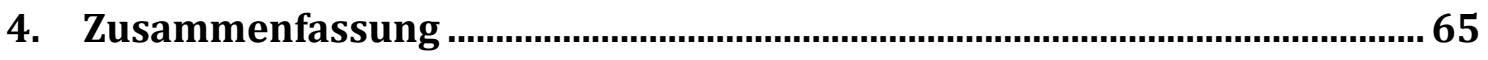

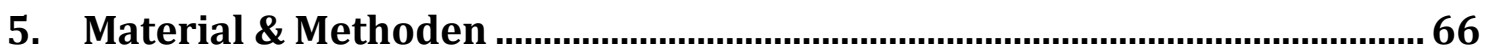

5.1. Chemikalien, Reagenzien und Pufferlösungen.................................................. 66

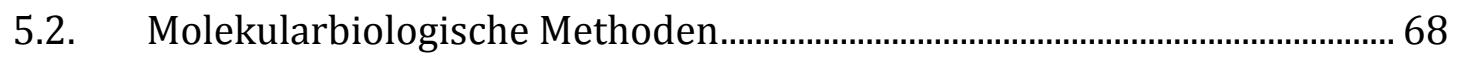

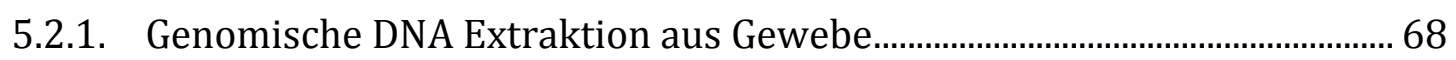

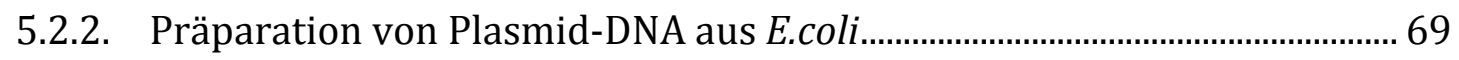

5.2.3. Phenol-Chloroform-Extraktion von DNA und Ethanolfällung..................... 69

5.2.4. Konzentrationbestimmung der DNA und RNA............................................... 70

5.2.5. Polymerase-Kettenreaktion (PCR) ................................................................ 70

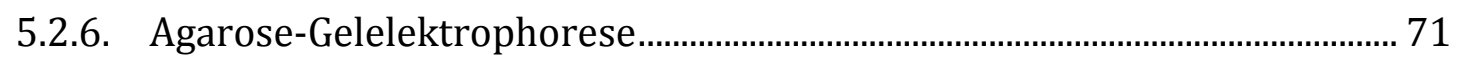

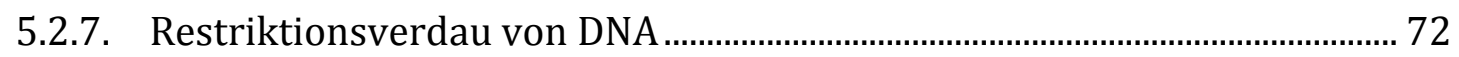

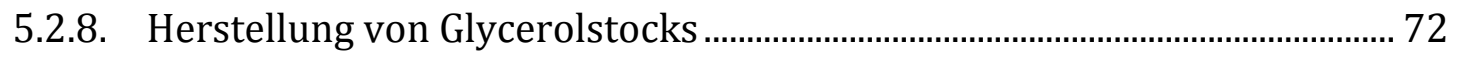

5.2.9. Aufreinigung von total-RNA aus Hefe ........................................................... 73

5.2.10. Herstellung DIG-markierter Proben ................................................................. 73

5.3. Tierexperimentelle Methoden ............................................................................. 74

5.3.1. Tiere

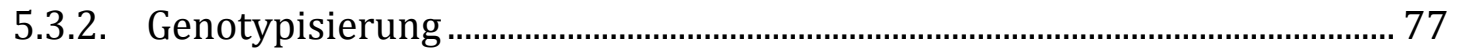

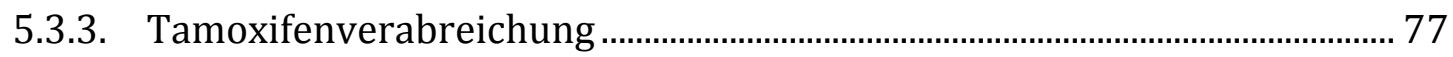

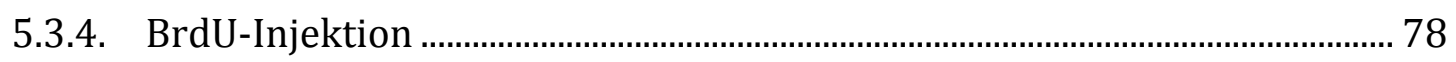

5.3.5. Präparation von Embryonen und Gehirnen ...................................................... 78

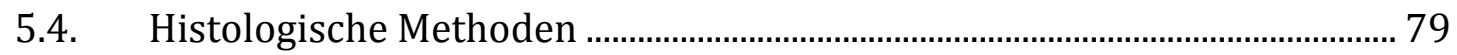

5.4.1. Einbettung der Embryonen und Gehirne in Kryomatrix.............................. 79

5.4.2. Einbettung der Embryonen und Gehirne in Paraffin ..................................... 79

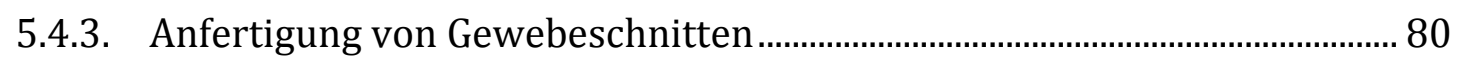

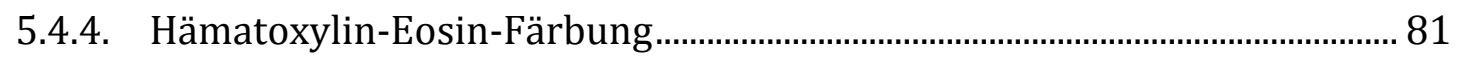

5.4.5. Indirekte Immunofluoreszenzfärbung (IIF) auf Gewebeschnitten........... 82 
5.4.6. BrdU- Färbung..

5.4.7. Detektion von RNA mittels in situ Hybridisierung (ISH) auf Gewebeschnitten 85

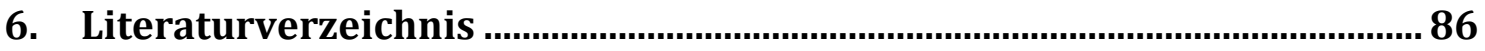

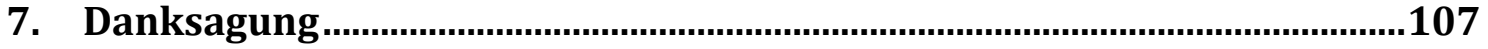

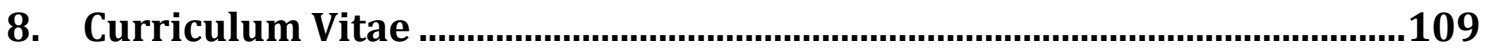




\section{Einleitung}

Die embryonale Entwicklung des Gehirns von der befruchteten Eizelle hin zum ausdifferenzierten Gewebe wird von verschiedenen, eng miteinander interagierenden molekularen Vorgängen gesteuert, wie z.B. der Zellteilung (Proliferation), Induktion, Musterbildung (Spezifizierung), Differenzierung, Migration und auch dem programmierten Zelltod (Apoptose). Dabei bestimmen extrinsische und intrinsische zelluläre Signale (Morphogene, Transkriptionsfaktoren und epigenetische Faktoren) das Schicksal einer jeden Zelle in Relation zu ihren Nachbarzellen (Gilbert, 2006; Sanes et al., 2006; Wolpert, 2007). Die Erforschung der genetischen und molekularen Faktoren, welche zur Etablierung von ausdifferenzierten funktionellen Nervenzellen als Teil eines neuronalen Netzwerkes, wie z.B. des dopaminergen Systems des Mittelhirns, notwendig sind, kann zu einem besseren Verständnis neurodegenerativer Krankheiten beitragen sowie neue Behandlungsmöglichkeiten eröffnen. Die Parkinsonsche Krankheit ist eine fortschreitende neurologische Erkrankung, bei der dopaminerge Neuronen des Mittelhirns (speziell der Substantia nigra) und somit auch des nigrostriatalen Systems degenerieren (Lang et al., 1998a; Hornykiewicz, 2001; Klockgether, 2004; Schulz et al., 2004).

In den folgenden Kapiteln werden zunächst die dopaminergen Neuronen im adulten murinen Mittelhirn beschrieben, bevor die embryonale Entwicklung der Maus mit Hinblick auf die Entstehung dieser Neuronen beschrieben wird. Dabei wird ein Überblick über die wichtigsten Mechanismen und Faktoren gegeben, die an der korrekten Entwicklung der dopaminergen Mittelhirnneuronen beteiligt sind. Nach einer spezielleren Beschreibung des Transkriptionsfaktors (TF) Pitx3 wird das Cre-loxP-System für gezielte genomische Veränderung bei der Maus beschrieben, bevor die Ergebnisse der in vivo Pitx3-Überexpression präsentiert und diese abschließend diskutiert werden.

\subsection{Lage und Funktion dopaminerger Neuronen im adulten Gehirn}

Bei den höheren Vertebraten stellen die dopaminergen Neuronen des Mittelhirns (mDA Neuronen) den Großteil der dopaminergen Neuronenpopulationen im ZNS 
dar (Björklund et al., 1984; Wallen et al., 2003). Dopaminerge Neuronen allgemein exprimieren das Enzym Tyrosinhydroxylase (TH), und nutzen den zu den katecholaminergen Neurotransmittern gehörenden Botenstoff Dopamin (Elsworth et al., 1997). Bei der Biosynthese von Dopamin wandelt das Enzym TH zunächst die Aminosäure Tyrosin in L-DOPA (L-3,4-Dihydroxyphenylalanin) um, bevor diese Zwischenstufe durch das Enzym AADC (Aromatische-L-AminosäureDecarboxylase) in Dopamin umgewandelt wird. Adrenerge Neuronen exprimieren ebenfalls TH und nutzen Dopamin als Zwischenstufe bei der Synthese zu Adrenalin. Allerdings exprimieren dopaminerge Neuronen kein DBH (Dopamin-ßhydroxylase), ein Enzym, das Dopamin in Noradrenalin, der Vorstufe zu Adrenalin, umwandelt (Goridis et al., 2002).

Die dopaminergen Neuronen des Mittelhirns werden, basierend auf der Anatomie und Lage der jeweiligen Zellkerne, sowie deren Projektionen zu bestimmten Arealen des Vorderhirns, in drei Subpopulationen unterteilt. Das ventrale tegmentale Areal (VTA, auch als A10 bezeichnet) liegt im ventro-medialen Bereich des Mittelhirns, und wird lateral von der Substantia nigra (SN, A9) flankiert (Abb. 1). Das retrorubale Feld (RRF, A8) liegt zwischen der SN und dem VTA und stellt eine Verbindung zwischen den beiden Gebieten her (Wallen \& Perlmann, 2003). Die Neuronen des VTA projizieren in das ventrale Striatum (Nucleus accumbens), die Amygdala, den Thalamus und Hippocampus, sowie in den präfrontalen Cortex. Damit ist das VTA ein Teil des mesolimbischen und mesokortikalen Signalweges, der u.a. kognitive Funktionen wie Motivation, Emotionen und Verlangen kontrolliert (Wallen \& Perlmann, 2003; Ang, 2006; Prakash et al., 2006a). Die Neuronen der SN projizieren in das dorsale Striatum und den Globus pallidus und bilden somit den nigrostriatalen Signalweg, der eine entscheidende Rolle bei der Bewegungssteuerung spielt (Wallen \& Perlmann, 2003; Ang, 2006; Prakash \& Wurst, 2006a). Bei der Parkinsonschen Krankheit degenerieren die Neuronen 
A)

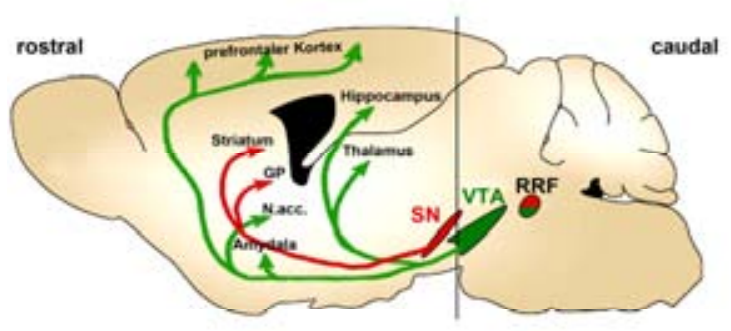

B)

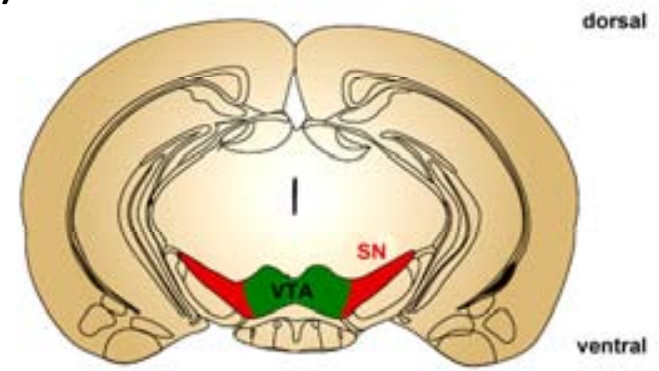

C)

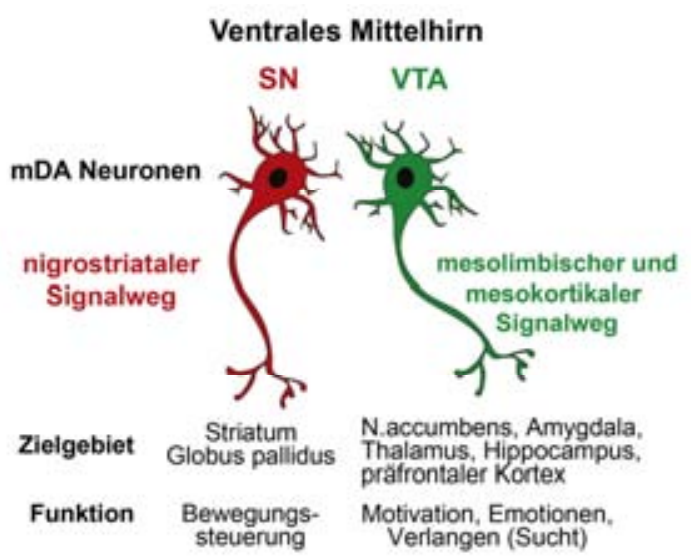

Abb. 1: Lage, axonale Projektionen und Funktion der dopaminergen Neuronen des Mittelhirns. A) Schematische Sagittalansicht eines adulten Mäusegehirns. Die Neuronen der Substantia nigra (SN, rot) projizieren in das dorsolaterale Striatum und den Globus Pallidus (GP), während Zielgebiete das ventrale tegmentale Areal (VTA, grün) in den Nucleus accumbens (N.acc.), die Amygdala, den präfrontalen Kortex, den Hippocampus und Thalamus projizieren. Die vertikale Linie zeigt die Schnittebene der Abb. B) Coronalschnitt durch das Mittelhirn mit der ventrolateralen SN und des medialen VTA. Im rostralen Mittelhirn ist nur die SN präsent, während im caudalen Mittelhirn das mediale VTA und das retrorubrale Feld (RRF) positioniert sind. C) Grafische Zusammenfassung des mDA Systems. Die Abbildungen wurden entnommen und abgewandelt nach (Prakash \& Wurst, 2006a; Smidt et al., 2007) (Joshi et al., 2011)

der SN und folglich ist auch der Nigrostriatale Signalweg affektiert, was zur sogenannten Schüttellähmung führt (Lang \& Lozano, 1998a; Lang et al., 1998b).

In der vorliegenden Arbeit werden die dopaminergen Neuronen des Mittelhirns (SN, VTA, RRF) als mDA Neuronen bzw. dopaminerge Neuronen bezeichnet - die übrigen dopaminergen Populationen des Vorder- und Zwischenhirns werden nicht beachtet.

\subsection{Die frühe Embryonalentwicklung der Maus}

Die Dauer der embryonalen Entwicklung der Maus beträgt von der Befruchtung der Eizelle bis zur Geburt 18 - 21 Tage (Wolpert, 2007). Nach erfolgreicher Verpaarung bildet sich bei der Maus ein Vaginalpfropfen (Plug), wodurch sich die embryonalen Entwicklungsstadien genau ermitteln lassen. Der Tag, an dem der Plug detektiert wurde, wird dabei als E $0.5(\mathrm{E}=$ Embryonalstadium) definiert. 


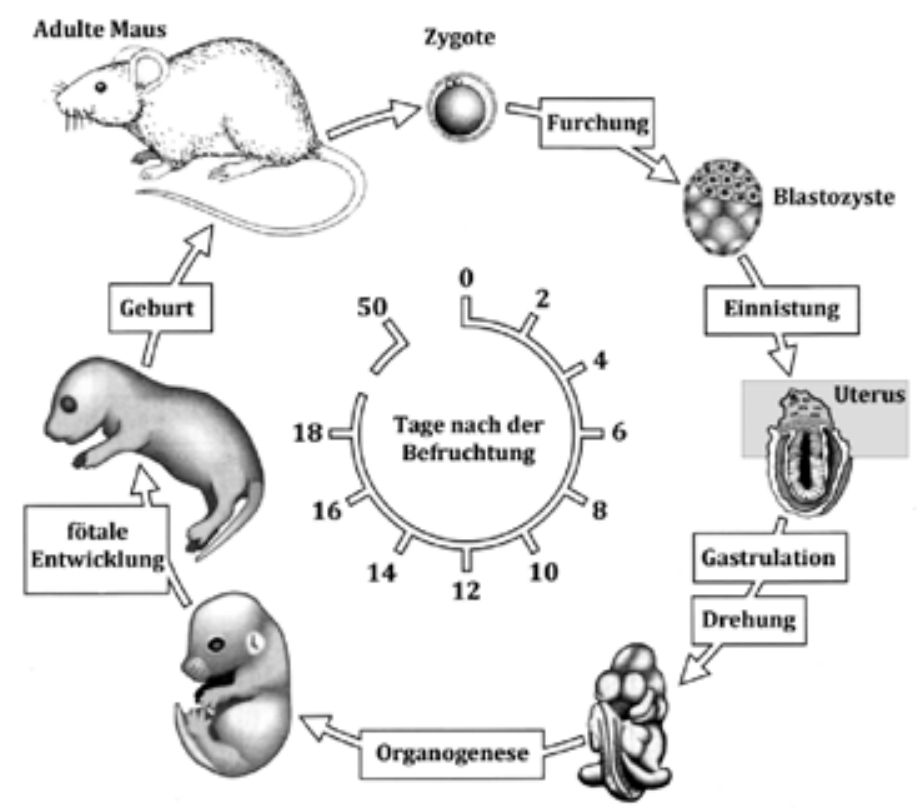

Abb. 2: Der Entwicklungszyklus der Maus. Die embryonale Entwicklung dauert 18-21 Tage, wobei der Tag nach der Befruchtung als E 0.5 definiert wird. Aus der befruchteten Eizelle (Zygote) bildet sich während der Furchung die Blastozyste, die sich in den Uterus einnistet. Während der Gastrulation und der folgenden Organogenese differenzieren sich sämtliche Gewebe in einer Phase von 7 Tagen ( E7.5 - E14.5). Die verbleibende Zeit bis zur Geburt unterliegt weitestgehend dem Gewebewachstum. Die Abbildung wurde entnommen und abgewandelt nach (Wolpert, 2007).

Aus der befruchteten Eizelle (Zygote) entwickelt sich durch mehrere symmetrische Zellteilungen (Furchung) zunächst eine Morula, dessen Zellen (Blastomere) sich bereits in Form, Polarität und Expression von Transkriptionsfaktoren (TF) unterscheiden. Sobald sich die Blastomeren in Trophektoderm und IZM differenziert haben, spricht man bei der Embryogenese von einer Blastozyste und dem Blastula-Stadium (E 3.5). Im weiteren Verlauf nistet sich die Blastozyste in die Gebärmutter ein (E 4.5) und das Gewebe des Trophektoderm und der IZM differenziert sich weiter. Aus dem Trophektoderm bildet sich das extraembryonale Gewebe (Plazenta), und die IZM differenziert sich zum Epiblast (primitives Ektoderm), aus dem der Embryo hervorgeht, sowie die mit ihm assoziierten Gewebe $(=$ primitives Endoderm $=$ Dottersack, Allantois, Amnion). Sechs Tage (E 6.5) nach der Befruchtung beginnt die Festlegung der Körperachsen und die Gastrulation setzt ein (Abb. 2). Während der Gastrulation immigrieren proliferierende Zellen durch den sich bildenden Primitivstreifen (Abb. 3), infolgedessen sich die drei Keimblätter, Endoderm, Mesoderm, und Ektoderm, bilden. Parallel dazu entstehen zwei Organisationzentren, welche die weiteren Entwicklungsvorgänge steuern. Der Knoten (das Äquivalent zum Hensenschen Knoten beim Huhn) kontrolliert die Entwicklung des gesamten 


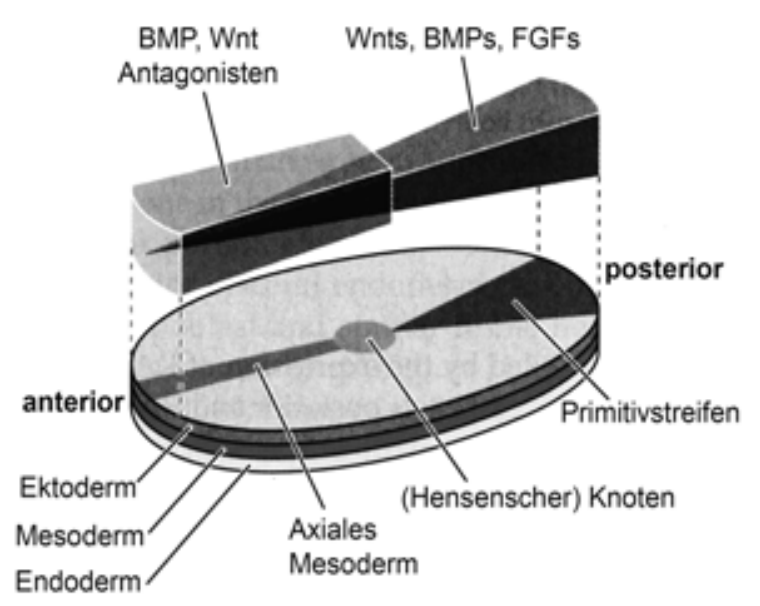

Abb. 3: Schematische Darstellung eines Mausembryos während der späten Gastrulation. Die anterioposteriore Ausrichtung wird durch entgegengesetzt wirkende Konzentrationsgradienten aus Signalmolekülen gebildet. Der Primitivstreifen und das posteriore Gewebe schütten Wnt-, Bmp-, und FgfSignalmoleküle aus, während der Knoten und das axiale Mesoderm dessen Antagonisten exprimieren. Die Abbildung wurde entnommen und abgewandelt nach (Gilbert, 2006)

Embryos, und zusammen mit dem anterior-visceralen Ektoderm (AVE) wird die Entstehung speziell der anterioren Regionen des Embryos gesteuert (Gilbert, 2006; Takaoka et al., 2012). In der späten Phase der Gastrulation besitzt der Embryo bereits eine klare anterior-posteriore Ausrichtung, entstanden durch einen Konzentrationsgradienten von Signalmolekülen und deren Antagonisten, welche vom Primitivstreifen und dem Knoten exprimiert werden (Abb. 3). Die posteriore Region exprimiert Proteine der Nodal-, Bmp-, Wnt, und Fgf-Familie, und in der anterioren Region werden deren Antagonisten (z.B. Lefty1 und Cerberus) exprimiert (Gilbert, 2006). Während der weiteren Embryonalentwicklung entsteht aus dem Endoderm der Verdauungstrakt, die Leber und Bauchspeicheldrüse sowie das Atmungssystem. Aus dem Mesoderm bilden sich die Knochen, Muskeln, die Niere, das Herz sowie Blutzellen, und aus dem Ektoderm geht die Epidermis sowie das zentrale Nervensystem (ZNS, Gehirn und Rückenmark) hervor (Gilbert, 2006; Wolpert, 2007).

\subsection{Die Entstehung des Zentralnervensystems}

Die Phase der Entwicklung des zentralen Nervensystems aus Zellen des Ektoderms wird als Neurulation bezeichnet, infolgedessen das Neuroektoderm determiniert, und sich das neuronale Gewebe in die verschiedenen Gehirnareale und Nervennetzwerke aufgliedert (Wolpert, 2007). Die neuronalen Vorläuferzellen des ZNS werden bereits in der späten Phase der Gastrulation spezifiziert, wobei die neurale Induktion des dorsalen Ektoderms durch Signale der primären Organisationszentren (Knoten und AVE, siehe Kap. 1.2) gesteuert wird. Im 
weiteren Verlauf geht aus den Zellen des dorsalen Ektoderms das Neuralrohr als Vorgängerstruktur des ZNS hervor (Abb. 4)(Wolpert, 2007).

Durch die neurale Induktion (E 7.0) differenziert sich das Neuroektoderm unter dem Einfluss des Notochord (Chorda dorsalis) und des axialen Mesoderms in drei dorsale Bereiche mit jeweils eigenem Entwicklungsschicksal. Aus dem dorsomedialen Neuroektoderm bildet sich die Neuralplatte, aus der sich das Neuralrohr entwickelt.

Aus dem lateral angrenzenden Bereich gehen die Neuralleistenzellen (engl. „neural crest cells") hervor, welche von dort aus in verschiedene Körperregionen einwandern, und aus denen verschiedene Gewebe hervorgehen (das periphere Nervensystem, Pigmentzellen sowie Teile der Knorpelgewebe des Kopfes). Die Neuralleistenzellen werden auf beiden Seiten von ektodermalen Gewebe flankiert, aus dem sich das Oberflächenektoderm (Epidermis, Haare, Talgdrüsen, Augen, usw.) entwickelt (Gilbert, 2006; Wolpert, 2007). Bereits kurz nach der Bildung der Neuralplatte senkt sich dessen medialer Bereich ab und bildet die Neuralrinne, während sich die beiden lateralen Rändern nach dorsal aufstülpen und als Neuralwülste bezeichnet werden. Die sich aufeinander $\mathrm{zu}$ bewegenden Neuralwülste fusionieren dorsal $\mathrm{zu}$ einem Neuralrohr mit einem zentralen Ventrikel, welches die Körperachse von anterior nach posterior (a-p) durchzieht (Abb. 4 A). Das Neuralrohr differenziert sich weiter in die verschiedenen Gehirnregionen (Regionalisierung), wobei zunächst die drei primären Gehirnventrikel entstehen (Abb. 4 B): das rostrale Prosencephalon (Vorderhirn), das Mesencephalon (Mittelhirn), das caudale Rhombencephalon (Hinterhirn) sowie das Rückenmark. Aus den drei primären Gehirnventrikeln gehen die fünf sekundären Gehirnventrikel hervor: Das Prosencephalon differenziert sich in das rostrale Telencephalon (Vorderhirn) und Diencephalon (Zwischenhirn), während das Mesencephalon (Mittelhirn) in seiner Struktur erhalten bleibt und sich nicht weiter untergliedert. Aus dem Rhombencephalon geht das Metencephalon (Hinterhirn) und das Myelencephalon (Nachhirn, Hirnstamm) hervor, wobei das Nachhirn und das Rückenmark später strukturell ineinander übergehen (Gilbert, 2006; Wolpert, 2007). Die Entwicklung des Neuralrohres in die verschiedenen anterior-posterioren Gehirnregionen wird dabei durch verschiedene Transkriptionsfaktoren (ausgeschüttet vom axialen Mesoderm, Notochord und Epidermis) und deren Signalwegen gesteuert, die miteinander 
A)

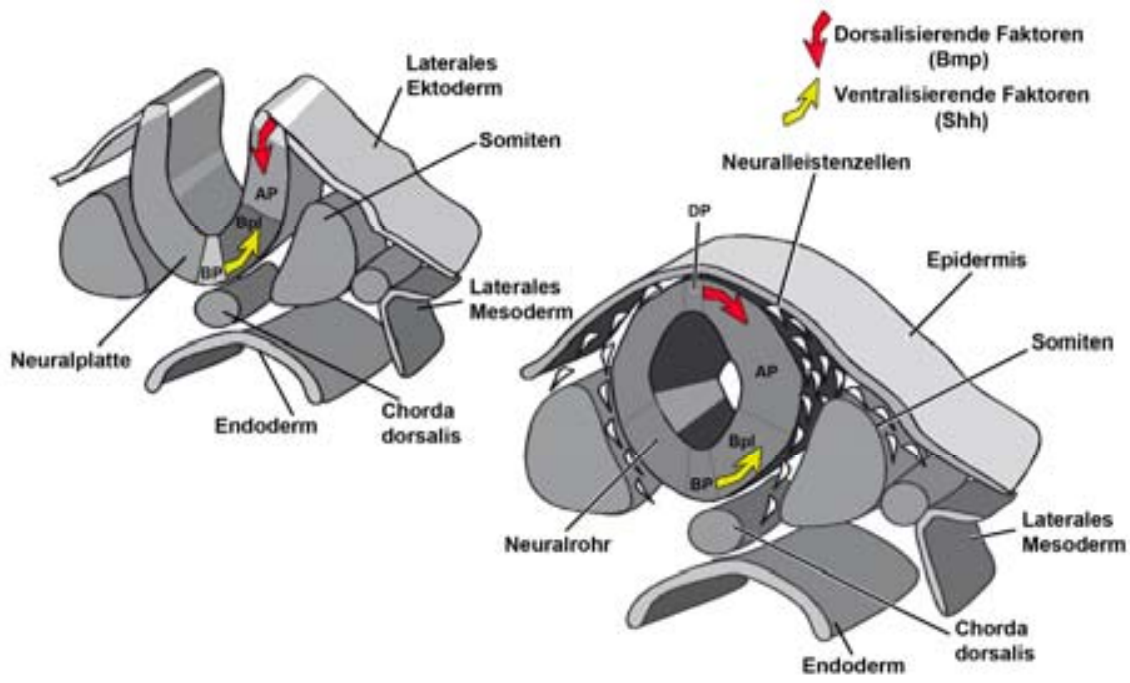

B)

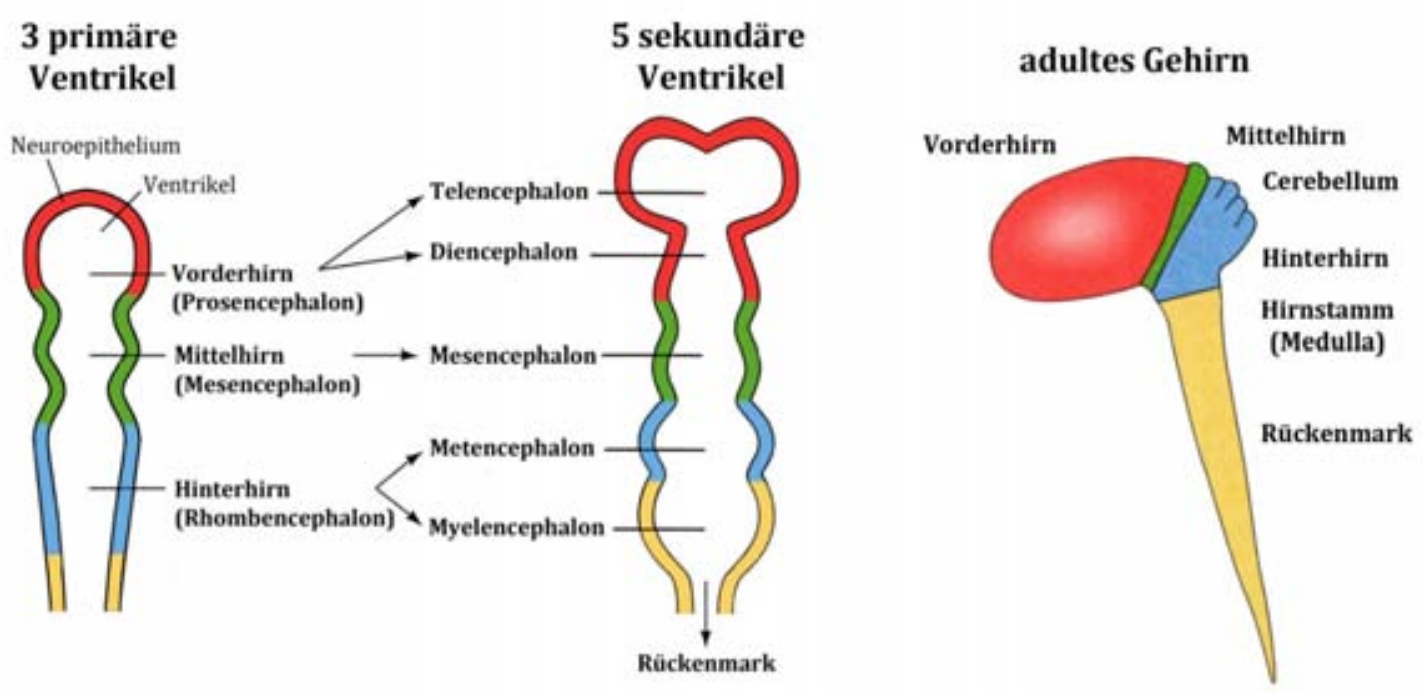

Abb. 4: Neurulation des Zentralen Nervensystems. A) Schematische Coronalansicht des sich entwickelnden Neuralrohres. Während der Neurulation differenziert sich das Neuroektoderm unter dem Einfluss der Chorda Dorsalis und des axiales Mesoderms in die Neuralplatte, Neuralleistenzellen und die Epidermis. Aus der Neuralplatte geht das Neuralrohr hervor, welches in die ventrale Bodenplatte (BP), Basalplatte (Bpl), Alarplatte (AP) und die dorsale Dachplatte (DP) untergliedert wird. Die DP exprimiert dorsalisierende Faktoren (Bmp), während die BP ventralisierende Faktoren (Shh) ausschüttet, und somit die dorso-ventrale Ausrichtung steuert. B) Schematische Transversalansicht des Neuralrohres. Die drei primären Gehirnvesikel Prosencephalon, Mesencephalon, und Rhombencephalon untergliedern sich während der Regionalisierung in die fünf sekundären Ventrikel (Telencephalon, Diencephalon, Mesencephalon, Metencephalon, Myelencephalon). Diese Untergliederung reflektiert die anatomische Organisation des adulten Gehirns (rot = Vorderhirn (Telencephalon, Diencephalon), grün $=$ Mittelhirn (Mesencephalon), blau $=$ Hinterhirn (Metencephalon) und gelb $=$ Rückenmark (Myelencephalon). Die Abbildungen wurden entnommen und abgewandelt nach (Gilbert, 2006; Sanes et al., 2006; Vieira et al., 2010)

interagieren (Wessely et al., 2002; Gilbert, 2006; Wolpert, 2007). Bei Mäusen, z.B. wird das Vorder- und Mittelhirn u. a. durch die Transkriptionsfaktoren Emx1/2 (engl. „Empty spiracles homolog“ 1/2) und Otx2 (engl. „Orthodenticle homolog“ 2) determiniert (Boncinelli et al., 1995; Suda et al., 2001; Kurokawa et al., 2004; Sanes et al., 2009). 
Neben der anterior-posterioren Achse besitzt das Neuralrohr und das sich daraus entwickelnde ZNS eine klare dorso-ventrale (d-v) Ausrichtung, wobei die Spezifizierung der dorsalen, intermediären und ventralen Regionen durch sich bildende Gradienten von Signalmolekülen gesteuert werden. Im ventralen Bereich des Neuralrohres wird die Bildung der Bodenplatte (BP, engl. „floor plate") durch das Signalmolekül Shh (engl. „Sonic hedgehog“) induziert, welches von der ventral gelegenen Chorda dorsalis (engl. „notochord“, mesodermaler Herkunft) ausgeschüttet wird (Abb. 4 A). Die BP exprimiert nun ebenfalls Shh und übernimmt in der weiteren Entwicklung wichtige induktive Funktionen im ventralen Neuralrohr (Marti et al., 1995; Roelink et al., 1995; Fuccillo et al., 2006). Die Determination der dorsalen Regionen des Neuralrohres erfolgt durch die Ausschüttung von Signalmolekülen der Tgf-ß Familie (engl. „Transforming growth factor beta"), ausgehend von der Epidermis und der sich bildenden Dachplatte (DP, engl. „roof plate“). Die dorsale DP und die ventrale BP sind zwei Organisationzentren, die das Neuralrohr auf seiner gesamten Länge durchziehen. Beide steuern durch die Ausschüttung von diffundierenden Proteinen (Morphogene) die weitere Entwicklung der dorsalen (DP), intermediären, und ventralen (BP) Neuralregionen. Die von der DP und BP abgegebenen Morphogene bilden entgegengesetzt wirkende Gradienten in dorso-ventraler Ausrichtung, und induzieren die Expression spezifischer Transkriptionsfaktoren (TF) (Lee et al., 1999; Briscoe et al., 2001). Das Neuralrohr differenziert sich dadurch in determinierte Areale, die sich von ventral nach dorsal in die Boden-, Basal-, Alarund Dachplatte einteilen lassen (Abb. 4 A) (Smits et al., 2006a; Smits et al., 2006b; Sanes \& Bao, 2009).

Die innerste Zellschicht in der Zentralregion des Neuralrohres, welche direkten Kontakt zum Ventrikel hat, wird als ventrikuläre Zone (VZ) bezeichnet. Die Zellen der VZ sind pluripotente neuronale Stammzellen, und sie sind die Vorläuferzellen aller späteren Neuronen sowie Gliazellen. Sie haben eine hohe Proliferationsrate, wobei sie sich symmetrisch und auch asymmetrisch teilen können (Götz et al., 2005). In den frühen Phasen der Gehirnentwicklung überwiegt die symmetrische Zellteilung, bei der sich wiederum zwei mitotische Vorläuferzellen bilden, während in den späten Phasen jeweils eine Vorgängerzelle und eine postmitotische Tochterzelle entsteht (asymmetrische Zellteilung). Diese migriert zunächst in die subventrikuläre Zone (SVZ) und schließlich in die Mantelzone (MZ), die äußerste 
Schicht des Neuralrohres. Während der Migration über die SVZ in die MZ beginnen die postmitotischen Zellen sich in ihre neuronalen Subtypen zu differenzieren (Gilbert, 2006; Sanes et al., 2006).

\subsection{Die Entwicklung dopaminerger Neuronen des Mittelhirns}

Die Entwicklung von ausdifferenzierten und funktionellen dopaminergen Neuronen aus neuronalen Vorläuferzellen ist ein schrittweiser Prozess, der von extrinsischen und intrinsischen Signalen gesteuert wird. Die einzelnen Phasen zeichnen sich durch die Expression von bestimmten Faktoren und Proteinen aus, und werden in (1) Regionalisierung, (2) frühe und (3) späte Differenzierung eingeteilt (Ang, 2006). Die Zellen des Mittelhirns werden unter dem Einfluss zweier Organisationszentren (Kapitel 1.4.1. und 1.4.2.) zunächst in dopaminerge Vorläuferzellen regional determiniert, bevor sie im weiteren Verlauf zu funktionellen mDA Neuronen ausdifferenzieren (Kapitel 1.4.3. und 1.4.4.) (Ang, 2006; Prakash \& Wurst, 2006a).

\subsubsection{Die Bedeutung der Bedeutung der BP und des IsO für die Entwicklung des ventralen Mittelhirns}

Die Induktion und die Entwicklung von mDA Neuronen ist abhängig von der korrekten Entwicklung des ventralen Mittelhirns sowie der morphologischen Grenze zwischen Mittel- und Hinterhirn. In diesen Bereichen befinden sich wichtige Organisationszentren (BP und IsO, s.u.), welche die Entwicklung der mDA Neuronen maßgeblich steuern (Burbach et al., 2003).

Die Bodenplatte des ventralen Neuralrohres (BP, Abb. 4 A, Kap. 1.3) wird zunächst durch Shh von der ventral gelegenen Chorda dorsalis als ventrales Organisationszentrum induziert (E7.0). Bei der Induktion der BP sind u.a. Gli2 (engl. „GLI-Kruppel family member GLI2") und Foxa2 (engl. „Forkhead box A2") als nachgeschaltete Effektorproteine des Shh-Signalweges beteiligt (Sasaki et al., 1994; Roelink et al., 1995; Ding et al., 1998; Matise et al., 1998). Die BP ist nun als ventrales Organisationszentrum etabliert und schüttet nun selbst das Morphogen Shh aus (E8.0), wodurch sich ein Konzentrationsgradient bildet, auf den die ventralen neuronalen Vorläuferzellen entlang des gesamten Neuralrohres 
reagieren (Echelard et al., 1993; Jessell, 2000; Placzek et al., 2005). Allerdings unterscheiden sich die Zellen der BP im Mittelhirn in ihren morphologischen und molekularen Eigenschaften von den übrigen Bereichen des sich entwickelnden ZNS. Im Mittelhirn besitzen die Zellen der BP neurogene Aktivität, d.h., dass aus ihnen selbst neuronale Zellen hervorgehen, was ein besonderes Alleinstellungsmerkmal des Mittelhirns ist (Placzek \& Briscoe, 2005; Kittappa et al., 2007; Ono et al., 2007; Bonilla et al., 2008). Im Hinterhirn und Rückenmark hingegen haben die Zellen der BP nur eine instruktive Funktion für die lateral der BP liegenden neuronalen Vorläuferzellen, und aus ihnen selbst gehen keine Neuronen hervor (Jessell, 2000). Nach der Induzierung der BP des Mittelhirns muss die weitere Expression von Shh in diesem Bereich geblockt werden, damit die Neurogenese der mDA Neuronen aus Zellen der BP stattfinden finden kann. Das Glykoprotein Wnt1 (eng. „Wingless-related MMTV integration site 1") und der damit verbundene kanonische Wnt-Signalweg inhibieren dabei die Expression von Shh im Mittelhirn, wodurch die Neurogenese der mDA Neuronen aus den Zellen der BP initiiert wird. Die Inhibierung der Shh-Expression durch Wnt1 im Mittelhirn ist somit ein entscheidender Aspekt für die neurogene Aktivität der BP und unterscheidet sich dadurch von der BP des Hinterhirns (Abb. 5 A) (Fasano et al., 2009; Joksimovic et al., 2009; Tang et al., 2009; Tang et al., 2010). Für die Generierung der mDA Neuronen ist also zunächst die korrekte Etablierung der BP durch Shh entscheidend, dessen Zellen anschließend in dopaminerge Vorläuferzellen spezifiziert werden.

Das zweite wichtige Organisationszentrum befindet sich im Bereich des Isthmus, der morphologischen Grenze zwischen dem Mittel- und Hinterhirn (Abb. 5 B). Dieses Isthmische Organisationszentrum (IsO) ist für die Entwicklung des gesamten Mittel- und anterioren Hinterhirns, und somit auch der mDA Neuronen, von entscheidender Bedeutung (Liu et al., 2001; Martinez-Barbera et al., 2001; Prakash et al., 2004). Dies konnte z.B. gezeigt werden, indem Gewebe des IsO in das Vorder- bzw. Zwischenhirn transplantiert wurde. Die Zellen in der Umgebung des ektopischen IsO begannen daraufhin, ektopische Faktoren zu exprimieren und Strukturen zu bilden, die für die MHG charakteristisch sind (Gardner et al., 1991; Martinez et al., 1991; Bally-Cuif et al., 1992). Das IsO bildet sich bereits während der 
A)

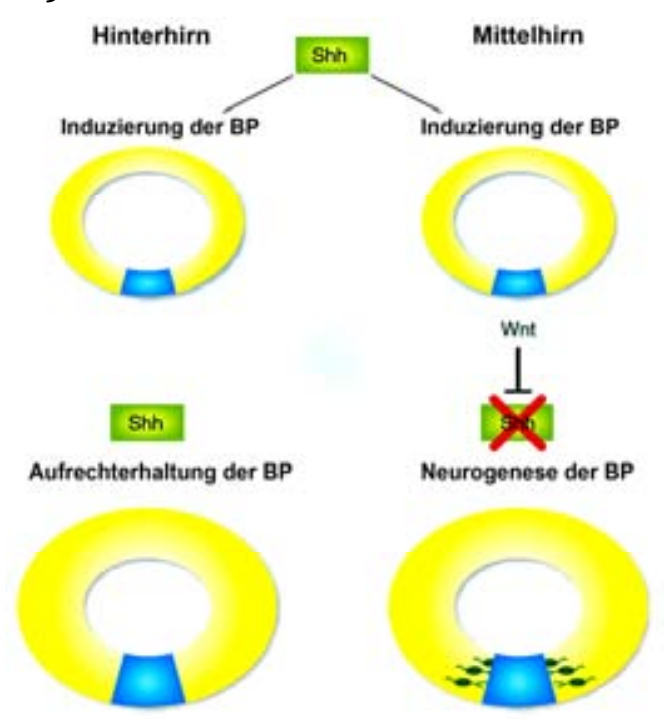

B)

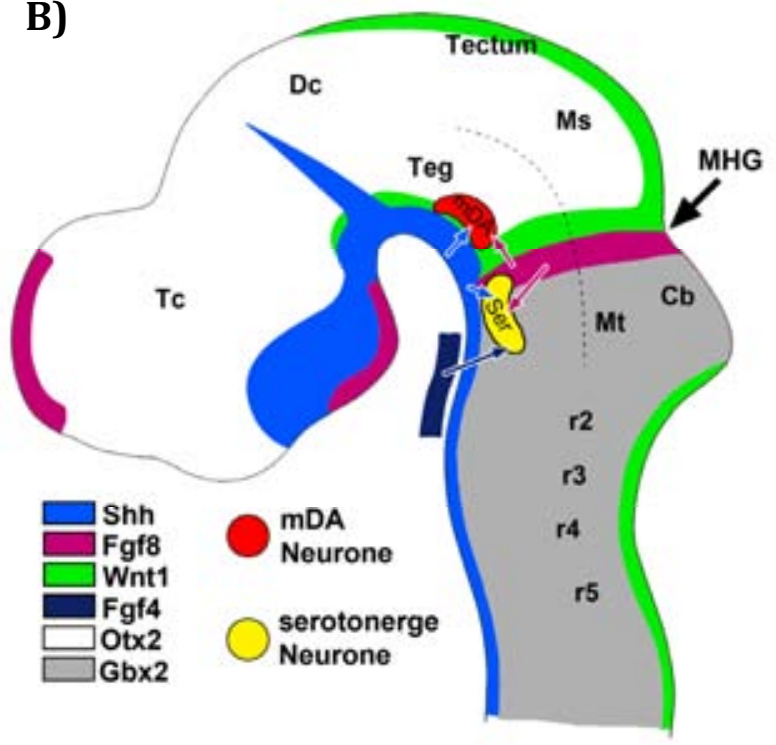

Abb. 5: Induktion der mDA Neuronen. A) Schematische Coronalansicht des Neuralrohres im Mittel- und Hinterhirn. Die ventrale Bodenplatte (blau) wird zunächst durch den Shh-Signalweg induziert. Die Shh- Expression im Hinterhirn wird aufrechterhalten und aus der BP gehen keine Neuronen hervor. Im Mittelhirn hingegen wird Shh nach der Induktion der BP durch den kanonischen Wnt-Signalweg inhibiert, was zur Neurogenese dopaminerger Neuronen aus Zellen der BP führt. B) Schematische Sagittalansicht des Neuralrohres eines Mausembryos am Tag E11.0 mit den Expressionsdomänen der wichtigsten Faktoren. Die mDA Neuronen (rot) werden durch eine Kombination verschiedener Faktoren anterior der Mittel-Hinterhirn-Grenze (MHG) induziert: Shh (blau) wird von der BP sezerniert, während Fgf8 (lila) vom Isthmischen Organisationszentrum der MHG exprimiert wird. Serotonerge Neuronen (Ser) liegen posterior der MHG und werden durch die Faktoren Shh, Fgf8 und Fgf4 induziert. Die mDA und die serotonergen Neuronen sind durch die MHG separiert. Die Expressionsdomänen der einzelnen Faktoren unterliegen einer transienten und dynamischen Expression - die hier gezeigten Expressionen sind nur eine Momentaufnahme des Embryonaltages E11.0; $\mathrm{Tc}=$ Telencephalon, $\mathrm{Dc}=$ Diencephalon, $\mathrm{Teg}=$ Tegmentum, Ms = Mesencephalon, $\mathrm{Mt}=$ Metencephalon, $\mathrm{Cb}=$ Cerebellum, $\mathrm{r} 2-\mathrm{r} 5=$ Rhombomere $2-5$. Die Abbildungen wurden entnommen und abgewandelt nach (Prakash \& Wurst, 2004; Fasano \& Studer, 2009).

Regionalisierungsphase des Neuralrohres (E7.5) durch komplexe Interaktionen von Transkiptionsfaktoren (z.B. Otx2, Gbx2, Fgf4, Lmx1b, Wnt1, Fgf8, En1, Pax2) (Wurst et al., 2001). Nach der neuronalen Induktion exprimiert der anteriore Teil des Neuroektoderms Otx2 (engl. „Orthodenticle homologue 2"), während in der posterioren Region Gbx2 (engl. „Gastrulation brain homeobox 2") gebildet wird. Diese beiden TF inhibieren sich gegenseitig, und in dem Bereich, in dem ihre Expressionsdomänen aufeinandertreffen, bildet sich die Mittel-Hinterhirn-Grenze (MHG, Abb. 5 B) und das IsO wird unter dem Einfluss des axialen Mesoderms induziert (Simeone, 2000; Liu \& Joyner, 2001; Wurst \& Bally-Cuif, 2001). Otx2 und Gbx2 spezifizieren dabei vielmehr die Lage des IsO und sind nicht an dessen Induktion beteiligt, denn in Abwesenheit beider TF werden spezifische Gene des IsO exprimiert (Liu \& Joyner, 2001). Ein Verlust von Otx2 bewirkt eine anteriore Verschiebung der Gbx2 Expressionsdomäne und folglich einen Verlust des Vorder-, 
Zwischen- und Mittelhirns. Dementsprechend entwickelt sich kein Hinterhirn, wenn ein Verlust an Gbx2 Expression vorliegt (Acampora et al., 1995; Matsuo et al., 1995; Wassarman et al., 1997; Millet et al., 1999). Parallel zur Entstehung der Otx2-Gbx2-Grenze wird Pax2 (engl. „Paired box gene 2“) beiderseits dieser Grenze exprimiert, während der TF Lmx1b (engl. „LIM homeodomain TF 1 beta“) anterior des IsO gebildet. Daraufhin wird die Expression von En1 (engl. „Engrailed 1“; E8.5) und Wnt1 (E8.0) innerhalb der Pax2-Domäne beiderseits der MHG initiiert. Ebenso beginnt die Expression von Fgf8 (engl. „Fibroblast growth factor 8“) in einem schmalen Bereich posterior der MHG. Einen halben Tag später startet in dem gleichen Bereich die Expression von Pax5 sowie En2. Die Expression von Wnt1 erstreckt sich bei E8.0 noch über das gesamte d-v Mittelhirn, und begrenzt sich am Embryonaltag E9.5 auf einen schmalen d-v Ring anterior der MHG sowie auf die DP und BP des Mittelhirns (Joyner, 1996; Joyner et al., 2000; Smidt et al., 2000; Prakash \& Wurst, 2004).

Ein entscheidender Faktor für die Entwicklung des Mittel- und Hinterhirns ist Fgf8, dessen Expression bei E8.5 im rostralen Mittelhirn initiiert wird und sich einen Tag später (E9.5) auf einen schmalen Streifen posterior der MHG beschränkt (Abb. 5 B) (Liu \& Joyner, 2001; Wurst \& Bally-Cuif, 2001). Bei einem Verlust der Fgf8 Expression ist die Funktion des IsO stark beeinträchtigt, da Gene des IsO wie Wnt1 und Gbx2 nicht länger exprimiert werden, und das Mittel- und Hinterhirn wird nicht entwickelt (Chi et al., 2003; Prakash \& Wurst, 2004). Durch Transplantationsstudien im Vorderhirn konnte nachgewiesen werden, dass Fgf8 allein in der Lage ist, Faktoren des IsO sowie Strukturen des Mittel- und Hinterhirns zu induzieren. (Crossley et al., 1996; Liu et al., 1999; Martinez et al., 1999). Fgf8 wird daher als Haupteffektor des IsO angesehen, der für dessen Bildung und Aufrechterhaltung von großer Bedeutung ist. Ein Verlust der Wnt1Expression führt zu einem schrittweisen Verlust der En1 und Fgf8 Expression, wobei Bereiche des Mittel- und Hinterhirns degenerieren (McMahon et al., 1990; Thomas et al., 1990; McMahon et al., 1992). Andererseits hat eine ektopische Überexpression von Wnt1 in der En1-Domäne keinen Einfluss auf die Funktion des IsO. Allerdings bewirkt diese ektopische Wnt1-Expression eine Vergrößerung der dorsalen Regionen der MHG, bedingt durch eine Überproliferation der Vorläuferzellen (Panhuysen et al., 2004). Die Autoren folgerten daraus, dass Wnt1 nicht an der Induktion, wohl aber an der Aufrechterhaltung des IsO entscheidend 
ist. Der TF Lmx1b kann bei E10.0 u.a. in der DP, BP und in der MHG detektiert werden, wo eine fast vollständige Koexpression mit Wnt1 vorliegt. Lmx1b kann Wnt1 induzieren und ist für die Aufrechterhaltung der Wnt1-Expression von Bedeutung (Adams et al., 2000; Matsunaga et al., 2002; Nakamura et al., 2005; Chung et al., 2009). Bei einem Verlust der Lmx1b Expression wird kein Wnt1 und Fgf8 mehr gebildet und Strukturen des Mittel- und Hinterhirns gehen verloren (O'Hara et al., 2005; Guo et al., 2007).

Die Entwicklung des ventralen Mittelhirns ist also ein Resultat eines komplexen molekularen Netzwerkes von TF (u.a. Otx2, Gbx2, Fgf8, Wnt1, Shh, Lmx1b). Ein Verlust oder eine Deregulierung eines dieser Gene hat Auswirkungen auf die Expression der anderen Gene und kann somit Missbildungen im Bereich des Mittel- und Hinterhirns hervorrufen (Wurst \& Bally-Cuif, 2001; Prakash \& Wurst, 2004).

\subsubsection{Induzierung des dopaminergen Areals und Determinierung der mDA Vorläuferzellen}

Die ausgeschütteten Signalmoleküle Shh (von der BP) sowie Fgf8 (vom IsO) sind für die Induzierung des dopaminergen Areals im ventralen Mittelhirn erforderlich, und es konnte gezeigt werden, dass diese beiden Faktoren für die Induktion ausreichend sind. Als Resultat bilden sich mDA Vorläuferzellen, die in a-p und d-vAchse regional determiniert sind. Weiterhin sind an diesem Prozess noch Wnt1 und Proteine der Tgf- $ß$ Familie beteiligt, die allein jedoch nicht ausreichen, um mDA Neuronen zu induzieren (Hynes et al., 1995a; Ye et al., 1998; Farkas et al., 2003; Prakash et al., 2006). Durch Shh und Fgf8 wird eine zeitlich geordnete Expression von intrinsischen Faktoren in Gang gesetzt, die z.B. die Proliferation und die Inhibierung alternativer Entwicklungsprozesse steuern. Die Expression von Otx2, En1/2 sowie Lmx1b kann bereits in den Vorläuferzellen der VZ bei E8.5 detektiert werden (Ang et al., 1994; Smidt et al., 2000), wobei diese Faktoren bereits für die Etablierung des Mittelhirnbereichs von Relevanz sind. Im gleichen Zeitraum wird die Expression von Lmx1a (engl. „LIM homeodomain TF 1 alpha“) und Msx1/2 (engl. „Muscle segment homeobox 1/2") in Vorläuferzellen der mDA Neuronen initiiert, bevor Ngn2 (engl. „Neurogenin 2“) detektiert werden kann und somit die Neurogenese initiiert wird (Failli et al., 2002; Andersson et al., 2006). Im 
Gegensatz zu Msx1/2, die nur in den mitotischen Vorläuferzellen in der VZ exprimiert werden, wird Lmx1a auch in postmitotischen Neuronen während der folgenden Differenzierung exprimiert. Es konnte gezeigt werden, dass Lmx1a erforderlich und ausreichend ist, die Bildung mDA Neuronen $\mathrm{zu}$ induzieren, während Msx1/2 dazu nicht in der Lage sind (Andersson et al., 2006; Lin et al., 2009; Nakatani et al., 2010). Durch Analysen in Hühnerembryonen wurde herausgefunden, dass Shh die Expression von Lmx1a induzieren kann, wodurch Msx1/2 aktiviert werden (Andersson et al., 2006). Allerdings sind weitere Faktoren bei dieser Induktion von Lmx1a, wie z.B. Foxa1/2 involviert, da ein spezifischer Verlust von Shh in der BP keine Auswirkung auf die Anzahl Lmx1apositiver Zellen hat (Lin et al., 2009; Mavromatakis et al., 2011). Lmx1a induziert Msx1/2, die wiederum die nachfolgende Expression von Ngn2 bei E10.5 aktivieren und somit die Initiation der Neurogenese dopaminerger Neuronen starten (Abb. 6 und 7 D). Gleichzeitig bewirken Msx1/2 eine Inhibierung von Nkx6.1 (engl. „NK6 homeobox 1“), einem TF, der die Bildung benachbarter Neuronenpopulationen (z.B. glutamaterge Neuronen) begünstigt. Dadurch wird das dopaminerge Feld gegen die lateralen neuronalen Domänen abgegrenzt (Andersson et al., 2006; Ang, 2006; Kele et al., 2006). Das Enzym Aldh1a1 (engl. „Aldehyde dehydrogenase family 1, subfamily A1“, auch bekannt als AHD2 und Raldh1) wandelt Retinaldehyd (Retinol) in Retinolsäure (RS) um, und kann in proliferierenden Zellen der ventrikulären Zone (VZ) am Tag E9.5 detektiert werden. Während der späteren Entwicklung ist Aldh1a1 auch in postmitotischen mDA Neuronen exprimiert und zeigt eine Koexpression mit TH. Es wird vermutet, dass Aldh1a1 und die synthetisierte Retinolsäure während der folgenden Differenzierung und Aufrechterhaltung der mDA Neuronen von Bedeutung sind (McCaffery et al., 1994; Haselbeck et al., 1999; Wallén et al., 1999; Wallen et al., 2001; Maden, 2007; Anderson et al., 2011; Jacobs et al., 2011).

Bei Mäusen mit einem Verlust des Wnt1 Gens liegt eine starke Reduzierung dopaminerger Neuronen bei gleichzeitiger Unterentwicklung des Mittel- und Hinterhirns vor (Prakash et al., 2006). Wnt1 beeinflusst die Neurogenese der dopaminergen Neuronen dabei in zweierlei Weise: Einerseits ist die Expression von Wnt1 für die Aufrechterhaltung der Otx2- und En1-Expression zwischen E9.5 - E11.5 erforderlich und stabilisiert somit das Gebiet des ventralen Mittelhirns (Danielian et al., 1996; Puelles et al., 2004; Prakash et al., 2006; Prakash \& Wurst, 
2006a; Prakash et al., 2006b). Andererseits wird Wnt1 zwischen E11.5 und E12.5 für die geordnete Differenzierung dopaminerger Neuronen benötigt - bei einem Verlust von Wnt1 werden zunächst dopaminerge Neuronen gebildet, die sich aber nicht weiter differenzieren und letztlich absterben. In vitro Analysen haben auch gezeigt, dass ektopische mDA Neuronen nur durch ein Zusammenspiel von Shh, Fgf8 und Wnt1 entstehen können (Prakash et al., 2006; Prakash \& Wurst, 2006a; Prakash \& Wurst, 2006b).

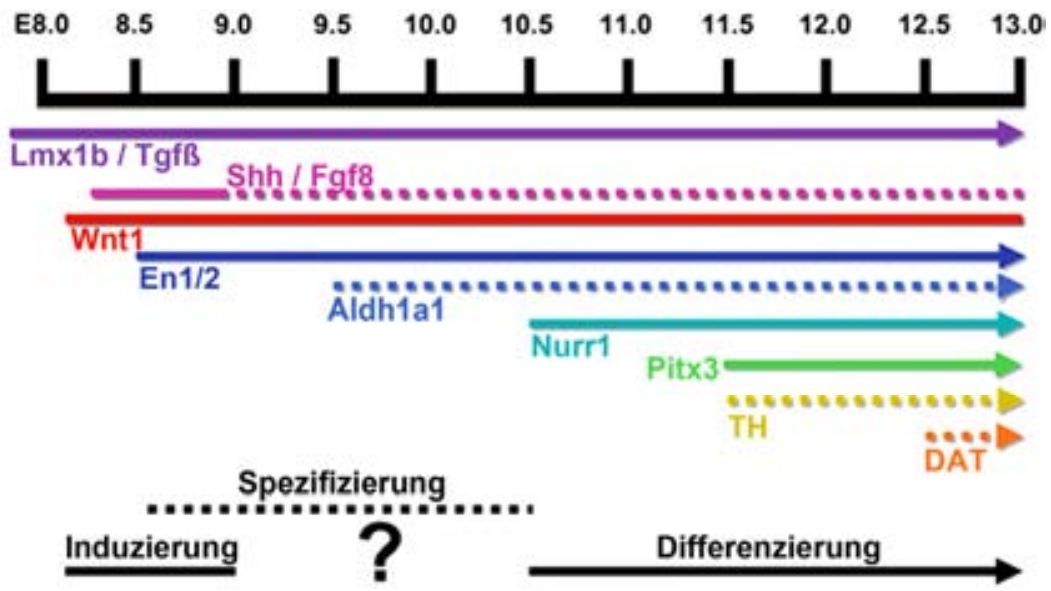

Abb.6: Überblick über die zeitliche Expression Faktoren, die für die Induktion und Differenzierung der mDA Neuronen relevant sind. Die obere Zeitleiste illustriert die Embryonaltage, beginnend mit der Neurulation bei E8.0 und endend am Tag E13.0, wenn der Großteil mDA Neuronen gebildet wurde. Die farblichen Balken stellen den jeweiligen Startpunkt und Dauer der Expression der Faktoren und Enzyme dar. Durchgehende Balken stehen für Faktoren, die für die mDA Entwicklung notwendig sind. Die Pfeile sagen aus, dass der entsprechende Faktor bzw. Enzym auch nach E13.0 exprimiert wird. Die gepunkteten Linien stehen für Faktoren, für die noch keine direkte Notwendigkeit für die mDA Entwicklung nachgewiesen wurde, bzw. dass ein Verlust dieses Faktors/ Enzyms keine Beeinträchtigung der mDA Neuronen nach sich zieht. Die Faktoren und molekularen Mechanismen, welche die Spezifizierung der mDA Neuronen steuern, sind noch unklar (Fragezeichen). Die Abbildung wurde entnommen und abgewandelt nach (Wallen \& Perlmann, 2003; Prakash \& Wurst, 2006a)

Die beiden redundanten Engrailed-Faktoren (En1/2) werden bereits während der Regionalisierung des Mittelhirns auf beiden Seiten der MHG exprimiert (E8.5), und sie sind für die Aufrechterhaltung des IsO und somit auch für die Entstehung der mDA von Bedeutung (Danielian \& McMahon, 1996; Scholpp et al., 2003). Während einer zweiten Expressionsphase werden sie in mDA Neuronen gebildet (E11.0) und beeinflussen maßgeblich das Überleben der dopaminergen Neuronen (Simon et al., 2001; Wallen \& Perlmann, 2003; Alvarez-Fischer et al., 2011; Alves dos Santos et al., 2011). In Mausmutanten mit En1/2 Defekten werden mDA Neuronen zunächst gebildet, gehen aber zwischen E12.0 und E14.0 verloren, was dem Zeitpunkt entspricht, in dem En1/2 in mDA Neuronen normalerweise exprimiert 
werden (Simon et al., 2001; Albéri et al., 2004). Bei Mausmutanten mit einem intakten Allel (En1+/-;En2-/) sind keine Defekte bis zur Geburt festzustellen. Nach der Geburt jedoch beginnen die Neuronen der SN zu degenerieren, woraus gefolgert wurde, dass die beiden Engrailed-Gene für das Überleben der mDA Neuronen von Bedeutung sind (Sgadò et al., 2006).

Ngn2 zählt zu den proneuralen Genen mit einer bHLH Domäne (engl. „Basic-helixloop-helix") und wird am Embryonaltag E10.5 in mDA Vorläuferzellen der VZ exprimiert, nachdem Ngn2 durch Lmx1a, Foxa2 und Msx1 aktiviert wurde. Die weitere Expression beschränkt sich auf die Vorläuferzellen der VZ und subventrikulären Zone (SVZ), und Ngn2 wird in ausdifferenzierten mDA der Mantelzone nicht mehr exprimiert (Kele et al., 2006; Andersson et al., 2006a). Bei einem Verlust der Ngn2 Expression werden zunächst mDA Vorläuferzellen gebildet, die aber keine Differenzierung bei E11.5 aufweisen und folglich zu einer Reduzierung der mDA Neuronen führt. Zwei Tage später jedoch (E13.5) sind wieder differenzierende dopaminerge Neuronen erkennbar, was durch die kompensierende Funktion eines weiteren bHLH- Gens, Mash1 (=Ascl1; engl. „Achaete-scute complex homolog 1“) erklärt wird (Kele et al., 2006).

\subsubsection{Frühe Differenzierung dopaminerger Neuronen}

Die mDA Neuronen der Maus entwickeln sich aus der VZ der Bodenplatte über einen Zeitraum von drei bis vier Tagen (E10.5 - E14.5), wobei die Neuronen kontinuierlich gebildet werden (Di Porzio et al., 1990; Bayer et al., 1995a). Ausgehend von der VZ migrieren die postmitotischen mDA Neuronen während der frühen Differenzierung ventral über die SVZ in die Mantelzone entlang der Fasern radialer Gliazellen (Abb. 7D). Von dort aus migrieren sie in der späten Differenzierungsphase weiter nach lateral entlang tangential angeordneter Nervenfasern (Kawano et al., 1995; Ohyama et al., 1998; Vitalis et al., 2005).

Während der Induzierung und Determinierung der mDA Neuronen befinden sich die Vorläuferzellen in der VZ und zeichnen sich durch eine hohe Zellteilungsrate aus. In der Maus konnte gezeigt werden, dass diese Vorläuferzellen den Zellzyklus zwischen E9.5 und E13.5 verlassen, in die SVZ wandern und die Differenzierung initiieren (Bayer et al., 1995b). In den Vorläuferzellen wird dabei Sox2 herunter reguliert (engl. „SRY-box containing gene 2“), ein Faktor für die Aufrechterhaltung 
der Proliferation, während allgemeine neuronale Marker wie z.B. ßIII-tubulin (auch bekannt als TuJ1) hochreguliert werden (Abb. 7A-C). Die ersten postmitotischen, unreifen mDA Neuronen können bereits am Embryonaltag E10.5 detektiert werden, und sie zeichnen sich dabei durch die Expression von Aldh1a1 sowie Nurr1 (=Nr4a2, engl. „Nuclear receptor subfamily 4, group A, member 2“) aus. Weiterhin werden auch die zuvor induzierten intrinsischen Faktoren wie z.B. Ngn2, En1/2, Lmx1a/b und Foxa2 exprimiert (Zetterström et al., 1996; Zetterstrom et al., 1997; Simon et al., 2001; Albéri et al., 2004; Perlmann et al., 2004; Ferri et al., 2007).

Nurr1 ist ein Kernrezeptor mit entscheidender Bedeutung für die Aufrechterhaltung der sich entwickelnden mDA Neuronen sowie für die Etablierung des dopaminergen Neurotransmitter-Phänotyps. Die Expression von Nurr1 in unreifen mDA Neuronen beginnt am Tag E10.5 und kann in diesen Zellen auch bei adulten Tieren detektiert werden. Außerhalb der dopaminergen Neuronen ist Nurr1 auch in anderen Regionen des ZNS exprimiert, wie z.B. im Kortex, Hippocampus, Thalamus und dem Rückenmark (Zetterström et al., 1996; Zetterstrom et al., 1997; Perlmann \& Wallen-Mackenzie, 2004). Bei einem Verlust an Nurr1 werden zunächst unreife dopaminerge Neuronen gebildet (En1/2+, Lmx1b+, und Foxa2+), welche jedoch Migrationsdefekte aufweisen und im späteren Verlauf der Entwicklung nicht mehr nachweisbar sind (Wallén et al., 1999; Tornqvist et al., 2002). Aus den zunächst gebildeten unreifen mDA Neuronen gehen keine funktionellen ausgereiften mDA Neuronen hervor. So kann keine Expression von TH (Tyrosinhydroxylase), VMAT2 (vesikulärer Monoamintransporter 2, auch bekannt als Slc18a2) sowie DAT (Dopamintransporter) detektiert werden (Saucedo-Cardenas et al., 1998; Wallén et al., 1999; Smits et al., 2003). Diese Proteine sind für die korrekte Synthese des Neurotransmitters Dopamin sowie für die generelle Funktion dopaminerger Neuronen unerlässlich. Interessanterweise wird bei diesen Nurr1\%- Mäusen Pitx3 (s.u.) zunächst exprimiert, ein Transkriptionsfaktor, der spezifisch in ausgereiften mDA Neuronen exprimiert wird (Saucedo-Cardenas et al., 1998). Diesbezüglich wurde schon länger davon ausgegangen, dass es mehrere parallele Signalwege gibt, die unabhängig voneinander die korrekte Entwicklung der mDA Neuronen regulieren (Lmx1b, En1/2, Nurr1) (Burbach et al., 2003; Wallen \& Perlmann, 2003; Vitalis et al., 2005; Chung et al., 2009). Inzwischen ist das Modell für die Funktion 
A)

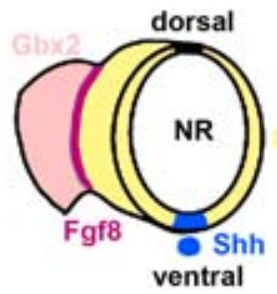

Induzierung

(Regionlisierung) E7.0 - E9.0

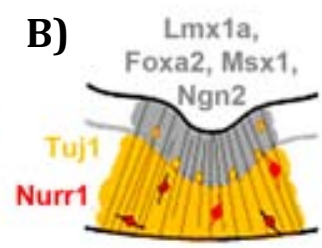

Spezifizierung

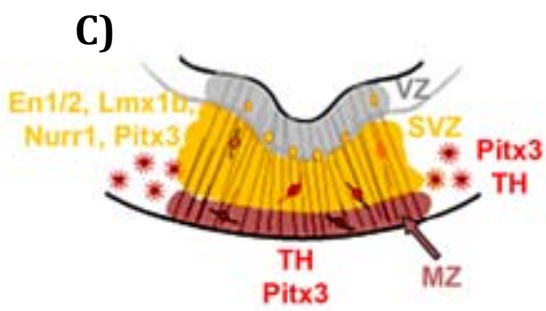

Differenzierung

E11.5 - E15
D)

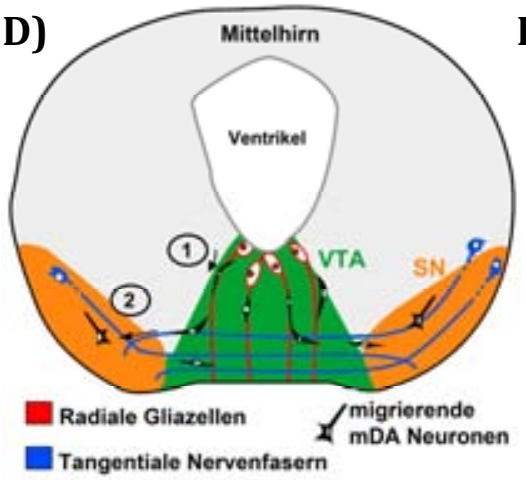

E)

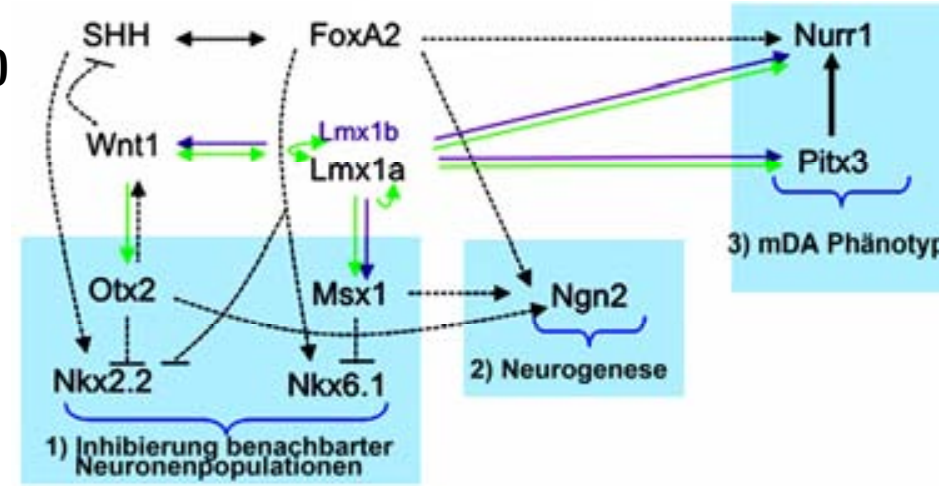

Abb. 7: Übersicht über die Entwicklung der mDA Neuronen. A-C) Induzierung, Spezifizierung und Differenzierung. A) Während der Induzierung wird das mDA Areal durch Shh (blau, sezerniert von der Chorda Dorsalis und BP) und Fgf8 (lila, MHG) innerhalb der Otx2-Domäne regionalisiert. B) Schematische coronale Darstellung des ventralen Mittelhirns. Der graue Bereich stellt die ventrikuläre Zone (VZ) dar, in der mDA Neuronen geboren werden und mitotisch aktiv sind. Die Spezifizierung findet innerhalb der VZ statt, in dessen Folge die mDA Vorläuferzellen den Zellzyklus verlassen und als postmitotische unreife mDA Neuronen in die Subventrikuläre Zone (gelb, SVZ) migrieren und u.a. TuJ1 und Nurr1 exprimieren. C) Während der folgenden Differenzierung wandern die mDA Neuronen weiter nach ventral in die Mantelzone (MZ, rot) und exprimieren TH und Pitx3. Dabei ist auffällig, dass im medialen Bereich (das spätere VTA) zuerst TH und danach Pitx3 exprimiert wird. Im lateralen Bereich (die spätere SN) wird zunächst Pitx3 und dann TH gebildet. D) mDA Neuronen migrieren während der Neurogenese von der VZ über die SVZ in die MZ. Dabei migrieren sie zunächst entlang radialer Gliazellen nach ventral, um dann entlang tangentialer Nervenfasern nach lateral in die SN zu wandern. E) Die Entwicklung der mDA Neuronen wird durch den Shh- und den kanonischen Wnt-Signalweg gesteuert. Dabei interagieren diese Signalwege während drei Phasen der mDA Neurogenese: 1) Ventralisierung und Inhibierung benachbarter Neuronenpopulationen, 2) Neurogenese, 3) mDA Phänotyp. Pfeile stehen für positive Regulierung und $-\mid$ steht für Inhibierung. Durchgehende Linien = direkte Regulierung, gepunktete Linien stehen für Interaktionen, für die bisher noch keine direkte Regulierung nachgewiesen werden konnte. Die Abbildungen wurden entnommen und abgewandelt nach (Vitalis et al., 2005; Gale et al., 2008; Chung et al., 2009; Jacobs et al., 2009a; Jacobs et al., 2009b)

von Nurr1 während der dopaminergen Neurogenese relativ gut verstanden.

Demnach reguliert Nurr1 die Aktivierung der Gene, die für die Synthese und den Metabolismus der dopaminergen Neuronen erforderlich sind, wie TH, AADC, VMAT2, DAT, D2R (Dopaminrezeptor D2). Weiterhin steuert Nurr1 die späte Differenzierung (Dlk1, Aldh1a1), das axonale Wachstum (Klhl1, Ptpru) sowie die Aufrechterhaltung adulter dopaminerger Neuronen (Ret, BDNF, GDNF). Bei vielen dieser Prozesse ist der Transkriptionsfaktor Pitx3 involviert, und reguliert die 
genannten Prozesse in Kooperation mit Nurr1 (Cazorla et al., 2000; Jacobs et al., 2009a; Jacobs et al., 2009b; Kadkhodaei et al., 2009).

\subsubsection{Späte Differenzierung dopaminerger Neuronen}

In der späten Phase der dopaminergen Differenzierung wandern die postmitotischen, unreifen Zellen weiter aus der SVZ in die Mantelzone und behalten die Expression von Lmx1a/b, Nurr1, En1/2 und Foxa2 bei, während kein Ngn2 Protein mehr gebildet wird (Ang, 2006). Die ersten ausgereiften mDA Neuronen können am Tag E11.5 aufgrund der Expression von TH und Pitx3 (engl. „Paired-like homeodomain transcription factor 3") in der Mantelzone detektiert werden (Abb. 7C). Eine Koexpression von TH und Pitx3 ist ein spezifisches Charakteristikum für adulte mDA Neuronen, da Pitx3 nur in diesen Neuronen gebildet wird (Smidt et al., 1997). Basierend auf der zeitlichen und räumlichen Expression von TH und Pitx3 lassen sich während früher Entwicklungsphasen bereits die Subpopulationen der mDA Neuronen unterscheiden. Die dorsomedial gelegenen mDA Neuronen der MZ exprimieren zunächst TH und daraufhin Pitx3, und aus diesen Zellen bildet sich das ventrale tegmentale Areal (VTA). Die Substantia nigra (SN) entwickelt sich aus den ventrolateralen Neuronen des mDA Areals, deren Vorläuferzellen zuerst Pitx3 bilden, bevor eine Expression von TH detektiert werden kann (Maxwell et al., 2005a). Interessanterweise sind bei einem Verlust der Pitx3 Expression hauptsächlich die dopaminergen Neuronen der SN betroffen, während das VTA nur leichte Defekte aufweist (Nunes et al., 2003; van den Munckhof et al., 2003; Smidt et al., 2004a). Auf den Transkriptionsfaktor Pitx3 wird in Kapitel 1.5. näher eingegangen.

Neben Nurr1 ist für die Aufrechterhaltung adulter mDA Neuronen ebenfalls der bereits erwähnte TF Lmx1b von Bedeutung. Bei einem Verlust der Lmx1b Expression können zunächst ausgereifte TH- und Nurr1-positiven mDA Neuronen an E12.5 detektiert werden, deren Expression bei E16.5 jedoch nicht mehr nachweisbar ist. Interessanterweise wird bei einem Verlust von Lmx1b kein Pitx3Protein gebildet, obwohl ausgereifte TH-positive mDA Neuronen vorhanden sind (Smidt et al., 2000). Hierzu wurde ein Modell vorgeschlagen, demzufolge mindestens zwei voneinander unabhängige Signalwege für die Differenzierung der mDA Neuronen existieren, die durch Lmx1b und Nurr1 reguliert werden (Wallen \& 
Perlmann, 2003; Vitalis et al., 2005). Durch einen Verlust der Nurr1 Expression kann Pitx3 zunächst detektiert werden, wobei jedoch kein TH gebildet wird. Bei einem Verlust von Lmx1b können Nurr1 und TH zunächst detektiert werden, wobei jedoch kein Pitx3 gebildet wird. Die Expression von Lmx1b ist bei Mausmutanten mit einem Verlust an Nurr1- bzw. Pitx3-Epxression unverändert (Wallen \& Perlmann, 2003).

\subsection{Pitx3}

Der Transkriptionsfaktor „Paired-like homeodomain TF 3“ (Pitx3, auch „Pituitary homeobox 3“) gehört $\mathrm{zu}$ der Familie der „Bicoid-realted Homeodomain“ Transkriptionsfaktoren und wird mit den paralogen Pitx1 und Pitx2 in der „Rieg/Pitx Homeobox“ Unterfamilie zusammengefasst (Gage et al., 1999; Li et al., 2009). Pitx1 und Pitx2 sind während der Neurogenese im Auge und in der Hypophyse (engl. „pituitary gland“) exprimiert, wo sie an deren Entwicklung und Funktion beteiligt sind (Lamonerie et al., 1996; Gage et al., 1997; Gage \& Suh..., 1999). Das Pitx3 Gen der Maus (1379 bp) liegt auf dem Chromosom 19 und kodiert für ein 302 Aminosäuren umfassendes Protein, welches eine Homeodomäne (auch Homeobox genannt) und eine OAR-Sequenz besitzt. Die Homeodomäne ist für die DNA-Bindung von Bedeutung, und es sind auch Proteininteraktionen bekannt, während die OAR-Sequenz von Pitx3 wahrscheinlich an Proteininteraktionen sowie an Transaktivierungsprozessen während der Transkription beteiligt ist (Hanes et al., 1989; Gehring et al., 1994; Wolberger, 1996; Semina et al., 1997; Gage \& Suh..., 1999; Li et al., 2009). Pitx3 zeigt während der Entwicklung eine spezifische Expression in den sich entwickelnden sowie ausgereiften mDA Neuronen. In parkinsonschen Tiermodellen und bei Parkinsonpatienten selbst ist die Anzahl der Pitx3-positiven mDA Neuronen reduziert (de Mena et al., 2010; Guo et al., 2011; Haubenberger et al., 2011; Le et al., 2011). Bei der natürlich vorkommenden aphakia-Mausmutante liegt ein Gendefekt in der Pitx3Promotorregion vor und es kann folglich kein Pitx3 Protein gebildet werden (Pitx3\%/-)(Varnum et al., 1968; Semina et al., 2000). Bei diesen Mutanten sind die dopaminergen Neuronen der SN drastisch reduziert und exprimieren kein TH, was die Wichtigkeit von Pitx3 während der Entwicklung auf Aufrechterhaltung dopaminerger Neuronen nahelegt (Varnum \& Stevens, 1968; Semina et al., 1997; 
Smidt et al., 1997; Semina et al., 2000; Ardayfio et al., 2008; Fuchs et al., 2009; Li et al., 2009).

\subsubsection{Die Expression von Pitx3}

In der Maus wird der TF Pitx3 in Muskeln, im Auge sowie im ventralen Mittelhirn exprimiert. In den Muskeln wird Pitx3 während der Myoblastendifferenzierung sowie in ausdifferenzierten Muskelzellen exprimiert, und es wird angenommen, dass Pitx3 und Pitx2 an der Differenzierung und Aufrechterhaltung von Muskelzellen beteiligt sind (L'Honore et al., 2007). Während der Augenentwicklung wird Pitx3 in der Augenlinse und im Augenmesenchym exprimiert, während es später nur noch im Linsenepithel detektiert werden kann. Ein Verlust der Pitx3-Expression führt zu einer reduzierten Proliferation der Vorläuferzellen sowie einer vorzeitigen und deregulierten Differenzierung, wodurch die Augen unterentwickelt sind und sich keine Augenlinsen ausbilden (Grimm et al., 1998; Ho et al., 2009; Medina-Martinez et al., 2009).

In dopaminergen Neuronen des ventralen Mittelhirns der Maus wird Pitx3 am Embryonaltag E11.0 - E11.5 in postmitotischen dopaminergen Neuronen der Mantelzone exprimiert, und kann auch im adulten Gehirn in der SN und im VTA detektiert werden (Smidt et al., 1997). Pitx3 ist der einzige bekannte Transkriptionsfaktor, der nur in dopaminergen Neuronen des Mittelhirns (mDA Neuronen) gebildet wird, und dort eine fast vollständige Koexpression mit TH aufweist. In anderen dopaminergen Neuronen wird Pitx3 hingegen nicht exprimiert (Smidt et al., 1997; Zhao et al., 2004; Maxwell et al., 2005b). Durch das zeitliche Expressionsprofil von TH und Pitx3 können bereits bei E12.0 die Subpopulation der mDA Neuronen, die SN und die VTA, unterschieden werden (Kap. 1.4.4).

\subsubsection{Die Funktion von Pitx3 während der Embryonalentwicklung}

Aufgrund der Pitx3-positiven und TH-negativen Neuronen im ventrolateralen Bereich wurde angenommen, dass Pitx3 die Expression von TH reguliert, und es konnte in vitro nachgewiesen werden, dass Pitx3 die TH Promotor aktivieren kann (Cazorla et al., 2000; Lebel et al., 2001; Messmer et al., 2007). Weiterhin konnte 
gezeigt werden, dass Pitx3 die Expression von VMAT2 (Vesikulärer Monoamintransporter 2) und sowie den Dopamintransporter (DAT) regulieren kann, beides wichtige Komponenten für die Dopaminspeicherung und wiederaufnahme an der Synapse (Hwang et al., 2009). Bei dieser Regulation liegt jedoch eine enge Kooperation mit Nurr1 vor (Cazorla et al., 2000; Jacobs et al., 2009a). Bei Analysen der aphakia-Mausmutanten hat sich herausgestellt, dass mDA Neuronen gebildet werden können, die TH, VMAT2 und DAT exprimieren. Allerdings werden ab dem Tag E12.5 die ventrolateralen TH-positiven mDA Neuronen nicht gebildet, während die Neuronen der VTA TH-positive Zellen in leicht reduzierter Zahl exprimieren (Nunes et al., 2003; van den Munckhof et al., 2003; Smidt et al., 2004b). In der adulten aphakia-Mutante sind die Defekte klarer ausgebildet, wobei die dopaminergen Neuronen der SN nicht detektierbar sind, und eine leichte Reduzierung TH-positiver Zellen im VTA nachgewiesen werden konnte (Hwang et al., 2003; Nunes et al., 2003; Maxwell et al., 2005a). Konsequenterweise ist das dorsale Striatum als Innervationsgebiet der SN betroffen und es kann kein TH detektiert werden, wodurch die aphakia Maus als Modell für die Parkinsonsche Krankheit angesehen wird (Singh et al., 2007; Ardayfio et al., 2008). Die Bewegungsdefizite der aphakia Mutanten können durch eine Applikation von L-DOPA in das Striatum wieder ausgeglichen werden (Nunes et al., 2003; van den Munckhof et al., 2003; Smidt et al., 2004a). Interessanterweise sind die TH-positiven Zellen der VTA nur leicht reduziert und exprimieren die charakteristischen dopaminergen Neurotransmitter wie z.B. den Dopamintransporter (DAT) und -rezeptor (D2R). Die Gründe für diesen selektiven Verlust der SN bei einem nur leicht beeinträchtigten VTA sind dabei noch nicht genau verstanden. Weiterhin konnte gezeigt werden, dass Pitx3 und Nurr1 die gleichen Promotorregionen verschiedener Gene regulieren (TH, DAT, Vmat2), welche bei der aphakia Maus vor allem in der SN verlorengehen, und dass die Kooperation von Pitx3 und Nurr1 für die Ausprägung des dopaminergen Phänotyps notwendig ist (Cazorla et al., 2000; Jacobs et al., 2009a). Diese kooperative Regulation von Pitx3 und Nurr1 beruht dabei auf einer Interaktion von Pitx3 mit einem Korepressorkomplex (SMRT, engl. „silencing mediator of retinoic acid and thyroid hormone receptor"), der Nurr1 in Abwesenheit von Pitx3 repremiert. In Anwesenheit von Pitx3 wird diese Inhibierung von Nurr1 aufgehoben und die Transkription der Nurr1-Zielgene aktiviert (Jacobs et al., 
2009b). Eine Kooperation zwischen Nurr1 und Pitx3 in mDA Neuronen konnte ebenfalls bei mDA Neuronen des Menschen nachgewiesen werden (Martinat et al., 2006). Durch in vitro Studien konnte gezeigt werden, dass eine Überexpression von Pitx3 die Differenzierung und Zellmorphologie beeinflusst, aber zu keiner erhöhten Anzahl TH-positiver Neuronen beiträgt (Roybon et al., 2008). Bisher konnten diese Daten nicht in vivo verifiziert werden. Die neurotrophischen Faktoren BDNF (engl. „Brain-derived neurotrophic factor") und GDNF (engl. „Glia cell line-derived neurotrophic factor ${ }^{\prime \prime}$ ) regulieren die Differenzierung, Aufrechterhaltung und das Überleben von mDA Neuronen (Lin et al., 1993; Seroogy et al., 1994). Sowohl in vitro als auch in vivo wurde gezeigt, dass Pitx3 an deren Regulation beteiligt ist (Peng et al., 2007; Yang et al., 2008; Peng et al., 2011). Allerdings ist auch bekannt, dass Nurr1 an der Regulierung von GDNF und BDNF beteiligt ist (Zetterstrom et al., 1997; Volpicelli et al., 2007).

Das Enzym Aldh1a1 synthetisiert Retinolsäure (RS) und wird u.a. in mDA Neuronen exprimiert. Pitx3 ist in der Lage, den Aldh1a1 Promotor zu aktivieren, und in vitro konnte eine Erhöhung Aldh1a1-positiven Zellen durch eine Überexpression von Pitx3 nachgewiesen werden. Der Phänotyp der aphakiaMausmutante konnte teilweise durch ektopische RS kompensiert werden, und es wird vermutet, dass ein RS-abhängiger und ein RS-unabhängiger Signalweg für die späte Differenzierung mDA Neuronen existiert, der unter dem Einfluss von Pitx3 steht. Hierbei ist jedoch anzumerken, dass Nurr1 ebenfalls in der Lage ist, Aldh1a1 $\mathrm{zu}$ aktivieren und somit in Kooperation mit Pitx3 dessen Expression reguliert (Chung et al., 2005; Jacobs et al., 2007; Jacobs et al., 2009a; Jacobs et al., 2011). Die microRNA 133b (miR-133b) kann im ventralen Mittelhirn detektiert werden und ist bei Parkinson Patienten und in der aphakia-Mausmutante signifikant reduziert. Pitx3 kann den miR-133b Promotor aktivieren und die Expression von miR-133b hochregulieren. Pitx3 wiederum besitzt eine Bindungssequenz für miR-133b, und es wurde gefolgert, dass zwischen Pitx3 und miR-133b eine negative Rückkopplung besteht (Kim et al., 2007; de Mena et al., 2010; Mouradian, 2012). In der miR-133b Knockout-Maus wurde jedoch gezeigt, dass die Expression von Pitx3 bei einem Verlust von miR-133b nicht beeinträchtigt ist. Die miR-133b Mausmutanten zeigen keine Veränderungen des mDA Systems, sodass miR-133b keine signifikante Bedeutung bei der dopaminergen Entwicklung in vivo hat (Heyer et al., 2012). 


\subsection{Das Cre-LoxP-System}

Für eine zeitlich und räumlich kontrollierte Aktivierung oder Inaktivierung von Genen hat sich das Cre-LoxP-System in der Maus als zuverlässige Methodik etabliert. Dabei wird eine gefloxte transgene Mauslinie mit einer transgenen CreMauslinie verpaart, um durch chromosomale Rekombination Veränderungen (Deletion, Insertion, Verdopplung, Inversion, Translokation) in einer gewünschten DNA-Region zu erzielen (Gu et al., 1994; Lewandoski, 2001; Mansouri, 2001; Brault et al., 2007; Gavériaux-Ruff et al., 2007). Eine LoxP-Sequenz (engl. „Locus of X-over $\left.P 1^{\prime \prime}\right)$ besteht aus einer Zentralsequenz aus acht Basenpaaren, die von zwei palindromischen Sequenzen flankiert wird. Je nach Lage und Orientierung der zwei LoxP-Sequenzen zueinander können DNA-Sequenzen herausgeschnitten, gespiegelt, oder auch größere Chromosomentranslokationen herbeigeführt werden (Ramirez-Solis et al., 1995; Metzger et al., 1999). Eine DNA-Sequenz, die zwischen zwei LoxP-Sequenzen mit gleicher Orientierung liegt, wird als "gefloxt" bezeichnet, und wird bei einer Cre-vermittelten Rekombination aus dem Chromosom herausgeschnitten. Die Rekombination ist ein molekulargenetischer Prozess aller Organismen, bei dem Rekombinasen eine Spaltung und Neuverknüpfung von DNA-Sequenzen katalysieren. Die Cre-Rekombinase (engl. „Cyclization recombination") stammt ursprünglich aus dem Bakteriophagen P1 und vermittelt die Rekombination zwischen zwei LoxP-Sequenzen in vivo und in vitro unabhängig von der Präsenz von molekularen Kofaktoren (Sternberg et al., 1981; Sauer et al., 1988; Nagy, 2000). Für eine gewebsspezifische Rekombination ist eine transgene Cre-Linie erforderlich, bei der die Cre-Rekombinase unter der Kontrolle eines bestimmten Genpromotors steht. Der Promotor bestimmt dabei die räumliche und zeitliche Aktvierung der Cre-Rekombination, abhängig vom Zeitpunkt und von den Zelltypen, in denen das Gen exprimiert wird. Durch die Verwendung einer induzierbaren Cre-Linie kann man zusätzlich den Zeitpunkt der Rekombination genau bestimmen. Es handelt sich dabei um eine Fusion aus der Cre-Rekombinase und einer mutierten Liganden-Bindungsdomäne von Steroidrezeptoren (z.B. des Östrogenrezeptors), die keine Affinität zum endogenen Liganden (z.B. Östradiol) besitzen und zunächst inaktiv sind. Nach Verabreichung eines synthetischen Liganden (z.B. Tamoxifen) wird die mutierte Cre-Rekombinase 
aktiviert, wodurch eine zeitliche und gewebsspezifische Rekombination erzielt werden kann (Feil et al., 1996; Danielian et al., 1998; Sauer, 1998; Hayashi et al., 2002; Brault et al., 2007). Um eine spezifische Inaktivierung oder Überexpression von Genen in der Maus zu erreichen, werden Tiere der gefloxten Mauslinie mit Tieren der (induzierbaren) Cre-Mauslinie verpaart, wodurch doppeltransgene Nachkommen entstehen, die den gewünschten Genotyp tragen.

In der vorliegenden Arbeit wurden transgene, gefloxte Mauslinien verwendet, die in unserem Labor mit dem Ziel einer konditionalen Überexpression von Pitx3 hergestellt wurde (Kap. 5.3.1). Das Transgen beinhaltet dabei eine von zwei LoxPSequenzen flankierte eGFP-Stopcodon-Sequenz, gefolgt von der zu überexprimierenden cDNA Sequenz (Pitx3, Lmx1a, Lmx1b), und einer IRES-LacZKassette. Das gesamte Konstrukt steht dabei unter der Kontrolle eines starken Promotors. Durch eine Verpaarung dieser transgenen Tiere mit verschiedenen Cre-Mäusen (Shh-Cre, Foxa2-Cre, Wnt1-Cre, En1-Cre) wird die gefloxte eGFPStopcodon-Sequenz mittels Rekombination herausgeschnitten und die Überexpression von Pitx3 (oder Lmx1a, Lmx1b) unter der Kontrolle der jeweiligen Cre-Promotoren initiiert. 


\subsection{Zielsetzung}

Die Entwicklung der dopaminergen Neuronen des Mittelhirns (mDA Neuronen) wird durch ein komplexes Netzwerk aus miteinander interagierenden Transkriptionsfaktoren (TF) und Signalmolekülen gesteuert. Dabei sind die TF Nurr1 und Pitx3 für die postmitotische Differenzierung dieser Neuronen von entscheidender Bedeutung. Eine Kooperation von Nurr1 und Pitx3 ist bei der Aktivierung verschiedener Faktoren und Enzyme, die für die Entwicklung und Funktion der mDA von Bedeutung. In der Vergangenheit wurde anhand der aphakia-Mausmutante gezeigt, dass bei einem Verlust der Pitx3-Expression vor allem die dopaminergen Neuronen der Substantia nigra (SN) nicht ausgebildet werden, während die mDA Neuronen des ventralen tegmentalen Areals (VTA) kaum betroffen sind. Die Ursachen für diesen selektiven Verlust sind dabei noch unklar. Um genauere Erkenntnisse über die Funktionen von Pitx3 während der Entwicklung zu erhalten, ist es neben der Analyse der Verlustmutante aphakia (Pitx3\%) erforderlich, auch Überexpressions-Experimente sowohl in vivo als auch in vitro zu nutzen, um die an der Interaktion mit Pitx3 beteiligten Faktoren zu identifizieren. Es wurden bislang allerdings nur verschiedene in-vitro-Analysen in der Zellkultur durchgeführt, und es sind bis heute keinerlei eindeutige in-vivo Ergebnisse publiziert (siehe Kapitel 1.5).

Um genauere Einblicke in die Funktion von Pitx3 während der Neurogenese der mDA Neuronen zu gewinnen, war das Ziel der vorliegenden Arbeit die Analyse der konditionale Überexpression von Pitx3 mittels des Cre-LoxP-Systems in der Maus in bestimmten Arealen des Mittelhirns (Kapitel 5.3). Dafür wurden vier verschiedene transgene Cre-Linien verwendet, um den TF Pitx3 in unterschiedlichen Regionen des Mittelhirns der Maus ektopisch zu exprimieren: Mittels der transgenen Shh-Cre- und Foxa2-Cre-Mauslinien wurde Pitx3 nur im Bereich des ventralen Mittelhirns überexprimiert. Die transgenen Mauslinien Wnt1-Cre und En1-Cre wurden verwendet, um Pitx3 in ventralen und dorsalen Bereichen des murinen Mittelhirns ektopisch $\mathrm{zu}$ exprimieren. Bei den resultierenden Mausmutanten (Shh-Cre ${ }^{+/ \mathrm{Pitx30E}}$, Foxa2-Cre ${ }^{+/ \mathrm{Pitx} 30 \mathrm{E}}$, Wnt1$\mathrm{Cre}^{+/ P i t x 30 E}$, und En1-Cre ${ }^{+/ P i t x 30 E}$, wurde jeweils die Entwicklung der mDA Neuronen an verschiedenen embryonalen Entwicklungsstadien mit Hilfe von Expressionsanalysen untersucht. 


\section{Ergebnisse}

Für die funktionelle Analyse von Pitx3 wurde das Cre-LoxP-System zur konditionalen Pitx3-Überexpression in Mäusen genutzt. Dabei wurden vier transgene Cre-Linien (Shh-Cre, Foxa2-Cre, Wnt1-Cre, En1-Cre) mit der transgenen Pitx30E-Mauslinie verpaart (Kap. 5.3.1), um Pitx3 bereits während der frühen Neurogenese im Mittelhirn ektopisch $\mathrm{zu}$ exprimieren. Die Ergebnisse der jeweiligen konditionalen Pitx3-Überexpression werden in zwei Teilkapiteln separat präsentiert: Für eine Pitx3-Überexpression im ventralen Mittelhirn wurden Tiere der transgenen gefloxten Pitx30E-Mauslinie mit transgenen Tieren der Shh-Cre- und Foxa2-Cre-Mauslinien verpaart. Die resultierenden doppelttransgenen Tiere werden mit Shh-Cre ${ }^{+/ P i t x 30 E}$ bzw. Foxa2-Cre ${ }^{+/ P i t x 30 E}$ bezeichnet (Kapitel 2.1). Für eine Überexpression von Pitx3 im ventralen und dorsalen Mittelhirn wurden Tiere der Pitx30E-Mauslinie mit transgenen Tieren der Wnt1-Cre- und En1-Cre-Mauslinien verpaart, und die doppelttransgenen Tiere tragen die Bezeichnung Wnt1-Cre ${ }^{+/ P i t x 30 E}$ bzw. En1-Cre+/Pitx30E (Kapitel 2.2).

Im Rahmen der Experimente wurden zwei unabhängig erstellte, transgene Pitx30E-Mauslinien verwendet (Linie 1 und 5), und die Experimente der im folgenden gezeigten Ergebnisse wurden jeweils drei Mal durchgeführt (sofern nicht besonders kenntlich gemacht). Dadurch wurde sichergestellt, dass die Phänotypen auf die konditionale Pitx3-Überexpression zurückzuführen sind und reproduzierbare Ergebnisse liefern.

Die im Folgenden präsentierten Ergebnisse zeigen den intermediären Bereich der mDA Neuronen, auf dem die laterale SN und das mediale VTA zusammen abgebildet sind. Bei der Betrachtung der Ergebnisse wurde das gesamte mDA System von rostral nach caudal betrachtet und ausgewertet, und die gezeigten Abbildungen stellen den repräsentativen Durchschnitt der Analyse des gesamten mDA Systems dar.

\section{1 Überexpression von Pitx3 im ventralen Mittelhirn: Shh-Cre ${ }^{+/ P i t x 30 E}$ und Foxa2-Cre ${ }^{+/ P i t x 30 E}$}

Das Signalmolekül Shh und der Transkriptionsfaktor Foxa2 werden in den dopaminergen Neuronen des ventralen Mittelhirns ab dem Embryonaltag E8.0 bzw. E8.5 exprimiert und sind wichtige Faktoren bei der Neurogenese der mDA 


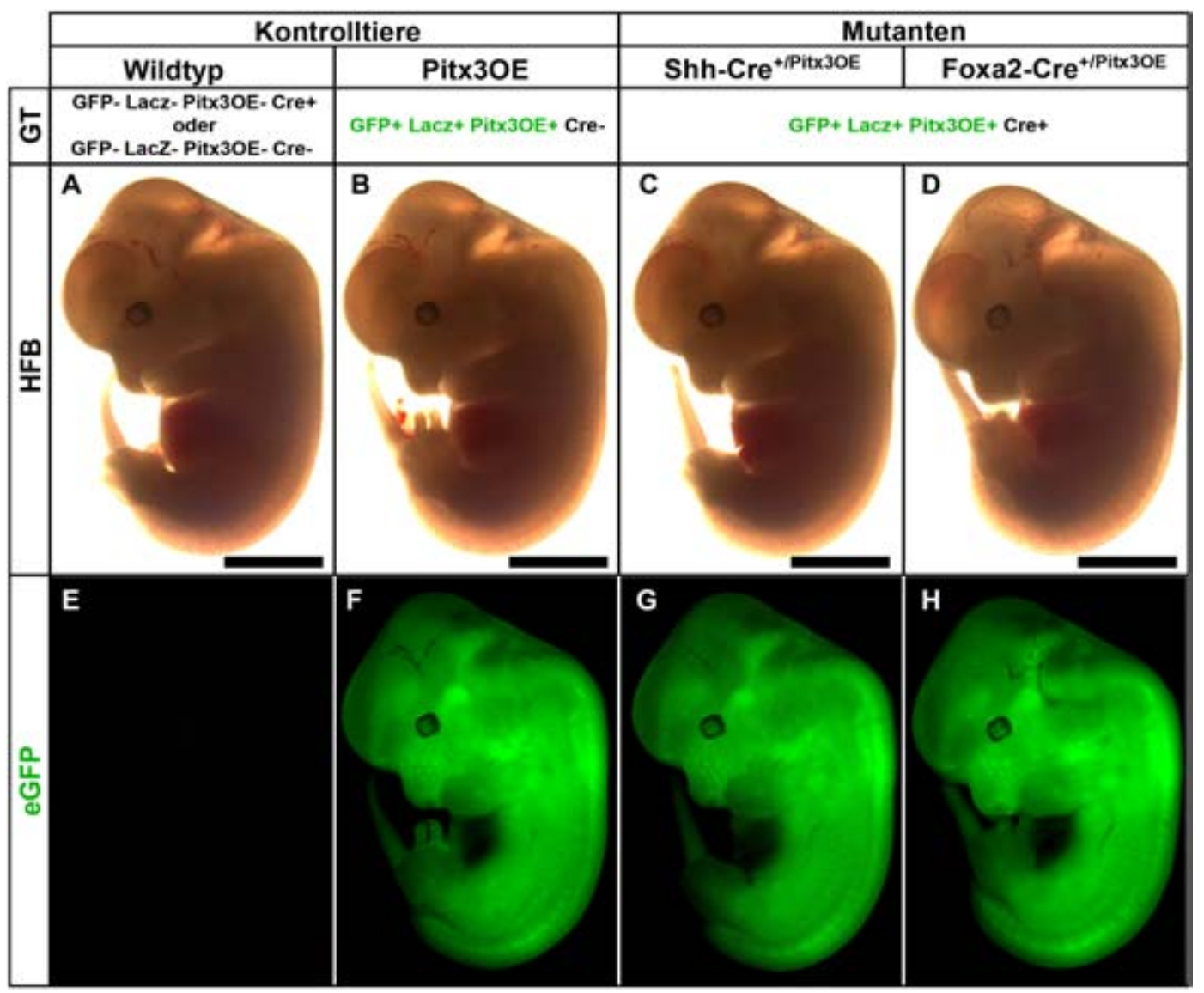

Abb. 8: Mausembryonen an Tag E12.5, Kontrolltiere (AE, BF) und doppeltransgene Mausmutanten Shh-Cre ${ }^{+/ P i t x 30 E}$ (CG) und Foxa2-Cre ${ }^{+/ P i t x 30 E}$ (DH). A-D) Sagittalansicht ganzer Embryonen, Hellfeldbelichtung (HFB); E-F) entsprechende eGFP Expression der Embryonen. Sowohl die transgenen Pitx30E-Embryonen (E) als auch die doppeltransgenen Mausmutanten $(G, H)$ zeigen eine starke Expression des eGFP-Reporters. GT = Genotyp; Skala $=2 \mathrm{~mm}$

Neuronen (Kapitel 1.4) (Hynes et al., 1995; Ferri et al., 2007; Hayes et al., 2011; Mavromatakis et al., 2011). Bei der transgenen Shh-Cre-Linie handelt es sich um eine nicht induzierbare Cre-Linie (Kapitel 2.2), d.h., dass die durch das Cre-LoxPSystem vermittelte Pitx3-Überexpression bereits in der Chorda Dorsalis (E7.0) und etwas später in der BP (E8.0) induziert wird (vgl. Kapitel 1.4.2). Für die Überexpression von Pitx3 unter der Kontrolle der Foxa2-Promotors (Foxa2-Cre) wurde eine durch Tamoxifeninjektion induzierbare Cre-Linie verwendet (Kapitel 2.2). Foxa2 wird vor dem Embryonaltag E8.0 in endodermalen und mesodermalen Gewebe exprimiert, und zeigt ab E8.5 eine spezifische Expression in den Zellen der BP (Park et al., 2008). Um eine zu frühe Pitx3-Überexpression in Zellen des Endound Mesoderms zu vermeiden, wurde den Muttertieren am Embryonaltag E8.5 Tamoxifen intraperitoneal injiziert, damit eine spezifische Pitx3-Überexpression in Zellen der BP erreicht werden konnte. 
Die gewünschten doppeltransgenen Mausmutanten Shh-Cre+/Pitx30E bzw. Foxa2$\mathrm{Cre}^{+/ \mathrm{Pitx30E}}$ tragen den Genotyp GFP+(LacZ+/Pitx3OE+)/Cre+ (siehe Abb. 8). Als Kontrolltiere wurden Embryonen verwendet, die entweder keinerlei Transgen tragen (GFP- / LacZ- / Pitx3- / Cre-), nur Cre+ oder nur GFP+(LacZ+ / Pitx30E+) in sich tragen. Die Embryonen der doppeltransgenen Mutanten Shh-Cre+/Pitx30E und Foxa2-Cre ${ }^{+/ P i t x 30 E}$ sowie der transgenen Pitx30E-Mauslinie zeigten eine starke GFP-Expression bei E12.5 (Abb. 8) Die Mutanten unterschieden sich nicht von den Kontrolltieren bezüglich der Größe und Morphologie. Die Shh-Cre' ${ }^{+/ P i t x 30 E}$ Mutanten sind lebensfähig, fertil und zeigen keinerlei Verhaltensauffälligkeiten, wobei allerdings keine Verhaltensanalysen durchgeführt wurden. Aufgrund der Tamoxifeninjektion zur Aktivierung der konditionellen Pitx3- Überexpression (Kapitel 5.3) kann keine Aussage zur Lebensfähigkeit der Foxa2-Cre+/Pitx3_ Mutanten gegeben werden. Durch die Tamoxifenverabreichung wurden die Embryonen in den meisten Fällen vor der Geburt abgestoßen.

Aufgrund der Expression von Shh und Foxa2 im ventromedialen Neuralrohr ist bei den Embryonen äußerlich kein GFP-negativer Bereich erkennbar. Auf coronalen Gewebeschnitten durch das Mittelhirn an Embryonaltag E12.5 sind diese GFPnegativen Bereiche jedoch erkennbar (Abb. 9 B, C). Diese Bereiche entsprechen der jeweiligen Shh- bzw. Foxa2-Domäne, und durch indirekte Immunofluoreszenzfärbung (IIF) konnte in diesen Bereichen die Überexpression von Pitx3 im gesamten dopaminergen Areal des Mittelhirns nachgewiesen werden (Abb. 9 B, C). Die durch das Cre-LoxP-System vermittelte Überexpression von Pitx3 unter der Kontrolle des Shh- bzw. Foxa2-Promotors der jeweiligen transgenen Shh-Cre bzw. Foxa2-Cre-Mauslinien konnte somit nachgewiesen werden. Ebenso wurde durch die Detektion der Pitx3-Überexpression bei beiden Mutanten die Effizienz der Cre-Rekombinase und des Cre-LoxP-Systems verifiziert. Bei den Kontrolltieren kann Pitx3 in der subventrikulären Zone (SVZ) und der Mantelzone (MZ) detektiert werden, und diese endogene Expression korreliert mit der Expression der Tyrosinhydroxylase (TH, Abb. 8A, D). Bei den Mutanten erstreckt sich die Pitx3-Expression von der ventrikulären Zone (VZ) über die SVZ bis in die MZ hinein, und kann auch in der Basalplatte nachgewiesen werden (Abb. $9 \mathrm{~B}, \mathrm{C})$. 


\subsubsection{Pitx3 bewirkt eine Erhöhung der mDA Neuronen im Bereich des ventralen tegmentalen Areals (VTA)}

Für die Analyse der Entwicklung der mDA Neuronen wurde zunächst die Expression von TH, DAT und Nurr1 mittels IIF an Tag E12.5 untersucht. Bei einer quantitativen Analyse der TH-Expression am Tag E12.5 ist auffällig, dass bei den Shh-Cre ${ }^{+/ P i t x 30 E}$ und Foxa2-Cre ${ }^{+/ P i t x 30 E}$ Mutanten signifikant mehr TH+ Neuronen in der VTA detektiert werden können (110,7\% bzw. 108,8\%; Abb. 9 D-E, M) während in der SN keine signifikanten Veränderungen sichtbar sind. Bei einem Vergleich der gesamten mDA Neuronenpopulation (VTA und SN) ist eine leichte Erhöhung $\mathrm{TH}+$ Neuronen erkennbar, welche allerdings nur bei den Shh-Cre ${ }^{+/ P i t x 30 E}$ Mausmutanten signifikant ist (104,3\% bzw. 103,2\%; Abb. 9 M). Die Untersuchung der DAT-Expression zeigte eine geringe, nicht signifikante Erhöhung bei den Shh$\mathrm{Cre}^{+/ P i t x 30 E}$ und Foxa2-Cre ${ }^{+/ P i t x 30 E}$ Mutanten im Vergleich $\mathrm{zu}$ den Kontrolltieren (104,2\% bzw. 103,1\%; Abb. 9 G-I, N). Nurr1 wird während der frühen Differenzierung der mDA Neuronen gebildet und kann in der SVZ und in der MZ der Kontrolltiere und Mutanten detektiert werden (Abb. 9 J). Bei beiden Mausmutanten (Shh-Cre ${ }^{+/ P i t x 30 E}$ und Foxa2-Cre ${ }^{+/ P i t x 30 E}$ ) kann eine signifikante Erhöhung der gesamten Nurr1-positiven Neuronen nachgewiesen werden (112,3\% bzw. 106,7\%; Abb. 9 J-L, 0). Besonders auffällig ist hierbei die signifikante Erhöhung Nurr1-positiver Neuronen im Bereich der SVZ bei beiden Mutanten (119,5\% bzw. 117,0\%), während einer signifikanten Erhöhung im Bereich der MZ nur bei der Shh-Cre+/Pitx30E - Mutante detektierbar ist (106,3\%).

Die Differenzierung der mDA Neuronen beginnt am Embryonaltag E11.5 und erstreckt sich über einen Zeitraum von drei bis vier Tagen (Kapitel 1.4.3 und Abb. 7), in denen ausgereifte Neuronen kontinuierlich gebildet werden. Am Embryonaltag E12.5 konnte bei den Shh-Cre+/Pitx30E und Foxa2-Cre ${ }^{+/ P i t x 30 E}$ Mutanten bereits eine Erhöhung der mDA Neuronen, vor allem im medialen Bereich, nachgewiesen werden (Abb. 9). Um die weitere Entwicklung der mDA Neuronen bei diesen Mutanten zu einem späteren Zeitpunkt zu untersuchen, wurde die Expression von TH, DAT, und Nurr1 am Embryonaltag E15.5 analysiert. Dabei zeigte sich eine sich eine signifikante Erhöhung der Gesamtanzahl der THpositiven Zellen bei den Shh-Cre ${ }^{+/ P i t x 30 E}(107,8 \%)$ und Foxa2-Cre ${ }^{+/ P i t x 30 E}$ Mutanten $(104,6 \%)$. Diese Erhöhung ist dabei auf eine signifikante Erhöhung im Bereich des 


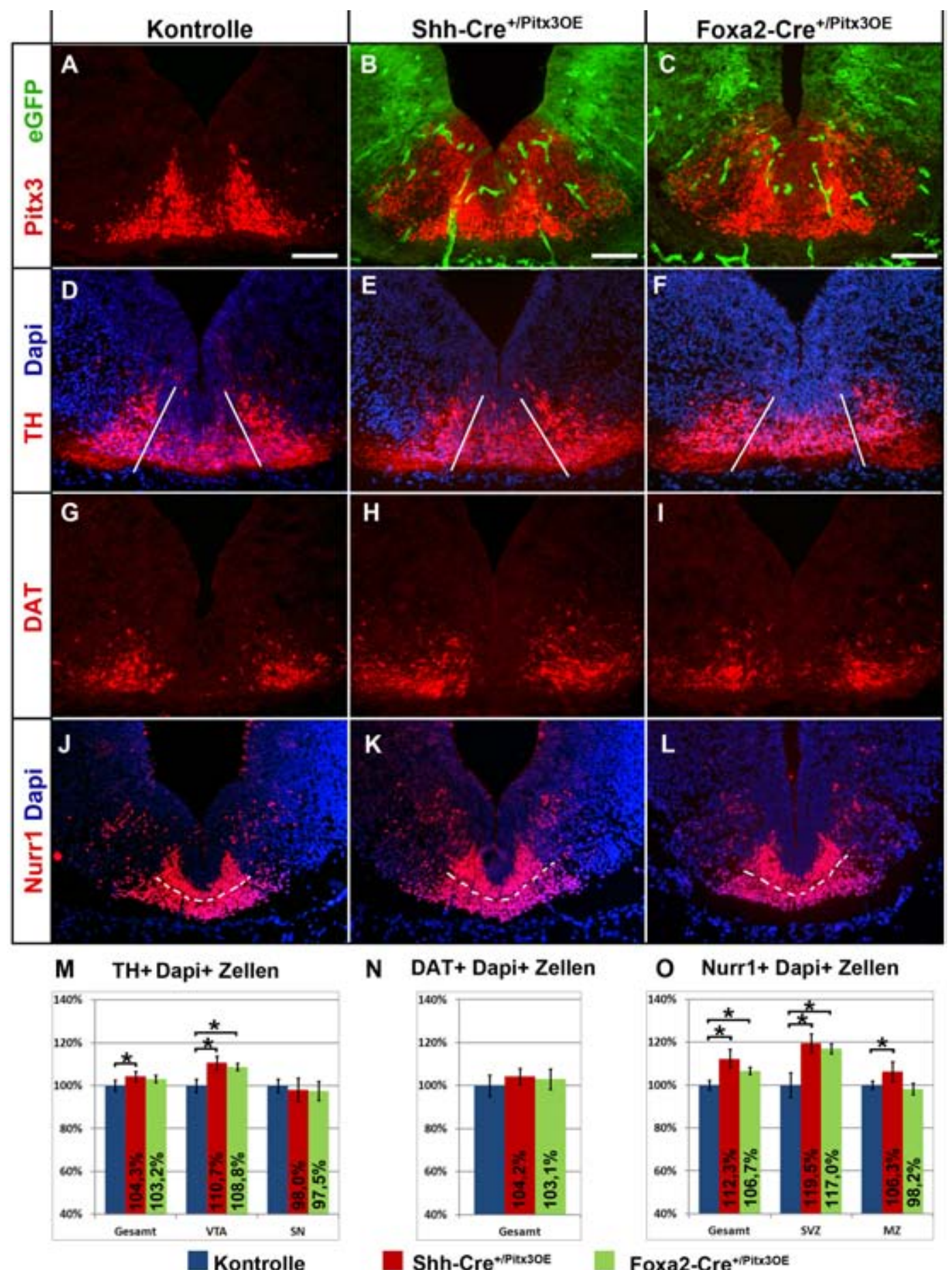

Abb.9: Die Überexpression von Pitx3 im ventralen Mittelhirn führt zu einer Erhöhung der mDA Neuronen an Tag E12.5. IIF auf coronalen Gewebeschnitten des ventralen murinen Mittelhirns. Kontrolltiere $(A, D, G, J)$, Mutanten Shh-Cre ${ }^{+/ P i t x 30 E}(B, E, H, K)$ und Foxa2-Cre ${ }^{+/ P i t x 30 E}(C, F, I, L)$ A-C) antiPitx3 IIF-Färbung und endogenes eGFP der Mutanten; D-F) anti-TH IIF-Färbung, die weißen Linien separieren den medialen Teil, aus dem das VTA hervorgeht, vom lateralen Areal, aus dem sich die SN entwickelt. G-I) anti-DAT IIF-Färbung J-L) anti-Nurr1 IIF-Färbung; die weiße gestrichelte Linie markiert die Grenze zwischen der subventrikulären Zone (SVZ) und der Mantelzone (MZ); M-0) Quantifizierung der gezeigten Marker aus A-L; die Fehlerbalken stehen für die Standardabweichungen und * gibt die Signifikanz an ( $\leq \leq 0,05)$, ermittelt mit dem „Student's T-Test“; Gesamt steht für die Anzahl aller Zellen, VTA (ventrales tegmentales Areal), SN (Substantia nigra), SVZ (Subventrikuläre Zone), MZ (Mantelzone). Dabei wurde die Anzahl der positiven Zellen der Kontrolltiere als 100\% definiert und die Anzahl der Zellen der Mutanten in Relation gesetzt. Alle gezeigten Expressionsanalysen wurden bei mind. drei Kontrolltieren und Mutanten aus verschiedenen Würfen durchgeführt. Skala in A-C $=100 \mu \mathrm{m}$ 
VTA zurückzuführen (112,8\% bzw. 109,1\%), während die Anzahl TH-positiver Zellen in der SN leicht reduziert ist (96,9\% bzw. 94,6\%, nicht signifikant; Abb. 10 A-C, J). Bei der Analyse der DAT-Expression konnte ebenfalls eine signifikante Erhöhung in der Gesamtzahl bei der Shh-Cre+/Pitx30E Mutante $(109,0 \%)$ sowie eine nicht signifikante (n.s.) Erhöhung bei der Foxa2-Cre+/Pitx30E Mutante (104,1\%)

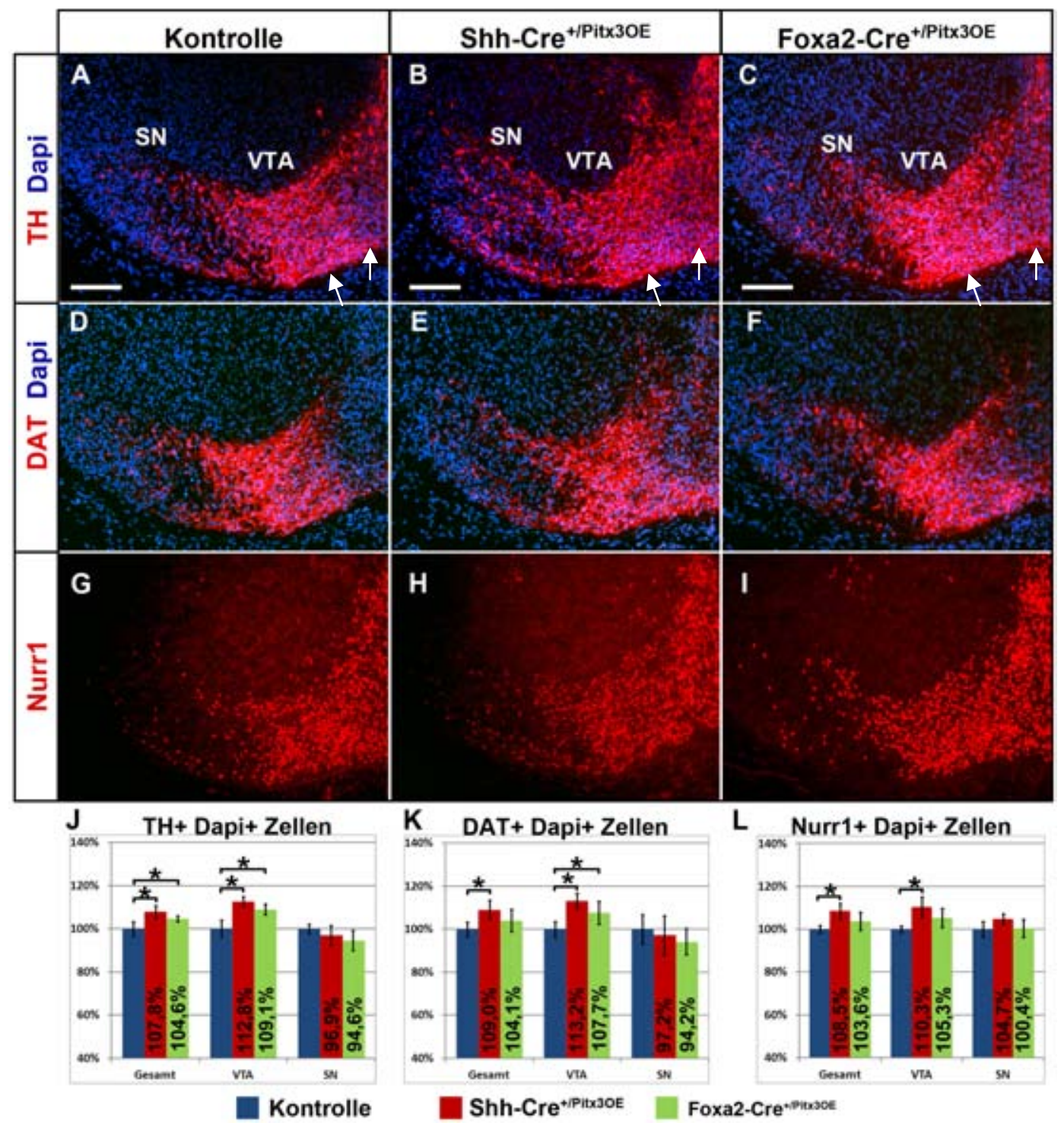

Abb. 10: Die Überexpression von Pitx3 im ventralen Mittelhirn führt zu einer Erhöhung der mDA Neuronen an Tag E15.5. IIF auf coronalen Gewebeschnitten des ventralen murinen Mittelhirns nur die linke Seite der mDA Neuronen ist gezeigt. Kontrolltiere (A,D,G), Mutanten Shh-Cre ${ }^{+/ P^{2} \times 30 E}$ $(B, E, H)$ und Foxa2-Cre ${ }^{+/ P i t x 30 E}(C, F, I)$ A-C) anti-TH IIF-Färbung. Die weißen Pfeile deuten auf erhöhte TH Expression des VTA. D-F) anti-DAT IIF-Färbung. G-I) anti-Nurr1 IIF-Färbung. Die TH-, DAT- und Nurr1- Färbungen wurden auf benachbarten Schnitten durchgeführt. J-L) Quantifizierung der gezeigten Marker aus A-I; die Fehlerbalken stehen für die Standardabweichungen und * gibt die Signifikanz an ( $\mathrm{p} \leq 0,05)$, ermittelt mit dem „Student's T-Test“; Gesamt steht für die Anzahl aller Zellen, VTA (ventrales tegmentales Areal), SN (Substantia nigra). Dabei wurde die Anzahl der positiven Zellen der Kontrolltiere als 100\% definiert und die Anzahl der Zellen der Mutanten in Relation gesetzt. Für die Quantifizierung bei E15.5 wurde jeder dritte Schnitt des gesamten Mittelhirns herangezogen. Alle gezeigten Expressionsanalysen wurden bei mind. drei Kontrolltieren und Mutanten aus verschiedenen Würfen durchgeführt. Zur Unterscheidung der SN und des VTA bei der Nurr1-Quantifizierung erfolgte durch einen Vergleich der TH und DAT Expression auf direkt benachbarten Schnitten. Skala in A-C $=100 \mu \mathrm{m}$ 
nachgewiesen werden (Abb. 10 D-F, K). Auch hierbei war diese Erhöhung auf den Bereich des VTA zurückzuführen: Bei beiden Mutanten zeigte sich eine signifikante Erhöhung (113,2\% bzw. 107,1\%), während die DAT-positiven Zellen der SN leicht reduziert sind (n.s.). Die Gesamtanzahl der Nurr1-positiven Zellen ist bei beiden Mutanten ebenfalls leicht erhöht (108,5\% bzw. 103,6\%), wobei diese Erhöhung aber nur bei den Shh-Cre ${ }^{+/ P i t x 30 E}$ Mutanten signifikant ist (Abb. 10 G-I, L). Im Bereich des VTA zeigte sich hierbei eine signifikante Erhöhung bei den ShhCre+/Pitx30E Mutanten (110,3\%), wobei auch die Nurr1-positiven Zellen der SN leicht erhöht sind $(104,7 \%$, n. s.).

\subsubsection{Pitx3 hat einen positiven Einfluss auf die Expression von Lmx1a und Lmx1b}

Für eine korrekte Determinierung der mDA Neuronen sind die Faktoren Lmx1a/b und Foxa2 von entscheidender Bedeutung, und es konnte in der Vergangenheit gezeigt werden, dass die Interaktion dieser drei Faktoren die Neurogenese der mDA Neuronen bedeutend beeinflusst (Nakatani et al., 2010). Dabei wurde gezeigt, dass eine ektopische Expression von Lmx1a, Lmx1b oder Foxa2 im ventralen Mittelhirn eine Erhöhung TH-positiver Neuronen bewirken kann. Die Shh$\mathrm{Cre}^{+/ P i t x 30 E}$ und Foxa2-Cre+/Pitx30E Mutanten zeigen ebenfalls eine Erhöhung THpositiver Neuronen im ventralen Mittelhirn (Abb. 9 und 10). Um herauszufinden, ob diese Erhöhung der TH-Expression ebenso durch den Einfluss von Lmx1a/b und Foxa2 hervorgerufen wird, wurden am Embryonaltag E12.5 Expressionsanalysen für diese Faktoren durchgeführt. Bei einer Betrachtung der Foxa2- Expression konnten keine Unterschiede zwischen Kontrolltieren und den Mutanten Shh-Cre ${ }^{+/ P i t x 30 E}$ und Foxa2-Cre ${ }^{+/ P i t x 30 E}$ detektiert werden (Abb. 11 A-C), wobei eine quantitative Analyse aufgrund der geringen Stichprobenzahl (jeweils zwei Mutanten) nicht durchgeführt wurde. Die Gesamtzahl der Lmx1a-positiven Zellen ist bei den Shh-Cre ${ }^{+/ P i t x 30 E}$ und Foxa2-Cre ${ }^{+/ P i t x 30 E}$ Mutanten leicht erhöht (105,1\% bzw. 103,5\%; Abb. 11 D-F, M), wobei keine Signifikanz ermittelt werden konnte. Bei einer getrennten Betrachtung der Lmx1a-Expression in der VZ, SVZ und der MZ konnten jedoch signifikante Unterschiede detektiert werden. Sowohl bei der Shh-Cre ${ }^{+/ P i t x 30 E}$ als auch bei der Foxa2-Cre ${ }^{+/ P i t x 30 E}$ Mutante zeigt sich eine signifikante Erhöhung Lmx1a-positiver Zellen in der VZ (111,2\% bzw. 109,6\%) 


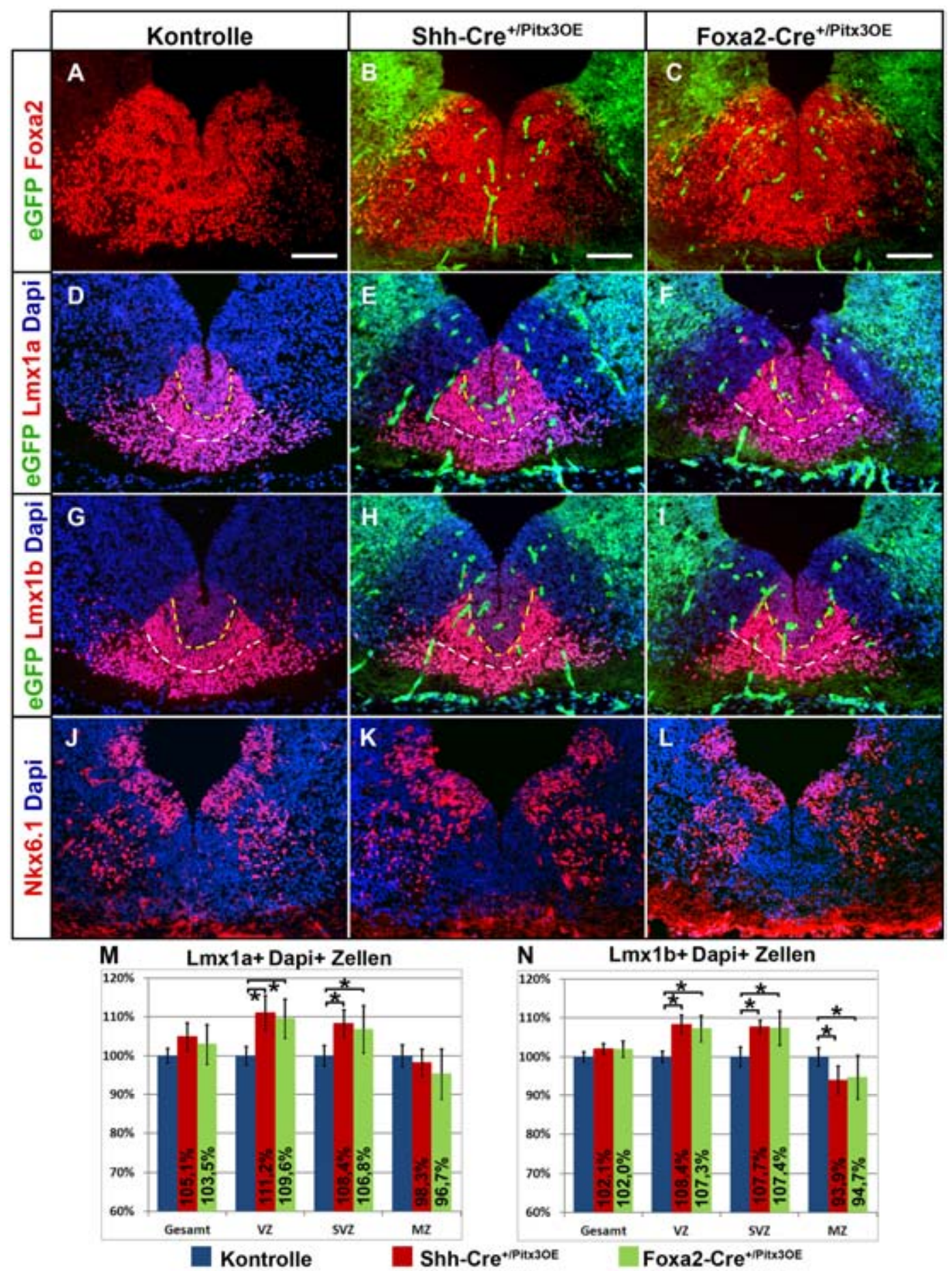

Abb. 11: Die Überexpression von Pitx3 im ventralen Mittelhirn führt zu einer Erhöhung der Lmx1a/b-positiven Zellen in der VZ und SVZ an Tag E12.5. IIF auf coronalen Gewebeschnitten des ventralen murinen Mittelhirns. Kontrolltiere (A,D,G,J), Mutanten Shh-Cre ${ }^{+/ P i t x 30 E}(B, E, H, K)$ und Foxa2-Cre ${ }^{+/ P i t x 30 E}(C, F, I, L)$ A-D) anti-Foxa2 IIF-Färbung und endogenes eGFP der Mutanten; D-F) anti-Lmx1a IIF-Färbung. G-I) anti-Lmx1b IIF-Färbung J-L) anti-Nkx6.1 IIF-Färbung. Die gelben Linien in D-I separieren die VZ (Ventrikulären Zone) von der SVZ (Subventrikulären Zone), und die weißen Linien separieren die SVZ von der MZ (Mantelzone).M, N) Quantifizierung der Lmx1a- u. Lmx1b-positiven Zellen aus D-I; die Fehlerbalken stehen für die Standardabweichungen und * gibt die Signifikanz an ( $\leq \leq 0,05)$, ermittelt mit dem „Student's T-Test“; Gesamt steht für die Anzahl aller Zellen - die Gesamtanzahl wurde weiterhin in VZ, SVZ, und MZ separiert. Dabei wurde die Anzahl der positiven Zellen der Kontrolltiere als 100\% definiert und die Anzahl der Zellen der Mutanten in Relation gesetzt. Die Expressionsanalysen von Lmx1a und Lmx1b wurden bei mind. drei Kontrolltieren und Mutanten aus verschiedenen Würfen durchgeführt. Für die Marker Foxa2 und Nkx6.1 wurden jeweils zwei Kontrollen und Mutanten aus zwei Würfen analysiert. Skala $=100 \mu \mathrm{m}$ 
und der SVZ (108,4\% bzw. 106,8\%; Abb. 11 D-F, M). In der Mantelzone (MZ) hingegen ist eine geringe, nicht signifikante Reduktion detektierbar. Die Gesamtanzahl der Lmx1b-positiven Zellen im ventralen Mittelhirn ist bei beiden Mutanten leicht erhöht (102,1\% bzw. 102,0\%), wobei keine Signifikanz ermittelt werden konnte. Betrachtet man wiederum die VZ, SVZ und die MZ getrennt voneinander, zeigt sich bei den Shh-Cre ${ }^{+/ P i t x 30 E}$ und Foxa2-Cre ${ }^{+/ P i t x 30 E}$ Mutanten eine signifikante Erhöhung Lmx1b-positiver Zellen in der VZ und der SVZ (108,4\% bzw. 107,3\%; Abb. 11 G-L, N). In der Mantelzone hingegen kann bei beiden Mutanten eine signifikante Reduktion der Lmx1b-positiven Zellen nachgewiesen werden (93,9\% bzw. 94,7\%).

Der Transkriptionsfaktor Nkx6.1 wird lateral des mDA Areals exprimiert und ist für die Neurogenese glutamaterger Neuronen (z.B. Nucleus ruber und Oculomotor Neuronen) von Bedeutung (Prakash et al., 2009). Um einen möglichen Effekt der Pitx3-Überexpression auf diese lateralen Neuronenpopulationen zu untersuchen, wurde die Expression von Nkx6.1 in beiden Mutanten analysiert. Hierbei zeigten sich keinerlei Unterschiede in der Expression von Nkx6.1 bei den Shh-Cre ${ }^{+/ P i t x 30 E}$ und Foxa2-Cre ${ }^{+/ P i t x 30 E}$ Mutanten, wobei eine Quantifizierung aufgrund der geringen Stichprobenanzahl $(\mathrm{n}=2)$ nicht durchgeführt wurde (Abb. $11 \mathrm{~J}-\mathrm{L})$.

\section{2 Überexpression von Pitx3 im dorsalen und ventralen Mittelhirn - Wnt1-Cre ${ }^{+/ P^{2} \times 30 E}$ und En1-Cre ${ }^{+/ P i t x 30 E}$}

Die beiden Signalmoleküle Wnt1 und En1 sind von entscheidender Bedeutung für die Etablierung und Stabilisierung des gesamten Bereiches des Mittel- und Hinterhirns. Weiterhin werden diese Faktoren in den sich entwickelnden mDA Neuronen exprimiert und sind u.a. für die Regionalisierung, Induktion, Differenzierung, und Aufrechterhaltung des dopaminergen Systems von besonderer Relevanz (Kapitel 1.4) (Alves dos Santos \& Smidt, 2011). Bei den transgenen Wnt1-Cre und En1-Cre Mauslinien handelt es sich um nicht induzierbare Cre-Linien (Kapitel 2.2). Die durch das Cre-LoxP-System vermittelte Pitx3-Überexpression wird folglich bei den Wnt1-Cre+/Pitx30E Mutanten bereits am Embryonaltag E8.0, und bei den En1-Cre ${ }^{+/ P i t x 30 E}$ Mutanten am Embryonaltag E8.5 induziert. (Kapitel 1.4.2). Wnt1 wird an E8.0 im gesamten dorsoventralen 


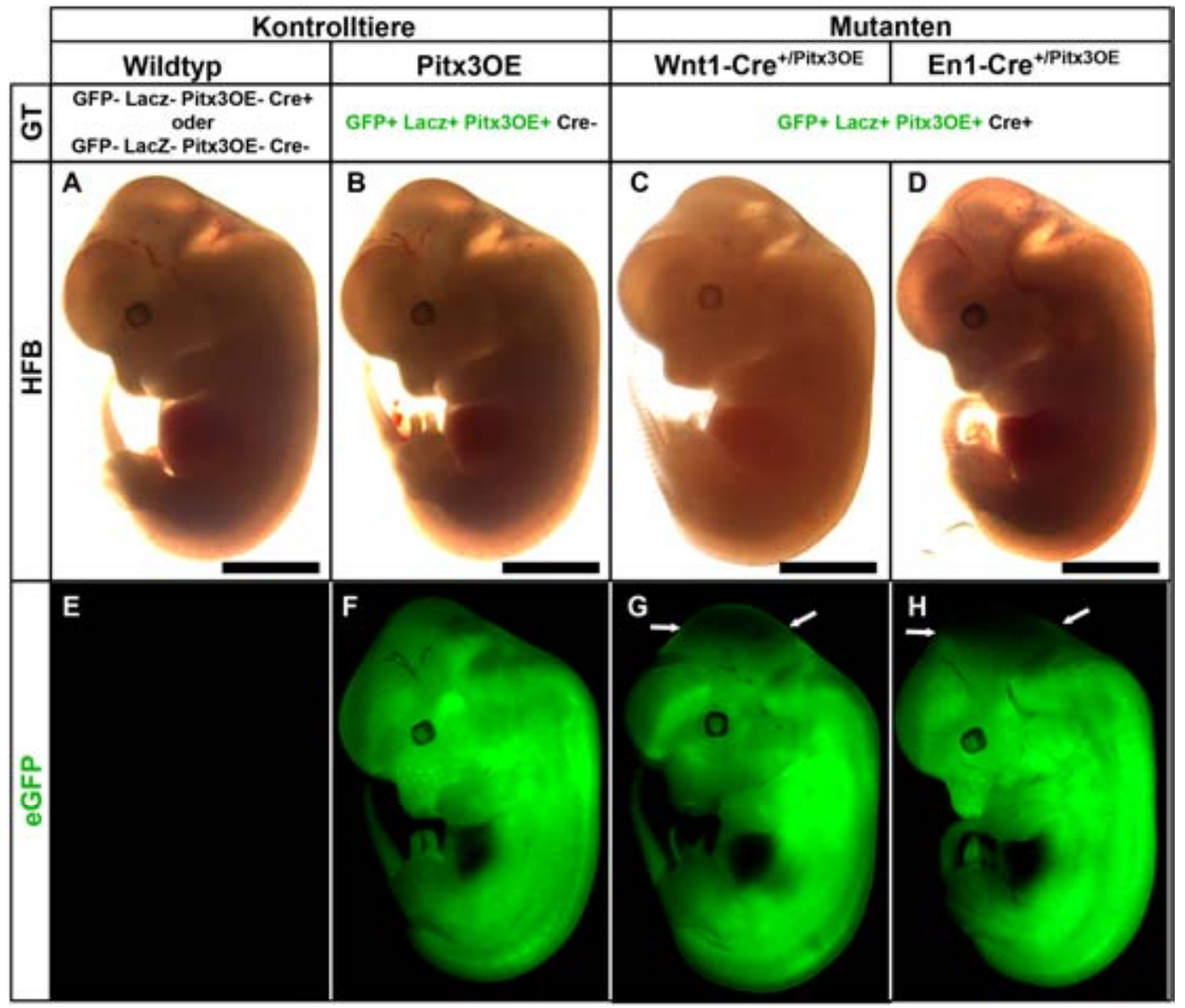

Abb. 12: Mausembryonen an Tag E12.5, Kontrolltiere (AE, BF) und doppeltransgene Mausmutanten Wnt1-Cre ${ }^{+/ P i t x 30 E}$ (CG) und En1-Cre ${ }^{+/ P i t x 30 E}$ (DH). A-D) Sagittalansicht ganzer Embryonen, Hellfeldbelichtung (HFB); E-F) entsprechende eGFP Expression der Embryonen. Sowohl die transgenen Pitx30E-Embryonen (E) als auch die doppeltransgenen Mausmutanten (G, H) zeigen eine starke Expression des eGFP-Reporters. Äußerlich sind bei beiden Mutanten GFPnegative Bereiche erkennbar (weiße Pfeile) - diese Bereiche entsprechen der jeweiligen Wnt1bzw. En1- Expressionsdomäne. GT = Genotyp; Skala = 2mm

Mittelhirn exprimiert, und die Expressionsdomäne beschränkt sich wenig später auf einen schmalen Bereich anterior der MHG im ventralen Mittelhirn. En1 wird an E8.5 im gesamten posterioren Mittelhirn und anterioren Hinterhirn im Bereich der MHG gebildet, und wird von allen differenzierenden mDA Neuronen kontinuierlich ab dem Tag E11.0 exprimiert (Wilkinson et al., 1987; Davis et al., 1988; Joyner, 1996; Joyner et al., 2000; Simon et al., 2001; Zervas et al., 2004).

Die gewünschten doppeltransgenen Mausmutanten Wnt1-Cre ${ }^{+/ P i t x 30 E}$ bzw. En1$\mathrm{Cre}^{+/ \mathrm{Pitx30E}}$ tragen den Genotyp GFP+(LacZ+/Pitx30E+)/Cre+ (siehe Abb. 12). Als Kontrolltiere wurden Embryonen verwendet, die entweder keinerlei Transgen tragen (GFP- / LacZ- / Pitx3- / Cre-), nur Cre+ oder nur GFP+(LacZ+ / Pitx30E+) in sich tragen. Die Embryonen der doppeltransgenen Mutanten Wnt1-Cre ${ }^{+/ P i t x 30 E}$ und En1-Cre ${ }^{+/ P i t x 30 E}$ sowie der transgenen Pitx30E-Mauslinie zeigten eine starke GFPExpression bei E12.5 (Abb. 12). Bei den Wnt1-Cre ${ }^{+/ P i t x 30 E ~-~ u n d ~ E n 1-C r e ~}{ }^{+/ P i t x 30 E}$ 
Mutanten sind äußerlich GFP-negative Bereiche erkennbar (weiße Pfeile in Abb. 12 G, H) - diese Bereiche entsprechen den jeweiligen Wnt1- bzw. En1- Domänen. Äußerlich sind bei beiden Mutanten am Embryonaltag E12.5 keine Auffälligkeiten bezüglich der Größe und Morphologie erkennbar. Die Wnt1-Cre+/Pitx30E Mutanten sind postnatal nicht lebensfähig und zeigen bereits starke Entwicklungsdefekte im Mittel- und Hinterhirn an E15.5 (Abb. 15 A, B). Die En1-Cre+/Pitx30E Mutanten sterben nach ca. vier Wochen nach der Geburt, sind deutlich kleiner als die Kontrolltiere aus dem gleichen Wurf, zeigen Defekte in der Entwicklung des Cerebellums (Abb. 15 A, C), und weisen Bewegungsdefizite auf.

Auf coronalen Gewebeschnitten durch das Mittelhirn am Embryonaltag E12.5 sind diese GFP-negativen Bereiche beider Mutanten genauer erkennbar (Abb. 13 B, C). Die GFP-negativen Bereiche entsprechen der jeweiligen Wnt1- bzw. En1-Domäne, und durch indirekte Immunofluoreszenzfärbung (IIF) konnte in diesen Bereichen die Überexpression von Pitx3 im dorso- ventralen Areal nachgewiesen werden (Abb. 13 B, C). Die durch das Cre-LoxP-System vermittelte Überexpression von Pitx3 unter der Kontrolle des Wnt1- bzw. En1-Promotors der jeweiligen transgenen Wnt1-Cre bzw. En1-Cre-Mauslinien konnte somit nachgewiesen werden. Ebenso wurde durch die Detektion der Pitx3-Überexpression bei beiden Mutanten die Effizienz der Cre-Rekombinase und des Cre-LoxP-Systems verifiziert. Bei den Kontrolltieren kann Pitx3 in der subventrikulären Zone (SVZ) und der Mantelzone (MZ) detektiert werden, und diese endogene Expression korreliert mit der Expression der Tyrosinhydroxylase (TH, Abb. 13A, D). Bei Wnt1-Cre ${ }^{+/ P i t x 30 E}$ und En1-Cre+/Pitx30E Mutanten erstreckt sich die Pitx3-Expression über das gesamte dorso-ventrale, rostrale Mittelhirn (Abb. 13 B, C).

\subsubsection{Pitx3 bewirkt eine Erhöhung der mDA Neuronen im Bereich des ventralen tegmentalen Areals (VTA)}

Für die Analyse der Entwicklung der mDA Neuronen wurde zunächst die Expression von TH, DAT und Nurr1 mittels IIF am Tag E12.5 untersucht. Bei einer quantitativen Analyse der TH-Expression am Tag E12.5 ist auffällig, dass bei den Wnt1-Cre ${ }^{+/ P i t x 30 E}$ und En1-Cre ${ }^{+/ P i t x 30 E}$ Mutanten signifikant mehr TH-positiven Neuronen im medialen Bereich der mDA Neuronen (VTA) detektiert werden können $(115,6 \%$ 


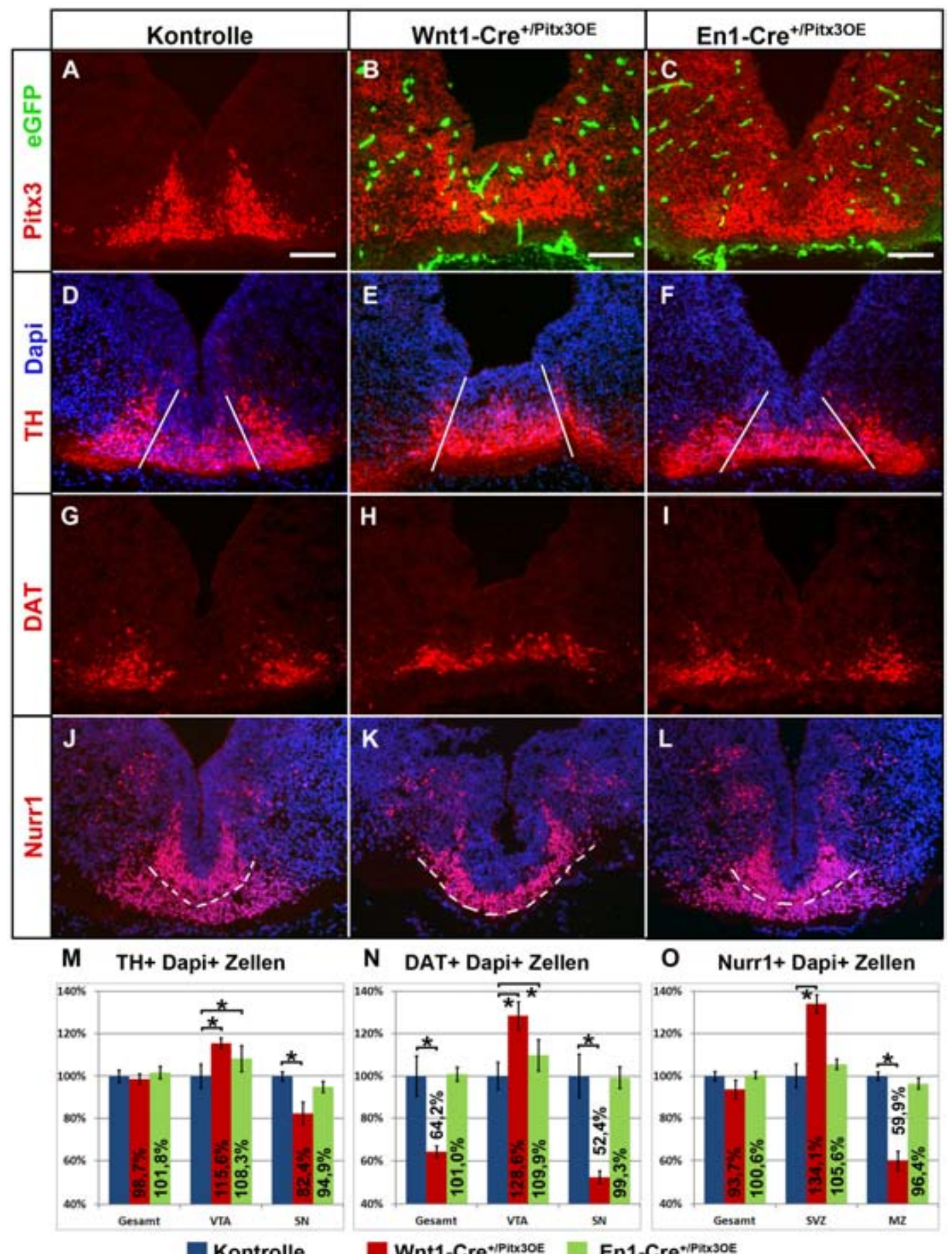

Abb. 13: Die Überexpression von Pitx3 im dorso-ventralen Mittelhirn führt zu einer Erhöhung der medialen mDA Neuronen an Tag E12.5. IIF auf coronalen Gewebeschnitten des ventralen murinen Mittelhirns. Kontrolltiere (A,D,G,J), Mutanten Wnt1-Cre ${ }^{+/ P i t x 30 E}(B, E, H, K)$ und En1-Cre ${ }^{+/ P_{i t x 30 E}}$ (C,F,I,L) A-C) anti-Pitx3 IIF-Färbung und endogenes eGFP der Mutanten. Bei beiden Mutanten ist im GFP-negativen Bereich die Pitx3-Überexpression detektierbar. Die vereinzelten GFP-Zellen sind Blutgefäße. D-F) anti-TH IIF-Färbung, die weißen Linien separieren den medialen Teil, aus dem das VTA hervorgeht, vom lateralen Areal, aus dem sich die SN entwickelt. G-I) anti-DAT IIF-Färbung JL) anti-Nurr1 IIF-Färbung; die weiße gestrichelte Linie markiert die Grenze zwischen der subventrikulären Zone (SVZ) und der Mantelzone (MZ); M-0) Quantifizierung der gezeigten Marker aus A-L; die Fehlerbalken stehen für die Standardabweichungen und ${ }^{*}$ gibt die Signifikanz an $(\mathrm{p} \leq$ 0,05), ermittelt mit dem „Student's T-Test“; Gesamt steht für die Anzahl aller Zellen, VTA (ventrales tegmentales Areal), SN (Substantia nigra), SVZ (Subventrikuläre Zone), MZ (Mantelzone). Dabei wurde die Anzahl der positiven Zellen der Kontrolltiere als 100\% definiert und die Anzahl der Zellen der Mutanten in Relation gesetzt. Alle gezeigten Expressionsanalysen wurden bei mind. drei Kontrolltieren und Mutanten aus verschiedenen Würfen durchgeführt. Skala in A-C = $100 \mu \mathrm{m}$ 
bzw. 108,3\%; Abb. 13 D-E, M). Im lateralen Bereich (SN) ist eine signifikante Reduktion TH-positiver Zellen bei den Wnt1-Cre+/Pitx30E Mutanten detektierbar $(82,4 \%)$, während bei den En1-Cre+/Pitx30E Mutanten eine nicht signifikante Reduktion vorhanden ist (94,9\%). Die Gesamtanzahl TH-positiver Zellen ist bei beiden Mutanten nicht verändert. Die Untersuchung der medialen DAT-Expression (VTA) bei den Wnt1-Cre ${ }^{+/ P i t x 30 E}$ Mutanten zeigte eine signifikante Erhöhung $(128,6 \%)$ bei gleichzeitiger signifikanter Reduktion im lateralen Bereich (SN, 52,4\%; Abb. 13 D, E, N). Die Gesamtanzahl der DAT-positiven Zellen ist bei diesen Mutanten signifikant reduziert (64,2\%). Bei den En1-Cre ${ }^{+/ P i t x 30 E}$ Mutanten konnte ebenfalls eine signifikante Erhöhung der DAT-positiven Zellen in der VTA nachgewiesen werden (109,9\%; Abb. 13G, I, N), wobei keine Veränderungen im lateralen Bereich und in der Gesamtzahl detektiert werden konnten (99,3\% bzw. 101,0\%). Nurr1 wird während der frühen Differenzierung der mDA Neuronen gebildet und kann in der SVZ und in der MZ der Kontrolltiere und En1-Cre ${ }^{+/ P i t x 30 E}$ Mutanten detektiert werden. Diese Mutanten zeigen eine leichte Erhöhung der Nurr1-positiven Zellen in der SVZ bei einer geringen Reduktion in der MZ, wobei keine Signifikanz gezeigt werden konnte (105,6\% bzw. 96,4\%; Abb. 13 J, L, 0). Die Gesamtanzahl ist unverändert. Bei den Wnt1-Cre ${ }^{+/ P i t x 30 E}$ Mutanten konnte jedoch eine signifikante Erhöhung der Nurr1- Expression in der SVZ nachgewiesen werden (134,1\%, Abb. 13 J, K, 0), während die Anzahl in der MZ stark reduziert ist (59,9\%). Die Gesamtanzahl der Nurr1-positiven Zellen ist dementsprechend nicht signifikant reduziert $(93,7 \%)$.

Die Differenzierung der mDA Neuronen beginnt am Embryonaltag E11.5 und erstreckt sich über einen Zeitraum von drei bis vier Tagen (Kapitel 1.4.3 und Abb. 7), in denen ausgereifte Neuronen kontinuierlich gebildet werden. Weil an E12.5 bei den Wnt1-Cre ${ }^{+/ P i t x 30 E}$ und En1-Cre ${ }^{+/ P i t x 30 E}$ Mutanten bereits eine Erhöhung der mDA Neuronen, vor allem im medialen Bereich, nachgewiesen werden konnte (Abb. 13), wurde die die weitere Entwicklung der mDA Neuronen bei diesen Mutanten zu einem späteren Zeitpunkt (E15.5) analysiert (Abb. 14). Dabei zeigte sich eine sich eine signifikante Erhöhung der Gesamtanzahl der TH-positiven Zellen bei den Wnt1-Cre ${ }^{+/ \operatorname{Pitx30E}}(113,4 \%)$ und En1-Cre ${ }^{+/ P i t x 30 E}$ Mutanten $(109,7 \%)$. Diese Erhöhung ist dabei auf eine signifikante Erhöhung im Bereich des VTA zurückzuführen (137,6\% bzw. 115,0\%; Abb. 14 A-C, J), während die Anzahl der TH-positiven Zellen in der SN bei den Wnt1-Cre ${ }^{+/ P i t x 30 E}$ Mutanten stark reduziert 


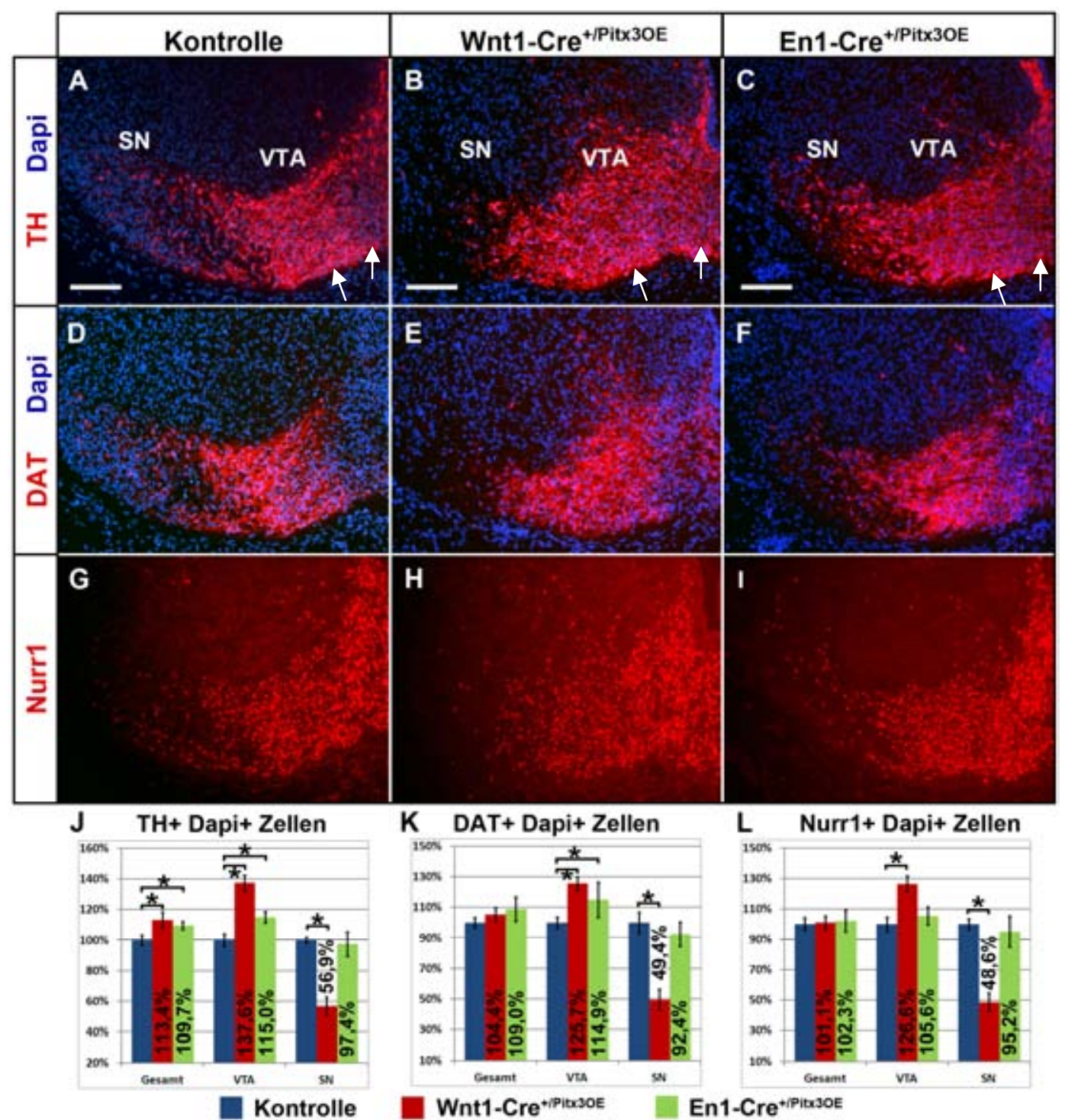

Abb. 14: Die Überexpression von Pitx3 im dorso-ventralen Mittelhirn führt zu einer Erhöhung der mDA Neuronen im VTA an Tag E15.5. IIF auf coronalen Gewebeschnitten des ventralen murinen Mittelhirns - nur die linke Seite der mDA Neuronen ist gezeigt. Kontrolltiere (A,D,G), Mutanten Wnt1-Cre ${ }^{+/ P i t x 30 E}(B, E, H)$ und En1-Cre ${ }^{+/ P i t x 30 E}(C, F, I)$ A-C) anti-TH IIF-Färbung. Die weißen Pfeile deuten auf erhöhte TH Expression des VTA. D-F) anti-DAT IIF-Färbung. G-I) anti-Nurr1 IIFFärbung. Die TH-, DAT- und Nurr1- Färbungen wurden auf benachbarten Schnitten durchgeführt. JL) Quantifizierung der gezeigten Marker aus A-I; die Fehlerbalken stehen für die Standardabweichungen und * gibt die Signifikanz an $(\mathrm{p} \leq 0,05)$, ermittelt mit dem „Student's TTest“; Gesamt steht für die Anzahl aller Zellen, VTA (ventrales tegmentales Areal), SN (Substantia nigra). Dabei wurde die Anzahl der positiven Zellen der Kontrolltiere als 100\% definiert und die Anzahl der Zellen der Mutanten in Relation gesetzt. Für die Quantifizierung bei E15.5 wurde das jeder dritte Schnitt des gesamten Mittelhirns herangezogen. Alle gezeigten Expressionsanalysen wurden bei mind. drei Kontrolltieren und Mutanten aus verschiedenen Würfen durchgeführt. Zur Unterscheidung der SN und des VTA bei der Nurr1-Quantifizierung erfolgte durch einen Vergleich der TH und DAT Expression auf direkt benachbarten Schnitten. Skala in A-C $=100 \mu \mathrm{m}$

ist (56,9\%). Die En1-Cre ${ }^{+/ P i t x 30 E}$ Mutanten zeigten eine geringe, nicht signifikante Reduktion in der SN (97,4\%). Bei der Analyse der DAT-Expression zeigte sich beiden Mutanten eine nicht signifikante Erhöhung der Gesamtzahl der DATExpression (104,4\% bzw. 109,0\%; Abb. 14 D-F, K). Bei den Wnt1-Cre ${ }^{+/ P i t x 30 E}$ Mutanten konnte eine signifikante Erhöhung der DAT-Expression im Bereich des 


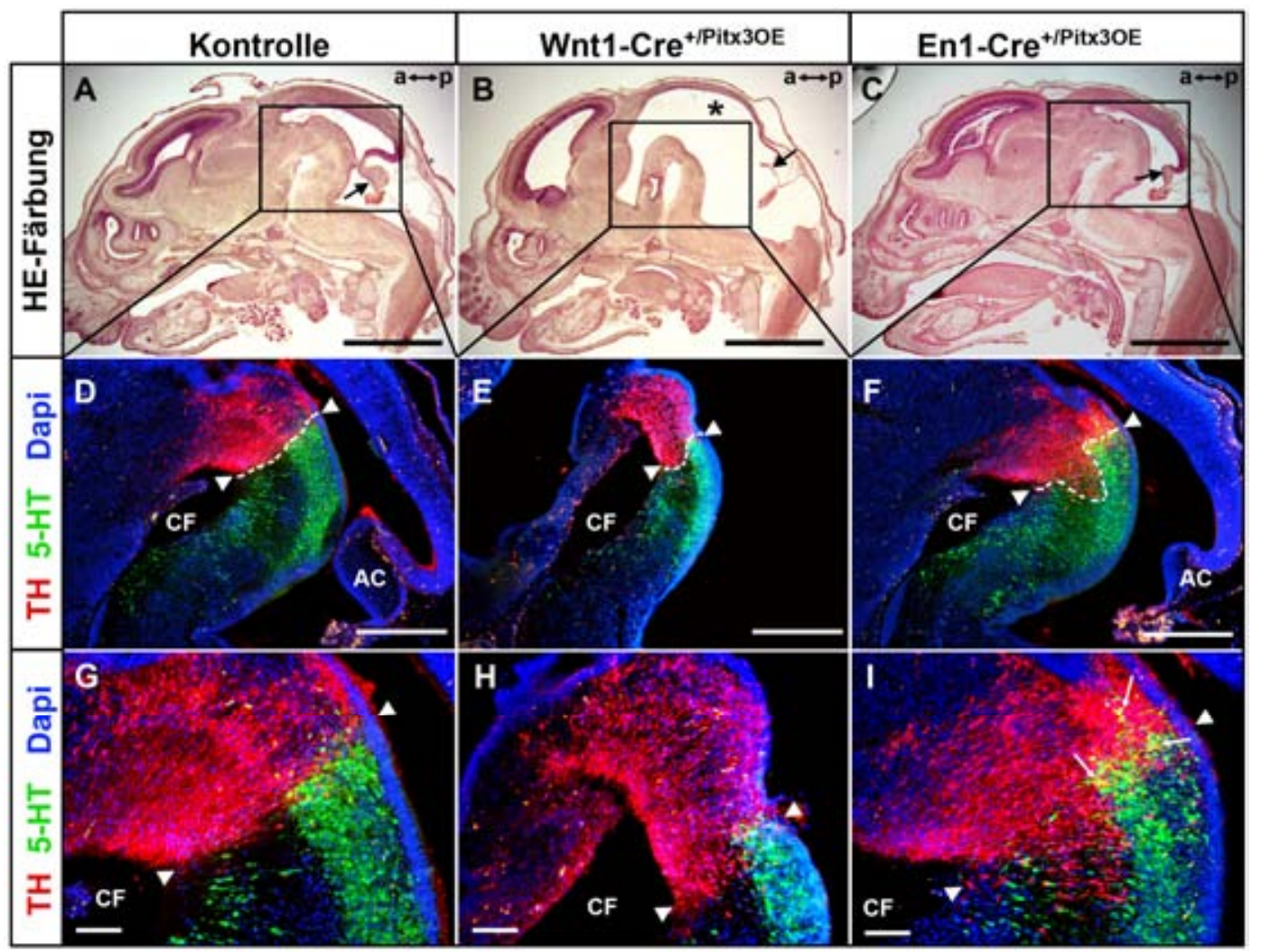

Abb. 15: Die Überexpression von Pitx3 im dorso-ventralen Mittelhirn bewirkt eine caudale Verschiebung der TH- Expression an Tag E15.5 und führt zu Entwicklungsstörungen im Bereich des Mittelhirns. A-C) Hämatoxylin-Eosin (HE) Färbung auf Sagittalschnitten von Kontrolltieren (A) sowie Wnt1-Cre $/$ Pitx30E - bzw. En1-Cre ${ }^{+/ P i t x 30 E}$ Mutanten (B,D). Die schwarzen Pfeile deuten auf die Anlage der Cerebellums, welche bei beiden Mutanten unterentwickelt ist. * in B deutet auf Entwicklungsdefizite im gesamten Mittel- und Hinterhirn. Anterior (a) ist links, posterior (p) ist rechts. D-F) TH/5-HT (Serotonin) IIF-Färbungen (benachbarte Schnitte zu den HE-Färbungen in AC). Bei den Kontrolltieren sind die mDA Neuronen (TH) von den serotonergen (5-HT) Neuronen durch die MHG (weiße Pfeilspitzen) separiert. Bei den Wnt1-Cre Pitx30E- und En1-Cre $^{+/ P_{i t x 30 E}}$ Mutanten (E, F) sind die mDA Neuronen nach caudal verschoben. Bei den En1-Cre ${ }^{+/ P i t x 30 E}$ Mutanten können vereinzelte $\mathrm{TH}$ - und 5-HT-positive Neuronen detektiert werden (weiße Pfeile). $\mathrm{CF}=$ Cephalische Flexur; AC = Anlage des Cerebellums. G-I) Vergrößerter Bereich der MHG aus Abb. D-F. Skala in $A-C=2 m m$, in D-F $=500 \mu \mathrm{m}$, in G-I $=100 \mu \mathrm{m}$

VTA $(125,7 \%)$ nachgewiesen werden bei gleichzeitiger Reduktion in der SN (49,4\%; Abb. 14 D, E, K). Die En1-Cre+/Pitx30E Mutanten zeigen eine signifikante Erhöhung der DAT-positiven Zellen in des VTA (114,9\%), wobei eine leichte, nicht signifikante Reduktion im Bereich der SN detektiert wurde (92,4\%; Abb. 14 D, F, K). Bei der Analyse der Nurr1- Expression konnte eine signifikante Erhöhung bei den Wnt1-Cre ${ }^{+/ P i t x 30 E}$ Mutanten im Bereich des VTA nachgewiesen werden bei einer gleichzeitigen signifikanten Reduktion im Bereich der SN (126,6\% bzw. 48,6\%; Abb. 14 G, H, L) - die Gesamtanzahl der Nurr1-positiven Zellen zeigte keine Veränderungen (101,1\%). Bei den En1-Cre ${ }^{+/ P i t x 30 E}$ Mutanten (Abb. 14 G, I, L) ist die Nurr1- Expression im Bereich des VTA nicht signifikant erhöht $(105,6 \%)$, während im Bereich der SN eine nicht signifikante Reduktion detektierbar ist $(95,2 \%)-$ die Gesamtanzahl ist unverändert (102,3\%). 
Bei beiden Mutanten ist anzumerken, dass bei der coronalen Expressionsanalyse (TH, DAT, Nurr1) im caudalen Mittelhirn im Übergangsbereich zum Hinterhirn eine Erhöhung der Expression der besagten Marker ersichtlich gewesen ist (Daten nicht gezeigt). Um diesen Phänotyp näher zu untersuchen, wurden im gleichen Entwicklungsstadium (E15.5) Sagittalschnitte von Kontrolltieren, Wnt1-Cre ${ }^{+/ P i t x 30 E}$ und En1-Cre ${ }^{+/ P i t x 30 E}$ Mutanten angefertigt und die Expression von TH sowie 5-HT (Serotonin) untersucht (Abb. 15). Bei den Kontrolltieren ist erkennbar, dass die dopaminergen Neuronen des Mittelhirns von den serotonergen Neuronen des Hinterhirns stets durch die Mittel- Hinterhirn- Grenze (MHG, weiße Pfeilspitzen in Abb. 15 D und F) separiert sind. Bei den Wnt1-Cre ${ }^{+/ P i t x 30 E ~ M u t a n t e n ~ s i n d ~ d i e s e ~}$ beiden Neuronenpopulationen zwar voneinander separiert, aber es sind ektopische dopaminerge Neuronen im rostralen Hinterhirn detektierbar, während die serotonergen Neuronen weiter nach caudal verschoben sind (Abb. 15 D,E,G,H). Weiterhin zeigen sich bei den Wnt1-Cre'/Pitx30E Mutanten drastische Entwicklungsstörungen im Bereich des ventralen Mittel- und Hinterhirns - das gesamte neuronale Gewebe im Bereich der Cephalischen Flexur (CF) ist bei diesen Mutanten unterentwickelt (Abb. 15 B, E, H). Diese Entwicklungsdefizite erstrecken sich dabei über das gesamte Gebiet des Mittel- und Hinterhirns der Wnt1$\mathrm{Cre}^{+/ P i t x 30 E}$ Mutanten, wie es im Rahmen von morphologischen Analysen (siehe * in Abb. 15 B; HE-Färbung = Hämatoxylin-Eosin-Färbung) nachgewiesen werden konnte. Auffällig ist hierbei die rudimentäre Entwicklung der Anlage des Cerebellums (schwarzer Pfeil in Abb. 15 B). Diese Entwicklungsdefizite sind bei den En1-Cre ${ }^{+/ P i t x 30 E}$ Mutanten nicht ausgebildet - es zeigte sich jedoch auch eine Entwicklungsstörung der Anlage des Cerebellums (schwarzer Pfeil in Abb. 15 C). Bei der Betrachtung der TH- und 5-HT Expression konnten ebenfalls ektopische dopaminerge Neuronen im rostralen Hinterhirn bei den En1-Cre ${ }^{+/ P i t x 30 E}$ Mutanten detektiert werden (Abb. 15 F, I), wobei dieser Phänotyp nicht so stark ausgebildet ist, wie es bei den Wnt1-Cre ${ }^{+/ P i t x 30 E}$ Mutanten der Fall ist (Vgl. Abb. 15 D-I). Weiterhin sind bei den En1-Cre ${ }^{+/ P i t x 30 E}$ Mutanten die dopaminergen (TH) und serotonergen (5-HT) Neuronenpopulationen nicht mehr klar voneinander separiert und es konnten vereinzelt TH- und 5-HT-positive Neuronen detektiert werden (Gelbe Neuronen in Abb. 15 I, weiße Pfeile). 


\subsubsection{Pitx3 hat einen positiven Einfluss auf die Expression von Lmx1a und Lmx1b in der Ventrikulären Zone (VZ)}

Wie bereits in Kapitel 2.1.2 erwähnt wurde, sind die Faktoren Lmx1a/b und Foxa2 von entscheidender Bedeutung für die Neurogenese der mDA Neuronen und für die Expression von TH (Nakatani et al., 2010). Die Wnt1-Cre+/Pitx30E und En1$\mathrm{Cre}^{+/ P i t x 30 E}$ Mutanten zeigen eine Erhöhung TH-positiver Neuronen im ventralen Mittelhirn (Abb. 13 und 14). Um herauszufinden, ob diese Erhöhung der THExpression ebenso durch den Einfluss von Lmx1a/b und Foxa2 hervorgerufen wird, wurden am Embryonaltag E12.5 Expressionsanalysen für diese Faktoren durchgeführt. Bei einer Betrachtung der Foxa2-Expressionsdomäne konnten keine Unterschiede zwischen Kontrolltieren und den Wnt1-Cre ${ }^{+/ P i t x 30 E}$ und En1$\mathrm{Cre}^{+/ P i t x 30 E}$ Mutanten detektiert werden (Abb. $16 \mathrm{~A}-\mathrm{C}$ ), wobei eine quantitative Analyse aufgrund der geringen Stichprobenzahl (jeweils zwei Mutanten) nicht durchgeführt wurde. Die Gesamtzahl der Lmx1a-positiven Zellen ist bei den Wnt1$\mathrm{Cre}^{+/ \mathrm{Pitx30E}}$ Mutanten signifikant reduziert (82,5\%). Bei einer separaten Betrachtung der VZ, SVZ und der MZ zeigten sich jedoch beachtliche Unterschiede (Abb. 16 D, E, M): In der VZ ist die Lmx1a- Expression signifikant erhöht (132,8\%), in der SVZ unverändert (98,1\%), und in der MZ signifikant reduziert auf 35,1\%. Bei den En1-Cre ${ }^{+/ P i t x 30 E}$ Mutanten zeigten sich keine Unterschiede in der Gesamtzahl der Lmx1a-positiven Zellen, und bei einer getrennten Betrachtung der VZ, SVZ und MZ sind ebenfalls keinen signifikanten Veränderung detektierbar (Abb. 16 D, F, M).

Die Gesamtzahl der Lmx1b-positiven Zellen ist bei den Wnt1-Cre ${ }^{+/ P i t x 30 E}$ Mutanten signifikant reduziert (78,1\%), wobei die Lmx1a-Expression in der VZ signifikant erhöht (134,8\%), in der SVZ und MZ signifikant reduziert ist (87,8\% bzw. 33,2\%; Abb. 16G, H, N). Bei den En1-Cre+/Pitx30E Mutanten zeigten sich keine Unterschiede in der Gesamtzahl der Lmx1b-positiven Zellen, und bei einer getrennten Betrachtung der VZ und MZ sind ebenfalls keinen signifikanten Veränderung detektierbar (Abb. 16 D, F, M). In der MZ zeigte sich jedoch eine nicht signifikante Reduktion auf $87,6 \%$.

Zur Überprüfung der lateralen Neuronenpopulationen wurde die Expression von Nkx6.1 analysiert, einem TF, der in glutamatergen Neuronen gebildet wird (Prakash et al., 2009). Hierbei zeigten sich keinerlei Unterschiede in der Expression von Nkx6.1 bei den Wnt1-Cre ${ }^{+/ P i t x 30 E}$ und En1-Cre+/Pitx30E Mutanten, 


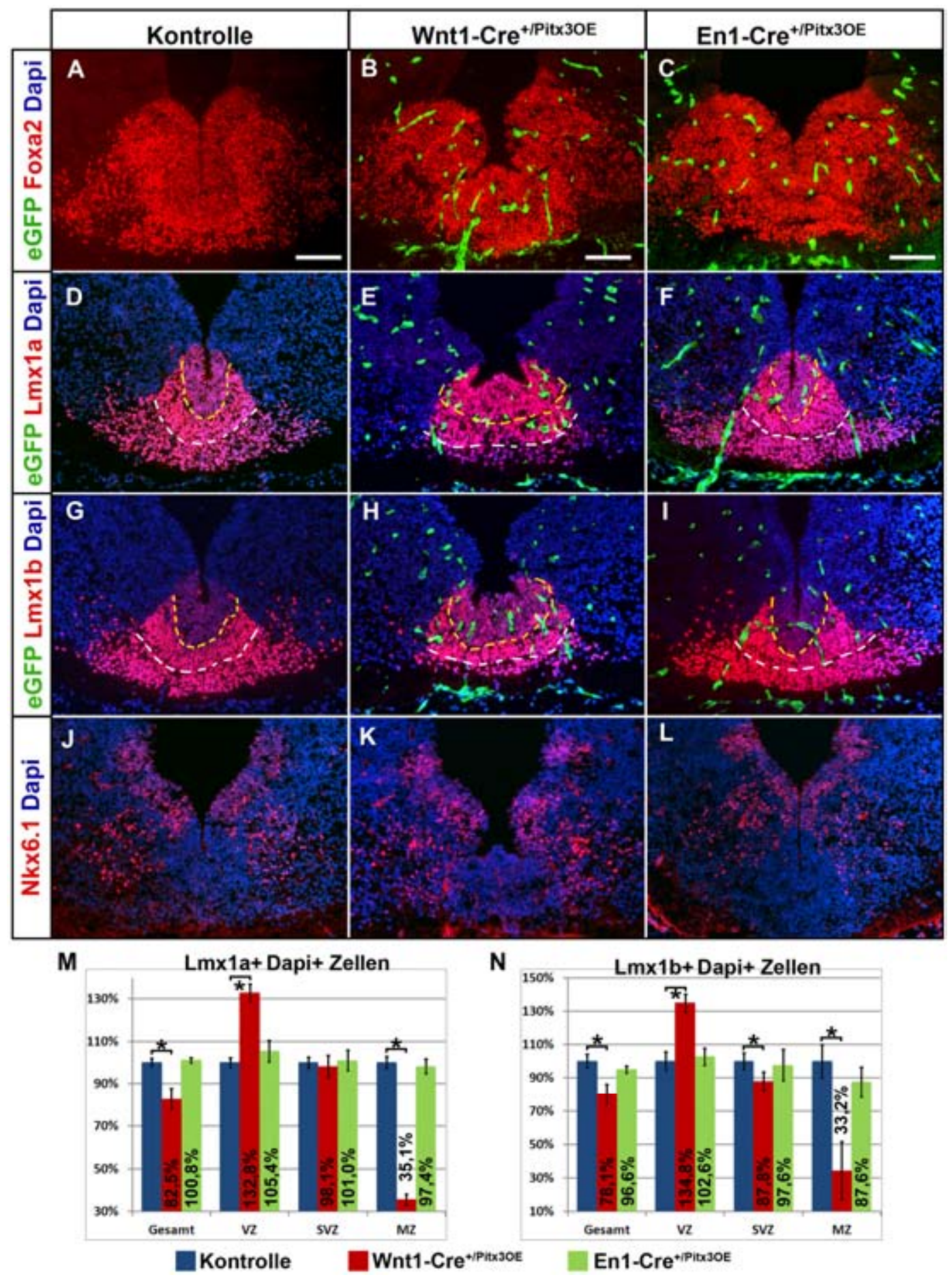

Abb. 16: Die Überexpression von Pitx3 im ventralen Mittelhirn führt zu einer Erhöhung der Lmx1a/b-positiven Zellen in der VZ an Tag E12.5. IIF auf coronalen Gewebeschnitten des ventralen murinen Mittelhirns. Kontrolltiere $(A, D, G, J)$, Mutanten Wnt1-Cre ${ }^{+/ P i t x 30 E}(B, E, H, K)$ und En1$\mathrm{Cre}^{+/ P i t x 30 E}($ C,F,I,L) A-D) anti-Foxa2 IIF-Färbung und endogenes eGFP der Mutanten; D-F) antiLmx1a IIF-Färbung. G-I) anti-Lmx1b IIF-Färbung J-L) anti-Nkx6.1 IIF-Färbung. Die gelben Linien in D-I separieren die VZ (Ventrikulären Zone) von der SVZ (Subventrikulären Zone), und die weißen Linien separieren die SVZ von der MZ (Mantelzone).M, N) Quantifizierung der Lmx1a- u. Lmx1bpositiven Zellen aus D-I; die Fehlerbalken stehen für die Standardabweichungen und ${ }^{*}$ gibt die Signifikanz an ( $\mathrm{p} \leq 0,05)$, ermittelt mit dem „Student's T-Test“; Gesamt steht für die Anzahl aller Zellen - die Gesamtanzahl wurde weiterhin in VZ, SVZ, und MZ separiert. Dabei wurde die Anzahl der positiven Zellen der Kontrolltiere als 100\% definiert und die Anzahl der Zellen der Mutanten in Relation gesetzt. Die Expressionsanalysen von Lmx1a und Lmx1b wurden bei mind. drei Kontrolltieren und Mutanten aus verschiedenen Würfen durchgeführt. Für die Marker Foxa2 und Nkx6.1 wurden jeweils zwei Kontrollen und Mutanten aus zwei Würfen analysiert. Skala $=100 \mu \mathrm{m}$ 
wobei eine Quantifizierung aufgrund geringer Stichprobenanzahl (jeweils zwei Mutanten) nicht durchgeführt wurde (Abb. 16 J-L).

\subsubsection{Die Pitx3-Überexpression in der Wnt1-Domäne (Wnt1- $\mathrm{Cre}^{+/ \mathrm{Pitx30E}}$ ) hat keinen Einfluss auf die radiale Migration der mDA Neuronen}

Während der mDA Neurogenese migrieren postmitotische mDA Vorläuferzellen von der VZ über die SVZ in die MZ entlang radialer Gliazellen (Kap. 1.4.3) (Kawano et al., 1995; Ohyama et al., 1998; Vitalis et al., 2005). Das Filamentprotein RC2 (engl. „Radial glial cell marker 2") wird in allen radialen Gliazellen exprimiert und wird zur Detektion der neuronalen Migration genutzt (Misson et al., 1988; ChanasSacre et al., 2000a; Chanas-Sacre et al., 2000b; Kang et al., 2010). ß-Catenin ist ein wichtiger Effektor des kanonischen Wnt1-Signalweges und wird ebenfalls in radialen Gliazellen exprimiert (Logan et al., 2004; Tang et al., 2009; Tang et al., 2010). Bei den Wnt1-Cre ${ }^{+/ P i t x 30 E}$ Mutanten ist die Neurogenese der mDA Neuronen an E12.5 und E15.5 gestört (Kap. 2.2.1) - im medialen Bereich des ventralen Mittelhirns (VTA) liegt eine Erhöhung der TH-positiven Neuronen vor, während im lateralen Bereich (SN) die TH-Expression drastisch reduziert ist

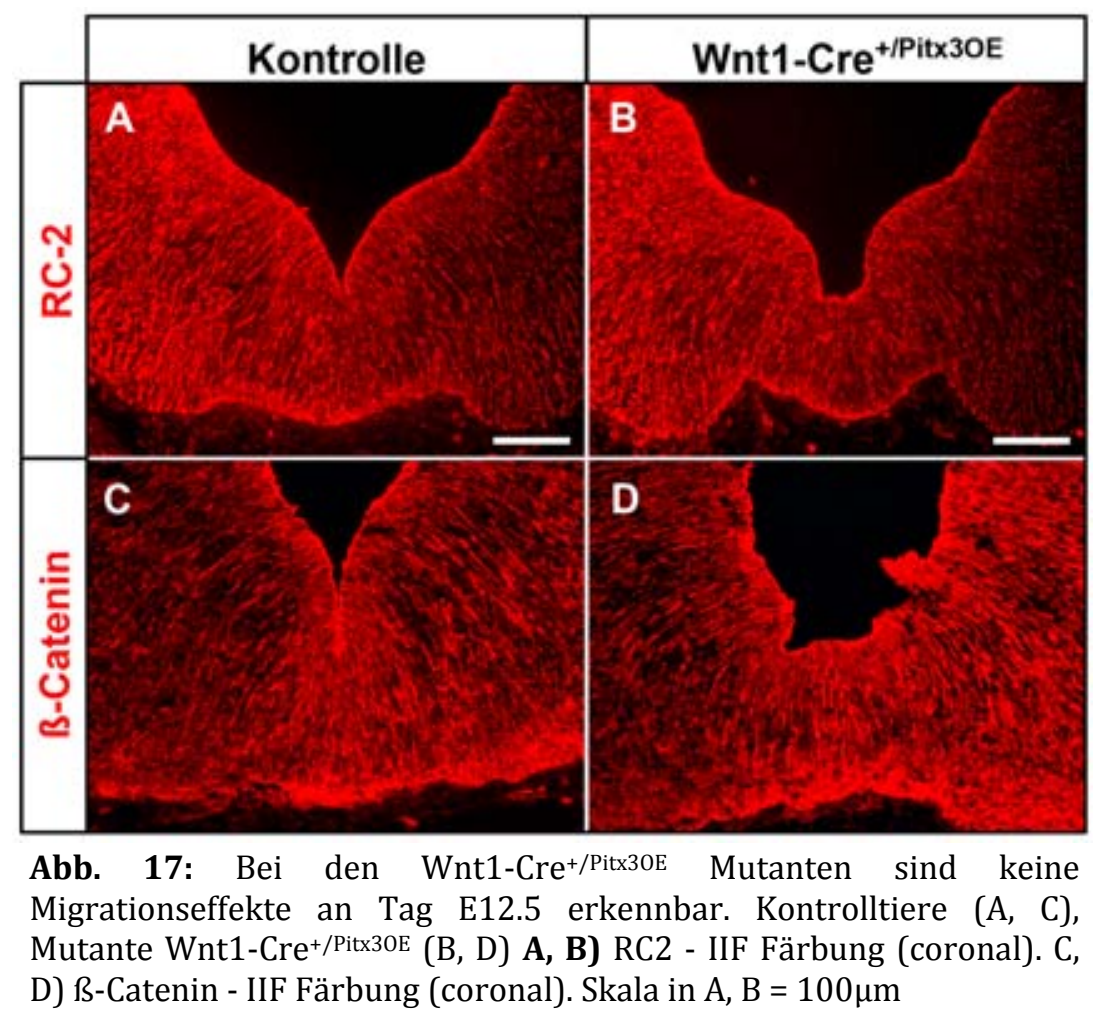


(Abb. 13 D, E und Abb. 14 A, B). Die beiden Marker RC2 und ß-Catenin wurden bei den Wnt1-Cre ${ }^{+/ P i t x 30 E}$ Mutanten verwendet, um mögliche Migrationseffekte an E12.5 zu untersuchen. Dabei ist ersichtlich, dass radiale Gliazellen von der VZ ausgehend nach ventral in die MZ projizieren. Bezüglich der Expression und Projektionen der RC2- und ß-Catenin-positiven radialen Gliazellen konnten keine Unterschiede zwischen den Kontrolltieren und den Mutanten an E12.5 detektiert werden (Abb. 17 A-D).

\subsubsection{Die Pitx3-Überexpression in der Wnt1-Domäne (Wnt1-

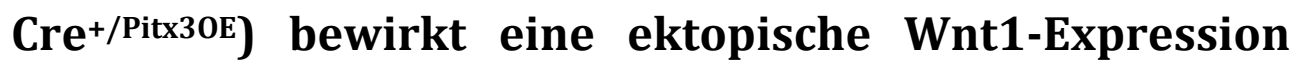 und erhöhte Proliferation im ventralen Mittelhirn}

Bei den Wnt1-Cre ${ }^{+/ P i t x 30 E}$ Mutanten konnte eine Erhöhung der mDA Neuronen (TH, DAT, Nurr1) im medialen Bereich des ventralen Mittelhirns nachgewiesen werden (Vgl. Abb. 13 - 15). Ebenso zeigte sich eine Erhöhung der Nurr1- Expression in der SVZ bei einem Verlust der späten Differenzierung in der MZ (Abb. 18 A, B). Dieser Phänotyp ist möglicherweise auf eine starke signifikante Erhöhung der Lmx1a und Lmx1b Expression in der Ventrikulären Zone des Mittelhirns zurückzuführen (Abb. 16). Durch verschiedene Studien wurde in der Vergangenheit gezeigt, dass durch eine molekulare Interaktion von Wnt1, Lmx1a und Lmx1b die Proliferation und Differenzierung der mDA Neuronen gesteuert wird (Prakash et al., 2006; Prakash et al., 2007; Chung et al., 2009). Um herauszufinden, ob die Erhöhung der Lmx1a und Lmx1b Expression der Wnt1-Cre+/Pitx30E Mutanten in der VZ durch diese Interaktion bedingt ist, wurde eine Wnt1-ISH durchgeführt. Dabei zeigte sich starke ektopische Wnt1-Expression im Bereich der VZ und SVZ des gesamten ventralen Mittelhirns, während bei den Kontrolltieren kein Wnt1- Transkript detektiert werden konnte (Abb. 18 C, D). Diesbezüglich bestehen Unstimmigkeiten in der Literatur, denn zwei Arbeitsgruppen konnten an diesem Stadium bei Kontrolltieren Wnt1 im Bereich der VZ nachweisen (Wilkinson et al., 1987; Prakash et al., 2006), während eine andere Gruppe keine Expression detektieren konnte (Davis \& Joyner, 1988). Diese Diskrepanz kann einerseits mit einer sehr punktuellen Wnt1- Expression an E12.5 erklärt werden, wodurch eine Detektion mittels ISH bei Kontrolltieren erschwert wird (Alves dos Santos \& Smidt, 2011). 


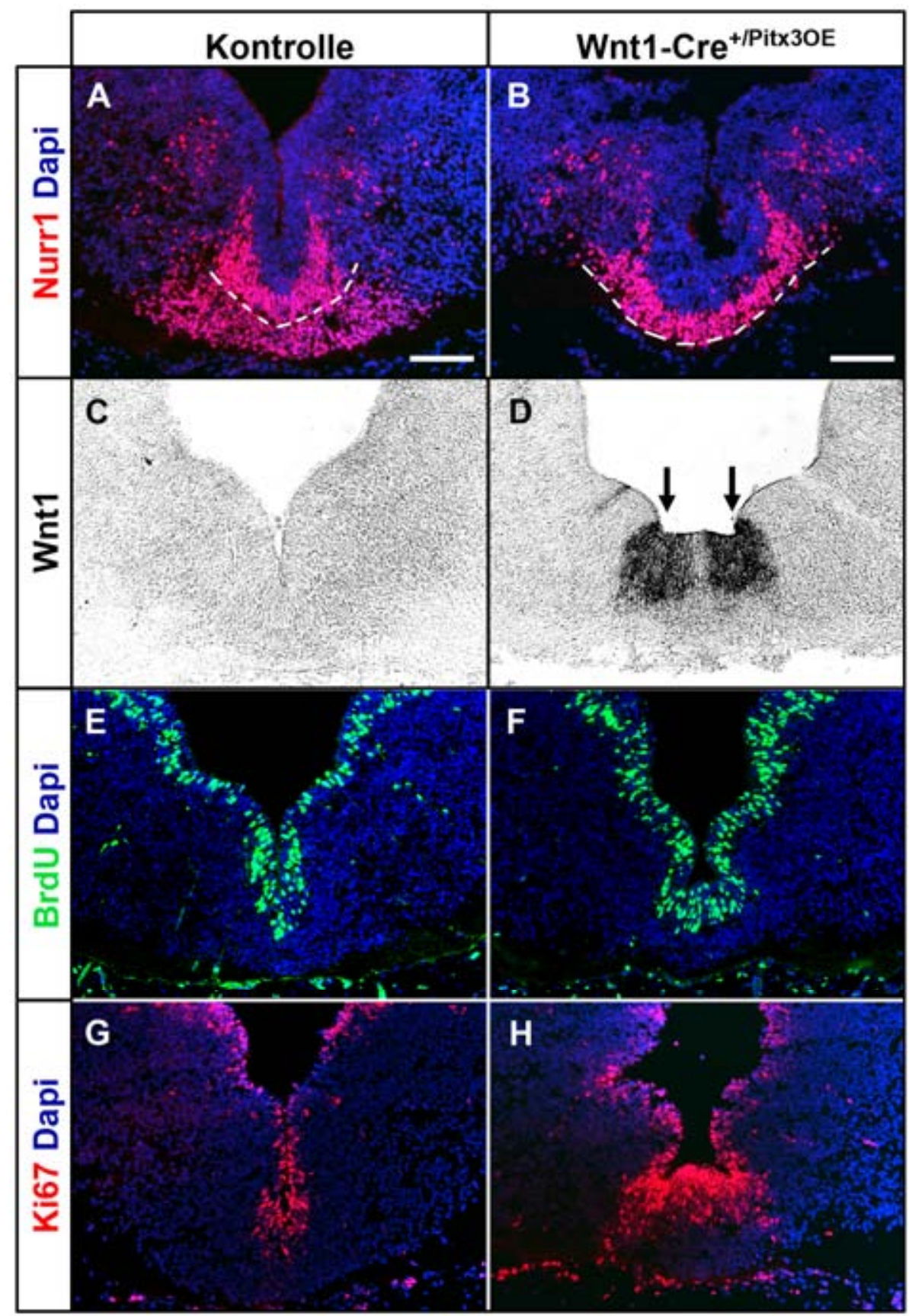

Abb. 18: Bei den Wnt1-Cre ${ }^{+/ P i t x 30 E}$ Mutanten zeigt sich eine starke ektopische Wnt1-Expression im Bereich der VZ und SVZ an Tag E12.5. Kontrolltiere (A, C, E, G), Mutanten Wnt1-Cre ${ }^{+/ \text {Pitx30E }}$ (B, D, F, H) A, B) Nurr1- IIF Färbung (coronal). Die weißen Linien separieren die Subventrikuläre Zone (SVZ) von der Mantelzone (MZ). C, D) Coronale Wnt1 in-situ Hybridisierung. Zur besseren Visualisierung wurden die Bilder mittels Photoshop in eine Grauskala umgewandelt. Die schwarzen Pfeile in D deuten auf die ektopische Wnt1-Expression sowie die verbreiterte Basis des VZ. E-H) Proliferationsanalyse des coronalen ventralen Mittelhirns mittels BrdU (E,F) und $\operatorname{Ki} 67(G, H)$. Skala in A, B = $100 \mu \mathrm{m}$

Anderseits kann dies an der verwendeten Wnt1-ISH Probe liegen, die im Rahmen der Arbeit genutzt wurde, und die sich wahrscheinlich im Design von denen anderer Gruppen unterscheidet. Am Tag E10.5 wurde jedoch auf Kontrolltieren die Spezifität der Wnt1-Probe überprüft, und die Expression stimmt mit den Literaturwerten überein. Die Wnt1-ISH-Färbungen wurden auch bei mehreren 


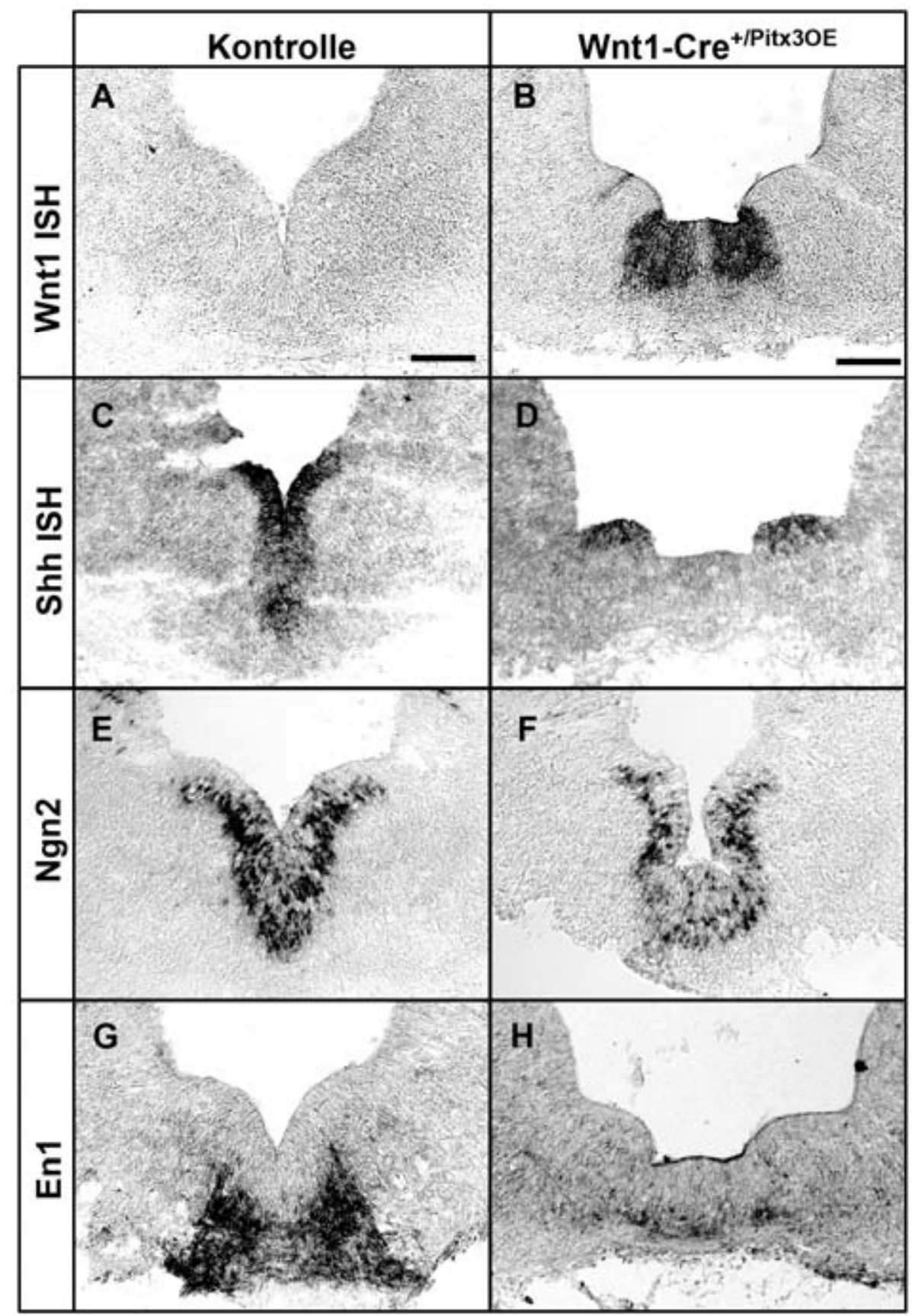

Abb. 19: Die ektopische Wnt1- Expression der Wnt1-Cre ${ }^{+/ P i t x 30 E}$ Mutanten bewirkt eine Inhibierung der Shh- Expression sowie eine reduzierte Neurogenese an Tag E12.5. Kontrolltiere (A, C, E, G), Mutanten Wnt1-Cre ${ }^{+/ P i t x 30 E}(B, D, F, H)$. Abgebildet sind die Ergebnisse der in-Situ Hybridisierung (ISH), wobei zur besseren Visualisierung die Bilder mittels Photoshop in eine Grauskala umgewandelt wurden. A,B) Wnt1 ISH. C,D) Shh ISH. E, F) Ngn2 ISH. G,H) En1 ISH. Die Analysen wurden auf benachbarten coronalen Kryoschnitten durchgeführt. Skala in A, B = 100 $\mu$ m

Kontrolltieren und Wnt1-Cre ${ }^{+/ P i t x 30 E}$ Mutanten durchgeführt, und immer zeigte sich eine starke ektopische Wnt1-Expression bei den Mutanten, während bei den Kontrolltieren ventral kein Signal detektiert werden konnte (in der DP, wo Wnt1 endogen vorkommt, konnte stets ein Signal detektiert werden).

Der kanonische Wnt1- Signalweg steuert während der Entwicklung des ZNS u.a. die Zellproliferation der neuronalen Vorläuferzellen (Alves dos Santos \& Smidt, 
2011). Um herauszufinden, ob durch die ektopische Wnt1- Expression in den Wnt1-Cre ${ }^{+/ P i t x 30 E}$ Mutanten die Zellteilungsrate affektiert ist, wurden am Embryonaltag Proliferationsanalysen (BrdU, Ki67) durchgeführt. Dabei konnte eine starke Erhöhung der Proliferation im Bereich der ektopischen Wnt1Expression im ventralen Mittelhirn

nachgewiesen werden (Abb. 18 E-H). Die erhöhte Proliferation ist auch der Grund für die verbreiterte Basis der Ventrikulären Zone (schwarze Pfeile in Abb. 18 D), und dieser morphologische Phänotyp war bei allen Analysen bei E12.5 ersichtlich.

Wie in Kapitel 1.4.1 und 1.4.2 beschrieben, inhibiert Wnt1 die Shh Expression bei der mDA Neurogenese in der Bodenplatte des Mittelhirns, um die Differenzierung einzuleiten. Um zu überprüfen, ob die Shh- Expression am Embryonaltag E12.5 affektiert ist, wurde auf benachbarten Coronalschnitten die Wnt1- und ShhExpression bei Kontrolltieren und den Wnt1-Cre+/Pitx30E Mutanten analysiert (Abb. 18 A-D). Dabei zeigte sich ein Verlust der Shh- Expression in den Bereich der ektopischen Wnt1- Expression bei den Mutanten.

Um herauszufinden, ob die Neurogenese sowie die Aufrechterhaltung der mDA Neuronen durch die erhöhte Proliferation bei den Wnt1-Cre ${ }^{+/ P i t x 30 E}$ Mutanten betroffen ist, wurde die Expression von Ngn2 sowie En1 mittels in-situ Hybridisierung am Tag E12.5 überprüft. Dabei zeigte sich eine Reduktion der Ngn2-positiven Zellen im Bereich der Ventrikulären Zone des ventralen Mittelhirns (Abb. 19 E, F). Die En1- Expression ist bei den Wnt1-Cre (Pitx30E $^{+}$ Mutanten im Vergleich zu den Kontrolltieren im mittleren Bereich der mDA Neuronen reduziert, (Abb. 19 G, H).

\section{3 Überexpression von Lmx1a und Lmx1b in der Wnt1- Domäne - Wnt1-Cre ${ }^{+/ \operatorname{Lm} x 1 a 0 E}$ und Wnt1-Cre ${ }^{+/ \operatorname{Lm} \times 1 b 0 E}$}

In der Vergangenheit konnte in mehreren Studien gezeigt werden, dass die Neurogenese der mDA Neuronen vor allem durch die Interaktion von Wnt1, Shh, Lmx1a und Lmx1b reguliert wird (Prakash et al., 2006; Prakash \& Wurst, 2007; Chung et al., 2009). Hierbei hatte sich gezeigt, dass Wnt1 die Expression von Lmx1a und Lmx1b, und Lmx1a wiederum die Expression von Wnt1 regulieren kann. Weiterhin steuern die Faktoren Lmx1a und Lmx1b u.a. die Expression von Nurr1 und Pitx3 (Vgl. Abb. 7E) (Chung et al., 2009). 


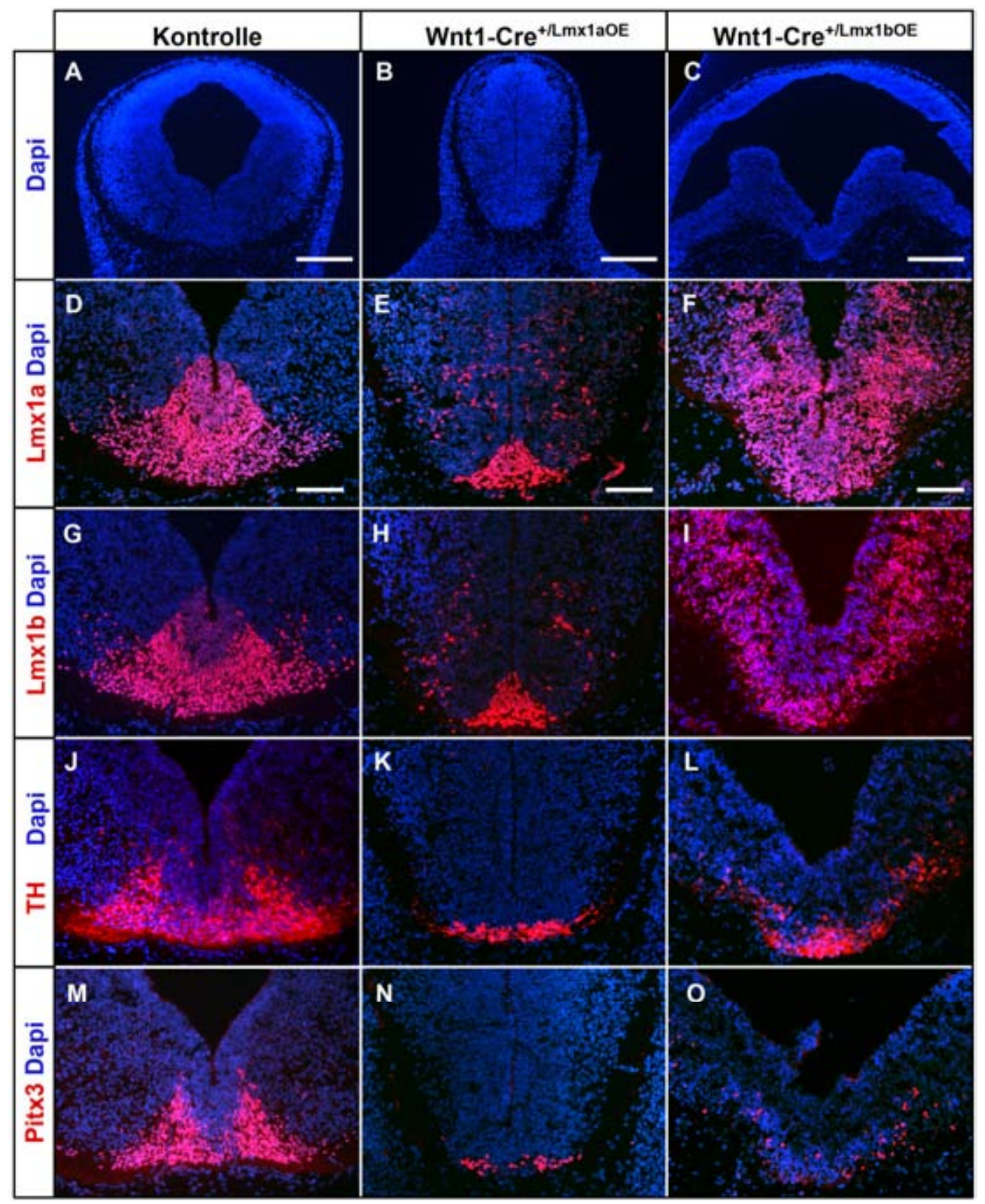

Abb. 20: Die Überexpression von Lmx1a bzw. Lmx1b in der Wnt1- Domäne (Wnt1-Cre+/Lmx1aOE bzw. Wnt1-Cre ${ }^{+/ L m x 1 b O E}$ ) bewirkt Entwicklungsdefekte und eine starke Reduktion der mDA Neuronen an Tag E12.5. Coronalschnitte von Kontrolltiere (A, D, G, J, M), Wnt1-Cre ${ }^{+/ L m x 1 a 0 E}(B, E, H, K, N)$ bzw. Wnt1-Cre ${ }^{+/ L m x 1 b 0 E}$ Mutanten. A-C) Ansicht des coronalen intermediären Mittelhirns mittels DapiFärbung. D-F) anti-Lmx1a IIF- Färbung. G-I) anti-Lmx1b IIF-Färbung. J-L) anti-TH IIF-Färbung. M0) anti-Pitx3 IIF-Färbung. Die gezeigten Färbungen der Kontrolltiere und Mutanten wurden jeweils auf benachbarten Coronalschnitten durchgeführt. Es wurden jeweils zwei Mutanten aus zwei unterschiedlichen Würfen getestet. Skala in A-C $=300 \mu \mathrm{m}$, in D-F $=100 \mu \mathrm{m}$

Im Rahmen der bisherigen Analyse der Pitx3-Überexpression, sowohl im ventralen

Mittelhirn (Shh-Cre ${ }^{+/ P i t x 30 E}$, Foxa2-Cre $\left.{ }^{+/ P i t x 30 E}\right)$ als auch um dorso-ventralen Mittelhirn (Wnt1-Cre ${ }^{+/ P i t x 30 E}$ ), konnte eine Erhöhung der Lmx1a und Lmx1b Expression in der VZ und SVZ am Embryonaltag E12.5 nachgewiesen werden (Vgl. Abb. 11 und 16). Dies ist vor allem bei den Wnt1-Cre+/Pitx30E Mutanten ausgebildet, 
und bei diesen Mutanten konnte ebenfalls eine starke ektopische Wnt1Expression im ventralen Bereich (VZ, SVZ) des gesamten Mittelhirns gezeigt werden. Um genauere Erkenntnisse über die Interaktionen von Wnt1, Lmx1a, Lmx1b und Pitx3 zu erhalten, wurden die TF Lmx1a und Lmx1b ebenfalls in der Wnt1- Domäne überexprimiert (siehe Kapitel 5.3). Die erhaltenen Mutanten wurden als Wnt1-Cre ${ }^{+/ L m x 1 a O E}$ bzw. Wnt1-Cre ${ }^{+/ L m x 1 b 0 E}$ bezeichnet.

Bei beiden Mutanten sind am Embryonaltag E12.5 Entwicklungsdefizite im Mittelhirn ersichtlich: Bei den Wnt1-Cre ${ }^{+/ L m x 1 a 0 E}$ Mutanten ist das gesamte Mittelhirn unterentwickelt und ist bedeutend kleiner als bei den Kontrolltieren (Abb. 20 A, B). Im Gegensatz dazu ist bei den Wnt1-Cre ${ }^{+/ L m x 1 b 0 E}$ Mutanten das gesamte Mittelhirn größer als bei den Kontrolltieren und weißt Missbildungen auf (Abb. 20 A, C). Bei den Wnt1-Cre ${ }^{+/ L m \times 1 a O E ~ M u t a n t e n ~ s i n d ~ e k t o p i s c h e ~ L m x 1 a-~}$ positive Zellen im gesamten dorso-ventralen Mittelhirn detektierbar. Dabei

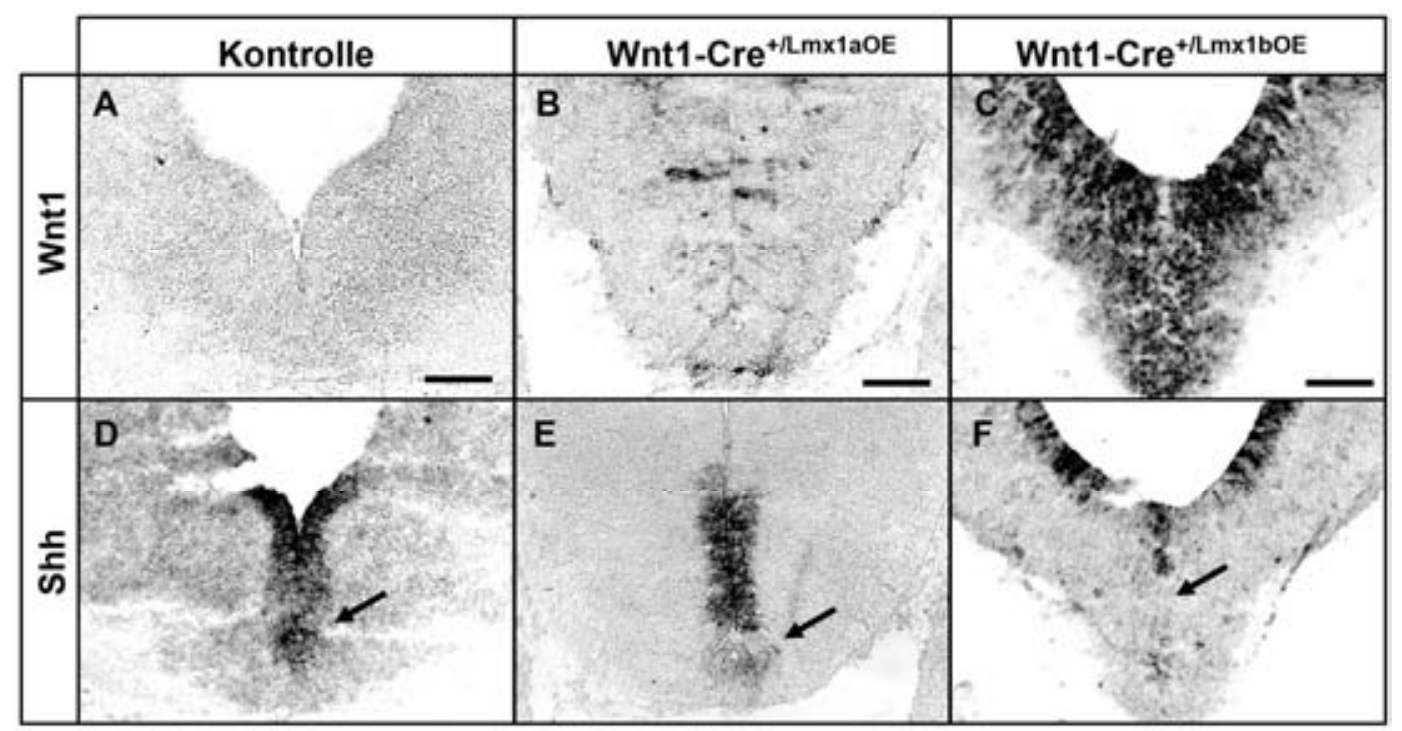

Abb. 21: Die ektopische Expression von Lmx1a bzw. Lmx1b in der Wnt1- Domäne bewirkt eine ektopische Expression von Wnt1 sowie eine Reduktion der Shh-Expression am Tag E12.5. Kontrolltiere (A,D) Wnt1-Cre ${ }^{+/ \operatorname{Lm} \times 1 a 0 E}(\mathrm{~B}, \mathrm{E})$ bzw. Wnt1-Cre ${ }^{+/ \operatorname{Lm} \times 1 b 0 E}$ Mutanten (C, F). Abgebildet sind die Ergebnisse der in-Situ Hybridsierung (ISH), wobei zur besseren Visualisierung die Bilder mittels Photoshop in eine Grauskala umgewandelt wurden. A-C) Wnt1 ISH. D-F) Shh ISH. Die Wnt1 und Shh ISH wurden bei den Kontrolltieren und Mutanten auf benachbarten Coronalschnitten durchgeführt. Die schwarzen Pfeile in D-F deuten auf die ventrale Shh Expression - diese ist bei den Wnt1-Cre ${ }^{+/ L m \times 1 a O E}$ und Wnt1-Cre ${ }^{+/ L m \times 1 b o E}$ Mutanten reduziert. Skala in A-C $=100 \mu \mathrm{m}$

exprimieren allerdings nicht alle Zellen Lmx1a, wie es bei den Wnt1-Cre ${ }^{+/ P i t x 30 E}$ der Fall gewesen ist. Die Lmx1a-Expressionsdomäne in der Bodenplatte ist unverändert, wobei allerdings bedeutend weniger Zellen Lmx1a exprimieren (Abb. 20 D, E). Bei der Betrachtung der Lmx1b-Expression auf benachbarten Coronalschnitten ist ersichtlich, dass Lmx1b ebenfalls in den gleichen dorsoventralen Bereichen ektopisch exprimiert wird (Abb. 20 G, H). Die mDA Neuronen 
können im ventralen Bereich durch die Expression von TH und Pitx3 nachgewiesen werden, wobei sich die Anzahl der TH- und Pitx3-positiven Zellen drastisch reduziert hat (Abb. $20 \mathrm{~J}, \mathrm{~K}, \mathrm{M}, \mathrm{N}$ ). Hierbei wurde aufgrund der geringen

Stichprobenzahl (zwei Mutanten aus unterschiedlichen Würfen) keine Quantifizierung durchgeführt. Bei den Wnt1-Cre ${ }^{+/ L m x 1 b o E}$ Mutanten erstreckt sich die ektopische Lmx1b- Expression ebenfalls über das gesamte dorso-ventrale Mittelhirn - hierbei exprimierten nahezu alle Zellen des Mittelhirn im Vergleich zu den Kontrolltieren Lmx1b. (Abb. 20 G, I). Auf den benachbarten Coronalschnitten ist ersichtlich, dass Lmx1a ebenfalls in den gleichen dorso-ventralen Bereichen ektopisch gebildet wird (Abb. 20 D, F). Interessanterweise sind die TH- und Pitx3positiven mDA Neuronen des ventralen Mittelhirns auch in diesem Fall drastisch reduziert Abb. $20 \mathrm{~J}, \mathrm{~L}, \mathrm{M}, 0)$. Im Vergleich zu den Wnt1-Cre ${ }^{+/ L m x 1 a O E}$ Mutanten zeigten die Wnt1-Cre ${ }^{+/ \operatorname{Lm} x 1 \mathrm{bOE}}$ Mutanten eine geringere Reduktion der TH- und Pitx3-positiven Zellen.

Bei der Betrachtung der Wnt1 und Shh Expression mittels in-Situ Hybridisierung ergaben sich bei beiden Mutanten sehr unterschiedliche Phänotypen. Im Vergleich zu den Kontrolltieren konnten bei den Wnt1-Cre+/Lmx1aOE Mutanten ektopische Wnt1-exprimierende Zellen in den Bereichen detektiert werden, in denen durch die Überexpression Lmx1a nachgewiesen wurde (Abb. 21 A, B). Die ShhExpressionsdomäne erscheint unverändert, wobei jedoch im Bereich der Bodenplatte kein Shh mehr detektiert werden konnte (schwarze Pfeile in Abb. 21 D und E). Bei den Wnt1-Cre ${ }^{+/ L m x 1 b 0 E}$ Mutanten wurden Wnt1-exprimierende Zellen im gesamten dorso-ventralen Mittelhirn nachgewiesen, und zwar in den gleichen Bereichen, in den auch die Lmx1b-Expression induziert wurde (Vgl. Abb. 21 A, C und Abb. 20 G, I). Die Shh- Expression auf benachbarten Coronalschnitten zeigte eine Reduktion in den Bereichen, in denen ektopisches Wnt1 nachgewiesen wurde, wobei auch hierbei im Bereich der Bodenplatte eine Reduktion an Shh-Expression vorlag (schwarze Pfeile in Abb. 21 D, F). 


\section{Diskussion}

Der Transkriptionsfaktor Pitx3 wird innerhalb des ZNS nur im Auge und in den mDA Neuronen des ventralen Mittelhirns exprimiert. Obwohl Pitx3 mit TH in der Substantia nigra (SN) und im ventralen tegmentalen Areal (VTA) koexprimiert wird, ist die Entwicklung der mDA Neuronen des VTA bei einem Verlust von Pitx3 nur leicht beeinträchtigt, während die mDA Neuronen der SN nicht ausgebildet werden. Die molekularen Mechanismen, die diesen selektiven Verlust der lateralen mDA Neuronen hervorrufen, sowie die Funktionen von Pitx3 während der Neurogenese der mDA Neuronen sind noch weitestgehend unklar. Die bisherigen Erkenntnisse über die Funktion von Pitx3 stammen dabei nur aus der Analyse der aphakia-Verlustmutante (Pitx3\%)(Kap. 1.5) sowie aus in vitro Experimenten bisher liegen keine Studien über eine in vivo Überexpression von Pitx3 vor.

In der vorliegenden Arbeit sollte analysiert werden, welche Rolle Pitx3 bei der Neurogenese der mDA spielt, indem Pitx3 im murinen Mittelhirn spezifisch überexprimiert wurde. Dazu wurde Pitx3, mittels des Cre-LoxP-Systems, im ventralen Mittelhirn, unter der Kontrolle des Shh- bzw. Foxa2-Promotors (Shh$\mathrm{Cre}^{+/ P i t x 30 E}$ und Foxa2-Cre+/Pitx30E $)$, und im gesamten dorsoventralen Mittelhirn unter der Kontrolle des Wnt1- bzw. En1-Promotors (Wnt1-Cre ${ }^{+/ P i t x 30 E}$ und En1$\mathrm{Cre}^{+/ \mathrm{Pitx30E}}$ ) überexprimiert. Bei der Analyse von Markern von dopaminergen Neuronen wie TH, DAT, und Nurr1 konnte bei allen vier Mutanten ein gemeinsamer Phänotyp detektiert werden. Die Expression von TH-, DAT- und Nurr1-positiven Zellen im medialen Bereich des dopaminergen Areals, aus dem das VTA hervorgeht, war dabei besonders bei den Wnt1-Cre+/Pitx30E stark erhöht. Dieser Anstieg der mDA Neuronen ist wahrscheinlich auf die erhöhte Expression von Lmx1a und Lmx1b in der VZ und SVZ des ventralen Mittelhirns zurückzuführen. Bei genauerer Analyse der Wnt1-Cre+/Pitx30E Mutanten zeigte sich in diesen Bereichen eine starke ektopische Wnt1-Expression am Embryonaltag E12.5 sowie eine gesteigerte Proliferation (BrdU, Ki67) bei gleichzeitiger leichter Reduktion der Neurogenese (Ngn2). In den Bereichen der ektopischen Wnt1Expression konnte weiterhin eine Inhibierung der Shh-Expression an E12.5 festgestellt werden.

Die vorliegende Arbeit präsentiert die ersten Ergebnisse einer in vivo Pitx3Überexpressionsstudie in der Maus. Diese lassen die Schlussfolgerung zu, dass 
Pitx3 nicht nur an der Differenzierung, sondern auch an Prozessen der Koordination von Proliferation und Spezifikation - im Sinne von Aufrechterhaltung des mDA Bereiches bzw. der Abgrenzung alternativer neuronaler Zellschicksale beteiligt ist. Dabei beeinflusst Pitx3 wahrscheinlich indirekt den kanonischen WntSignalweg, indem es eine Rückkopplungsschleife mit Lmx1a und/ oder Lmx1b, oder einem Zwischenfaktor bildet.

\section{1. Überexpression von Pitx3 im Mittelhirn}

Pitx3 wird in der Maus ab dem Embryonaltag E11.0 in postmitotischen mDA Neuronen bis ins Erwachsenenalter hinein exprimiert (Smidt et al., 1997; Zhao et al., 2004; Maxwell et al., 2005b). Die Phase der mDA Neurogenese bei der Maus liegt zwischen Tagen E10.5 und E14.5, und die höchste Zunahme der mDA Neuronen kann an E12.5 detektiert werden (Di Porzio et al., 1990; Bayer et al., 1995a).

An E12.5 wird Pitx3 bei den Kontrolltieren in allen postmitotischen TH-positiven mDA Neuronen des ventralen Mittelhirns exprimiert (Abb. 9 A, D). Außerhalb des ventralen Bereiches der Bodenplatte (SVZ und MZ) konnte keine Expression von Pitx3 detektiert werden. Bei allen doppeltransgenen Mutanten konnte jeweils eine spezifische Überexpression von Pitx3 im ventralen (Shh-Cre+/Pitx30E und Foxa2$\mathrm{Cre}^{+/ \text {Pitx30E }}$ ) bzw. dorsoventralen Mittelhirn (Wnt1-Cre ${ }^{+/ P i t x 30 E}$ und En1-Cre ${ }^{+/ P i t x 30 E}$ ) detektiert werden. In den Bereichen der ektopischen Pitx3-Expression konnte bei allen vier Mutanten kein eGFP-Reporter mehr detektiert werden (Vgl. Abb. 9 A-C, Abb. 13 A - C). Die in unserem Labor hergestellte transgene Mauslinie Pitx30E (Kap. 5.3, M. S. Diaconu, U. Franke und (Collombat et al., 2007) funktioniert somit zuverlässig für die konditionale Pitx3-Überepxression. Es wurden zwei unabhängige Pitx30E Linien im Rahmen der vorliegenden Arbeit verwendet (Linie 1 und 5), und die doppeltransgenen Embryonen zeigten jeweils das gleiche Pitx3Überexpressionmuster und reproduzierbare Phänotypen. 


\subsection{Pitx3 bewirkt eine Erhöhung der mDA Neuronen im Bereich des ventralen tegmentalen Areals (VTA)}

Um die Konsequenzen der ventralen (Shh-Cre+/Pitx30E und Foxa2-Cre+/Pitx30E) bzw. dorsoventralen (Wnt1-Cre ${ }^{+/ P i t x 30 E}$ und En1-Cre ${ }^{+/ P i t x 30 E}$ ) Überexpression von Pitx3 auf die Entwicklung der mDA Neuronen zu untersuchen, wurde die Expression von Nurr1, TH, und DAT an E12.5 und E15.5 untersucht. Bei der Analyse der TH und DAT Expression an E12.5 wurde der mediale Teil der mDA Neuronen als VTA definiert und der laterale Bereich der sich entwickelnden SN zugeordnet (weiße Linien in Abb. 9 D-F und 13 D-F). Bei der Analyse der Nurr1 Expression wurde eine getrennte Betrachtung der SVZ und der MZ vorgenommen. Bei der Betrachtung der TH, DAT und Nurr1 Expression an E15.5 sind die Bereich des medialen VTA und der lateralen SN bereits voneinander unterscheidbar. Zur Überprüfung wurde auf benachbarten Coronalschnitten die Expression von Calbindin und Girk2 untersucht (Ergebnisse nicht gezeigt) - Calbindin wird v.a. in TH-positiven mDA Neuronen des VTA, und Girk2 (engl. „G-protein-gated inwardly rectifying K channel subunit") wird v.a. in TH-positiven mA Neuronen der SN exprimiert (German et al., 1993; Thompson et al., 2005).

An E12.5 wird bei den Kontrolltieren Pitx3 in postmitotischen TH- und Nurr1positiven mDA Neuronen in der SVZ und MZ exprimiert. DAT ist dabei hauptsächlich in den schon weiter migrierten und ausdifferenzierten mDA Neuronen der SN exprimiert (Abb. 9 A, D, G, J). Bei allen vier Mutanten (Shh-

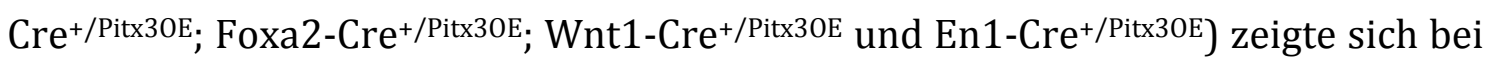
kaum veränderter Gesamtanzahl TH-positiver mDA Neuronen eine signifikante Erhöhung der TH-positiven mDA Neuronen um 8,3\% - 15,6\% im Bereich des VTA, während ein leichter Rückgang an TH-Expression in der SN zu beobachten war (Abb. 9D - F, M und Abb. 13 D-F, M). Dieser Phänotyp der TH- Expression ist bei den Wnt1-Cre ${ }^{+/ P i t x 30 E}$ Mutanten am stärksten ausgebildet, mit einer Zunahme um 15,6\% im VTA und einem Rückgang um 17,6\% in der SN (die Gesamtanzahl THpositiver Zellen zeigte keine Signifikanz, Abb. 13 D, E, M). Die Gesamtzahl der DATpositiven Zellen ist an E12.5 bei den Shh-Cre+/Pitx30E, Foxa2-Cre ${ }^{+/ P i t x 30 E}$ und En1Cre+/Pitx30E Mutanten unverändert (Abb. 9 G-I, N und Abb. 13 G.I, N). Bei den Wnt1$\mathrm{Cre}^{+/ P i t x 30 E}$ Mutanten jedoch zeigte sich eine Abnahme bei der Gesamtzahl der DATpositiven Zellen um 35,8\%, wobei eine signifikante Erhöhung in der VTA $(28,6 \%)$ 
beobachtet werden konnte und die SN eine starke Reduktion um 47,6\% aufwies (Abb. 13 G, H, N). Die Erhöhung der TH- und DAT-Expression im VTA könnte durch die direkte Interaktion von Pitx3 mit den jeweiligen Promotoren hervorgerufen werden, da dies durch in vitro Experimente bereits gezeigt werden konnte (Cazorla et al., 2000; Lebel et al., 2001; Messmer et al., 2007; Hwang et al., 2009). Allerdings ist auch von anderen Faktoren bekannt, dass sie an den TH- bzw. DAT-Promotor in vitro binden und dessen Expression regulieren können, wie z.B. Nurr1 (Sakurada et al., 1999; Iwawaki et al., 2000; Kim et al., 2003; Martinat et al., 2006; Reddy et al., 2011). Durch Genexpressionsstudien (Microarray, ChIP, ISH) der Verlustmäuse von Nurr1 bzw. Pitx3 konnte in der Vergangenheit gezeigt werden, dass Nurr1 und Pitx3 miteinander interagieren, um u.a. die Expression von TH und DAT zu aktivieren. Dabei hebt Pitx3 die Inhibierung von Nurr1 durch einen SMRT-HDACRepressorkomplex auf und die Transkription der Nurr1-Zielgene wird initiiert (Cazorla et al., 2000; Jacobs et al., 2009a; Jacobs et al., 2009b). Andererseits kann Nurr1 die Expression von Pitx3 in vitro regulieren, indem es Nurr1 direkt an den Pitx3-Promotor binden und dessen Transkription initiieren kann (Volpicelli et al., 2012). Weiterhin wurde von Jacobs et al. (2009) gezeigt, dass Pitx3 die Expression von Dlk1 (engl. „Delta-like 1 protein“, auch FA1 genannt) inhibieren kann, während dessen Expression aktiviert. Dlk1 ist in mDA Neuronen exprimiert und dessen Rolle während der mDA Neurogenese ist noch unklar. Die Dlk1-Verlustmutante zeigt eine erhöhte und vorzeitige DAT-Expression v.a. im Bereich des VTA, und es wurde gefolgert, dass Dlk1 eine vorzeitige Differenzierung zu DAT-positiven mDA Neuronen inhibiert (Jensen et al., 2001; Christophersen et al., 2007; Jacobs et al., 2009a; Jacobs et al., 2009b). Somit könnte das ektopische Pitx3 also auch indirekt die vorzeitige DAT-Expression in der VTA beeinflussen, indem es Dlk1 inhibiert und dadurch DAT exprimiert wird. Dies aber würde bedeuten, dass eine eventuelle Inhibierung von Dlk1, verursacht durch die Pitx3-Überexpression, wiederum durch die Nurr1 kompensiert werden würde.

Interessanterweise wurde an E12.5 und E15.5 bei allen Mutanten (Shh-Cre ${ }^{+/ P i t x 30 E ;}$ Foxa2-Cre ${ }^{+/ P i t x 30 E}$; Wnt1-Cre ${ }^{+/ P i t x 30 E}$ und En1-Cre $\left.{ }^{+/ P i t x 30 E}\right)$ ebenfalls eine Erhöhung der Nurr1-positiven Zellen im Bereich der SVZ bzw. des VTA detektiert. Dabei konnte eine um 5,6\% - 28,6\% erhöhte Nurr1-Expression in der SVZ an E12.5 detektiert werden, während an E15.5 eine 5,3\% - 26,6\% Erhöhung beobachtet werden konnte (Abb. 9, 10, 13, 14). Somit korreliert bei allen Mutanten die erhöhte 
Nurr1-Expression mit den Bereichen, in denen ebenfalls mehr TH und DAT beobachtet wurden (Vgl. Abb. 9, 10, 13, 14). Wie bereits erwähnt, können Pitx3 und Nurr1 jeweils an die TH- und DAT-Promotoren binden und deren Expression initiieren, und Pitx3 hebt die eine Inhibierung von Nurr1 auf (Sakurada et al., 1999; Cazorla et al., 2000; Iwawaki et al., 2000; Lebel et al., 2001; Kim et al., 2003; Martinat et al., 2006; Messmer et al., 2007; Hwang et al., 2009; Jacobs et al., 2009a; Jacobs et al., 2009b). Daher ist es sehr wahrscheinlich, dass die erhöhte TH- und DAT-Expression in den Mutanten einerseits durch die direkte Interaktion von Pitx3 und Nurr1 mit den TH- und DAT-Promotoren, und andererseits durch die gesteigerte Interaktion von Pitx3 und Nurr1 untereinander hervorgerufen wird.

Die erhöhte Expression von Nurr1 in den Shh-Cre ${ }^{+/ P i t x 30 E}$, Foxa2-Cre ${ }^{+/ P i t x 30 E}$, Wnt1$\mathrm{Cre}^{+/ P i t x 30 E}$ und En1-Cre ${ }^{+/ P i t x 30 E}$ Mutanten ist aber sehr wahrscheinlich nicht das Resultat der Pitx3-Überexpression. Nurr1 wird normalerweise bereits an E10.5 in postmitotischen mDA Vorläuferzellen in der SVZ exprimiert, also einen Tag, bevor Pitx3 und TH detektiert werden können (Perlmann \& Wallen-Mackenzie, 2004; Ang, 2006; Prakash \& Wurst, 2006a; Prakash \& Wurst, 2006b). Bei der Pitx3 Verlustmutante (aphakia) konnte keine Veränderung in der Nurr1 Expression detektiert werden, was darauf deutet, dass Pitx3 keinen Einfluss auf die Expression von Nurr1 hat (Jacobs et al., 2009a; Jacobs et al., 2009b). Außerdem sind bisher keine Faktoren bekannt, welche die Expression von Nurr1 in mDA Neuronen aktivieren und regulieren. Zudem gibt es inzwischen immer mehr Hinweise, dass Nurr1 und Pitx3 Bestandteile von zwei unterschiedlichen Signalwegen bei der mDA Neurogenese sind, die unabhängig voneinander reguliert werden, und bei der Ausreifung der mDA Neuronen wieder miteinander interagieren. Demnach existiert ein Shh-Foxa2-Nurr1-Signalweg, der parallel zu einem Wnt1-Lmx1a/bPitx3-Signalweg agiert, und beide Signalwege laufen schließlich durch die Interaktionen von Pitx3 und Nurr1 zusammen (Abb. 7 E) (Smidt et al., 2000; Wallen \& Perlmann, 2003; Martinat et al., 2006; Prakash et al., 2006; Chung et al., 2009; Jacobs et al., 2009b). In vitro Experimente haben gezeigt, dass Lmx1a/b an den Promotorsequenzen von Nurr1 binden und dessen Expression induzieren können (Chung et al., 2009), und bei den Shh-Cre ${ }^{+/ P i t x 30 E}$, Foxa2-Cre ${ }^{+/ P i t x 30 E}$, Wnt1$\mathrm{Cre}^{+/ P i t x 30 E}$ und En1-Cre+/Pitx30E Mutanten konnte an E12.5 eine signifikante Erhöhung der Lmx1a und Lmx1b Expression in der VZ und teilweise auch in der SVZ detektiert werden (Abb. 11 D-I, M, N und Abb. 16 D-I, M, N). Es ist daher 
wahrscheinlich, dass die erhöhte Nurr1 Expression in der SVZ bzw. VTA der Shh$\mathrm{Cre}^{+/ \text {Pitx3OE, Foxa2-Cre }}{ }^{+/ \text {Pitx30E, Wnt1-Cre }}{ }^{+/ P i t x 30 E}$ und En1-Cre ${ }^{+/ P i t x 30 E}$ Mutanten durch die erhöhte Lmx1a- und Lmx1b-Expression in der VZ (und SVZ) hervorgerufen wird. Weiterhin konnte kürzlich gezeigt werden, dass Lmx1a ebenfalls an den DAT-Promotor binden und dessen Transkription regulieren kann (Chung et al., 2012), womit die in den Wnt1-Cre+/Pitx30E Mutanten beobachtete Erhöhung der DAT-Expression in der VTA auch auf Lmx1a zurückzuführen sein könnte. Interessanterweise ist Lmx1a bei allen Mutanten und besonders bei den Wnt1-Cre ${ }^{+/ P i t x 30 E}$ Mutanten in der VZ erhöht (Abb. 16 E). Somit ist es also eher wahrscheinlich, dass die in den Mutanten beobachtete Erhöhung der mDA Neurone im VTA sowohl durch Pitx3, Nurr1 und Lmx1a/b hervorgerufen wird.

Der beobachtete Phänotyp der TH-, DAT- und Nurr1- Expression an E12.5 ist an E15.5 deutlicher ausgebildet. Dabei zeigten alle Mutanten eine Erhöhung in der Anzahl ausdifferenzierter mDA Neuronen (TH, DAT, Nurr1) im VTA um 5,3\% 37,6\% (Abb. 10 und 14), die bei den Wnt1-Cre ${ }^{+/ P i t x 30 E ~ M u t a n t e n ~ a m ~ s t a ̈ r k s t e n ~}$ ausgeprägt war. Bei diesen Mutanten zeigte sich jedoch auch gleichzeitig eine Reduktion der TH-, DAT- und Nurr1-positiven Zellen in der SN. Dieser Phänotyp könnte von Migrationsdefekten in der späten Phase der Neurogenese hervorgerufen werden. Zunächst migrieren die postmitotischen mDA Neuronen während der frühen Differenzierung ausgehend von der VZ nach ventral über die SVZ in die Mantelzone entlang der Fasern radialer Gliazellen. Von dort aus wandern sie in der späten Differenzierungsphase weiter nach lateral entlang tangential angeordneter Nervenfasern und bilden die Subpopulation der SN (Kawano et al., 1995; Ohyama et al., 1998; Vitalis et al., 2005). Die frühe Migration zumindest scheint bei den Wnt1-Cre ${ }^{+/ P i t x 30 E}$ Mutanten nicht betroffen zu sein, wie es anhand der RC2- und ß-Catenin-Färbung gezeigt werden konnte (Abb. 17). Ob die spätere Migration betroffen ist, muss hierbei noch überprüft werden. In Reelinbzw. Dab1-Verlustmäusen (reeler bzw. yotari Mäuse) konnte zumindest ein ähnlicher Phänotyp beobachtet werden: Eine erhöhte Anzahl von mDA Neuronen im VTA, während in der SN eine Reduktion vorlag. Die Autoren konnten zeigen, dass bei einem Verlust an Reelin bzw. Dab1 die laterale Migration der mDA Neuronen gestört ist, und die migrierenden Neuronen in der VTA akkumulieren und nicht in die SN einwandern können (Nishikawa et al., 2003; Kang et al., 2010). 
Allerdings ist die Funktion von Reelin bzw. Dab1 während der mDA Neurogenese bisher kaum untersucht worden.

Es erscheint ebenso möglich, das die Akkumulation der mDA Neurone im VTA, vor allem bei den Wnt1-Cre+/Pitx30E Mutanten, durch andere Vertreter der Wnt-Familie bedingt sein könnten. Bei einem Verlust an Wnt5a ist ein ähnliche Phänotyp wie bei den Wnt1-Cre ${ }^{+} /$Pitx30E Mutanten zu beobachten und die Autoren folgerten, dass Wnt5a die Morphogenese, die Proliferation und die Differenzierung von mDA Neuronen regulieren kann (Andersson et al., 2008).

Bei den Wnt1-Cre ${ }^{+/ P i t x 30 E}$ und En1-Cre ${ }^{+/ P i t x 30 E}$ Mutanten konnte auch eine ektopische TH- Expression im rostralen Hinterhirn an E15.5 beobachtet werden (weiße Pfeilspitzen in Abb. 15). Im Fall der Wnt1-Cre ${ }^{+/ P i t x 30 E}$ Mutanten waren die ektopischen mDA Neuronen $\left(\mathrm{TH}^{+}\right)$noch klar von den nach caudal verschobenen serotonergen $\left(5-\mathrm{HT}^{+}\right)$getrennt, während bei den En1-Cre ${ }^{+/ P i t x 30 E}$ Mutanten auch vereinzelt TH- und 5-HT-positive Neuronen gefunden wurden. Um diese Beobachtung $\mathrm{zu}$ stützen, sind genauere Analysen mittels konfokaler Laserscanmikroskopie erforderlich. Es bestehen bei beiden Mutanten scheinbar Defekte innerhalb des molekularen Netzwerkes des IsO der MHG, da die mDA Neuronen bei den Kontrolltieren stets von den serotonergen durch die MHG separiert sind, was bei den Wnt1-Cre ${ }^{+/ P i t x 30 E}$ und En1-Cre ${ }^{+/ P i t x 30 E}$ Mutanten nicht der Fall ist. Der IsO reguliert die Entwicklung des gesamten Mittel- und Hinterhirns durch Ausschüttung spezieller Signalmoleküle (siehe Kapitel 1.4.1). Die Position des IsO wird dabei durch die Expression von Otx2 im Vorder- und Mittelhirn, und Gbx2 im Hinterhirn bestimmt (Liu \& Joyner, 2001; Martinez-Barbera et al., 2001; Prakash \& Wurst, 2004). Aufgrund der Detektion ausgereifter TH-positiver mDA und 5-HT-positiver serotonerger Neuronen in den Wnt1-Cre ${ }^{+/ P i t x 30 E}$ und En1$\mathrm{Cre}^{+/ P i t x 30 E}$ Mutanten kann davon ausgegangen werden, dass sich der IsO an der MHG entwickelt hat und zumindest eingeschränkt die neuronale Entwicklung des Mittel- und Hinterhirns steuern kann. Der Defekt des IsO macht sich besonders an den morphologischen Phänotypen der Wn1-Cre ${ }^{+/ P i t x 30 E}$ und En1-Cre $/$ Pitx30E Mutanten bemerkbar: Bei beiden ist die Anlage des Cerebellums (AC, schwarze Pfeile in Abb. 15 A) unterentwickelt, und die Wn1-Cre ${ }^{+/ P i t x 30 E}$ Mutanten sind nicht lebensfähig, was sehr wahrscheinlich auf die drastischen Entwicklungsdefizite im gesamten Mittel- und Hinterhirn zurückzuführen ist. Die Gründe für diese Defekte wurden nicht untersucht, und es kann nur vermutet werden, dass Störungen 
innerhalb des IsO vorliegen könnten. Bei den Wn1-Cre+/Pitx30E Mutanten konnte zumindest im ventralen Mittelhirn eine ektopische Expression von Wnt1 detektiert werden (Abb. 18 D), wobei der Bereich des IsO nicht untersucht wurde. Dies sollte unbedingt noch analysiert werden, weil Wnt1 ein wichtiger Regulator des IsO ist, indem er z.B. mit Fgf8 und Otx2 interagiert. Bei einer ektopischen Expression von Otx2-Expression unter der Kontrolle von En1 konnte z.B. beobachtet werden, dass sich die MHG und damit auch der IsO nach caudal verschoben hat und dopaminerge Neuronen im Hinterhirn exprimiert wurden, wobei auch Defekte in der cerebralen Anlage festgestellt werden konnten (Broccoli et al., 1999; Omodei et al., 2008). Somit ist es auch möglich, dass Otx2 bei den Wn1-Cre ${ }^{+/ P i t x 30 E}$ Mutanten ektopisch in den Bereichen exprimiert sein könnte, wo ektopische THExpression festgestellt werden konnte (Abb. 15). Von Chung et al. (2009) wurde gezeigt, dass Wnt1 an den Otx2-Promotor binden und diesen aktivieren kann (Chung et al., 2009), und es könnte also sein, dass bei den Wn1-Cre+/Pitx30E und En1-Cre ${ }^{+/ P i t x 30 E}$ Mutanten auch eine Veränderung in der Otx2-Expression vorliegt. Weiterhin konnte in der Vergangenheit gezeigt werden, dass der Shh-Signalweg (inkl. Gli2A und Gli3R) für das Wachstum des gesamten dorso-ventralen Mittelund Hinterhirns von Bedeutung ist, indem es u.a. die Proliferation regulieren und die Apoptose unterdrücken kann (Blaess et al., 2006; Blaess et al., 2011). Eine Beeinträchtigung des Shh-Signalweges zeigt dabei Störungen in der Entwicklung des Mittel- und Hinterhirns, was dem beobachteten Phänotyp der Wn1-Cre ${ }^{+/ P i t x 30 E}$ und En1-Cre+/Pitx30E Mutanten ähnelt (Vgl. Abb. 15 A-C und (Blaess et al., 2006)). Interessanterweise konnte bei den Wn1-Cre ${ }^{+/ P i t x 30 E}$ Mutanten zumindest im ventralen Mittelhirn eine Reduktion der Shh-Expression festgestellt werden (Abb. 19) und diese Mutanten haben starke Entwicklungsdefizite im Mittel- und Hinterhirn (Abb. 15). Die Expression von Shh im Bereich der MHG wurde hierbei nicht untersucht und sollte bei der weiteren Analyse berücksichtigt werden.

\subsection{Pitx3 hat einen positiven Einfluss auf die Expression von Lmx1a/b und Wnt1}

Bei den Shh-Cre ${ }^{+/ P i t x 30 E}$, Foxa2-Cre ${ }^{+/ P i t x 30 E}$, Wnt1-Cre ${ }^{+/ P i t x 30 E}$ und En1-Cre $/$ Pitx30E Mutanten zeigte sich also eine Erhöhung der TH- und DAT-Expression in der VTA, die sehr wahrscheinlich durch die ebenfalls erhöhte Nurr1-Expression 
hervorgerufen werden. Es ist bekannt, dass die beiden redundanten TF Lmx1a und Lmx1b, teilweise in Kooperation mit Foxa2, die Spezifizierung und weitere Differenzierung der mDA Neuronen regulieren (Ferri et al., 2007; Lin et al., 2009; Nakatani et al., 2010; Deng et al., 2011; Mavromatakis et al., 2011; Yan et al., 2011). Weiterhin konnte gezeigt werden, dass durch eine Überexpression von Lmx1a, Lmx1b und/oder Foxa2 im ventralen Mittelhirn eine Erhöhung der TH- und Nurr1positiven mDA Neuronen zur Folge hat (Nakatani et al., 2010). Bei der Lmx1aVerlustmutante dreher ist die Expression von Pitx3 und Nurr1 merklich reduziert, und in vitro Experimente haben gezeigt, dass Lmx1a/b an die Promotorsequenzen von Pitx3 und Nurr1 binden und deren Expression induzieren können (Chung et al., 2009).

Die Foxa2 Expression an E12.5 scheint bei den Shh-Cre ${ }^{+/ P i t x 30 E}$, Foxa2-Cre $/$ Pitx30E und En1-Cre ${ }^{+/ P i t x 30 E}$ Mutanten unverändert, während bei den Wnt1-Cre+/Pitx30E Mutanten eine scheinbar erhöhte Expression in der VZ vorliegt. Die Expression von Foxa2 wurde in der vorliegenden Arbeit nicht quantifiziert, und daher kann diesbezüglich keine klare Aussage getroffen werden. Für die weitere Analyse ist es wichtig, der Fragestellung nach der Foxa2-Expression in den Wnt1-Cre ${ }^{+/ P i t x 30 E}$ Mutanten näher nachzugehen, da Foxa2 u.a. an der Regulierung der Spezifizierung und Differenzierung der mDA Neuronen beteiligt ist. Foxa2 reguliert die Neurogenese, indem es an der Kontrolle der Nurr1 Expression beteiligt ist, und zusammen mit Lmx1a und Msx1 die Expression von Ngn2 reguliert. Weiterhin ist Foxa2 für das Überleben der mDA Neuronen sowie an der Neurogenese benachbarter Neuronenpopulationen beteiligt, indem es Nkx2.2 blockieren und Nkx6.1 aktivieren kann (Andersson et al., 2006; Ferri et al., 2007; Kittappa et al., 2007; Arenas, 2008; Chung et al., 2009; Lin et al., 2009; Lee et al., 2010; Nakatani et al., 2010). Bei den Shh-Cre ${ }^{+/ P i t x 30 E}$, Foxa2-Cre ${ }^{+/ P i t x 30 E}$, Wnt1-Cre ${ }^{+/ P i t x 30 E}$ und En1$\mathrm{Cre}^{+/ P i t x 30 E}$ Mutanten zeigte die Nkx6.1 Expression an E12.5 keine Auffälligkeiten im ventralen Mittelhirn (Abb. 11 J-L, Abb. 16 J-L). Die Pitx3- Überexpression und die damit verbundene Erhöhung von Lmx1a/b hat also scheinbar keinen Einfluss auf die Entwicklung der lateralen Neuronenpopulationen. Um dies mit Sicherheit sagen zu können, sind jedoch weitere Analysen der lateralen Marker (z.B. Nkx2.2, Pax6) erforderlich.

Bei den Shh-Cre $/$ Pitx30E, Foxa2-Cre ${ }^{+/ P i t x 30 E}$, Wnt1-Cre $/$ Pitx30E und En1-Cre $/$ Pitx30E Mutanten konnte an E12.5 eine Erhöhung der Lmx1a und Lmx1b Expression in der 
VZ und teilweise auch in der SVZ detektiert werden (Abb. 11 D-I, M, N und Abb. 16 D-I, M, N), die besonders bei den Wnt1-Cre ${ }^{+/ P i t x 30 E}$ Mutanten festgestellt werden konnte. Aus der Literatur ist bekannt, dass eine Rückkopplungsschleife zwischen Wnt1, Lmx1a und Lmx1b besteht: Wnt1 kann die Expression von Lmx1a/b regulieren, und Lmx1a wiederum kann die Expression von Wnt1 steuern (Prakash et al., 2006; Chung et al., 2009). Aufgrund der erhöhten Expression von Lmx1a und Lmx1b in den Wnt1-Cre+(Pitx30E Mutanten wurde daher die Expression von Wnt1 untersucht. Dabei konnte in den Mutanten im gesamten ventralen Mittelhirn im Bereich der VZ und SVZ an E12.5 ektopische Wnt1-Expression detektiert werden (Abb. 18 D). Die ektopische Wnt1-Expression in den Wnt1-Cre ${ }^{+/ P i t x 30 E}$ Mutanten ist sehr wahrscheinlich auf die erhöhte Expression von Lmx1a/b in der VZ zurückzuführen. Es ist aber auch möglich, dass Pitx3 zunächst Wnt1 aktiviert, was wiederum zu einer Erhöhung von Lmx1a/b führen würde. Um herauszufinden, ob die ektopische Wnt1 Expression in den Wnt1-Cre ${ }^{+/ P i t x 30 E}$ Mutanten (Abb. 19) eine Konsequenz der erhöhten Lmx1a- oder Lmx1b- Expression ist, wurde entweder Lmx1a oder Lmx1b in der Wnt1-Domäne überexprimiert (Kap. 2.3), wobei die Expression von Lmx1a, Lmx1b, TH, Pitx3, Wnt1 und Shh analysiert wurde. Bei den Wnt1-Cre ${ }^{+/ L m x 1 a O E}$ bzw. Wnt1-Cre ${ }^{+/ L m x 1 b 0 E}$ Mutanten konnte eine ektopische Wnt1Expression in den Bereichen detektiert werden, in denen Lmx1a bzw. Lmx1b überexprimiert wurden (Abb. $21 \mathrm{~A}-\mathrm{C}$ ). Dies deckt sich mit der Beobachtung bei den Wnt1-Cre+/Pitx30E Mutanten, bei denen ebenfalls ektopisches Wnt1 in den Bereichen erhöhter Lmx1a- und Lmx1b- Expression gefunden wurde (Vgl. Abb. 16 und Abb. 18). Es kann daher gefolgert werden, dass die beobachtete ektopische Wnt1-Expression bei den Wnt1-Cre ${ }^{+/ P i t x 30 E}$ Mutanten wahrscheinlich indirekt durch die Pitx3-Überexpression induziert wurde, und zwar über Lmx1a und/oder Lmx1b.

Bei den Wnt1-Cre ${ }^{+/ L m x 1 a O E}$ bzw. Wnt1-Cre ${ }^{+/ L m x 1 b 0 E}$ Mutanten zeigte sich in den Bereichen des ektopischen Wnt1 zumindest teilweise eine Inhibierung der ShhExpression im ventralen Teil des Mittelhirns (schwarze Pfeile in Abb. 20 D - F). Interessanterweise sind die TH- und Pitx3-positiven mDA Neuronen an E12.5 bei den Wnt1-Cre ${ }^{+/ L m x 1 a 0 E}$ bzw. Wnt1-Cre ${ }^{+/ L m x 1 b O E}$ Mutanten drastisch reduziert (Abb. 20 J-0). Die Gründe für diese Reduktion trotz erhöhter Lmx1a/b und Wnt1 Expression können an dieser Stelle nicht geklärt werden. Es kann nur spekuliert werden, dass aufgrund Lmx1a/b-Überexpression und der beobachteten 
ektopischen Wnt1-Expression die Funktion des IsO gestört sein könnte. Für die weitere Analyse der Wnt1-Cre ${ }^{+/ \operatorname{Lmx1aOE}}$ bzw. Wnt1-Cre ${ }^{+/ \operatorname{Lmx} 1 \mathrm{bOE}}$ Mutanten ist es daher erforderlich, wichtige Faktoren des IsO (z.B. Fgf8, Otx2, Gbx2 und Pax2) an E10.5 und E12.5 zu untersuchen.

Wnt1 und der damit verbunden kanonische Wnt-Signalweg kontrollieren viele wichtige Prozesse während der Entwicklung der mDA Neuronen, unter anderem steuert Wnt1 die Proliferation im Mittel- und Hinterhirn (Dickinson et al., 1994; Megason et al., 2002; Panhuysen et al., 2004; Castelo-Branco et al., 2006; Alves dos Santos \& Smidt, 2011). Damit übereinstimmend konnte bei den Wnt1-Cre ${ }^{+/ P i t x 30 E}$ Mutanten an E12.5 in den Bereichen der ektopischen Wnt1-Expression eine starke Erhöhung der Proliferation (BrdU, Ki67) im Bereich der VZ (Abb. 18 E-H) beobachtet werden. Dies erklärt wahrscheinlich auch die veränderte Morphologie des ventralen Mittelhirns bei den Wnt1-Cre ${ }^{+/ P i t x 30 E}$ Mutanten, bei denen die Basis der VZ verbreitert ist (Abb. 18 D). Dieser Phänotyp war im gesamten ventralen Mittelhirn der Mutanten zu beobachten. Mit der gesteigerten Proliferation, hervorgerufen durch die ektopische Wnt1-Expression in den Wnt1-Cre ${ }^{+/ P i t x 30 E}$ Mutanten, ist die Differenzierung der mDA Neuronen vermindert, was durch die Ngn2 ISH gezeigt werden konnte (Abb. 19 F). Allerdings wurde in diesem Bereich mehr TH und DAT an E12.5 detektiert (Abb. 13 E, H, M, N), was einer verminderten Neurogenese widerspricht. Wahrscheinlich kompensiert hierbei die gesteigerte Lmx1a/b Expression in der VZ diesen Defekt, indem die beiden Faktoren, wie oben beschrieben, möglicherweise Nurr1, TH und DAT induzieren, was wiederum zu einer gesteigerten TH und DAT Expression führt.

Bei den Wnt1-Cre+/Pitx30E Mutanten zeigte sich eine starke ektopische Wnt1 Expression in der VZ und SVZ der BP. Auf benachbarten Coronalschnitten konnte in den Bereichen der ektopischen Wnt1-Expression an E12.5 keine ShhExpression detektiert werden (Abb. 19 A - D). Im Mittelhirn inhibiert Wnt1 und der damit verbundene kanonische Wnt-Signalweg im Laufe der Spezifizierung der mDA Neuronen die Expression von Shh (Fasano \& Studer, 2009; Joksimovic et al., 2009). Nach der Induktion der BP und somit des mDA Areals durch Shh an E8.5 E9.5 muss die weitere Expression von Shh durch Wnt1 im Mittelhirn ab E9.5 inhibiert werden, damit die Neurogenese der mDA Neuronen aus den Zellen der BP selbst initiiert werden kann (Hynes et al., 1995a; Hynes et al., 1995b; Fasano \& Studer, 2009; Joksimovic et al., 2009; Tang et al., 2009; Tang et al., 2010). Die 
verminderte Shh-Expression im ventralen Mittelhirn der Wnt1-Cre ${ }^{+/ P i t x 30 E}$ Mutanten kann also mit der bekannten Inhibierung von Shh durch Wnt1 erklärt werden. Aufgrund der Tatsache, dass mDA Neuronen an E12.5 und E15.5 bei den Wnt1-Cre ${ }^{+/ P i t x 30 E}$ Mutanten detektiert werden können, kann aber davon ausgegangen werden, dass die Shh-Expression während der Induktionsphase an E8.5 - E9.5 bei den Wnt1-Cre ${ }^{+/ P i t x 30 E ~ M u t a n t e n ~ n o c h ~ k o r r e k t ~ e x p r i m i e r t ~ w i r d . ~}$ Tatsächlich konnte bei einer Wnt1-Cre ${ }^{+/ P i t x 30 E}$ Mutante mittels Shh-IIF an E10.5 keine Veränderung detektiert werden (nicht gezeigt). Für die weitere Analyse der Wnt1-Cre ${ }^{+/ P i t x 30 E}$ Mutanten sind aber weitere Expressionsstudien an E9.5 und E10.5 erforderlich, um die Interaktionen des Wnt- und Shh-Signalweges während der frühen mDA Neurogenese zu untersuchen. Hierbei empfiehlt es sich, auch die Effektoren der beiden Signalwege wie z.B. ß-Catenin (Wnt-Signalweg) und Gli1Gli3 (Shh-Signalweg) näher zu analysieren.

Interessanterweise ist die Expression von En1 bei den Wnt1-Cre ${ }^{+/ P i t x 30 E}$ Mutanten drastisch reduziert (Abb. 19 G, H). Die Funktion von En1 während der mDA Neurogenese ist noch nicht vollständig geklärt. Der Verlust von En1 (sowie En2) führt zu einer Degeneration der mDA Neuronen ab E14.5 aufgrund gesteigerter Apoptose, und daraus wurde gefolgert, dass En1 für das Überleben der mDA Neuronen von Bedeutung ist (Albéri et al., 2004; Alves dos Santos \& Smidt, 2011). En1 scheint dabei die Zellen vor mitochondrialen Schäden zu schützen, die durch oxidativen Stress innerhalb der Zelle verursacht werden (Alvarez-Fischer et al., 2011). Die erniedrigte En1-Expression bei den Wnt1-Cre ${ }^{+/ P i t x 30 E}$ Mutanten steht somit im Widerspruch zu dem späteren TH- und DAT- Phänotyp dieser Mutanten. Bei einer Verringerung der En1 Expression könnte man davon ausgehen, dass an E15.5 weniger TH- und DAT-positive mDA Neuronen detektiert werden können. Tatsächlich konnte bei den Wnt1-Cre+/Pitx30E Mutanten eine Unterentwicklung der SN beobachtet werden, während das VTA allerdings eine Erhöhung der TH- und DAT-Expression aufwies (Abb. 14). Möglicherweise ist in den Wnt1-Cre ${ }^{+/ P i t x 30 E}$ Mutanten die En1-Expression nur verzögert und an E15.5 wieder normalisiert. Hierzu sind aber weitere Analysen bezüglich der En1 und En2 Expression erforderlich, um dieser Frage nachzugehen. Auch sollte bei den Wnt1-Cre ${ }^{+/ P i t x 30 E}$ Mutanten die Apoptose untersucht werden, die bei einer Reduktion der En1 Expression zu erwarten wäre. 


\subsection{Schlussfolgerung}

Zusammenfassend kann gesagt werden, dass die Überexpression von Pitx3 unter der Kontrolle von Faktoren, die auch während der normalen mDA Neurogenese von Relevanz sind (Shh, Foxa2, Wnt1, En1), eine Erhöhung der dopaminergen Neurone beobachtet werden konnte. Dabei beschränkte sich Steigerung der TH-, DAT- und Nurr1-Expression auf den Bereich des VTA. Wahrscheinlich ist die drastische Unterentwicklung der $\mathrm{SN}$ in den Wnt1-Cre ${ }^{+/ P i t x 30 E}$ Mutanten auf tangentiale Migrationsdefekte zurückzuführen, was allerdings noch überprüft werden muss. Die Erhöhung der mDA in medialen Bereich könnte dabei auf Pitx3, Nurr1, und Lmx1a/b zurückzuführen sein und kann auch mit Literaturangaben belegt werden (Kap. 3.2 und 3.3). Interessanterweise geben die Ergebnisse der Wnt1-Cre ${ }^{+/ P i t x 30 E}$ Mutanten auch Hinweise auf eine neue mögliche Funktionsweise von Pitx3 während der Neurogenese der mDA Neuronen. Pitx3 scheint hierbei direkt mit Lmx1a/b oder Wnt1 zu interagieren, denn in den Wnt1-Cre ${ }^{+/ P i t x 30 E}$ Mutanten konnte eine starke Erhöhung von Lmx1a/b sowie ektopische Expression von Wnt1 festgestellt werden. Durch die Analysen der Wnt1-Cre ${ }^{+/ L m x 1 a 0 E}$ und Wnt1-Cre+/Lmx1boe Mutanten scheint es eher wahrscheinlich, dass Lmx1a und Lmx1b eine ektopische Wnt1-Expression induzieren können. Somit wäre die ektopische Wnt1-Expression in den Wnt1-Cre ${ }^{+/ P i t x 30 E}$ Mutanten indirekt durch Pitx3 verursacht, indem Pitx3 zunächst mit Lmx1a/b interagiert. Um dies jedoch mit Gewissheit sagen zu können, ist es für die weitere Analyse dringend erforderlich, die Möglichkeiten einer Interaktion von Pitx3 mit Lmx1a/b bzw. Pitx3 mit Wnt1, in vitro mittels ChIP-Experimente zu verifizieren.

\section{Zusammenfassung}

Der Transkriptionsfaktor Pitx3 wird nur in postmitotischen mDA Neuronen des Mittelhirns exprimiert und zeigt eine vollständige Koexpression mit TH im VTA und der SN. Bei einem Verlust an Pitx3-Expression (aphakia-Maus) zeigen die mDA Neurone des VTA nahezu keine Veränderung, während sich jedoch die Neuronen der SN nicht entwickeln. Die Gründe hierfür sind bisher unklar.

In der vorliegenden Arbeit sollte analysiert werden, welche Rolle Pitx3 bei der Neurogenese der mDA spielt, indem Pitx3 im murinen Mittelhirn spezifisch 
überexprimiert wurde. Dies sind die ersten Ergebnisse einer in vivo Pitx3Überexpressionsstudie in der Maus und die Ergebnisse könne wie folgt zusammengefast werden:

- Die Expression von TH-, DAT- und Nurr1-positiven Zellen im medialen Bereich des dopaminergen Areals, aus dem das VTA hervorgeht, ist bei allen Mutanten (Shh-Cre+/Pitx30E, Foxa2-Cre ${ }^{+/ P i t x}$, Wnt1-Cre ${ }^{+/ P i t x 30 E}$ und En1-Cre ${ }^{+/ P i t x 30 E}$ ) signifikant erhöht. Dabei war dieser Phänotyp besonders bei den Wnt1$\mathrm{Cre}^{+/ \text {Pitx30E }}$ Mutanten ausgebildet.

- An E12.5 ist die Expression von Lmx1a und Lmx1b bei allen Mutanten in der VZ signifikant erhöht.

- Bei den Wnt1-Cre ${ }^{+/ P i t x 30 E}$ Mutanten zeigte sich an E12.5 eine starke ektopische Wnt1-Expression in den Bereichen der VZ und SVZ. Ebenso konnte eine gesteigerte Proliferation (BrdU, Ki67) bei gleichzeitiger leichter Reduktion der Neurogenese (Ngn2) beobachtet werden. In den Bereichen der ektopischen Wnt1-Expression konnte weiterhin eine Inhibierung der Shh-Expression an E12.5 festgestellt werden.

- An E12.5 konnte bei den Wnt1-Cre ${ }^{+/ \operatorname{Lmx1aOE}}$ und Wnt1-Cre ${ }^{+/ L m \times 1 b 0 E}$ Mutanten eine ektopische Wnt1-Expression in den Bereichen festgestellt werden, in denen Lmx1a/b konditional überexprimiert wurde. Hierbei zeigte sich eine starke Reduktion der TH- und Pitx3-Expression, die aber wahrscheinlich durch eine Störung des IsO hervorgerufen sein könnte.

Im Allgemeinen kann also gesagt werden, dass Pitx3 nicht nur an der Differenzierung, sondern auch an Prozessen der Koordination von Proliferation und Spezifikation - im Sinne von Aufrechterhaltung des mDA Bereiches bzw. der Abgrenzung alternativer neuronaler Zellschicksale beteiligt sein könnte. Dabei beeinflusst Pitx3 wahrscheinlich indirekt den kanonischen Wnt-Signalweg, indem es eine Rückkopplungsschleife mit Lmx1a und/oder Lmx1b, oder einem Zwischenfaktor bildet. 


\section{Material \& Methoden}

\subsection{Chemikalien, Reagenzien und Pufferlösungen}

\begin{tabular}{|c|c|}
\hline Bezeichnung & Hersteller, Bezugsquelle \\
\hline Agarose & Roth, \#3810.4 \\
\hline Ammoniumacetat & Merck Emsure, \#101116 \\
\hline Bacto-Agar & BD Becton \& Dickinson Bacto Agar, \#214030 \\
\hline Bacto-Trypton & BD Becton \& Dickinson Bacto Trypton, \#211699 \\
\hline Borsäure & Roth, \#6943 \\
\hline Blockpulver & Roche Blocking Reagent, \#1096170 \\
\hline CHAPS & $\begin{array}{l}\text { 3-[(3-Cholamidopropyl)dimethylammonio]-1-propanesulfonate, } \\
\text { Merck, Molecular Biology Grade, \#220201; }\end{array}$ \\
\hline Chloroform & Merck Emsure 1.02445 \\
\hline Dapi-Lösung & Vector Vectashield Mounting Media with Dapi, \#H-1200 \\
\hline DEPC $\left(-\mathrm{H}_{2} \mathrm{O} /-\mathrm{PBS}\right)$ & Diethyl Pyrocarbonat, Sigma, D-5758 \\
\hline DNase & RQ1 RNase-Free DNase, Promega, \#M610 \\
\hline dNTP Nukleotid-Mix & Genecraft, DNA Polymerization Mix 20mM, \#GC-013-002 \\
\hline EDTA & Ethylendiamin-tetraessigsäure, Roth, \#8043.4 \\
\hline Eosin-Lösung & Merck, \#115935; 0,1\% gelöst in $\mathrm{dH}_{2} \mathrm{O}$, \\
\hline Ethanol & $\begin{array}{l}\text { vergällt, 99\%, Chemie Vertrieb Hannover } \\
\text { unvergällt, Merck Emsure, \#1.00983.1011 }\end{array}$ \\
\hline Formamid & VWR AnalaR Normapur, 24311.291 \\
\hline Glutaraldehyd & $25 \%$ Grade II, Sigma, \#G6257 \\
\hline Glycerol & Merck, \#1.04092 \\
\hline Glycin & $\begin{array}{l}\text { Sigma Ultra, ,\#G7403, } \\
\text { eine 2\%ige Glycin-Lösung wurde mit DEPC-PBS hergestellt }\end{array}$ \\
\hline GoTaq-Polymerase & $\begin{array}{l}\text { GoTaq Polymerase, Promega \#M3175 (beinhaltet 5x PCR Puffer \#M791A und } \\
\text { DNA Polymerase \#M830B) }\end{array}$ \\
\hline Hämatoxylin-Lösung & Sigma, \#MHS16 \\
\hline HCl & $\begin{array}{l}\text { Salzsäure } 1 \mathrm{M} \mathrm{HCl}, \text { Merck \# } 1.09057 \\
\text { rauchende Salzsäure, } 37 \% \mathrm{HCl} \text {, Merck \#1.00317 }\end{array}$ \\
\hline Hefeextrakt & BD Becton \& Dickinson Bacto Yeast Extract, \#212720 \\
\hline Hefe-RNA & RNA aus der Hefe, Roche, \#109223 \\
\hline Heparin & Sigma, \# H3393, 1 g gelöst in $10 \mathrm{ml} \mathrm{dH_{2 } \mathrm { O }}$ \\
\hline Histoclear & Tissue Tek Paraffin Cleaning Reagent, Sakura, \#1426 \\
\hline Isopropanol & Merck, \#1.09634 \\
\hline Kaliumacetat & Sigma, \#P-5708 \\
\hline KCl & Kaliumchlorid , Merck Emsure, \#1.04936 \\
\hline Keimöl & „Cornoil“, Sigma \#C8267 \\
\hline Kryomatrix & Tissue Freezing Medium, Einbettmedium, Jung \#020108926 \\
\hline Levamisol & Sigma, (-)-Tetramisol Hydrochlorid, \#L9756 \\
\hline LiCl & Lithiumchlorid, Calbiochem, \#438002 \\
\hline $\mathrm{MgCl}_{2}$ & Magnesiumchlorid, Merck Emsure, \#1.05833 \\
\hline Mowiol & Mowiol-488, Roth, \#0713 \\
\hline $\mathrm{NaCl}$ & Natriumchlorid, Merck, \#1.06404 \\
\hline $\mathrm{NaOH}$ & Natriumhydroxid, Merck, \#1.09137 \\
\hline Natriumcitrat & Merck Emsure, \#106447, tri-Natriumcitrat-Dihydrat \\
\hline NBT/BCIP & NBT/BCIP Stock Solution, Roche, \#11681451001, Version 07 \\
\hline Paraffin & McCormick Scientific, USA, Paraplast Tissue Embedding Medium, \#39501006 \\
\hline PCI & Phenol-Chloroform-Isoamylalkohol (25:24:1), Roth, \#A156.1 \\
\hline PFA & Paraformaldehyd, Sigma-Aldrich \#158127; gelöst in PBS-Puffer bei pH 7,8 \\
\hline
\end{tabular}




\begin{tabular}{|l|l|}
\hline Phenol & Amresco, pH 4,5 \\
\hline ProteinaseK & Roche, \# 03115828001; $10 \mathrm{mg} / \mathrm{ml}$ gelöst in 50mM Tris-HCl pH 8,0 sowie 1,5 \\
\hline SDS & M Kalziumacetat \\
\hline Sucrose & Sodium Dodecyl Sulfat, Merck Omnipur \#7910-OP; für eine 10\%-Lösung \\
\hline Toluol & Merck \#1.07687; gelöst in PBS-Puffer \\
\hline Tris & Merck, \#1.08325 \\
\hline Tris-HCl & Tris(hydroxymethyl)aminomethan, VWR \\
\hline Triton X-100 & 1 M Tris, VWR AnalR Normapur \#103156X, \\
\hline Tween-20 & gelöst in dH 0, mit HCl auf entsprechenden pH-Wert eingestellt \\
\hline
\end{tabular}

Tab. 1: Verwendete Chemikalien und Reagenzien, die im Rahmen der vorliegenden Arbeit verwendet wurden.

\begin{tabular}{|c|c|}
\hline $\begin{array}{l}\text { ProteinaseK-Lösung für } \\
\text { die ISH }\end{array}$ & $20 \mu \mathrm{g} / \mathrm{ml}$ ProteinaseK, $50 \mathrm{mM}$ Tris- $\mathrm{HCl} \mathrm{pH}$ 8,0, $5 \mathrm{mM}$ EDTA in DEPC- $\mathrm{H}_{2} \mathrm{O}$ \\
\hline Lysis-Puffer & 100mM Tris-HCl pH 8; 5mM EDTA; 2\% SDS; 200mM NaCl; (autoklaviert) \\
\hline PBS-Puffer & $\begin{array}{l}\text { 10x PBS (Lonza Accugene \#1387) verdünnt mit dH2O auf 1x PBS, } \\
\text { autoklaviert }\end{array}$ \\
\hline SSC (20x) & $\begin{array}{l}3 \mathrm{M} \mathrm{NaCl}, 0,3 \mathrm{M} \text { Natriumcitrat in } \mathrm{dH} 2 \mathrm{O} \text { gelöst und mit } \mathrm{HCl} \text { auf } \\
\text { entsprechenden pH-Wert eingestellt (autoklaviert) }\end{array}$ \\
\hline Demaskierungs-Lösung & Vector Antigen Unmasking Solution, \#H-3300; 1:100 in $\mathrm{dH}_{2} \mathrm{O}$ \\
\hline TE-Puffer & 10mM Tris-HCl; 1mM EDTA; gelöst in $\mathrm{ddH}_{2} \mathrm{O}$; RNA pH=8,0; DNA pH=7,5 \\
\hline TBE-Puffer & 89mM Tris- $\mathrm{HCl}$ pH 8,0; 89mM Borsäure; 2mM EDTA; gelöst in dd $\mathrm{H}_{2} \mathrm{O}$ \\
\hline Blockpuffer für IIF & $\begin{array}{l}\text { 10\% FCS (fetales Kälberserum) und 0,1\% Triton X-100 gelöst in 1x PBS- } \\
\text { Puffer }\end{array}$ \\
\hline $\begin{array}{l}\text { Hybridisierungspuffer } \\
\text { (ISH) }\end{array}$ & 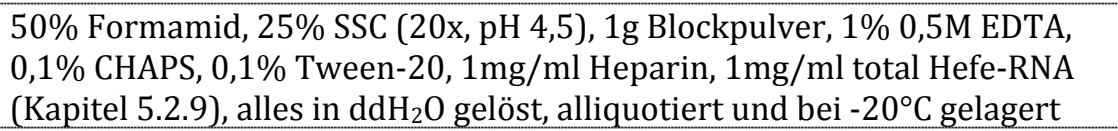 \\
\hline KTBT-Puffer (ISH) & $\begin{array}{l}100 \mathrm{ml} 1 \mathrm{M} \text { Tris- } \mathrm{HCl}(\mathrm{pH} 7,5), 60 \mathrm{ml} 5 \mathrm{M} \mathrm{NaCl}, 20 \mathrm{ml} 1 \mathrm{M} \mathrm{KCl}, 20 \mathrm{ml} \text { Tween- } \\
20, \text { mit d d } \mathrm{H}_{2} \mathrm{O} \text { auf } 2 \mathrm{~L} \text { aufgefüllt }\end{array}$ \\
\hline NTMT (ISH) & $\begin{array}{l}100 \mathrm{ml} 1 \mathrm{M} \text { Tris- } \mathrm{HCl}(\mathrm{pH} 9,5), 20 \mathrm{ml} 5 \mathrm{M} \mathrm{NaCl}, 50 \mathrm{ml} 1 \mathrm{M} \mathrm{MgCl}_{2}, 1 \mathrm{ml} \text { Tween- } \\
20, \text { mit d d } \mathrm{H}_{2} \mathrm{O} \text { auf } 1 \mathrm{l} \text { aufgefüllt und mit } 0,24 \mathrm{~g} \text { Levamisole versetzt }\end{array}$ \\
\hline StandardIAmp-Medium & $\begin{array}{l}10 \text { g Bacto Trypton, } 5 \text { g Hefeextrakt, } 10 \mathrm{~g} \mathrm{NaCl}, 7,5 \mathrm{ml} \mathrm{1M} \mathrm{NaOH,} \mathrm{mit} \\
\mathrm{ddH}_{2} \mathrm{O} \text { auf } 1 \text { l aufgefüllt (pH 7,0) }\end{array}$ \\
\hline StandardIAmp-Agarplatten & StandardIAmp-Medium versetzt mit 15 g Bacto Agar \\
\hline
\end{tabular}

Tab. 2: Angesetzte Puffer-Lösungen, die im Rahmen der vorliegenden Arbeit verwendet wurden

\subsection{Molekularbiologische Methoden}

\subsubsection{Genomische DNA Extraktion aus Gewebe}

Nachdem unter sterilen Bedingungen eine Gewebeprobe des Embryos entnommen und in ein 1,5 ml Reaktionsgefäß inklusive $400 \mu$ l Lysispuffer (Tab. 2) und $20 \mu \mathrm{l}$ Proteinase K $(10 \mathrm{mg} / \mathrm{ml}$ gelöst in $50 \mathrm{mM}$ Tris- $\mathrm{HCl} \mathrm{pH} 8,0$ sowie $1,5 \mathrm{M}$ Kalziumacetat) überführt wurde, lysierte die Gewebeprobe auf einem ThermoMixer bei mittlerer Geschwindigkeit und bei $55^{\circ} \mathrm{C}$ für 6 Stunden. Anschließend 
wurde $400 \mu \mathrm{l}$ Isopropanol zugegeben und gevortext, um die DNA zu fällen. Darauf folgte eine Zentrifugation für 6 Minuten bei $13000 \mathrm{rpm}$. Der Überstand wurde verworfen und das Pellet mit $500 \mu \mathrm{l}$ 70\%igem Ethanol gewaschen, worauf eine weitere Zentrifugation für 6 Minuten bei $13000 \mathrm{rpm}$ folgte. Der Überstand wurde wiederum verworfen und das Pellet für 6 Minuten bei Raumtemperatur getrocknet. Um abschließend die im Pellet enthaltene, gereinigte DNA für die Genotypsierung nutzen zu können, wurde 50 - $100 \mu$ l autoklaviertes dH20 zugegeben und bei leichtem Schütteln $\left(37^{\circ} \mathrm{C}\right)$ gelöst. Bis zur Verwendung wurden die DNA-Lösungen bei $4^{\circ} \mathrm{C}$ gelagert.

\subsubsection{Präparation von Plasmid-DNA aus E.coli}

Die jeweiligen plasmidtragenden Bakterienstämme wurden auf StandardI Amp_ Agarplatten (Tab. 2) ausplattiert und über Nacht im $37^{\circ} \mathrm{C}$-Raum inkubiert. Am folgenden Tag wurden Einzelkolonien gepickt, in $2 \mathrm{ml}$ StandardIAmp-Medium gegeben und für 6 Stunden bei $37^{\circ} \mathrm{C}$ unter leichtem Schütteln inkubiert. Von der jeweiligen Vorkultur wurde ein Glycerol-Stock (s.u.) angelegt. Zur weiteren Isolierung der DNA wurde $50 \mathrm{ml}$ StandardIAmp-Medium (Tab. 2) mit $100 \mu \mathrm{l}$ der Vorkultur angeimpft und bei $37^{\circ} \mathrm{C}$ und leichtem Schütteln über Nacht inkubiert. Am folgenden Tag wurde die Plasmid-DNA mittels des HiSpeed Plasmid Midi Kits (Quiagen, \#12643) aus der Bakterienlösung isoliert. Hierzu wurde nach den Angaben des Herstellers verfahren.

\subsubsection{Phenol-Chloroform-Extraktion von DNA und Ethanolfällung}

Um die DNA von Zellrückständen (Proteine, Enzyme usw.) zu befreien, wurde eine Phenol-Chloroform-Extraktion durchgeführt. Hierzu wurde ein Volumenanteil Roti Phenol-Cloroform-Isoamylalkohol (Roth, Verhältnis 25:24:1) zu der DNA-Lösung gegeben und für zwei Minuten stark gevortext. Daraufhin wurde die Lösung für 5 Minuten bei 13000 rpm (RT) zentrifugiert und die wässrige Phase in ein neues Reaktionsgefäß überführt. Die Menge der wässrigen Phase wurde genau bestimmt, und wiederum wurde ein Volumenanteil Phenol-Cloroform-Isoamylalkohol zugegeben, gevortext und zentrifugiert. Schließlich wurde die wässrige DNALösung in ein neues Reaktionsgefäß überführt und mit 1/25 Volumen Ammoniumacetat (7M) sowie einem 2,5 fachen Volumen eiskalten 100\% 
unvergälltem Ethanol versetzt. Die Lösung wurde zur Fällung entweder über Nacht bei $-80^{\circ} \mathrm{C}$ gelagert oder für 5 Minuten in flüssigen Stickstoff gegeben. Daraufhin wurde bei $4^{\circ} \mathrm{C}$ und $18000 \mathrm{rpm}$ für 15 Minuten zentrifugiert. Nach dem Verwerfen des Überstandes wurde das Pellet zwei Mal mit 70\%igen Ethanol (unvergällt)

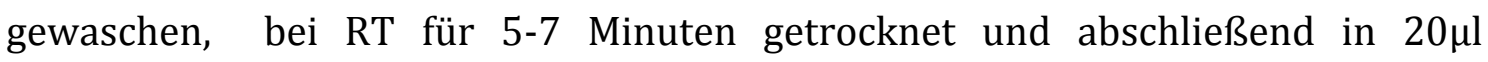
autoklaviertem $\mathrm{dH}_{2} \mathrm{O}$ aufgenommen.

\subsubsection{Konzentrationbestimmung der DNA und RNA}

Für die Bestimmung des DNA-Gehalts einer Probe wurde ein Nanodrop ND-1000 Spektrophotometer (PeQlab) verwendet, wobei die optische Dichte (OD) der Probe bei $280 \mathrm{~nm}$ und $260 \mathrm{~nm}$ gemessen wurde. Dabei ergibt der Quotient aus der OD (260 nm und $280 \mathrm{~nm}$ ) den Reinheitsgrad der Probe - die DNA-Probe wurde nur weiterverwendet, wenn dieser Wert zwischen 1,7 und 2,1 lag.

\subsubsection{Polymerase-Kettenreaktion (PCR)}

Die Polymerase-Kettenreaktion (PCR = „polymerase chain reaction“) (Mullis et al., 1987) erlaubt die spezifische und exponentielle Amplifizierung von DNAAbschnitten mittels spezifischer Primerpaare.

In der vorliegenden Arbeit wurde die PCR vorwiegend für die Genotypisierung der gewonnenen Embryonen sowie der jeweiligen Mauslinien (Abb. 22) verwendet. Hierzu wurde entsprechend der Probenanzahl eine PCR-Lösung nach dem Standard-Rezept (Tab. 3) hergestellt - die verwendeten Primer und die entsprechenden Sequenzen sind in Tabelle 4 aufgelistet und wurden bei SigmaAldrich Genosys bestellt.

\begin{tabular}{|lc|}
\hline Reagenz & Menge \\
\hline autoklaviertes $\mathrm{dH}_{2} \mathrm{O}$ & $240 \mu \mathrm{l}$ \\
$\begin{array}{l}\text { 5x PCR Puffer } \\
\text { (GoTaq, Promega, \#M791A) }\end{array}$ & $61,5 \mu \mathrm{l}$ \\
\hline $\begin{array}{l}20 \mathrm{mM} \text { dNTP Nukleotid-Mix } \\
\text { (Genecraft \#GC-013-002-0500, 20mM) }\end{array}$ & $3,1 \mu \mathrm{l}$ \\
\hline Primer Forward & $1 \mu \mathrm{l}$ \\
\hline Primer Revers & $1 \mu \mathrm{l}$ \\
$\begin{array}{l}\text { DNA-Polymerase } \\
\text { (GoTaq, Promega, \#M830B, 5u/ } \mu \mathrm{l})\end{array}$ & $1,5 \mu \mathrm{l}$ \\
\hline DNA-Template & $1,5 \mu \mathrm{l}$ \\
\hline
\end{tabular}

Tab. 3: Standardansatz für eine PCR mit 10 Proben 


\begin{tabular}{|ccl|}
\hline Primer & Forward $/$ Revers & Sequenz $\mathbf{5}^{\mathbf{}} \rightarrow \mathbf{3}^{\prime}$ \\
\hline \multirow{2}{*}{ Cre } & Forward & ATGCTTCTGTCCGTTTGCCG \\
\cline { 2 - 3 } GFP & Revers & CCTGTTTTGCACGTTCACCG \\
\cline { 2 - 3 } & Forward & ACCCTGAAGTTCATCTGCACCA \\
\hline \multirow{2}{*}{ Lacz } & Revers & TGGGTGCTCAGGTAGTGGTTGT \\
\cline { 2 - 3 } Lmx1a0E & Forward & TTGGCGTAAGTGAAGCGAC \\
\cline { 2 - 3 } & Revers & AGCGGCTGATGTTGAACTG \\
\hline \multirow{2}{*}{ Pitx30E } & Forward & ATCTGTACTCCATGCAGAATTCCTAT \\
\cline { 2 - 3 } & Forward & TTAACCTCGACTAAACACACGTAAAG \\
\hline
\end{tabular}

Tab. 4: Verwendete Primer zur Genotypsierung unter Angabe der Orientierung und Sequenz.

Für die Durchführung der PCR-Reaktionen wurde ein Mastercycler Gradient (Eppendorf) mit dem in Tab. 5 aufgeführten Standardprogramm verwendet, wobei die Anlagerungstemperatur den verwendeten Primerpaaren angepasst wurde. Die Produkte der PCR wurden anschließend auf ein Agarose-Gel aufgetragen (Kap. 5.2.6) und ausgewertet.

\begin{tabular}{|clll|}
\hline Prozess-Nr. & \multicolumn{1}{c}{ Vorgang } & \multicolumn{1}{c|}{ Temperatur } & Dauer \\
\hline 1 & Initiale Denaturierung & $94^{\circ} \mathrm{C}$ & $4 \mathrm{~min}$ \\
\hline 2 & Denaturierung & $94^{\circ} \mathrm{C}$ & $45 \mathrm{sek}$ \\
\hline 3 & Primeranlagerung & $55^{\circ} \mathrm{C}-65^{\circ} \mathrm{C}$ & $45 \mathrm{sek}$ \\
\hline 4 & Elongation & $72^{\circ} \mathrm{C}$ & $1 \mathrm{~min}$ \\
\hline 5 & Abschließende & $72^{\circ} \mathrm{C}$ & $5 \mathrm{~min}$ \\
\hline 6 & Elongation & $4^{\circ} \mathrm{C}$ & $\infty$ \\
\hline
\end{tabular}

Tab. 5: Standard-PCR Programm. Die Prozesse 2-4 wurden 30-35 Mal wiederholt (Zyklenanzahl).

\subsubsection{Agarose-Gelelektrophorese}

Für die Überprüfung und Analyse von PCR-Produkten, durchgeführten Restriktionsverdau-Ansätzen, sowie RNA-Probensynthesen, wurden diese mittels Agarose-Gelen der Größe nach aufgetrennt. Dabei wurde die Konzentration des Gels entsprechend der zu trennenden DNA- oder RNA-Fragmente ausgewählt $(0,8 \%-1,5 \%)$. Zunächst wurde für die Herstellung des Gels die entsprechend der Konzentration gewünschte Menge Agarose abgewogen, mit TBE-Puffer (Tab. 2) versetzt und erhitzt, bis sich die Agarose vollständig gelöst hat. Nach einer kurzen 
Abkühlphase (5min) wurde Ethidiumbromid (Roth \#2218.1, 10 mg/ml) zugegeben, leicht gemischt und bei Raumtemperatur (RT) in einer Gelelektrophoresekammer polymerisiert. Nach dem Aushärten wurde das Gel in eine Laufkammer (inkl. TBEPuffer) gegeben und die einzelnen Proben aufgetragen. Die Elektrophorese wurde bei 60 - 120 Volt (je nach Größe des Gels) durchgeführt. Abschließend wurde das Gel auf einen UV-Tisch gelegt und die Ergebnisse bei $280 \mathrm{~nm}$ sichtbar gemacht und protokolliert.

\subsubsection{Restriktionsverdau von DNA}

Um die in Kapitel 5.2.2 und 5.2.3 gewonnene Plasmid-DNA zu linearisieren und somit für die weitere Verwendung vorzubereiten, wurde ein Restriktionsverdau durchgeführt, wobei die verwendeten Enzyme (New England Biolabs, Promega) nach den Vorgaben der Hersteller verwendet wurden. Pro Reaktionsansatz wurde 100 - $300 \mu \mathrm{l}$ DNA-Lösung (je nach DNA-Konzentration der Probe; 2 - $3 \mu \mathrm{g} / \mu \mathrm{l}$ DNAGehalt) mit 1/10 Enzym-Puffer und 1/10 Enzym aufgefüllt und bei $37^{\circ} \mathrm{C}$ für zwei Stunden bei leichtem Schütteln inkubiert. Im Anschluss wurde das Ergebnis mittel Agarose-Gelelektrophorese überprüft. Die in der vorliegenden Arbeit verwendeten Plasmide sind in Tabelle 6 aufgelistet.

\begin{tabular}{|cccccc|}
\hline $\begin{array}{c}\text { Plasmidna } \\
\text { me }\end{array}$ & $\begin{array}{c}\text { eingefügte } \\
\text { cDNA }\end{array}$ & $\begin{array}{c}\text { Größe der } \\
\text { cDNA }\end{array}$ & $\begin{array}{c}\text { Restriktions- } \\
\text { Enzym }\end{array}$ & $\begin{array}{c}\text { RNA } \\
\text { Polymerase }\end{array}$ & Herkunft \\
\hline pBS-Otx2 & Otx2 & $1000 \mathrm{bp}$ & XbaI & T3 & AS \#102926 \\
\hline Gbx2-HA-FL & Gbx2 & $900 \mathrm{bp}$ & HindIII & T7 & AS \#102445 \\
\hline Hh16.1 & Shh & $640 \mathrm{bp}$ & HindIII & T3 & AS \#101861 \\
\hline pGEM-3 int & Wnt1 & $480 \mathrm{bp}$ & EcoRI & Sp6 & AS \#101542 \\
\hline En-1 & En1 & $578 \mathrm{bp}$ & Hind III & T7 & AS \#101763 \\
\hline Math4A & Ngn2 & $1500 \mathrm{bp}$ & BamHI & T7 & AS \#103354 \\
\hline p17-1/1 & Wnt5a & $2511 \mathrm{bp}$ & EcoRI & SP6 & AS \#103185 \\
\hline FGF-8 $(4.1)$ & Fgf8 & $800 \mathrm{bp}$ & SmaI & T7 & AS \#102377 \\
\hline
\end{tabular}

Tab. 6: Verwendete Plasmide unter Angabe der eingefügten cDNA Sequenzen. AS = Abteilungsstock 


\subsubsection{Herstellung von Glycerolstocks}

Zur langfristigen Lagerung der aus der Vorkultur erhaltenen Bakterienlösungen (Kap. 5.2.2) wurde jeweils ein Glycerolstock angelegt. Hierzu wurden $700 \mu \mathrm{l}$ Bakterienlösung mit $300 \mu \mathrm{l}$ Glycerol (50\%, autoklaviert) vermischt und bei $-80^{\circ} \mathrm{C}$ gelagert.

\subsubsection{Aufreinigung von total-RNA aus Hefe}

Die total-RNA aus der Hefe wurde als Bestandteil des Hybridisierungspuffers (Tab. 2) im Rahmen der in situ Hybridisierung (ISH, Kap. 5.4.7) genutzt, um unspezifische Hybridisierungen der jeweiligen Sonden mit den Gewebeproben zu vermeiden, und somit eine Reduzierung der Hintergrundfärbung zu erreichen. Zur Aufreinigung der Hefe-RNA wurden $250 \mathrm{mg}$ total-RNA (Roche) abgewogen, in ein $50 \mathrm{ml}$ Reaktionsgefäß gegeben und mit $25 \mathrm{ml}$ TE-Puffer $\mathrm{pH} \mathrm{7,5} \mathrm{(Tab.} \mathrm{2)} \mathrm{versetzt.}$ Die Lösung wurde in einem Wasserbad bei $60^{\circ} \mathrm{C}$ vollständig gelöst, wobei zwischenzeitlich mehrmals gevortext wurde. Anschließend wurde ein Volumenanteil (VA) Phenol pH 4,5 (Amresco) zugegeben, insgesamt für eine Stunde stark gevortext, für $20 \mathrm{~min}$ bei $4000 \mathrm{rpm}\left(4^{\circ} \mathrm{C}\right)$ zentrifugiert, und die wässrige Phase in ein neues Reaktionsgefäß überführt. Wiederum wurde ein VA Phenol zugegeben, gevortext, zentrifugiert und die wässrige Phase weiterverwendet - diese Extraktionsschritte wurden dreimal wiederholt. Nachdem $1 \mathrm{ml} 5 \mathrm{M} \mathrm{NaCl}$ zu der wässrigen Phase zugegeben und gevortext wurde, folgten drei Extraktionsschritte (Vortexen, Zentrifugation, Weiterverwendung des Überstandes) wobei jeweils 1 VA Chloroform verwendet wurde. Nach abschließender Zentrifugation wurden zu der wässrigen Phase 2,5 VA unvergällter Ethanol (100\%, eisgekühlt) zugegeben, leicht gemischt, und über Nacht bei $-80^{\circ} \mathrm{C}$ präzipitiert. Anschließend wurde die Lösung bei $10000 \mathrm{rpm}$ für $20 \mathrm{~min}$ und $4^{\circ} \mathrm{C}$ zentrifugiert. Das Pellet wurde mit 80\%igen unvergälltem Ethanol gewaschen, zentrifugiert und bei Raumtemperatur angetrocknet. Das Pellet wurde abschließend mit $10 \mathrm{ml}$ TE-Puffer (pH 7,5) gelöst, und der RNA-Gehalt wurde bestimmt (Kap. 5.2.4). 


\subsubsection{Herstellung DIG-markierter Proben}

Die DIG-Markierungsmethode (DIG = Digoxigenin-11-UTP)(Kessler et al., 1990) basiert auf einem isoliertem Steroid der Digitalis-Pflanze und ermöglicht die nichtradioaktive Detektion von DNA und RNA mittels DIG-markierter DNA- bzw. RNA-Sonden im Rahmen der in situ Hybridisierung (Kap. 5.4.7). Als DNA-Template für die Herstellung der DIG-markierten RNA-Sonden wurden die in den Kapiteln 5.2.2, 5.2.3 und 5.2.7 isolierten und linearisierten Plasmid-DNAs verwendet. Der Reaktionsansatz (Tab. 7) für die Sondensynthese wurde jeweils pipettiert und bei

\begin{tabular}{|ll|}
\hline Reagenz & Menge \\
\hline ddH ${ }_{2} \mathbf{O}$ (autoklaviert) & $13,5 \mu \mathrm{l}$ \\
\hline $\begin{array}{l}\text { 10x Transkriptionspuffer } \\
\text { (ROCHE, \#11465384001) }\end{array}$ & $2 \mu \mathrm{l}$ \\
\hline $\begin{array}{l}\text { DIG-markierter Nukleotid-Mix } \\
\text { (ROCHE, \#11277073910) }\end{array}$ & $2 \mu \mathrm{l}$ \\
\hline DNA-Template & $2 \mu \mathrm{l}(1-2 \mu \mathrm{g})$ \\
\hline RNasin (Promega, \#N211A, 2500U) & $1 \mu \mathrm{l}$ \\
\hline $\begin{array}{l}\text { RNA-Polymerase T3/T7/SP6 } \\
\text { (ROCHE, \#11031171001, } \\
\text { \#10881775001, \#10810274001) }\end{array}$ & $1 \mu \mathrm{l}$ \\
\hline
\end{tabular}

Tab. 7: Reaktionsansatz für die Herstellung einer DIGmarkierten Probe aus cDNA-Templates (Vgl. Tab. 6).

den vom Hersteller angegebenen Temperaturen für 4 Stunden bei leichtem Schütteln inkubiert $\left(\mathrm{T} 3 / \mathrm{T} 7=37^{\circ} \mathrm{C}\right.$; SP $\left.6=40^{\circ} \mathrm{C}\right)$. Anschließend wurde zur Kontrolle der Synthese $1 \mu \mathrm{l}$ des Reaktionsansatzes entnommen, und zusammen mit dem DNA-Template als Kontrolle des Verdaus auf ein 1\%iges Agarosegel aufgetragen. Zu dem Reaktionsansatz wurden dann $2 \mu$ l DNase (Promega \#M610) zugegeben und bei 30 min bei $37^{\circ} \mathrm{C}$ inkubiert, um das im Reaktionsansatz verwendete DNATemplate zu verdauen - danach wurden zum Abstoppen der DNase $2 \mu \mathrm{l}$ 0,2 M EDTA zugegeben. Im Anschluss wurden zur Fällung der RNA 2,5 $\mu \mathrm{l} 4 \mathrm{M} \mathrm{LiCl}$ sowie $75 \mu \mathrm{l}$ 100\%iger Ethanol (unvergällt) zugegeben, und über Nacht bei $-80^{\circ} \mathrm{C}$ präzipitiert. Danach wurde für 15 min bei $13000 \mathrm{rpm}\left(4^{\circ} \mathrm{C}\right)$ zentrifugiert und der Überstand verworfen. Das Pellet wurde mit 70\%igen unvergälltem Ethanol gewaschen, für $5 \mathrm{~min}$ bei zentrifugiert (13000 rpm, $4^{\circ} \mathrm{C}$ ), der Überstand verworfen und das Pellet bei RT getrocknet. Abschließend wurden $75 \mu \mathrm{LEPC}-\mathrm{H}_{2} \mathrm{O}$ zugegeben 
und das RNA-Pellet bei $37^{\circ} \mathrm{C}$ gelöst. Es folgte eine abschließende Überprüfung und Abschätzung der RNA-Qualität mit einem 1\%igen Agarosegel (s.o.), und die so hergestellte DIG-RNA-Sonde wurde bei $-20^{\circ} \mathrm{C}$ gelagert.

\subsection{Tierexperimentelle Methoden}

\subsubsection{Tiere}

Die in der vorliegenden Arbeit verwendeten Mauslinien sind in Tabelle 8 aufgelistet. Alle Cre-Mauslinien wurden auf einen C57/BL6 Hintergrund gekreuzt und auf diesem weitergezüchtet. Die in unserer Abteilung hergestellten, transgenen Überexpressionslinien (Pitx30E, Lmx1aOE, Lmx1bOE, Msx10E; M.S.Diaconu, U. Franke, (Collombat et al., 2007)) wurden mit CD1-Wildtypmäusen gekreuzt und auch auf diesem Hintergrund gehalten. Die Haltung und Verwendung der Tiere erfolgte entsprechend dem Tierschutzgesetz Deutschlands sowie den europäischen Richtlinien. Die Maushaltung erfolgte unter gleichbleibenden, standardisierten Bedingungen.

Die transgene Mauslinie Pitx30E (sowie die OE-Linien von Lmx1a/b und Msx1) wurde in unserem Labor hergestellt (M. S. Diaconu, U. Franke und (Collombat et al., 2007)) und soll hier nur kurz beschrieben werden. Das Transgen beinhaltet eine von zwei loxP-Sequenzen (gefloxt) flankierte GFP-Stopcodon-Sequenz, gefolgt von der Pitx3-cDNA, und einer IRES-LacZ-Kassette. Das gesamte Konstrukt steht dabei unter der Kontrolle eines starken Promotors (pCAG). Die transgenen Tiere können aufgrund des eGFP-Markers unter einem Fluoreszenzbinokulars erkannt werden, wobei die Signalstärke des eGFP in der Schwanzregion betrachtet wurde. Aufgrund des Stopcodons wird nur das eGFP exprimiert, nicht aber die dahinterliegende Pitx3-cDNA. Die drei weiteren Überexpressionslinien Lmx1aOE, Lmx1bOE, und Msx10E tragen das gleiche Basiskonstrukt, nur dass anstelle der Pitx3-cDNA die jeweiligen cDNAs von Lmx1a, Lmx1b, und Msx1 inseriert wurden.

Für die konditionale Überexpression von Pitx3 wurden jeweils Tiere der entsprechenden transgenen Mauslinie (Pitx3OE) mit Mäusen der Cre-Linien (En1Cre, Foxa2-Cre, Shh-Cre, Wnt1-Cre) verpaart (Abb. 22). Die Cre-Rekombinase schneidet dabei die gefloxte eGFP-Stopcodon-Sequenz heraus, und die gewebsspezifische Überexpression von Pitx3 in den vier verschiedenen Cre- 


\begin{tabular}{|c|c|c|}
\hline $\begin{array}{l}\text { Name der } \\
\text { Mauslinie }\end{array}$ & Beschreibung der Mauslinien & Herkunft \\
\hline CD1 & Wildtyptiere (CD1 Auszuchtstamm) & $\begin{array}{l}\text { CRLab (DTCC Consortium, } \\
\text { USA) }\end{array}$ \\
\hline C57/BL6 & Wildtyptiere (C57/BL6 Inzuchtstamm) & $\begin{array}{l}\text { CRLab (DTCC Consortium, } \\
\text { USA) }\end{array}$ \\
\hline En1-Cre & $\begin{array}{l}\text { transgene Cre-Linie unter der Kontrolle } \\
\text { des En1-Promotors (n.ind.) }\end{array}$ & (Zervas et al., 2004) \\
\hline Foxa2-Cre & $\begin{array}{l}\text { transgene Cre-Linie unter der Kontrolle } \\
\text { des Foxa2-Promotors (ind.) }\end{array}$ & (Park et al., 2008) \\
\hline Shh-Cre & $\begin{array}{l}\text { transgene Cre-Linie unter der Kontrolle } \\
\text { des Shh-Promotors (n.ind.) }\end{array}$ & JAX Laboratory \#005622 \\
\hline Wnt1-Cre & $\begin{array}{l}\text { transgene Cre-Linie unter der Kontrolle } \\
\text { des Wnt1-Promotors (n.ind.) }\end{array}$ & $\begin{array}{l}\text { JAX Laboratory \#009107 } \\
\text { (McMahon \& Bradley, 1990) }\end{array}$ \\
\hline Pitx30E & gefloxte transgene Pitx30E Linie & $\begin{array}{l}\text { M. S. Diaconu, U. Franke und } \\
\text { (Collombat et al., 2007) }\end{array}$ \\
\hline Lmx1a0E & gefloxte transgene von Lmx1a Linie & $\begin{array}{l}\text { M. S. Diaconu, U. Franke und } \\
\text { (Collombat et al., 2007) }\end{array}$ \\
\hline Lmx1b0E & gefloxte transgene von Lmx1b Linie & $\begin{array}{l}\text { M. S. Diaconu, U. Franke und } \\
\text { (Collombat et al., 2007) }\end{array}$ \\
\hline
\end{tabular}

Tab. 8: Verwendete transgene Mauslinien für die konditionale Überexpression von Pixt3 (und Lmx1a und Lmx1b) mittels des Cre-LoxP-Systems. ind. = induzierbar mit Tamoxifen; n.ind. = nicht induzierbar; JAX = The Jackson Laboratory, Maine, USA; CRLab

$=$ Charles River Laboratories, Wilmington, USA

\begin{tabular}{|ll|}
\hline Bezeichnung & Überexpression (OE) von \\
\hline Shh-Cre+/Pitx30E & Pitx3 unter der Kontrolle des Shh-Promotors \\
\hline Foxa2-Cre + /Pitx30E & Pitx3 unter der Kontrolle des Foxa2-Promotors \\
\hline En1-Cre $/$ Pitx30E & Pitx3 unter der Kontrolle des En1-Promotors \\
\hline Wnt1-Cre+/Pitx30E & Pitx3 unter der Kontrolle des Wnt1-Promotors \\
\hline Wnt1-Cre+/Lmx1b0E & Lmx1b unter der Kontrolle des Wnt1-Promotors \\
\hline Wnt1-Cre+/Lmx1aOE & Lmx1a unter der Kontrolle des Wnt1 \\
\hline
\end{tabular}

Tabelle 9: Verwendete Bezeichnung der doppeltransgenen Pitx3 Mausmutanten.

Expressionsdomänen wird erreicht. In der vorliegenden Arbeit werden diese doppeltransgenen Nachkommen wie in Tabelle 9 bezeichnet. Im Fall von Lmx1aOE und Lmx1b0E wurde nur mit der Wnt1-Cre-Linie verpaart. Bei der induzierbaren Foxa2-Cre Mauslinie wurde den tragenden Muttertieren Tamoxifen injiziert (Kap. 5.3.3) um die Überexpression zu aktivieren. Bei den übrigen drei Cre-Linien handelt es sich um nicht induzierbare Cre-Linien, die keine Tamoxifen- 
Verabreichung erforderten. Die Mäuse wurden über Nacht verpaart und die Weibchen wurden am nächsten Tag auf die Bildung des Vaginalpfropfens (plug) untersucht. Sobald sich ein plug nach erfolgreicher Verpaarung gebildet hatte, wurde der jeweilige Tag als E 0,5 (E = Embryonalstadium post coitum) definiert.

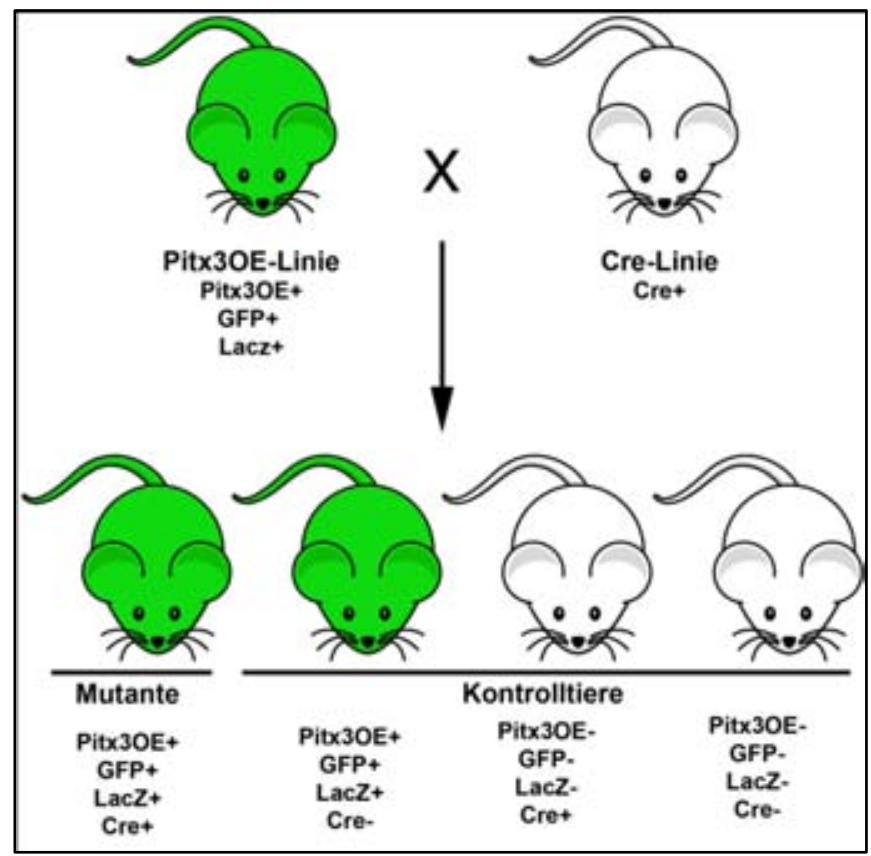

Abb. 22: Verpaarungsschema der konditionalen Pitx3Überexpression unter Angabe der Genotypen. Hierfür wurden die gefloxten Überexpressionslinien (Pitx30E, Lmx1aOE, Lmx1bOE) mit den transgenen Cre-Linien verpaart.

\subsubsection{Genotypisierung}

Für die Genotypsierung der OE-Mauslinien sowie der durch Verpaarung hervorgegangenen Embryonen wurde zunächst die Signalstärke des GFPReportgens kontrolliert, wobei der Schwanz der Maus mit Hilfe eines FluoreszenzBinokulars (Olympus SZX12) bei $509 \mathrm{~nm}$ betrachtet und die GFP-Intensität überprüft wurde.

Die Genotypisierung mittels PCR erfolgte mit den entsprechenden Primern in Tabelle 4. Als Kontrolltiere wurden Wildtyptiere (GFP-/LacZ-/Cre-), heterozygote OE-Tiere (GFP+/LacZ+/Cre-) oder Tiere der Cre-Linien (Cre+) verwendet. In der vorliegenden Arbeit werden alle Kontrolltiere als Wildtyp (WT) zusammengefasst. Die konditionalen OE-Tiere (Mutanten) hatten den Genotyp GFP+/Lacz+/Cre+ und werden in der vorliegenden Arbeit wie in Tab. 9 bezeichnet. 


\subsubsection{Tamoxifenverabreichung}

Zur Herstellung einer injizierbaren Tamoxifenlösung wurden 20 mg Tamoxifen (Sigma) in einem Milliliter Keimöl (Sigma) bei $37^{\circ} \mathrm{C}$ bei leichtem Schütteln und unter Lichtausschluss gelöst. Am Tag E 8,5 wurde den Muttertieren die vorgewärmte Tamoxifenlösung (0,05 mg pro Gramm Körpergewicht des Muttertieres) intraperitoneal injiziert. Der Zeitpunkt und die Menge der Tamoxifen-Verabreichung wurden der zughörigen Veröffentlichung der transgenen Foxa2-Cre-Mauslinie entnommen (Park et al., 2008).

\subsubsection{BrdU-Injektion}

Das synthetische Thymidinanalogon BrdU (5'Brom-2'desoxyuridin) wurde für die Durchführung von Proliferationsanalysen verwendet. Während der DNAReplikation wird das verabreichte BrdU in den neu synthetisierten DNA-Strang eingebaut. Durch eine spezifische Antikörperfärbung (Kap. 5.4.5) kann das inkorporierte BrdU sichtbar gemacht und als Marker für proliferierende Zellen in der S-Phase verwendet werden.

Um eine injizierbare BrdU-Lösung herzustellen, wurden $14 \mathrm{mg}$ BrdU (Roche) in $857 \mathrm{ml} \mathrm{PBS}$-Puffer bei $37^{\circ} \mathrm{C}$ gelöst und bis zur Verwendung bei $-20^{\circ} \mathrm{C}$ gelagert. Am Embryonaltag E12.5 wurde den tragenden Weibchen $\mathrm{zu}$ einem festgelegten Zeitpunkt $100 \mu \mathrm{l}$ BrdU-Lösung $\left(37^{\circ} \mathrm{C}\right)$ pro $10 \mathrm{~g}$ Körpergewicht intraperitoneal injiziert. Nach einer Stunde wurden die Muttertiere getötet und die Embryonen entnommen.

\subsubsection{Präparation von Embryonen und Gehirnen}

Für die Berechnung der Embryonalstadien wurde der Morgen des detektierten Vaginalplugs als E 0,5 definiert. Am entsprechenden Morgen des gewünschten Embryonalstadiums wurden die Muttertiere mittels Genickbruch getötet, die Embryonen entnommen und zunächst in eiskalten PBS-Puffer aufgenommen. Die Embryonen wurden danach unter dem einem Binokular in eiskalten PBS-Puffer isoliert, in sterile Petrischalen inkl. PBS überführt, und unter einem FluoreszenzBinokular (Olympus SZX12, 509nm) auf GFP-Expression kontrolliert. Bis zum Embyronalstadium E 12.5 wurden die Köpfe abgetrennt, und ab dem Stadium E 
15.5 wurden die Gehirne heraus präpariert, und weiterverwendet. Für die Genotypisierung (Kap. 5.3.2) wurden von den einzelnen Embryonen Gewebeproben unter sterilen Bedingungen entnommen.

\subsection{Histologische Methoden}

Die isolierten Embryonen (Kap. 5.3.4) wurden je nach Verwendungszweck entweder in Kryomatrix (Kap. 5.4.1) oder Paraffin (Kap. 5.4.2) eingebettet.

\subsubsection{Einbettung der Embryonen und Gehirne in Kryomatrix}

Nach der Isolierung der Embryonen (Kap. 5.3.5) wurden die Köpfe bzw. die Gehirne in 4\%igen PFA-Lösung fixiert, wobei die Fixierungsdauer der Größe des jeweiligen Gewebes angepasst wurde (Tab. 10).

\begin{tabular}{|ccc|}
\hline $\begin{array}{c}\text { Embryonalstadium } \\
\text { (E) in Tagen }\end{array}$ & Art des Gewebes & Dauer der Fixierung \\
\hline E10,5 & Kopf & 1 Stunde \\
\hline E12,5 & Kopf & 2 Stunden \\
\hline E15,5 & Gehirn & 2 Stunden \\
\hline E19,0 & Gehirn & 3 Stunden \\
\hline
\end{tabular}

Tab. 10: Fixierungsdauer des embryonalen Gewebes in einer 4\%igen PFA-Lösung.

Nach der Fixierung wurde das Gewebe dreimal für je 20 Minuten in eiskalten PBSPuffer gewaschen. Es folgte eine Inkubation in 15\%iger Sucroselösung (Merck) gelöst in PBS-Puffer) für 30 - 60 Minuten, bevor es in eine 30\% Sucrose-Lösung überführt wurde. Dort verblieb das Gewebe, bis es vollständig abgesunken war. Im Anschluss wurde das Gewebe für eine Stunde in eine 1:1-Mischung aus 30\% Sucrose-Lösung und Kryomatrix (Jung) gegeben, bevor es abschließend für ein bis zwei Stunden in Kryomatrix inkubiert wurde. Alle Inkubationsschritte erfolgten bei $4^{\circ} \mathrm{C}$ und leichtem Schütteln. Für die Einbettung wurde das Gewebe in Einbettformen inkl. Kryomatrix gegeben, entsprechend ausgerichtet (coronal oder sagittal) und auf Trockeneis eingebettet. Die so eingebetteten Gewebe wurden bei $80^{\circ} \mathrm{C}$ gelagert. 


\subsubsection{Einbettung der Embryonen und Gehirne in Paraffin}

Nachdem die Embryonen isoliert wurden, folgte eine Fixierung in 4\%igen PFA über Nacht bei $4^{\circ} \mathrm{C}$ und leichtem Schütteln. Am nächsten Tag wurde das Gewebe dreimal für 20 Minuten in PBS gewaschen und anschließend für 30 Minuten in Saline $(0,89 \% \quad \mathrm{NaCl})$ überführt. Als nächstes folgte eine aufsteigende Lösungsmittelreihe (Tab. 11), um das Gewebe vollständig zu entwässern:

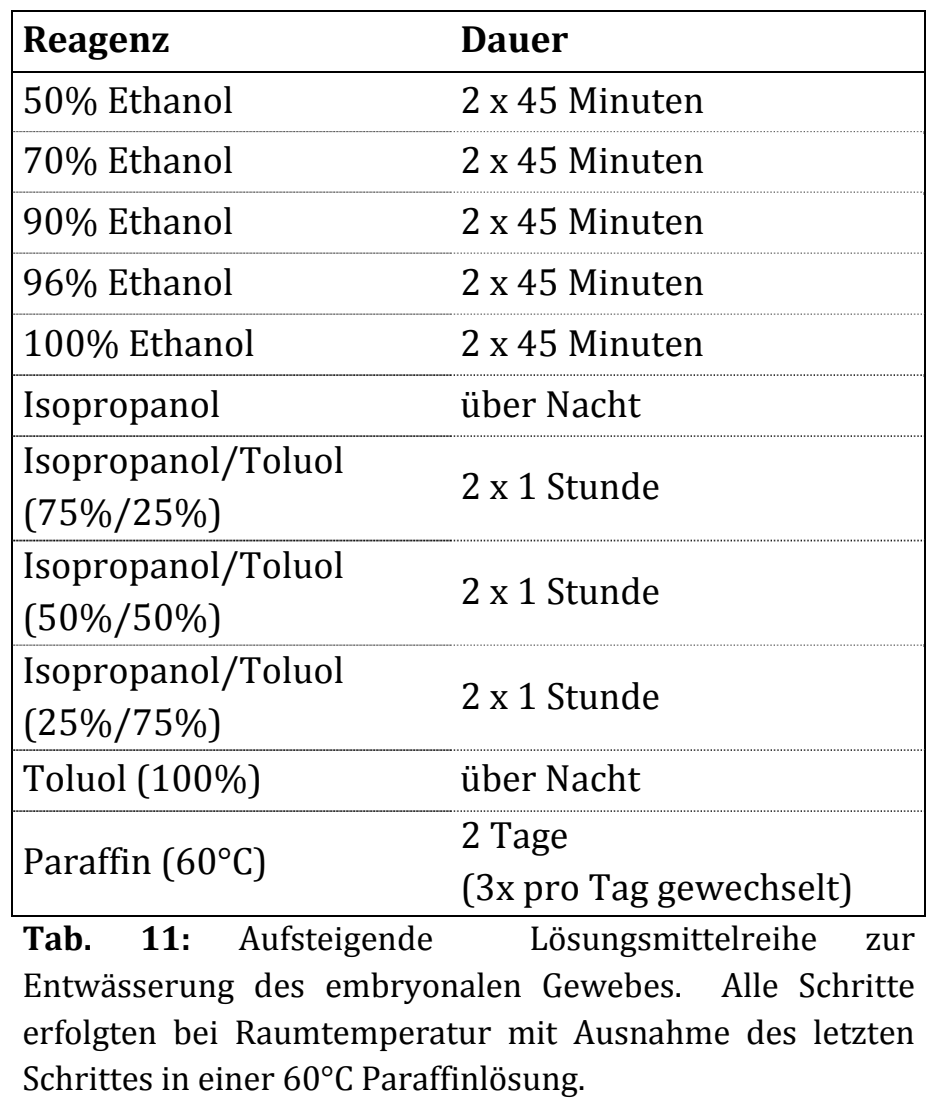

Abschließend wurden die Embryonen Hilfe einer Einbettmaschine (Leica EG1160) der gewünschten Schnittebene entsprechend in Paraffin eingebettet. Die Lagerung der erhärteten Gewebeblöcke erfolgte bei $4^{\circ} \mathrm{C}$.

\subsubsection{Anfertigung von Gewebeschnitten}

Alle angefertigten Gewebeschnitte wurden nach einem Referenzatlas (Schambra et al., 1992) während des Anschneidens ausgerichtet.

Die in Kryomatrix eingebetteten Embryonen bzw. Gehirne wurden mit einem Kryostat (Leica, CM3050S) bei $-15^{\circ} \mathrm{C}$ bis $-20^{\circ} \mathrm{C}$ geschnitten. Hierbei besaßen die 
Gewebeschnitte, je nach vorgesehener Färbemethode, eine Schnittdicke von $10 \mu \mathrm{m}$ (IIF = indirekte Immunofluoreszenzfärbung) oder $18 \mu \mathrm{m}(\mathrm{ISH}=$ in situ Hybridisierung). Sie wurden auf alternierende Adhäsionsobjektträger (Thermo Scientific Menzel-Gläser, Superfrost Ultra Plus) aufgezogen, für eine halbe Stunde bei $37^{\circ} \mathrm{C}$ getrocknet und bis zur Verwendung bei $-80^{\circ} \mathrm{C}$ gelagert.

Die Paraffinblöcke wurden an einem Mikrotom (Leica RM2165) geschnitten $(10 \mu \mathrm{m}$ Schnittdicke), in ein Wasserbad $\left(37^{\circ} \mathrm{C}\right)$ überführt, und die Gewebeschnitte wurden nach ca. 30 Minuten alternierend aufgezogen (Adhäsionsobjektträger, siehe oben). Nachdem die Schnitte bei $37^{\circ} \mathrm{C}$ über Nacht getrocknet wurden, erfolgte die Lagerung bis zur Verwendung bei $4^{\circ} \mathrm{C}$.

\subsubsection{Hämatoxylin-Eosin-Färbung}

Um die morphologischen Gehirnstrukturen bei Mausembryonen sichtbar zu machen, wurde eine Hämatoxylin-Eosin-Färbung (HE-Färbung) durchgeführt.

\begin{tabular}{|c|c|}
\hline Reagenz & Dauer \\
\hline Histoclear & $3 \times 6$ Minuten \\
\hline $100 \%$ Ethanol & 5 Minuten \\
\hline $90 \%$ Ethanol & 5 Minuten \\
\hline $70 \%$ Ethanol & 5 Minuten \\
\hline $50 \%$ Ethanol & 5 Minuten \\
\hline $\mathrm{ddH}_{2} \mathrm{O}$ & 2 Minuten \\
\hline Hämatoxylin-Lösung & 7 Minuten \\
\hline Leitungswasser & $3 \times 5$ Minuten \\
\hline $\begin{array}{l}\text { HCl-Ethanol } \\
(300 \mathrm{ml} 70 \% \text { Ethanol, } 3 \mathrm{ml} \mathrm{37 \%} \mathrm{HCl})\end{array}$ & 20 Sekunden \\
\hline Leitungswasser & $2 \times 5$ Minuten \\
\hline $\mathrm{ddH}_{2} \mathrm{O}$ & 2 Minuten \\
\hline Eosin-Lösung & 50 Sekunden \\
\hline $\mathrm{ddH}_{2} \mathrm{O}$ & 10 Sekunden \\
\hline $50 \%$ Ethanol & 50 Sekunden \\
\hline 70\% Ethanol & 1 Minute \\
\hline $90 \%$ Ethanol & 2 Minuten \\
\hline $100 \%$ Ethanol & $2 \times 2$ Minuten \\
\hline Histoclear & $2 \times 3$ Minuten \\
\hline
\end{tabular}

Tab. 12.: Protokoll für die Hämatoxylin-Eosin-Färbung (HE-Färbung) auf Paraffinschnitten. Alle Schritte erfolgten bei Raumtemperatur. 
Hierzu wurden die Paraffin-Gewebeschnitte zunächst entparaffinisiert, in einer absteigenden Alkoholreihe rehydriert, gefärbt und wieder dehydriert (Tab. 12).

Abschließend wurden die gefärbten Gewebeschnitte mit Eukitt (O. Kindler, Deutschland) eingedeckelt und bei RT getrocknet. Die Betrachtung und Protokollierung erfolgte mit einem Binokular (Olympus SZX12) mit angeschlossener Kamera und Software (Soft Imaging Systems, ColorView Kamera, Cell* Imaging Software). Die Fotos wurden mit Adobe Photoshop CS4 aufbereitet.

\subsubsection{Indirekte Immunofluoreszenzfärbung (IIF) auf Gewebeschnitten}

Für die Immunofluoreszenzfärbung (IIF) wurden die bei $-80^{\circ} \mathrm{C}$ gelagerten KryoGewebeschnitte zunächst für fünf Minuten bei RT aufgetaut, bevor mit einem Fettstift eine Umrandung um die zu färbenden Gewebeschnitte gezogen wurde. Nach kurzem Antrocknen des Fettsstifts (ImmEdge Pen, Vector, \#H-4000) wurden die Objektträger dreimal für fünf Minuten in einfachem PBS gewaschen. Es folgte das Abblocken unspezifischer Bindungen durch Inkubation des Gewebes mit Blockpuffer (Tab. 2). Das Abblocken erfolgte in einer lichtdichten Feuchtkammer für 1,5 Stunden bei Raumtemperatur. Anschließend wurde der gewünschte primäre Antikörper (Tab. 13), entsprechend verdünnt in Abblockpuffer, auf die Gewebeschnitte gegeben, und über Nacht bei $4^{\circ} \mathrm{C}$ in der Feuchtkammer inkubiert. Am folgenden Tage wurden die Objektträger dreimal für 5 Minuten in einfachen PBS-Puffer gewaschen, bevor der passende sekundäre Antikörper (Tab. 14) mit einer Verdünnung von 1:1000 auf die Schnitte gegeben wurde. Die Inkubation erfolgte für eine Stunde in der Feuchtkammer (RT). Danach wurden die Objektträger wieder dreimal für 5 Minuten in einfachen PBS gewaschen. Abschließend wurden die Schnitte mit Dapi-Lösung (Vector) eingedeckelt und das Deckglas wurde mittels Nagellack mit dem Objektträger versiegelt.

Die spezifisch angefärbten Gewebeschnitte wurden unter einem Fluoreszenzmikroskop (Olympus BX60) bei den entsprechenden Wellenlängen betrachtet. Es wurden alle relevanten Ergebnisse mit angeschlossener Kamera und Software (Soft Imaging Systems, ColorView Kamera, Cell* Imaging Software) protokolliert. Die abschließende Betrachtung und Bearbeitung der Bilder erfolgte mit dem Grafikprogramm Adobe Photoshop CS4. 


\begin{tabular}{|c|c|c|c|c|}
\hline Antikörper & Spezies & Bezugsquelle & Verdünnung & Verwendung \\
\hline anti -5-HT & Kaninchen & Diasorin, \#20080 & $1: 4000$ & IIF-P \\
\hline anti -BrdU & Maus & Roche, \#11202693001 & $1: 50$ & IIF-K \\
\hline anti -DAT & Ratte & Santa Cruz \# SC-32258 & $1: 100$ & IIF-K \\
\hline anti-En1 & Maus & DSHB \# 4G11 (K.) & $1: 100$ & IIF-K \\
\hline $\begin{array}{c}\text { anti-Foxa2 } \\
\text { (anti-HNF3ß) }\end{array}$ & Ziege & Santa Cruz \# SC-6554 & $1: 150$ & IIF-K \\
\hline anti -Lmx1a & Kaninchen & Millipore \# AB10533 & $1: 3000$ & IIF-K \\
\hline anti -Lmx1b & Meerschwein & Prof. Dr. C. Birchmeier & $1: 20000$ & IIF-K \\
\hline anti -Lmx1b & Kaninchen & Prof. Dr. C. Birchmeier & $1: 20000$ & IIF-K \\
\hline anti -Nkx6.1 & Maus & DSHB \#F55A10 (K.) & 1:50 & IIF-K \\
\hline anti -Nurr1 & Ziege & B\&D Systems \# AF2156 & $1: 150$ & IIF-K \\
\hline anti -Pitx3 & Kaninchen & Zymed (Invitrogen) \# 38-2850 & $1: 300$ & IIF-K \\
\hline anti -RC-2 & Maus & DSHB \# RC2 (K) & $1: 100$ & IIF-K \\
\hline anti -Shh & Maus & DSHB \# 5E1 (pS.) & unverdünnt & IIF-K \\
\hline $\begin{array}{l}\text { anti }-ß- \\
\text { Catenin }\end{array}$ & Kaninchen & Abcam \# AB6302 & $1: 1000$ & IIF-K \\
\hline anti - TH & Kaninchen & $\begin{array}{l}\text { Millipore (ehem. Chemicon)\# } \\
\text { AB152 }\end{array}$ & $1: 300$ & IIF-K \\
\hline anti - TH & Maus & Sigma-Aldrich \# T2928 & $1: 10000$ & IIF-P \\
\hline
\end{tabular}

Tab. 13.: Liste der verwendeten primären Antikörper für die IIF auf Gewebeschnitten. IIF-K = indirekte Immunofluoreszenz-Färbung auf Kryoschnitten; IIF-P = indirekte Immunofluoreszenz-Färbung auf Paraffinschnitten; DSHB = Developmental Studies Hybridoma Bank; K. = Konzentrat; pS = pures Serum

\begin{tabular}{|cccc|}
\hline Antikörper & Spezies & Chromogen & Katalognummer \\
\hline anti -Ratte & Ziege & Alexa Fluor 594 IgG & \#A11007 \\
anti -Ziege & Huhn & AlexaFluor 594 IgG & \#A21468 \\
anti -Kaninchen & Ziege & AlexaFluor 594 IgG & \#A11012 \\
\hline anti -Kaninchen & Ziege & AlexaFluor 488 IgG & \#A11008 \\
\hline anti -Maus & Ziege & AlexaFluor 594 IgG & \#A11032 \\
\hline anti -Maus & Esel & AlexaFluor 594 IgG & \#A21203 \\
\hline anti -Maus & Ziege & AlexaFluor 568 IgM & \#A21043 \\
\hline anti -Meerschwein & Ziege & AlexaFluor 594 IgG & \#A11076 \\
\hline anti -Maus & Ziege & AlexaFluor 488 IgG & \#A11001 \\
\hline
\end{tabular}

Tab. 14: Liste der verwendeten sekundären Antikörper für die IIF auf Gewebeschnitten. Alle sekundären Antikörper wurden bei Invitrogen Molecular Probes bestellt. 
Für die IIF-Färbung der Paraffin-Gewebeschnitte mussten diese zunächst entparaffinisiert und durch eine absteigende Ethanolreihe sowie eine AntigenDemaskierung für die oben beschrieben IIF vorbereitet werden (Tab. 15).

\begin{tabular}{|ll|}
\hline Reagenz & Dauer \\
\hline Histoclear & $3 \times 10$ Minuten \\
\hline $100 \%$ Ethanol & $2 \times 2$ Minuten \\
\hline $95 \%$ Ethanol & 5 Minuten \\
\hline $90 \%$ Ethanol & 5 Minuten \\
\hline $70 \%$ Ethanol & 5 Minuten \\
\hline $50 \%$ Ethanol & 5 Minuten \\
\hline $30 \%$ Ethanol & 5 Minuten \\
dd ${ }_{2} \mathrm{O}$ & 2 Minuten \\
\hline Demaskierung & $\begin{array}{l}\text { Demaskierungslösung } \\
\text { (Schnellkochtopf) }\end{array}$ \\
\hline dd $_{2} \mathrm{O}$ & 2 Minuten \\
\hline
\end{tabular}

Tab. 15: Protokoll für die IIF auf ParaffinGewebeschnitten. Alle Schritte erfolgten bei Raumtemperatur mit Ausnahme der Demaskierung.

Nach dem letzten Waschschritt in $\mathrm{ddH}_{2} \mathrm{O}$ wurde mit der Färbung wie zu Beginn des Kapitels beschrieben verfahren.

\subsubsection{BrdU- Färbung}

Die BrdU-Färbung wurde zur Detektion von proliferierenden Zellen auf KryoGewebeschnitten verwendet, und es wurden Embryonen verwendet, deren Muttertieren zuvor BrdU verabreicht wurde (Kap 5.3.4).

Die Gewebeschnitte wurden zunächst bei Raumtemperatur für 5 Minuten aufgetaut und die Schnitte auf den Objektträgern wurden mit einem Fettstift umrandet. Sie wurden daraufhin für 15 Minuten in einfachem PBS-Puffer bei leichtem Schütteln gewaschen. Dann wurden die Objektträger in $2 \mathrm{~N} \mathrm{HCl} \mathrm{überführt}$ und für 30 Minuten bei $37^{\circ} \mathrm{C}$ inkubiert. Es folgte ein zweimaliger Waschschritt in PBS-Puffer (2 x $30 \mathrm{~min}$ ) bevor die Gewebeschnitte für 60 Minuten bei Raumtemperatur in einer Feuchtkammer abgeblockt wurden (10\% FCS, 0,1\% Tween-20 in PBS-Puffer). Anschließend wurde der primäre Antikörper (Roche, 
Maus-anti-BrdU, 1:50 in Abblockpuffer) auf die Schnitte gegeben und über Nacht bei $4^{\circ} \mathrm{C}$ inkubiert. Am nächsten Tag wurden die Gewebeschnitte für zweimal 15 Minuten in PBS-Puffer gewaschen und der sekundäre Antikörper (Ziege-anti-Maus, 1:1000, Tab. 14) auf die Schnitte gegeben. Die Inkubation erfolgte in einer Feuchtkammer für eine Stunde (RT). Nach zwei abschließenden Waschschritten wurden die Gewebeschnitte mit Dapi-Lösung (Vector) und einem Deckglas eingedeckelt und mit Nagellack versiegelt. Die Färbungen wurden mit einem Fluoreszenzmikroskop (s.o.) analysiert.

\subsubsection{Detektion von RNA mittels in situ Hybridisierung (ISH) auf Gewebeschnitten}

Um die Expression von RNA-Transkripten auf geschnittenen KryoGewebeschnitten $(18 \mu \mathrm{m}$ Schnittdicke) nachzuweisen, wurde eine in-situ Hybridisierung (ISH) nach (Moorman et al., 2001) durchgeführt. Hierfür wurden die zuvor hergestellten DIG-markierten RNA-Proben (siehe Kap. 5.2.10) verwendet.

Zunächst wurden die Kryo-Gewebeschnitte bei Raumtemperatur für 5 Minuten aufgetaut und mit einer Umrandung versehen (Fettstift). Nach einer 20 minütigen Fixierung in 4\%iger PFA-Lösung (inkl. DEPC) wurden die Schnitte für $2 \times 5$ Minuten in PBS (inkl. DEPC) gewaschen. Zur Permeabilisierung des Gewebes folgte ein Waschschritt in ProteinaseK-Lösung $(20 \mu \mathrm{g} / \mathrm{ml}$ ProteinaseK, $50 \mathrm{mM}$ Tris- $\mathrm{HCl}$ pH 8,0, 5 mM EDTA in DEPC- $\mathrm{H}_{2} \mathrm{O}$ ) für 3 Minuten bei Raumtemperatur, was durch einen 5 minütigen Waschschritt in 2\%iger Glycin-Lösung abgestoppt wurde. Nach zweimaligem Waschen für 5 Minuten in PBS-Puffer wurden die Gewebeschnitte erneut für 20 Minuten fixiert (4\% PFA und 0,2\% Glutaraldehyd in PBS-Puffer), woraufhin weitere Waschschritte in PBS-Puffer (2 x $5 \mathrm{~min}$ ) folgten. Die Schnitte wurden dann in eine Feuchtkammer (50\% 2xSSC pH 4,5 und 50\% Formamid in $\left.\mathrm{dH}_{2} \mathrm{O}\right)$ gegeben, mit Hybridisierungpuffer $\left(70^{\circ} \mathrm{C}, \mathrm{Tab} .2\right)$ bedeckt, und für 2 Stunden bei $70^{\circ} \mathrm{C}$ inkubiert. Die in Kap. 5.2.10 hergestellten DIG-markierten RNA-Sonden wurden zunächst für 3 Minuten bei $80^{\circ} \mathrm{C}$ denaturiert und in vorgewärmten Hybridisierungpuffer $\left(70^{\circ} \mathrm{C}\right.$, Tab. 2) verdünnt (je nach RNA-Qualität, 1:20 - 1:100).

Daraufhin wurde diese RNA-haltige Hybridisierungs-Lösung auf die Gewebeschnitte gegeben und über Nacht bei $70^{\circ} \mathrm{C}$ in der gleichen Feuchtkammer 
inkubiert. Am nächsten Tag wurden die Gewebeschnitte zunächst in 2xSSC (pH 4,5) bei Raumtemperatur gewaschen, bevor sie mit in einer Formamid-Lösung (2xSSC, $50 \%$ Formamid in $\mathrm{dH}_{2} \mathrm{O}$ ) bei $65^{\circ} \mathrm{C}$ in einem Wasserbad inkubiert wurden (3 x $30 \mathrm{~min}$ ). Im Anschluss folgte eine Equilibrierung des Gewebes bei Raumtemperatur für 2 x 10 Minuten in KTBT-Puffer (Tab. 2). Zum Abblocken der Gewebeschnitte wurden die Schnitte für zwei Stunden bei Raumtemperatur mit $20 \%$ FCS in KTBT-Puffer abgeblockt (Feuchtkammer mit $\mathrm{dH}_{2} \mathrm{O}$ ). Über Nacht erfolgte daraufhin eine Inkubation mit anti-DIG-Antikörper (1:2000, AntiDigoxigenin-AP $\mathrm{F}_{\mathrm{ab}}$-Fragmente, Roche \#11093274910 in Abblockpuffer) in einer Feuchtkammer bei $4^{\circ} \mathrm{C}$. Am Nächsten Morgen wurde die über Nacht inkubierten Gewebeschnitte intensiv in KTBT-Puffer gewaschen $(3 \times 3$ min und $3 \times 30$ min; RT). Danach folgte ein dreimaliger Waschschritt in NTMT (Tab. 2, 3 x 5 min bei RT). Schließlich wurde die in NTMT verdünnte Färbelösung (1:50, NBT/BCIP, Roche, \#11681451001) auf die Schnitte gegeben und bei Raumtemperatur in einer Feuchtkammer inkubiert. Jede Stunde wurde der Fortschritt der Farbreaktion unter einem Binokular kontrolliert und die Färbelösung mehrmals ausgewechselt. Wenn sich am Abend noch keine ausreichende Anfärbung der RNA ergeben hatte, wurden die Schnitte über Nacht bei $4^{\circ} \mathrm{C}$ aufbewahrt und am nächsten Morgen weiterkontrolliert. Nachdem eine ausreichende Anfärbung erreicht war, wurde die Reaktion abgestoppt, indem mit PBS-Tween (PBS-Puffer, $1 \mathrm{ml}$ DEPC, 1ml Tween20) für 3 x 10 Minuten gewaschen wurde. Abschließend wurden die Schnitte mit Mowiol (Roth) und Deckglas eingedeckelt. Die Schnitte wurde unter einem Lichtmikroskop (Olympus, SZX-12) betrachtet und mittels angeschlossener Kamera und Software (s.o.) protokolliert, wobei abschließend das HelligkeitsKontrast-Verhältnis mit Adobe Photoshop CS4 optimiert wurde. 


\section{Literaturverzeichnis}

Acampora, D., Mazan, S., Lallemand, Y., Avantaggiato, V., Maury, M., Simeone, A.\&Brulet, P. (1995) 'Forebrain and midbrain regions are deleted in Otx2-/mutants due to a defective anterior neuroectoderm specification during gastrulation', Development 121(10): 3279-90.

Adams, K., Maida, J.\&Golden..., J. (2000) 'The transcription factor Lmx1b maintains Wnt1 expression within the isthmic organizer', Development(7f98c4ba-4618bb3b-bde8-713126ea5243).

Albéri, L., Sgadò, P.\&Simon, H. (2004) 'Engrailed genes are cell-autonomously required to prevent apoptosis in mesencephalic dopaminergic neurons', Development (Cambridge, England) 131(56adfaec-e43f-cc92-62e1713126ed2f0d): 3229-3265.

Alvarez-Fischer, D., Fuchs, J., Castagner, F., Stettler, O., Massiani-Beaudoin, O., Moya, K., Bouillot, C., Oertel, W., Lombès, A., Faigle, W. et al. (2011) 'Engrailed protects mouse midbrain dopaminergic neurons against mitochondrial complex I insults', Nature neuroscience 14(fd8b32f0-aca8-8e46-6f47713126ef5ae3): 1260-1266.

Alves dos Santos, M.\&Smidt, M. (2011) 'En1 and Wnt signaling in midbrain dopaminergic neuronal development', Neural development 6(c07af664-8bec5cae-384e-713127f06abb): 23.

Anderson, D. W., Schray, R. C., Duester, G.\&Schneider, J. S. (2011) 'Functional significance of aldehyde dehydrogenase ALDH1A1 to the nigrostriatal dopamine system', Brain Research 1408: 81-7.

Andersson, E., Jensen, J. B., Parmar, M., Guillemot, F.\&Bjorklund, A. (2006a) 'Development of the mesencephalic dopaminergic neuron system is compromised in the absence of neurogenin 2', Development 133(3): 507-16.

Andersson, E., Prakash, N., Cajanek, L., Minina, E., Bryja, V., Bryjova, L., Yamaguchi, T., Hall, A., Wurst, W.\&Arenas, E. (2008) 'Wnt5a regulates ventral midbrain morphogenesis and the development of A9-A10 dopaminergic cells in vivo', PLoS ONE 3(7e247a5c-6586-60ed-6228-713126ef3964).

Andersson, E., Tryggvason, U., Deng, Q., Friling, S., Alekseenko, Z., Robert, B., Perlmann, T.\&Ericson, J. (2006) 'Identification of intrinsic determinants of midbrain dopamine neurons', Cell 124(2): 393-405.

Ang, S.-L. (2006) 'Transcriptional control of midbrain dopaminergic neuron development', Development (Cambridge, England) 133(88aff2e6-2152-99a3e53f-713126f140fd): 3499-4005. 
Ang, S., Conlon, R.\&Jin..., O. (1994) 'Positive and negative signals from mesoderm regulate the expression of mouse Otx2 in ectoderm explants', Development(ab7108f9-d6e6-bfe6-28a6-713126f13e17).

Ardayfio, P., Moon, J., Leung, K., Youn-Hwang, D.\&Kim, K.-S. (2008) 'Impaired learning and memory in Pitx3 deficient aphakia mice: a genetic model for striatum-dependent cognitive symptoms in Parkinson's disease', Neurobiology of Disease 31(573f0f1d-89d9-cd1f-b14d-713126f2eef3): 406-418.

Arenas, E. (2008) 'Foxa2: the rise and fall of dopamine neurons', Cell Stem Cell 2(72797d9e-2bf1-8f0f-43ea-713126f2ebc0): 110-112.

Bally-Cuif, L., Alvarado-Mallart, R. M., Darnell, D. K.\&Wassef, M. (1992) 'Relationship between Wnt-1 and En-2 expression domains during early development of normal and ectopic met-mesencephalon', Development 115(4): 999-1009.

Bayer, S., Wills, K.\&Triarhou..., L. (1995a) 'Time of neuron origin and gradients of neurogenesis in midbrain dopaminergic neurons in the mouse', Experimental brain research(987ef19a-59b2-4ced-2009-713126f75fca).

Bayer, S. A., Wills, K. V., Triarhou, L. C., Verina, T., Thomas, J. D.\&Ghetti, B. (1995b) 'Selective vulnerability of late-generated dopaminergic neurons of the substantia nigra in weaver mutant mice', Proc Natl Acad Sci U S A 92(20): 9137-40.

Björklund, A.\&Hökfelt, T. (1984) Classical transmitters in the CNS, part I, Amsterdam: Elsevier.

Blaess, S., Bodea, G., Kabanova, A., Chanet, S., Mugniery, E., Derouiche, A., Stephen, D.\&Joyner, A. (2011) 'Temporal-spatial changes in Sonic Hedgehog expression and signaling reveal different potentials of ventral mesencephalic progenitors to populate distinct ventral midbrain nuclei', Neural development 6(206ab9d93ee2-b4b8-9793-713126f9dd96): 29.

Blaess, S., Corrales, J. D.\&Joyner, A. L. (2006) 'Sonic hedgehog regulates Gli activator and repressor functions with spatial and temporal precision in the mid/hindbrain region', Development 133(9): 1799-809.

Boncinelli, E., Gulisano, M., Spada, F.\&Broccoli, V. (1995) 'Emx and Otx gene expression in the developing mouse brain', Ciba Foundation symposium 193: 100-16; discussion 117-26.

Bonilla, S., Hall, A. C., Pinto, L., Attardo, A., Gotz, M., Huttner, W. B.\&Arenas, E. (2008) 'Identification of midbrain floor plate radial glia-like cells as dopaminergic progenitors', Glia 56(8): 809-20. 
Brault, V., Besson, V., Magnol, L.\&Duchon..., A. (2007) 'Cre/loxP-mediated chromosome engineering of the mouse genome', ... : an approach to disease ...(7be4eea9-d421-4f1d-e4d2-713126fcc5b6).

Briscoe, J.\&Ericson, J. (2001) 'Specification of neuronal fates in the ventral neural tube', Current Opinion in Neurobiology 11(6426a11e-fb5b-4499-6116713126fdc47a): 43-52.

Broccoli, V., Boncinelli, E.\&Wurst, W. (1999) 'The caudal limit of Otx2 expression positions the isthmic organizer', Nature 401(6749): 164-8.

Burbach, J., Smits, S.\&Smidt, M. (2003) 'Transcription factors in the development of midbrain dopamine neurons', Annals of the New York Academy of Sciences 991(c9305d00-e004-380e-aa05-713128ddad83): 61-69.

Castelo-Branco, G.\&Arenas, E. (2006) 'Function of Wnts in dopaminergic neuron development', Neuro-degenerative diseases 3(1-2): 5-11.

Cazorla, P., Smidt, M., O'Malley, K.\&Burbach, J. (2000) 'A response element for the homeodomain transcription factor Ptx3 in the tyrosine hydroxylase gene promoter', Journal of Neurochemistry 74(8597f10d-0cae-d614-77a071312703c999): 1829-1866.

Chanas-Sacre, G., Rogister, B., Moonen, G.\&Leprince, P. (2000a) 'Radial glia phenotype: origin, regulation, and transdifferentiation', Journal of Neuroscience Research 61(4): 357-63.

Chanas-Sacre, G., Thiry, M., Pirard, S., Rogister, B., Moonen, G., Mbebi, C., VerdiereSahuque, M.\&Leprince, P. (2000b) 'A 295-kDA intermediate filamentassociated protein in radial glia and developing muscle cells in vivo and in vitro', Developmental dynamics : an official publication of the American Association of Anatomists 219(4): 514-25.

Chi, C. L., Martinez, S., Wurst, W.\&Martin, G. R. (2003) 'The isthmic organizer signal FGF8 is required for cell survival in the prospective midbrain and cerebellum', Development 130(12): 2633-44.

Christophersen, N. S., Gronborg, M., Petersen, T. N., Fjord-Larsen, L., Jorgensen, J. R., Juliusson, B., Blom, N., Rosenblad, C.\&Brundin, P. (2007) 'Midbrain expression of Delta-like 1 homologue is regulated by GDNF and is associated with dopaminergic differentiation', Experimental Neurology 204(2): 791-801.

Chung, S., Hedlund, E., Hwang, M., Kim, D. W., Shin, B. S., Hwang, D. Y., Jung Kang, U., Isacson, 0.\&Kim, K. S. (2005) 'The homeodomain transcription factor Pitx3 facilitates differentiation of mouse embryonic stem cells into AHD2-expressing dopaminergic neurons', Mol Cell Neurosci 28(2): 241-52. 
Chung, S., Kim, C.-H.\&Kim, K.-S. (2012) 'Lmx1a regulates dopamine transporter gene expression during ES cell differentiation and mouse embryonic development', Journal of Neurochemistry(b129955a-6856-afbe-8c417131270928e4).

Chung, S., Leung, A., Han, B. S., Chang, M. Y., Moon, J. I., Kim, C. H., Hong, S., Pruszak, J., Isacson, 0.\&Kim, K. S. (2009) 'Wnt1-Imx1a forms a novel autoregulatory loop and controls midbrain dopaminergic differentiation synergistically with the SHH-FoxA2 pathway', Cell Stem Cell 5(6): 646-58.

Collombat, P., Hecksher-Sorensen, J., Krull, J., Berger, J., Riedel, D., Herrera, P. L., Serup, P.\&Mansouri, A. (2007) 'Embryonic endocrine pancreas and mature beta cells acquire alpha and PP cell phenotypes upon Arx misexpression', The Journal of clinical investigation 117(4): 961-70.

Crossley, P. H., Martinez, S.\&Martin, G. R. (1996) 'Midbrain development induced by FGF8 in the chick embryo', Nature 380(6569): 66-8.

Danielian, P.\&McMahon, A. (1996) 'Engrailed-1 as a target of the Wnt-1 signalling pathway in vertebrate midbrain development', Nature 383(1f90d6ea-68b72034-c6dc-7131270b3d40): 332-336.

Danielian, P., Muccino, D., Rowitch, D., Michael, S.\&McMahon, A. (1998) 'Modification of gene activity in mouse embryos in utero by a tamoxifeninducible form of Cre recombinase', Current biology : CB 8(7aff847f-10e67c9e-2f01-7131270b2e71): 1323-1329.

Davis, C. A.\&Joyner, A. L. (1988) 'Expression patterns of the homeo box-containing genes En-1 and En-2 and the proto-oncogene int-1 diverge during mouse development', Genes \& Development 2(12B): 1736-44.

de Mena, L., Coto, E., Cardo, L. F., Diaz, M., Blazquez, M., Ribacoba, R., Salvador, C., Pastor, P., Samaranch, L., Moris, G. et al. (2010) 'Analysis of the Micro-RNA-133 and PITX3 genes in Parkinson's disease', American journal of medical genetics. Part B, Neuropsychiatric genetics : the official publication of the International Society of Psychiatric Genetics 153B(6): 1234-9.

Deng, Q., Andersson, E., Hedlund, E., Alekseenko, Z., Coppola, E., Panman, L., Millonig, J., Brunet, J.-F., Ericson, J.\&Perlmann, T. (2011) 'Specific and integrated roles of Lmx1a, Lmx1b and Phox2a in ventral midbrain development', Development (Cambridge, England) 138(d33ff1b9-a577-9183af8b-7131270c1133): 3399-3807.

Di Porzio, U., Zuddas, A., Cosenza-Murphy, D. B.\&Barker, J. L. (1990) 'Early appearance of tyrosine hydroxylase immunoreactive cells in the mesencephalon of mouse embryos', International journal of developmental 
neuroscience : the official journal of the International Society for Developmental Neuroscience 8(5): 523-32.

Dickinson, M. E., Krumlauf, R.\&McMahon, A. P. (1994) 'Evidence for a mitogenic effect of Wnt-1 in the developing mammalian central nervous system', Development 120(6): 1453-71.

Ding, Q., Motoyama, J., Gasca, S., Mo, R., Sasaki, H., Rossant, J.\&Hui, C. C. (1998) 'Diminished Sonic hedgehog signaling and lack of floor plate differentiation in Gli2 mutant mice', Development 125(14): 2533-43.

Echelard, Y., Epstein, D., St-Jacques, B.\&Shen..., L. (1993) 'Sonic hedgehog, a member of a family of putative signaling molecules, is implicated in the regulation of CNS polarity', Cell(fb8f3747-89d0-797b-c877-713127300f67).

Elsworth, J. D.\&Roth, R. H. (1997) 'Dopamine synthesis, uptake, metabolism, and receptors: relevance to gene therapy of Parkinson's disease', Experimental Neurology 144(1): 4-9.

Failli, V., Bachy, I.\&Retaux, S. (2002) 'Expression of the LIM-homeodomain gene Lmx1a (dreher) during development of the mouse nervous system', Mech Dev 118(1-2): 225-8.

Farkas, L., Dünker, N.\&Roussa..., E. (2003) 'Transforming growth factor- $\beta$ s are essential for the development of midbrain dopaminergic neurons in vitro and in vivo', The Journal of ...(695df0bb-c637-8ab2-e707-71312747db4c).

Fasano, C. A.\&Studer, L. (2009) 'Too much Sonic, too few neurons', Nature neuroscience 12(2): 107-8.

Feil, R., Brocard, J., Mascrez, B., LeMeur, M., Metzger, D.\&Chambon, P. (1996) 'Ligand-activated site-specific recombination in mice', Proceedings of the National Academy of Sciences of the United States of America 93(20): 10887-90.

Ferri, A. L., Lin, W., Mavromatakis, Y. E., Wang, J. C., Sasaki, H., Whitsett, J. A.\&Ang, S. L. (2007) 'Foxa1 and Foxa2 regulate multiple phases of midbrain dopaminergic neuron development in a dosage-dependent manner', Development 134(15): 2761-9.

Fuccillo, M., Joyner, A.\&Fishell, G. (2006) 'Morphogen to mitogen: the multiple roles of hedgehog signalling in vertebrate neural development', Nature reviews. Neuroscience 7(d2b6cf25-45d1-c211-a8d7-71312a42c835): 772-855.

Fuchs, J., Mueller, J. C., Lichtner, P., Schulte, C., Munz, M., Berg, D., Wullner, U., Illig, T., Sharma, M.\&Gasser, T. (2009) 'The transcription factor PITX3 is associated with sporadic Parkinson's disease', Neurobiology of Aging 30(5): 731-8.

Gage, P.\&Suh..., H. (1999) 'The bicoid-related Pitx gene family in development', Mammalian Genome(4e7a6e15-faf3-4d6f-ea9b-713127644990). 
Gage, P. J.\&Camper, S. A. (1997) 'Pituitary homeobox 2, a novel member of the bicoid-related family of homeobox genes, is a potential regulator of anterior structure formation', Hum Mol Genet 6(3): 457-64.

Gale, E.\&Li, M. (2008) 'Midbrain dopaminergic neuron fate specification: Of mice and embryonic stem cells', Molecular brain 1: 8.

Gardner, C. A.\&Barald, K. F. (1991) 'The cellular environment controls the expression of engrailed-like protein in the cranial neuroepithelium of quailchick chimeric embryos', Development 113(3): 1037-48.

Gavériaux-Ruff, C.\&Kieffer, B. (2007) 'Conditional gene targeting in the mouse nervous system: Insights into brain function and diseases', Pharmacology \& therapeutics 113(e7f2a270-b318-d8d8-56ac-7131276f6314): 619-653.

Gehring, W. J., Qian, Y. Q., Billeter, M., Furukubo-Tokunaga, K., Schier, A. F., Resendez-Perez, D., Affolter, M., Otting, G.\&Wuthrich, K. (1994) 'Homeodomain-DNA recognition', Cell 78(2): 211-23.

German, D. C.\&Manaye, K. F. (1993) 'Midbrain dopaminergic neurons (nuclei A8, A9, and A10): three-dimensional reconstruction in the rat', The Journal of comparative neurology 331(3): 297-309.

Gilbert, S. F. (2006) Developmental biology, Sunderland, Mass.: Sinauer Associates, Inc. Publishers.

Goridis, C.\&Rohrer, H. (2002) 'Specification of catecholaminergic and serotonergic neurons', Nat Rev Neurosci 3(7): 531-41.

Götz, M.\&Huttner, W. (2005) 'The cell biology of neurogenesis', Nature reviews. Molecular cell biology 6(86ddcb9e-c73f-d32f-dacc-713127839c9c): 777-865.

Grimm, C., Chatterjee, B., Favor, J., Immervoll, T., Loster, J., Klopp, N., Sandulache, R.\&Graw, J. (1998) 'Aphakia (ak), a mouse mutation affecting early eye development: fine mapping, consideration of candidate genes and altered Pax6 and Six3 gene expression pattern', Developmental genetics 23(4): 299-316.

Gu, H., Marth, J. D., Orban, P. C., Mossmann, H.\&Rajewsky, K. (1994) 'Deletion of a DNA polymerase beta gene segment in $\mathrm{T}$ cells using cell type-specific gene targeting', Science 265(5168): 103-6.

Guo, C., Qiu, H. Y., Huang, Y., Chen, H., Yang, R. Q., Chen, S. D., Johnson, R. L., Chen, Z. F.\&Ding, Y. Q. (2007) 'Lmx1b is essential for Fgf8 and Wnt1 expression in the isthmic organizer during tectum and cerebellum development in mice', Development 134(2): 317-25.

Guo, Y., Le, W. D., Jankovic, J., Yang, H. R., Xu, H. B., Xie, W. J., Song, Z.\&Deng, H. (2011) 'Systematic genetic analysis of the PITX3 gene in patients with 
Parkinson disease', Movement disorders : official journal of the Movement Disorder Society 26(9): 1729-32.

Hanes, S. D.\&Brent, R. (1989) 'DNA specificity of the bicoid activator protein is determined by homeodomain recognition helix residue 9', Cell 57(7): 1275-83.

Haselbeck, R. J., Hoffmann, I.\&Duester, G. (1999) 'Distinct functions for Aldh1 and Raldh2 in the control of ligand production for embryonic retinoid signaling pathways', Developmental genetics 25(4): 353-64.

Haubenberger, D., Reinthaler, E., Mueller, J., Pirker, W., Katzenschlager, R., Froehlich, R., Bruecke, T., Daniel, G., Auff, E.\&Zimprich, A. (2011) 'Association of transcription factor polymorphisms PITX3 and EN1 with Parkinson's disease', Neurobiology of Aging 32(0ba8cb26-d12d-c1f4-c096713127867573): 302-309.

Hayashi, S.\&McMahon, A. (2002) 'Efficient recombination in diverse tissues by a tamoxifen-inducible form of Cre: a tool for temporally regulated gene activation/inactivation in the mouse', Developmental Biology 244(ba5d03d0c093-b7fe-3049-713128eb62c7): 305-323.

Hayes, L., Zhang, Z., Albert, P., Zervas, M.\&Ahn, S. (2011) 'Timing of Sonic hedgehog and Gli1 expression segregates midbrain dopamine neurons', The Journal of comparative neurology 519(15): 3001-18.

Heyer, M. P., Pani, A. K., Smeyne, R. J., Kenny, P. J.\&Feng, G. (2012) 'Normal Midbrain Dopaminergic Neuron Development and Function in miR-133b Mutant Mice', The Journal of neuroscience : the official journal of the Society for Neuroscience 32(32): 10887-10894.

Ho, H. Y., Chang, K. H., Nichols, J.\&Li, M. (2009) 'Homeodomain protein Pitx3 maintains the mitotic activity of lens epithelial cells', Mech Dev 126(1-2): 1829.

Hornykiewicz, O. (2001) Parkinson Disease eLS: John Wiley \& Sons, Ltd.

Hwang, D.-Y., Ardayfio, P., Kang, U., Semina, E.\&Kim, K.-S. (2003) 'Selective loss of dopaminergic neurons in the substantia nigra of Pitx3-deficient aphakia mice', Brain research. Molecular brain research 114(3f342c38-ee12-cf28-e4007131278c7342): 123-154.

Hwang, D. Y., Hong, S., Jeong, J. W., Choi, S., Kim, H., Kim, J.\&Kim, K. S. (2009) 'Vesicular monoamine transporter 2 and dopamine transporter are molecular targets of Pitx3 in the ventral midbrain dopamine neurons', Journal of Neurochemistry 111(5): 1202-12.

Hynes, M., Porter, J., Chiang, C., Chang, D., Tessier-Lavigne, M., Beachy, P.\&Rosenthal, A. (1995) 'Induction of midbrain dopaminergic neurons by 
Sonic hedgehog', Neuron 15(cea4de15-e04a-305a-42de-7131278d423c): 3579.

Hynes, M., Porter, J. A., Chiang, C., Chang, D., Tessier-Lavigne, M., Beachy, P. A.\&Rosenthal, A. (1995a) 'Induction of midbrain dopaminergic neurons by Sonic hedgehog', Neuron 15(1): 35-44.

Hynes, M., Poulsen, K., Tessier-Lavigne, M.\&Rosenthal, A. (1995b) 'Control of neuronal diversity by the floor plate: contact-mediated induction of midbrain dopaminergic neurons', Cell 80(1): 95-101.

Iwawaki, T., Kohno, K.\&Kobayashi, K. (2000) 'Identification of a potential nurr1 response element that activates the tyrosine hydroxylase gene promoter in cultured cells', Biochemical and Biophysical Research Communications 274(3): 590-5.

Jacobs, F. M., Smits, S. M., Noorlander, C. W., von Oerthel, L., van der Linden, A. J., Burbach, J. P.\&Smidt, M. P. (2007) 'Retinoic acid counteracts developmental defects in the substantia nigra caused by Pitx3 deficiency', Development 134(14): 2673-84.

Jacobs, F. M., van der Linden, A. J., Wang, Y., von Oerthel, L., Sul, H. S., Burbach, J. P.\&Smidt, M. P. (2009a) 'Identification of Dlk1, Ptpru and Klhl1 as novel Nurr1 target genes in meso-diencephalic dopamine neurons', Development 136(14): 2363-73.

Jacobs, F. M., van Erp, S., van der Linden, A. J., von Oerthel, L., Burbach, J. P.\&Smidt, M. P. (2009b) 'Pitx3 potentiates Nurr1 in dopamine neuron terminal differentiation through release of SMRT-mediated repression', Development 136(4): 531-40.

Jacobs, F. M., Veenvliet, J. V., Almirza, W. H., Hoekstra, E. J., von Oerthel, L., van der Linden, A. J., Neijts, R., Koerkamp, M. G., van Leenen, D., Holstege, F. C. et al. (2011) 'Retinoic acid-dependent and -independent gene-regulatory pathways of Pitx3 in meso-diencephalic dopaminergic neurons', Development 138(23): 5213-22.

Jensen, C. H., Meyer, M., Schroder, H. D., Kliem, A., Zimmer, J.\&Teisner, B. (2001) 'Neurons in the monoaminergic nuclei of the rat and human central nervous system express FA1/dlk', Neuroreport 12(18): 3959-63.

Jessell, T. (2000) 'Neuronal specification in the spinal cord: inductive signals and transcriptional codes', Nature reviews. Genetics 1 (14bcc0cb-6b1f-1f6a-8daf71312792c388): 20-29.

Joksimovic, M., Yun, B., Kittappa, R., Anderegg, A., Chang, W., Taketo, M., McKay, R.\&Awatramani, R. (2009) 'Wnt antagonism of Shh facilitates midbrain floor 
plate neurogenesis', Nature neuroscience 12(73b25ecc-c985-48eb-e4ef71312794a25c): 125-156.

Joshi, R. L., Torero Ibad, R., Rheey, J., Castagner, F., Prochiantz, A.\&Moya, K. L. (2011) 'Cell non-autonomous functions of homeoproteins in neuroprotection in the brain', FEBS Letters 585(11): 1573-8.

Joyner, A. (1996) 'Engrailed, Wnt and Pax genes regulate midbrain--hindbrain development', Trends in genetics : TIG 12(0a292e49-33ee-5b94-f06d713127965d9b): 15-35.

Joyner, A., Liu, A.\&Millet, S. (2000) 'Otx2, Gbx2 and Fgf8 interact to position and maintain a mid-hindbrain organizer', Current opinion in cell biology 12(3a9abaf6-71b9-94d6-952d-713127974ac1): 736-777.

Kadkhodaei, B., Ito, T., Joodmardi, E., Mattsson, B., Rouillard, C., Carta, M., Muramatsu, S., Sumi-Ichinose, C., Nomura, T., Metzger, D. et al. (2009) 'Nurr1 is required for maintenance of maturing and adult midbrain dopamine neurons', The Journal of neuroscience : the official journal of the Society for Neuroscience 29(50): 15923-32.

Kang, W.-Y., Kim, S.-S., Cho, S.-K., Kim, S., Suh-Kim, H.\&Lee, Y.-D. (2010) 'Migratory defect of mesencephalic dopaminergic neurons in developing reeler mice', Anatomy \& cell biology 43(8755cbf5-39e0-4dc4-2a1f-7131279a7ff0): 241-292.

Kawano, H., Ohyama, K., Kawamura, K.\&Nagatsu, I. (1995) 'Migration of dopaminergic neurons in the embryonic mesencephalon of mice', Brain Res Dev Brain Res 86(1-2): 101-13.

Kele, J., Simplicio, N., Ferri, A. L., Mira, H., Guillemot, F., Arenas, E.\&Ang, S. L. (2006) 'Neurogenin 2 is required for the development of ventral midbrain dopaminergic neurons', Development 133(3): 495-505.

Kessler, C., Holtke, H. J., Seibl, R., Burg, J.\&Muhlegger, K. (1990) 'Non-radioactive labeling and detection of nucleic acids. I. A novel DNA labeling and detection system based on digoxigenin: anti-digoxigenin ELISA principle (digoxigenin system)', Biological chemistry Hoppe-Seyler 371(10): 917-27.

Kim, J., Inoue, K., Ishii, J., Vanti, W. B., Voronov, S. V., Murchison, E., Hannon, G.\&Abeliovich, A. (2007) 'A MicroRNA feedback circuit in midbrain dopamine neurons', Science 317(5842): 1220-4.

Kim, K. S., Kim, C. H., Hwang, D. Y., Seo, H., Chung, S., Hong, S. J., Lim, J. K., Anderson, T.\&Isacson, 0. (2003) 'Orphan nuclear receptor Nurr1 directly transactivates the promoter activity of the tyrosine hydroxylase gene in a cell-specific manner', J Neurochem 85(3): 622-34. 
Kittappa, R., Chang, W., Awatramani, R.\&McKay, R. (2007) 'The foxa2 gene controls the birth and spontaneous degeneration of dopamine neurons in old age', PLoS Biology 5(bfbcf6df-5d9b-fb88-0655-713127a0e620).

Klockgether, T. (2004) 'Parkinson's disease: clinical aspects', Cell and Tissue Research 318(1): 115-20.

Kurokawa, D., Kiyonari, H., Nakayama, R., Kimura-Yoshida, C., Matsuo, I.\&Aizawa, S. (2004) 'Regulation of Otx2 expression and its functions in mouse forebrain and midbrain', Development 131(14): 3319-31.

L'Honore, A., Coulon, V., Marcil, A., Lebel, M., Lafrance-Vanasse, J., Gage, P., Camper, S.\&Drouin, J. (2007) 'Sequential expression and redundancy of Pitx2 and Pitx3 genes during muscle development', Dev Biol 307(2): 421-33.

Lamonerie, T., Tremblay, J. J., Lanctot, C., Therrien, M., Gauthier, Y.\&Drouin, J. (1996) 'Ptx1, a bicoid-related homeo box transcription factor involved in transcription of the pro-opiomelanocortin gene', Genes Dev 10(10): 1284-95.

Lang, A. E.\&Lozano, A. M. (1998a) 'Parkinson's disease. First of two parts', The New England journal of medicine 339(15): 1044-53.

Lang, A. E.\&Lozano, A. M. (1998b) 'Parkinson's disease. Second of two parts', The New England journal of medicine 339(16): 1130-43.

Le, W., Nguyen, D., Lin, X. W., Rawal, P., Huang, M., Ding, Y., Xie, W., Deng, H.\&Jankovic, J. (2011) 'Transcription factor PITX3 gene in Parkinson's disease', Neurobiology of Aging 32(4): 750-3.

Lebel, M., Gauthier, Y., Moreau, A.\&Drouin, J. (2001) 'Pitx3 activates mouse tyrosine hydroxylase promoter via a high-affinity binding site', Journal of Neurochemistry 77(2): 558-67.

Lee, H.-S., Bae, E.-J., Yi, S.-H., Shim, J.-W., Jo, A. Y., Kang, J.-S., Yoon, E.-H., Rhee, Y.-H., Park, C.-H., Koh, H.-C. et al. (2010) 'Foxa2 and Nurr1 synergistically yield A9 nigral dopamine neurons exhibiting improved differentiation, function, and cell survival', Stem cells (Dayton, Ohio) 28(eb2e6b2f-081a-3520-7225713127a71f6d): 501-513.

Lee, K.\&Jessell, T. (1999) 'The specification of dorsal cell fates in the vertebrate central nervous system', Annual review of neuroscience 22(4cb0adfc-89f90c3b-d767-713127a7d0bc): 261-355.

Lewandoski, M. (2001) 'Conditional control of gene expression in the mouse', Nature reviews. Genetics 2(33db594a-1731-9e1a-f95e-713128ef35eb): 743798. 
Li, J., Dani, J. A.\&Le, W. (2009) 'The role of transcription factor Pitx3 in dopamine neuron development and Parkinson's disease', Current topics in medicinal chemistry 9(10): 855-9.

Lin, L. F., Doherty, D. H., Lile, J. D., Bektesh, S.\&Collins, F. (1993) 'GDNF: a glial cell line-derived neurotrophic factor for midbrain dopaminergic neurons', Science 260(5111): 1130-2.

Lin, W., Metzakopian, E., Mavromatakis, Y., Gao, N., Balaskas, N., Sasaki, H., Briscoe, J., Whitsett, J., Goulding, M., Kaestner, K. et al. (2009) 'Foxa1 and Foxa2 function both upstream of and cooperatively with Lmx1a and Lmx1b in a feedforward loop promoting mesodiencephalic dopaminergic neuron development', Developmental Biology 333(72c88914-a87c-45f7-0195713127abeb15): 386-482.

Liu, A.\&Joyner, A. (2001) 'Early anterior/posterior patterning of the midbrain and cerebellum', Annual review of neuroscience 24(4824a0b3-2489-d949-69b1713127ad25d9): 869-965.

Liu, A., Losos, K.\&Joyner, A. (1999) 'FGF8 can activate Gbx2 and transform regions of the rostral mouse brain into a hindbrain fate', Development (Cambridge, England) 126(62930a43-3ed5-a091-25e7-713127ace159): 4827-4865.

Logan, C. Y.\&Nusse, R. (2004) 'The Wnt signaling pathway in development and disease', Annual review of cell and developmental biology 20: 781-810.

Maden, M. (2007) 'Retinoic acid in the development, regeneration and maintenance of the nervous system', Nature reviews. Neuroscience 8(10): 75565.

Mansouri, A. (2001) Knockout and Knock-in Animals eLS: John Wiley \& Sons, Ltd.

Marti, E., Takada, R., Bumcrot, D. A., Sasaki, H.\&McMahon, A. P. (1995) 'Distribution of Sonic hedgehog peptides in the developing chick and mouse embryo', Development 121(8): 2537-47.

Martinat, C., Bacci, J. J., Leete, T., Kim, J., Vanti, W. B., Newman, A. H., Cha, J. H., Gether, U., Wang, H.\&Abeliovich, A. (2006) 'Cooperative transcription activation by Nurr1 and Pitx3 induces embryonic stem cell maturation to the midbrain dopamine neuron phenotype', Proceedings of the National Academy of Sciences of the United States of America 103(8): 2874-9.

Martinez-Barbera, J. P., Signore, M., Boyl, P. P., Puelles, E., Acampora, D., Gogoi, R., Schubert, F., Lumsden, A.\&Simeone, A. (2001) 'Regionalisation of anterior neuroectoderm and its competence in responding to forebrain and midbrain inducing activities depend on mutual antagonism between OTX2 and GBX2', Development 128(23): 4789-800. 
Martinez, S., Crossley, P. H., Cobos, I., Rubenstein, J. L.\&Martin, G. R. (1999) 'FGF8 induces formation of an ectopic isthmic organizer and isthmocerebellar development via a repressive effect on Otx2 expression', Development 126(6): 1189-200.

Martinez, S., Wassef, M.\&Alvarado-Mallart, R. M. (1991) 'Induction of a mesencephalic phenotype in the 2-day-old chick prosencephalon is preceded by the early expression of the homeobox gene en', Neuron 6(6): 971-81.

Matise, M., Epstein, D., Park, H.\&Platt..., K. (1998) 'Gli2 is required for induction of floor plate and adjacent cells, but not most ventral neurons in the mouse central nervous system', Development(fbc8dcdd-abc7-162e-8706713127c692c8).

Matsunaga, E., Katahira, T.\&Nakamura, H. (2002) 'Role of Lmx1b and Wnt1 in mesencephalon and metencephalon development', Development 129(22): 5269-77.

Matsuo, I., Kuratani, S., Kimura, C., Takeda, N.\&Aizawa, S. (1995) 'Mouse Otx2 functions in the formation and patterning of rostral head', Genes \& Development 9(21): 2646-58.

Mavromatakis, Y., Lin, W., Metzakopian, E., Ferri, A., Yan, C., Sasaki, H., Whisett, J.\&Ang, S.-L. (2011) 'Foxa1 and Foxa2 positively and negatively regulate Shh signalling to specify ventral midbrain progenitor identity', Mechanisms of Development 128(01e41d6d-431e-0232-f8d1-713127c7c8d7): 90-193.

Maxwell, S., Ho, H.-Y., Kuehner, E., Zhao, S.\&Li, M. (2005a) 'Pitx3 regulates tyrosine hydroxylase expression in the substantia nigra and identifies a subgroup of mesencephalic dopaminergic progenitor neurons during mouse development', Developmental Biology 282(f9623758-6a50-199c-6a10-713127c77d8b): 467546.

Maxwell, S. L., Ho, H. Y., Kuehner, E., Zhao, S.\&Li, M. (2005b) 'Pitx3 regulates tyrosine hydroxylase expression in the substantia nigra and identifies a subgroup of mesencephalic dopaminergic progenitor neurons during mouse development', Developmental Biology 282(2): 467-79.

McCaffery, P.\&Drager, U. C. (1994) 'High levels of a retinoic acid-generating dehydrogenase in the meso-telencephalic dopamine system', Proceedings of the National Academy of Sciences of the United States of America 91(16): 77726.

McMahon, A.\&Bradley, A. (1990) 'The Wnt-1 (int-1) proto-oncogene is required for development of a large region of the mouse brain', Cell 62(55fdc499-2ddc846b-480b-713127c82e34): 1073-1158. 
McMahon, A., Joyner, A., Bradley, A.\&McMahon, J. (1992) 'The midbrain-hindbrain phenotype of Wnt-1-/Wnt-1- mice results from stepwise deletion of engrailedexpressing cells by 9.5 days postcoitum', Cell 69(f6061a3f-2c97-1996-68e5713127c71938): 581-676.

Medina-Martinez, O., Shah, R.\&Jamrich, M. (2009) 'Pitx3 controls multiple aspects of lens development', Dev Dyn.

Megason, S.\&McMahon, A. (2002) 'A mitogen gradient of dorsal midline Wnts organizes growth in the CNS', Development (Cambridge, England) 129(b0579812-5779-de4c-4a38-713127c92c43): 2087-2185.

Messmer, K., Remington, M., Skidmore, F.\&Fishman, P. (2007) 'Induction of tyrosine hydroxylase expression by the transcription factor Pitx3', International journal of developmental neuroscience : the official journal of the International Society for Developmental Neuroscience 25(d83c7cee-6036-647d2121-713127ca1801): 29-66.

Metzger, D.\&Feil, R. (1999) 'Engineering the mouse genome by site-specific recombination', Current opinion in biotechnology 10(5): 470-6.

Millet, S., Campbell, K., Epstein, D., Losos, K., Harris, E.\&Joyner, A. (1999) 'A role for Gbx2 in repression of Otx2 and positioning the mid/hindbrain organizer', Nature 401(1da3bbd3-dfeb-1bd6-af72-713127cb3dda): 161-165.

Misson, J. P., Edwards, M. A., Yamamoto, M.\&Caviness, V. S., Jr. (1988) 'Identification of radial glial cells within the developing murine central nervous system: studies based upon a new immunohistochemical marker', Brain research. Developmental brain research 44(1): 95-108.

Moorman, A. F., Houweling, A. C., de Boer, P. A.\&Christoffels, V. M. (2001) 'Sensitive nonradioactive detection of mRNA in tissue sections: novel application of the whole-mount in situ hybridization protocol', J Histochem Cytochem 49(1): 1-8.

Mouradian, M. M. (2012) 'MicroRNAs in Parkinson's disease', Neurobiology of Disease 46(2): 279-84.

Mullis, K. B.\&Faloona, F. A. (1987) 'Specific synthesis of DNA in vitro via a polymerase-catalyzed chain reaction', Methods in enzymology 155: 335-50.

Nagy, A. (2000) 'Cre recombinase: the universal reagent for genome tailoring', Genesis 26(2): 99-109.

Nakamura, H., Katahira, T., Matsunaga, E.\&Sato, T. (2005) 'Isthmus organizer for midbrain and hindbrain development', Brain research. Brain research reviews 49(2): 120-6.

Nakatani, T., Kumai, M., Mizuhara, E., Minaki, Y.\&Ono, Y. (2010) 'Lmx1a and Lmx1b cooperate with Foxa2 to coordinate the specification of dopaminergic neurons 
and control of floor plate cell differentiation in the developing mesencephalon', Developmental Biology 339(1): 101-13.

Nishikawa, S., Goto, S., Yamada, K., Hamasaki, T.\&Ushio, Y. (2003) 'Lack of Reelin causes malpositioning of nigral dopaminergic neurons: evidence from comparison of normal and Reln(rl) mutant mice', The Journal of comparative neurology 461(ac02593d-3356-cfdd-d93d-713127d5c7dd): 166-239.

Nunes, I., Tovmasian, L., Silva, R., Burke, R.\&Goff, S. (2003) 'Pitx3 is required for development of substantia nigra dopaminergic neurons', Proceedings of the National Academy of Sciences of the United States of America 100(c0485e6b8ba1-1529-4316-713127d60f9a): 4245-4295.

O'Hara, F. P., Beck, E., Barr, L. K., Wong, L. L., Kessler, D. S.\&Riddle, R. D. (2005) 'Zebrafish Lmx1b.1 and Lmx1b.2 are required for maintenance of the isthmic organizer', Development 132(14): 3163-73.

Ohyama, K., Kawano, H., Asou, H., Fukuda, T., Oohira, A., Uyemura, K.\&Kawamura, K. (1998) 'Coordinate expression of L1 and 6B4 proteoglycan/phosphacan is correlated with the migration of mesencephalic dopaminergic neurons in mice', Brain research. Developmental brain research 107(07957386-0088a851-acad-713127d86094): 219-245.

Omodei, D., Acampora, D., Mancuso, P., Prakash, N., Di Giovannantonio, L., Wurst, W.\&Simeone, A. (2008) 'Anterior-posterior graded response to Otx2 controls proliferation and differentiation of dopaminergic progenitors in the ventral mesencephalon', Development (Cambridge, England) 135(9b58f845-9856de81-a298-713127d9a0d9): 3459-3529.

Ono, Y., Nakatani, T., Sakamoto, Y., Mizuhara, E., Minaki, Y., Kumai, M., Hamaguchi, A., Nishimura, M., Inoue, Y., Hayashi, H. et al. (2007) 'Differences in neurogenic potential in floor plate cells along an anteroposterior location: midbrain dopaminergic neurons originate from mesencephalic floor plate cells', Development 134(17): 3213-25.

Panhuysen, M., Vogt Weisenhorn, D., Blanquet, V., Brodski, C., Heinzmann, U., Beisker, W.\&Wurst, W. (2004) 'Effects of Wnt1 signaling on proliferation in the developing mid-/hindbrain region', Molecular and cellular neurosciences 26(647b9ca5-dfc5-9e2f-7577-713127dba51e): 101-112.

Park, E. J., Sun, X., Nichol, P., Saijoh, Y., Martin, J. F.\&Moon, A. M. (2008) 'System for tamoxifen-inducible expression of cre-recombinase from the Foxa2 locus in mice', Developmental dynamics : an official publication of the American Association of Anatomists 237(2): 447-53.

Peng, C., Aron, L., Klein, R., Li, M., Wurst, W., Prakash, N.\&Le, W. (2011) 'Pitx3 is a critical mediator of GDNF-induced BDNF expression in nigrostriatal 
dopaminergic neurons', The Journal of neuroscience : the official journal of the Society for Neuroscience 31(36): 12802-15.

Peng, C., Fan, S., Li, X., Fan, X., Ming, M., Sun, Z.\&Le, W. (2007) 'Overexpression of pitx3 upregulates expression of BDNF and GDNF in SH-SY5Y cells and primary ventral mesencephalic cultures', FEBS Letters 581(7): 1357-61.

Perlmann, T.\&Wallen-Mackenzie, A. (2004) 'Nurr1, an orphan nuclear receptor with essential functions in developing dopamine cells', Cell and Tissue Research 318(1): 45-52.

Placzek, M.\&Briscoe, J. (2005) 'The floor plate: multiple cells, multiple signals', Nature reviews. Neuroscience 6(4fe92a38-e585-78a8-3dea-713127e2b503): 230-270.

Prakash, N., Brodski, C., Naserke, T., Puelles, E., Gogoi, R., Hall, A., Panhuysen, M., Echevarria, D., Sussel, L., Weisenhorn, D. et al. (2006) 'A Wnt1-regulated genetic network controls the identity and fate of midbrain-dopaminergic progenitors in vivo', Development (Cambridge, England) 133(ef9da94c-35f0d9d2-84c9-713127e313e7): 89-187.

Prakash, N., Puelles, E., Freude, K., Trumbach, D., Omodei, D., Di Salvio, M., Sussel, L., Ericson, J., Sander, M., Simeone, A. et al. (2009) 'Nkx6-1 controls the identity and fate of red nucleus and oculomotor neurons in the mouse midbrain', Development 136(15): 2545-55.

Prakash, N.\&Wurst, W. (2004) 'Specification of midbrain territory', Cell Tissue Res 318(1): 5-14.

Prakash, N.\&Wurst, W. (2006a) 'Development of dopaminergic neurons in the mammalian brain', Cellular and molecular life sciences : CMLS 63(2): 187-206.

Prakash, N.\&Wurst, W. (2006b) 'Genetic networks controlling the development of midbrain dopaminergic neurons', The Journal of Physiology 575(Pt 2): 403-10.

Prakash, N.\&Wurst, W. (2007) 'A Wnt signal regulates stem cell fate and differentiation in vivo', Neuro-degenerative diseases 4(4): 333-8.

Puelles, E., Annino, A., Tuorto, F., Usiello, A., Acampora, D., Czerny, T., Brodski, C., Ang, S.-L., Wurst, W.\&Simeone, A. (2004) 'Otx2 regulates the extent, identity and fate of neuronal progenitor domains in the ventral midbrain', Development (Cambridge, England) 131(92883e09-76ea-25f8-31f3-713127e553b3): 20372085.

Ramirez-Solis, R., Liu, P.\&Bradley, A. (1995) 'Chromosome engineering in mice', Nature 378(6558): 720-4.

Reddy, S., Rayala, S., Ohshiro, K., Pakala, S., Kobori, N., Dash, P., Yun, S., Qin, J., O'Malley, B.\&Kumar, R. (2011) 'Multiple coregulatory control of tyrosine 
hydroxylase gene transcription', Proceedings of the National Academy of Sciences of the United States of America 108(3e3d596f-1a3c-eb56-2c02713127e8fa4b): 4200-4205.

Roelink, H., Porter, J. A., Chiang, C., Tanabe, Y., Chang, D. T., Beachy, P. A.\&Jessell, T. M. (1995) 'Floor plate and motor neuron induction by different concentrations of the amino-terminal cleavage product of sonic hedgehog autoproteolysis', Cell 81(3): 445-55.

Roybon, L., Hjalt, T., Christophersen, N. S., Li, J. Y.\&Brundin, P. (2008) 'Effects on differentiation of embryonic ventral midbrain progenitors by Lmx1a, Msx1, Ngn2, and Pitx3', The Journal of neuroscience : the official journal of the Society for Neuroscience 28(14): 3644-56.

Sakurada, K., Ohshima-Sakurada, M., Palmer, T. D.\&Gage, F. H. (1999) 'Nurr1, an orphan nuclear receptor, is a transcriptional activator of endogenous tyrosine hydroxylase in neural progenitor cells derived from the adult brain', Development 126(18): 4017-26.

Sanes, D. H.\&Bao, S. (2009) 'Tuning up the developing auditory CNS', Current Opinion in Neurobiology 19(2): 188-99.

Sanes, D. H., Reh, T. A.\&Harris, W. A. (2006) Development of the nervous system, Amsterdam ; Boston: Elsevier.

Sasaki, H.\&Hogan, B. (1994) 'HNF-3 beta as a regulator of floor plate development', Cell 76(41b20023-488b-440b-61ac-713127f1f8c7): 103-118.

Saucedo-Cardenas, O., Quintana-Hau, J. D., Le, W. D., Smidt, M. P., Cox, J. J., De Mayo, F., Burbach, J. P.\&Conneely, O. M. (1998) 'Nurr1 is essential for the induction of the dopaminergic phenotype and the survival of ventral mesencephalic late dopaminergic precursor neurons', Proceedings of the National Academy of Sciences of the United States of America 95(7): 4013-8.

Sauer, B. (1998) 'Inducible gene targeting in mice using the Cre/lox system', Methods (San Diego, Calif.) 14(e044ed4f-7f18-3416-b6b4-713128f99d43): 381-473.

Sauer, B.\&Henderson, N. (1988) 'Site-specific DNA recombination in mammalian cells by the Cre recombinase of bacteriophage P1', Proceedings of the National Academy of Sciences of the United States of America 85(14): 5166-70.

Schambra, U. B., Silver, J.\&Lauder, J. M. (1992) Atlas Of The Prenatal Mouse Brain: Academic Press, Inc., San Diego, USA.

Scholpp, S., Lohs, C.\&Brand, M. (2003) 'Engrailed and Fgf8 act synergistically to maintain the boundary between diencephalon and mesencephalon', Development 130(20): 4881-93. 
Schulz, J. B.\&Falkenburger, B. H. (2004) 'Neuronal pathology in Parkinson's disease', Cell and Tissue Research 318(1): 135-47.

Semina, E., Murray, J., Reiter, R., Hrstka, R.\&Graw, J. (2000) 'Deletion in the promoter region and altered expression of Pitx3 homeobox gene in aphakia mice', Human molecular genetics 9(978f73c5-fbc7-aab6-d32d-713127f5d516): 1575-1660.

Semina, E. V., Reiter, R. S.\&Murray, J. C. (1997) 'Isolation of a new homeobox gene belonging to the Pitx/Rieg family: expression during lens development and mapping to the aphakia region on mouse chromosome 19', Human molecular genetics 6(12): 2109-16.

Seroogy, K. B., Lundgren, K. H., Tran, T. M., Guthrie, K. M., Isackson, P. J.\&Gall, C. M. (1994) 'Dopaminergic neurons in rat ventral midbrain express brain-derived neurotrophic factor and neurotrophin-3 mRNAs', J Comp Neurol 342(3): 32134 .

Sgadò, P., Albéri, L., Gherbassi, D., Galasso, S., Ramakers, G., Alavian, K., Smidt, M., Dyck, R.\&Simon, H. (2006) 'Slow progressive degeneration of nigral dopaminergic neurons in postnatal Engrailed mutant mice', Proceedings of the National Academy of Sciences of the United States of America 103(612eb2bda9bb-6c05-e8bc-713127f604dd): 15242-15249.

Simeone, A. (2000) 'Positioning the isthmic organizer where Otx2 and Gbx2meet', Trends in genetics : TIG 16(6): 237-40.

Simon, H. H., Saueressig, H., Wurst, W., Goulding, M. D.\&O'Leary, D. D. (2001) 'Fate of midbrain dopaminergic neurons controlled by the engrailed genes', $J$ Neurosci 21(9): 3126-34.

Singh, B., Wilson, J. H., Vasavada, H. H., Guo, Z., Allore, H. G.\&Zeiss, C. J. (2007) 'Motor deficits and altered striatal gene expression in aphakia (ak) mice', Brain Research 1185: 283-92.

Smidt, M.\&Burbach, J. (2007) 'How to make a mesodiencephalic dopaminergic neuron', Nature reviews. Neuroscience 8(afea2449-e33c-996a-fd25713127fe6414): 21-53.

Smidt, M., Smits, S., Bouwmeester, H., Hamers, F., van der Linden, A., Hellemons, A., Graw, J.\&Burbach, J. (2004a) 'Early developmental failure of substantia nigra dopamine neurons in mice lacking the homeodomain gene Pitx3', Development (Cambridge, England) 131(14071dbb-b249-9b24-b9d6-713127fe0082): 11451200.

Smidt, M. P., Asbreuk, C. H., Cox, J. J., Chen, H., Johnson, R. L.\&Burbach, J. P. (2000) 'A second independent pathway for development of mesencephalic dopaminergic neurons requires Lmx1b', Nat Neurosci 3(4): 337-41. 
Smidt, M. P., Smits, S. M., Bouwmeester, H., Hamers, F. P., van der Linden, A. J., Hellemons, A. J., Graw, J.\&Burbach, J. P. (2004b) 'Early developmental failure of substantia nigra dopamine neurons in mice lacking the homeodomain gene Pitx3', Development 131(5): 1145-55.

Smidt, M. P., van Schaick, H. S., Lanctot, C., Tremblay, J. J., Cox, J. J., van der Kleij, A. A., Wolterink, G., Drouin, J.\&Burbach, J. P. (1997) 'A homeodomain gene Ptx3 has highly restricted brain expression in mesencephalic dopaminergic neurons', Proc Natl Acad Sci U S A 94(24): 13305-10.

Smits, S.\&Smidt, M. (2006a) 'The role of Pitx3 in survival of midbrain dopaminergic neurons', Journal of neural transmission. Supplementum(ea9609bb-b01a-a4dd0723-7131280025d6): 57-117.

Smits, S. M., Burbach, J. P.\&Smidt, M. P. (2006b) 'Developmental origin and fate of meso-diencephalic dopamine neurons', Prog Neurobiol 78(1): 1-16.

Smits, S. M., Ponnio, T., Conneely, O. M., Burbach, J. P.\&Smidt, M. P. (2003) 'Involvement of Nurr1 in specifying the neurotransmitter identity of ventral midbrain dopaminergic neurons', Eur J Neurosci 18(7): 1731-8.

Sternberg, N.\&Hamilton, D. (1981) 'Bacteriophage P1 site-specific recombination. I. Recombination between loxP sites', Journal of molecular biology 150(4): 46786.

Suda, Y., Hossain, Z. M., Kobayashi, C., Hatano, O., Yoshida, M., Matsuo, I.\&Aizawa, S. (2001) 'Emx2 directs the development of diencephalon in cooperation with Otx2', Development 128(13): 2433-50.

Takaoka, K.\&Hamada, H. (2012) 'Cell fate decisions and axis determination in the early mouse embryo', Development (Cambridge, England) 139(5cb4b743-70dc53af-f7d9-7131280582d4): 3-17.

Tang, M., Miyamoto, Y.\&Huang, E. (2009) 'Multiple roles of beta-catenin in controlling the neurogenic niche for midbrain dopamine neurons', Development (Cambridge, England) 136(8b6d82d4-8b5a-e59d-6880713128066826): 2027-2065.

Tang, M., Villaescusa, J., Luo, S., Guitarte, C., Lei, S., Miyamoto, Y., Taketo, M., Arenas, E.\&Huang, E. (2010) 'Interactions of Wnt/beta-catenin signaling and sonic hedgehog regulate the neurogenesis of ventral midbrain dopamine neurons', The Journal of neuroscience : the official journal of the Society for Neuroscience 30(7191c6f5-3ad3-b394-80fe-713128065dd8): 9280-9371.

Thomas, K. R.\&Capecchi, M. R. (1990) 'Targeted disruption of the murine int-1 proto-oncogene resulting in severe abnormalities in midbrain and cerebellar development', Nature 346(6287): 847-50. 
Thompson, L., Barraud, P., Andersson, E., Kirik, D.\&Björklund, A. (2005) 'Identification of dopaminergic neurons of nigral and ventral tegmental area subtypes in grafts of fetal ventral mesencephalon based on cell morphology, protein expression, and efferent projections', The Journal of neuroscience : the official journal of the Society for Neuroscience 25(1efa66f8-660c-f3b6-2b5471312808954e): 6467-6544.

Tornqvist, N., Hermanson, E., Perlmann, T.\&Stromberg, I. (2002) 'Generation of tyrosine hydroxylase-immunoreactive neurons in ventral mesencephalic tissue of Nurr1 deficient mice', Brain research. Developmental brain research 133(1): 37-47.

van den Munckhof, P., Luk, K., Ste-Marie, L., Montgomery, J., Blanchet, P., Sadikot, A.\&Drouin, J. (2003) 'Pitx3 is required for motor activity and for survival of a subset of midbrain dopaminergic neurons', Development (Cambridge, England) 130(2291339c-e3fb-6839-bb99-713127cec9c4): 2535-2577.

Varnum, D. S.\&Stevens, L. C. (1968) 'Aphakia, a new mutation in the mouse', The Journal of heredity 59(2): 147-50.

Vieira, C., Pombero, A., García-Lopez, R., Gimeno, L., Echevarria, D.\&Martínez, S. (2010) 'Molecular mechanisms controlling brain development: an overview of neuroepithelial secondary organizers', The International journal of developmental biology 54(22b34eb6-6251-51ec-0181-7131280bcd87): 7-27.

Vitalis, T., Cases, O.\&Parnavelas, J. (2005) 'Development of the dopaminergic neurons in the rodent brainstem', Experimental Neurology 191 Suppl 1(6c418005-f174-ceb6-56cf-7131280c4784): 12.

Volpicelli, F., Caiazzo, M., Greco, D., Consales, C., Leone, L., Perrone-Capano, C., Colucci D'Amato, L.\&di Porzio, U. (2007) 'Bdnf gene is a downstream target of Nurr1 transcription factor in rat midbrain neurons in vitro', Journal of Neurochemistry 102(2): 441-53.

Volpicelli, F., De Gregorio, R., Pulcrano, S., Perrone-Capano, C., di Porzio, U.\&Bellenchi, G. C. (2012) 'Direct regulation of Pitx3 expression by Nurr1 in culture and in developing mouse midbrain', PLoS ONE 7(2): e30661.

Wallen, A.\&Perlmann, T. (2003) 'Transcriptional control of dopamine neuron development', Annals of the New York Academy of Sciences 991: 48-60.

Wallén, A., Zetterström, R., Solomin, L., Arvidsson, M., Olson, L.\&Perlmann, T. (1999) 'Fate of mesencephalic AHD2-expressing dopamine progenitor cells in NURR1 mutant mice', Experimental Cell Research 253(b66135e5-07cb-41b490a4-7131280d8429): 737-783.

Wallen, A. A., Castro, D. S., Zetterstrom, R. H., Karlen, M., Olson, L., Ericson, J.\&Perlmann, T. (2001) 'Orphan nuclear receptor Nurr1 is essential for Ret 
expression in midbrain dopamine neurons and in the brain stem', Molecular and cellular neurosciences 18(6): 649-63.

Wassarman, K., Lewandoski, M., Campbell, K., Joyner, A., Rubenstein, J., Martinez, S.\&Martin, G. (1997) 'Specification of the anterior hindbrain and establishment of a normal mid/hindbrain organizer is dependent on Gbx2 gene function', Development (Cambridge, England) 124(41514bc1-a923-9876-35797131280f32f3): 2923-2957.

Wessely, O.\&De Robertis, E. M. (2002) 'Neural plate patterning by secreted signals', Neuron 33(4): 489-91.

Wilkinson, D. G., Bailes, J. A.\&McMahon, A. P. (1987) 'Expression of the protooncogene int- 1 is restricted to specific neural cells in the developing mouse embryo', Cell 50(1): 79-88.

Wolberger, C. (1996) 'Homeodomain interactions', Current opinion in structural biology 6(9d81d4d5-32f1-5b38-a5d8-71312812c8f8): 62-70.

Wolpert, L. (2007) Principles of development, Oxford ; New York: Oxford University Press.

Wurst, W.\&Bally-Cuif, L. (2001) 'Neural plate patterning: upstream and downstream of the isthmic organizer', Nature reviews. Neuroscience 2(2): 99108.

Yan, C., Levesque, M., Claxton, S., Johnson, R.\&Ang, S.-L. (2011) 'Lmx1a and Imx1b function cooperatively to regulate proliferation, specification, and differentiation of midbrain dopaminergic progenitors', The Journal of neuroscience : the official journal of the Society for Neuroscience 31(6edc9c9fb6a5-68a3-5277-713128154b76): 12413-12438.

Yang, D., Peng, C., Li, X., Fan, X., Li, L., Ming, M., Chen, S.\&Le, W. (2008) 'Pitx3transfected astrocytes secrete brain-derived neurotrophic factor and glial cell line-derived neurotrophic factor and protect dopamine neurons in mesencephalon cultures', J Neurosci Res 86(15): 3393-400.

Ye, W., Shimamura, K., Rubenstein, J., Hynes, M.\&Rosenthal, A. (1998) 'FGF and Shh signals control dopaminergic and serotonergic cell fate in the anterior neural plate', Cell 93(9070f2d6-097f-6abb-468c-71312816b359): 755-821.

Zervas, M., Millet, S., Ahn, S.\&Joyner, A. (2004) 'Cell behaviors and genetic lineages of the mesencephalon and rhombomere 1', Neuron 43(38462dcd-b69f-bf9a4ce2-71312818d643): 345-402.

Zetterström, R., Williams, R., Perlmann, T.\&Olson, L. (1996) 'Cellular expression of the immediate early transcription factors Nurr1 and NGFI-B suggests a gene regulatory role in several brain regions including the nigrostriatal dopamine 
system', Brain research. Molecular brain research 41(ed79474d-2a79-2124a226-7131281990c8): 111-131.

Zetterstrom, R. H., Solomin, L., Jansson, L., Hoffer, B. J., Olson, L.\&Perlmann, T. (1997) 'Dopamine neuron agenesis in Nurr1-deficient mice', Science 276(5310): 248-50.

Zhao, S., Maxwell, S., Jimenez-Beristain, A., Vives, J., Kuehner, E., Zhao, J., O'Brien, C., de Felipe, C., Semina, E.\&Li, M. (2004) 'Generation of embryonic stem cells and transgenic mice expressing green fluorescence protein in midbrain dopaminergic neurons', Eur J Neurosci 19(5): 1133-40. 


\section{Danksagung}

An dieser Stelle möchte ich allen Personen danken, die zu dieser Doktorarbeit in verschiedenster Weise beigetragen und es mir ermöglichten haben, die Experimente in einer netten, produktiven Atmosphäre mit viel Wissensdrang und Freude durchzuführen.

Mein herzlicher Dank gilt...

... Prof. Dr. Ahmed Mansouri, der mich in die Arbeitsgruppe aufgenommen und es mir ermöglicht hat, an einem spannenden Thema forschen zu können. Danke auch für die immerwährende Bereitschaft zu kritischen Diskussionen rund um die Thematik. Durch die Hilfestellungen sind mir sicherlich so manche Fehlschläge erspart geblieben.

... Prof. Dr. Gregor Bucher für die Bereitschaft, die Betreuung meiner Arbeit zu übernehmen und bei Fragen immer erreichbar zu sein.

... Prof. Dr. Ralf Heinrich, Prof. Dr. Andreas Wodarz, Prof. Dr. Ernst. A. Wimmer sowie Prof. Dr. Reinhard Schuh für die Bereitschaft, Teil meiner Prüfungskommission zu sein.

... Thomas Schulz für das Lächeln zu jeder Zeit und für die Heiterkeit. Vielen Dank, dass du mir immer mit Rat und Tat beigestanden hast.

... Tamara Rabe, einfach für alles! Danke dass du mir damals als Frischling der Abteilung stets mit viel Freude geholfen hast und mir auch jederzeit zu Seite gestanden hast. Danke für die vielen Diskussionen und das Korrekturlesen. Simon Kordowich, Zeeshan Ahmad, Farnaz Shamsi, Helénè Foussard und Sharif Mahsur möchte ich ganz herzlich für die nette Atmosphäre, Gespräche und Diskussionen danken.

... Mihaela S. Diaconu, Ullrich Franke und dem BTL Team für die Herstellung der Konstrukte bzw. transgenen Pitx30E- bzw. Lmx1a/bOE-Mauslinien.

... den fleißigen Engeln Bojka, Manuela und Geli, dafür dass sie unseren Laboralltag mit ihrem steten Einsatz erleichtern und immer für einen da sind.

... Katrin Wenzel und dem BTL-Team für die liebevolle Pflege der vielen Mäusen.

... unseren Mann der Technik, Ralf Altschäffel. Danke, dass die Mikroskope immer funktionierten und dass stetig für Kaffee gesorgt war.

... Alex, Mehdi, Golnaz, Marco und allen Mitarbeitern der Abteilung Molekulare Zellbiologie, die hier nicht erwähnt habe, für die nette Atmosphäre und die vielen Hilfestellungen. 
... meiner Familie, sie immer hinter mir gestanden hat und stets an mich geglaubt hat. Vielen Dank für die bedingungslose Unterstützung in jeglicher Form.

... meiner Frau Daniela, mit der ich seit Studienbeginn durch Dick und Dünn gehe. Danke für das schöne wunderschöne Gefühl, dich nach der Arbeit in den Arm nehmen zu können. Ohne dich hätte ich so mache Hürde nicht geschafft. 


\section{Curriculum Vitae}

\section{Persönliche Angaben}

Dipl. Biol. Christian Krug

Geismar Landstraße 61

37083 Göttingen

ckrug@gwdg.de

christian.krug@web.de

Geburtsdatum: 18.02.1982 (Nordhausen)

Familienstand: verheiratet

Staatsangehörigkeit: deutsch

\section{Wissenschaftliche Ausbildung}

Seit 10/2008 Max-Planck-Institut für Biophysikalische Chemie, Göttingen

Abt. Molekulare Zelldifferenzierung

(Prof. Dr. Ahmed Mansouri)

Doktorand und Hilfswissenschaftler

- Thema der Doktorarbeit: „Funktionelle Analyse des Transkriptionsfaktors Pitx3 während der Entwicklung dopaminerger Neuronen im murinen Mittelhirn"

05/2008-9/2008 Orientierungs- und Bewerbungsphase nach Abschluss des Studiums

10/2002 - 4/2008 Georg-August-Universität zu Göttingen

Studium der Biologie (Diplom)

- Studienschwerpunkt: Zoologie

- Nebenfächer: Chemie, Biochemie

- Diplomarbeit: „Der Einfluss von Dopamin auf das Gesangsverhalten von Feldheuschrecken" $(1,0)$

- Gesamt-Abschlussnote: gut $(1,6)$

- Abschluss: Diplom Biologe

\section{Publikationen:}

Griesel, G., C. Krug, et al. (2011). "Generation of knockout mice expressing a GFPreporter under the control of the Lmx1a locus." Gene expression patterns : GEP 11(5-6): 345-348. 
Christian Krug

Geismar Landstraße 61

37083 Göttingen

Erklärung zu meiner Dissertation mit dem Titel:

„Funktionelle Analyse des Transkriptionsfaktors Pitx3 während der Entwicklung dopaminerger Neuronen im murinen Mittelhirn“

Sehr geehrte Damen und Herren,

hiermit erkläre ich, dass ich die beigefügte Dissertation selbstständig verfasst und keine anderen als die angegebenen Hilfsmittel genutzt habe. Alle inhaltlich übernommenen Stellen habe ich als solche gekennzeichnet.

Ich versichere außerdem, dass ich die beigefügte Dissertation nur in diesem und keinem anderen Promotionsverfahren eingereicht habe und, dass diesem Promotionsverfahren keine endgültig gescheiterten Promotionsverfahren vorausgegangen sind.

Göttingen, 25.09.2012

Ort, Datum
Christian Krug

Unterschrift 